Universidad Nacional de La Plata - Facultad de Ciencias Exactas.

\title{
"HIPERTROFIA CARDÍACA PATOLÓGICA: ESTUDIO EXPERIMENTAL DE SU MODIFICACIÓN CON EL EJERCICIO-VÍAS DE SEÑALIZACIÓN INTRACELULAR INVOLUCRADAS".
}

Mariela Beatriz Nolly

\author{
Director \\ Dr. Horacio Eugenio Cingolani
}

Co-Director

Dra. Irene Lucía Ennis

Asesor Científico

Dr. Alejandro Rebolledo

- Tesis Doctoral 2012 -

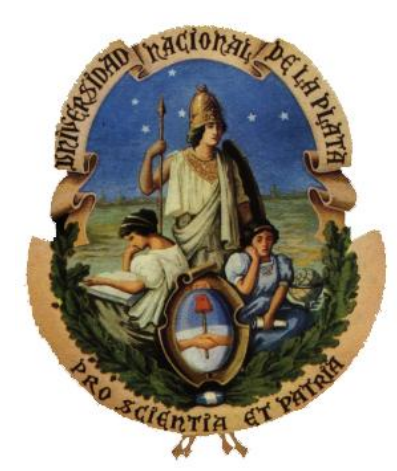

Centro de Investigaciones Cardiovasculares, Facultad de Ciencias Médicas, UNLP. 


\section{Agradecimientos}

Al Dr. Horacio Cingolani, mi Director, por darme la oportunidad de ingresar al Centro de Investigaciones Cardiovasculares y permitirme trabajar en sus proyectos. Brindándome sus conocimientos, experiencia y pasión por la ciencia.

A la Dra. Irene Ennis, mi Co-Directora, por enseñarme y acompañarme. Por su dedicación y preocupación en mi progreso.

Al Dr. Alejandro Rebolledo, mi Asesor Académico, por sugerirme y guiarme durante el doctorado.

A la Dra. Mattiazzi por permitirme desarrollar este trabajo de tesis en el Centro de Investigaciones Cardiovasculares.

Al Dr. Escudero por su ayuda en la realización de este trabajo.

A Carolina por su amistad y toda la ayuda que me brindó.

A todos los integrantes del Centro de Investigaciones Cardiovasculares Luisa, Juliana, Gisel, Omar V, Andrés, Jesica, Lorena, Nacho PN, Verónica C, Romina, Luciana, Alejandro O, Noelia, Nacho L, Alejandra, Luis, Verónica DG, Carolina C, Susana, Chichita, Gustavo P, Margarita, Leticia, Patricio, Claudia, Julieta, Alejandro A, Martín, Gustavo R, Charly, Matilde, Cecilia M, Celeste, Bernardo, Mónica, Omar C, Albita, Rosana, Cecilia por su amistad y cariño.

A mi familia y a Pablo por darme su apoyo y afecto. 
ÍNDICE 


\section{$\underline{\text { ÍNDICE }}$}

- Introducción

- Objetivos .44

- Materiales y métodos

- Resultados .66

1. Características de los grupos experimentales.

2. Influencia del ejercicio en la función ventricular de las SHR.

3. Morfología de la hipertrofia cardíaca $(\mathrm{HC})$ en las SHR en ejercicio.

4. Histología de la HC en las SHR en ejercicio.

5. Características moleculares de la $\mathrm{HC}$ en las SHR en ejercicio.

6. Apoptosis y ejercicio.

- Discusión y Conclusión.

- Abreviaturas

- Referencias bibliográficas. 


\section{INTRODUCCIÓN}




\section{Introducción}

\section{HIPERTROFIA CARDÍACA (HC).}

Las enfermedades cardiovasculares son la principal causa de muerte a nivel mundial, superando de manera notable a otras enfermedades que poseen una elevada prevalencia, como el cáncer (1-3). La HC es el mayor predictor de enfermedad cardíaca progresiva. Con frecuencia se asocia a hipertensión arterial (HTA) e insuficiencia cardíaca (IC), procesos que inducen el agrandamiento del cardiomiocito (4). La HTA es una afección poligénica y multifactorial que afecta al $30 \%$ de la población adulta y es la principal causa de morbi-mortalidad cardiovascular. Estudios epidemiológicos muestran que en la HTA, la HC es un factor de riesgo agregado (5-7). En la IC el corazón es incapaz de mantener un gasto cardíaco adecuado a las necesidades metabólicas de los tejidos, o bien sólo puede hacerlo a expensas de altas presiones de llenado ventricular (8).

Concepto de HC. La HC se define como el aumento de la masa del corazón. A nivel macroscópico se caracteriza por un incremento del grosor de la pared y/o del septo interventricular (9), mientras que a nivel microscópico se observa un incremento del tamaño del cardiomiocito, sin incrementar el número de células, y un cambio en la organización de la estructura sarcomérica (10).

Los miocitos son células diferenciadas que pierden la capacidad de proliferar luego del nacimiento $(11,12)$. A pesar de ello son capaces de responder a estímulos externos que promueven su crecimiento, como péptidos vasoactivos, estimulación beta-adrenérgica, factores inductores de crecimiento, y principalmente al aumento del estrés mecánico debido a sobrecarga hemodinámica. Los cambios hemodinámicos pueden corresponder a un aumento de la precarga (hipertrofia por sobrecarga de volumen) o a un aumento de la postcarga (hipertrofia por sobrecarga de presión). Dichos estímulos promueven la síntesis de proteínas, entre ellas, las que constituyen los sarcómeros, contribuyendo así a la formación de los mismos, los cuales se incorporan a la maquinaria contráctil, aumentando el tamaño celular.

Se sabe que 2/3 partes de la población celular del corazón están compuestas por colágeno, vasos sanguineos, linfáticos, terminaciones nerviosas y principalmente fibroblastos que son importantes en el desarrollo de la HC. Los fibroblastos producen y liberan factores de crecimiento, citoquinas, proteínas de la matriz extracelular y proteasas. La pérdida del equilibrio entre ellas puede conducir a la HC (13). 


\section{Introducción}

De acuerdo a lo enunciado por la ley de Laplace, puede verse como aumentos progresivos en la presión o el radio influyen directamente sobre la tensión elevándola:

$$
\text { Tensión }=\text { Presión } \times \text { Radio } / 2 \times \text { Espesor }
$$

Es por ello que la $\mathrm{HC}$ ha sido clásicamente interpretada como una respuesta adaptativa del miocardio, ya que al aumentar el espesor de la pared ventricular, se normalizaría transitoriamente el estrés al que está sometido el ventrículo debido a una sobrecarga hemodinámica, optimizándose la función cardíaca. Sin embargo, existen evidencias que sustentan la idea de que la $\mathrm{HC}$ no solo no es necesaria para compensar funcionalmente una situación de sobrecarga hemodinámica a pesar de prevenir el aumento del estrés (14), sino que por el contrario constituye per se un factor independiente de riesgo cardiovascular $(5,15)$.

Clasificación de la HC. La HC puede ser clasificada como fisiológica (HCF) y patológica (HCP).

- La HCF se desarrolla en atletas sometidos a ejercicio físico intenso y durante el embarazo, para satisfacer las demandas metabólicas aumentadas $(16,17)$. No deteriora la función cardíaca e incluso puede mejorarla y es reversible. A nivel molecular se caracteriza por un incremento en la expresión de genes sarcoméricos como la cadena pesada $\alpha$ de la miosina ( $\alpha-M H C)$ y la $\alpha$-actina, entre otros (18).

- La HCP ocurre en respuesta a situaciones de estrés (HTA, valvulopatías e infarto de miocardio). Se acompaña de deterioro de la función contráctil y habitualmente evoluciona a IC (17). Constituye por si misma un factor de riesgo independiente de morbimortalidad cardiovascular (19). Su regresión implica una reducción de dicho riesgo independientemente del tratamiento por el que se logre $(20,21)$. La HCP se acompaña de aumento de la fibrosis intersticial, mayor incidencia de apoptosis (22), disminución de la densidad capilar y reprogramación de la expresión génica con inducción de genes fetales. Entre estos últimos se incluye a los genes de los péptidos natriuréticos atrial (ANP) y cerebral (BNP), así como a las isoformas fetales de las proteínas contráctiles $(23,24)$. En el presente trabajo se estudiará un modelo de HCP. 
Formas de evolución de la HC. El desarrollo de HC modifica la geometría ventricular. Según el estímulo que la origine se puede producir un incremento mayor del espesor parietal en relación al diámetro de la cavidad o de éste último en relación al espesor de la pared, surgiendo así los fenotipos de HC concéntrica o excéntrica respectivamente (Figura 1I). En la $\mathrm{HC}$ de tipo concéntrica el aumento del espesor de la pared se acompaña de una escasa o nula dilatación de la cavidad ventricular. Además, dado que la incorporación de sarcómeros es predominantemente en paralelo, el crecimiento de los cardiomiocitos es a lo ancho. Esta hipertrofia está generalmente asociada a estímulos que producen "sobrecarga crónica de presión" (HTA, estenosis aórtica). La HC excéntrica se caracteriza por un incremento menor del espesor de la pared ventricular y un gran aumento en el volumen de la cavidad. Esto se debe al agregado de sarcómeros en serie, lo que induce un crecimiento preferentemente en longitud del cardiomiocito. Es tipo de HC es debida a una "sobrecarga de volumen". En el post-infarto de miocardio existe sobrecarga de presión y de volumen sobre las zonas no infartadas y el resultado es una combinación de HC concéntrica y excéntrica. El aumento de la fibrosis, como resultado de una mayor síntesis de colágeno por los fibroblastos, está presente en los tres patrones de HC. 


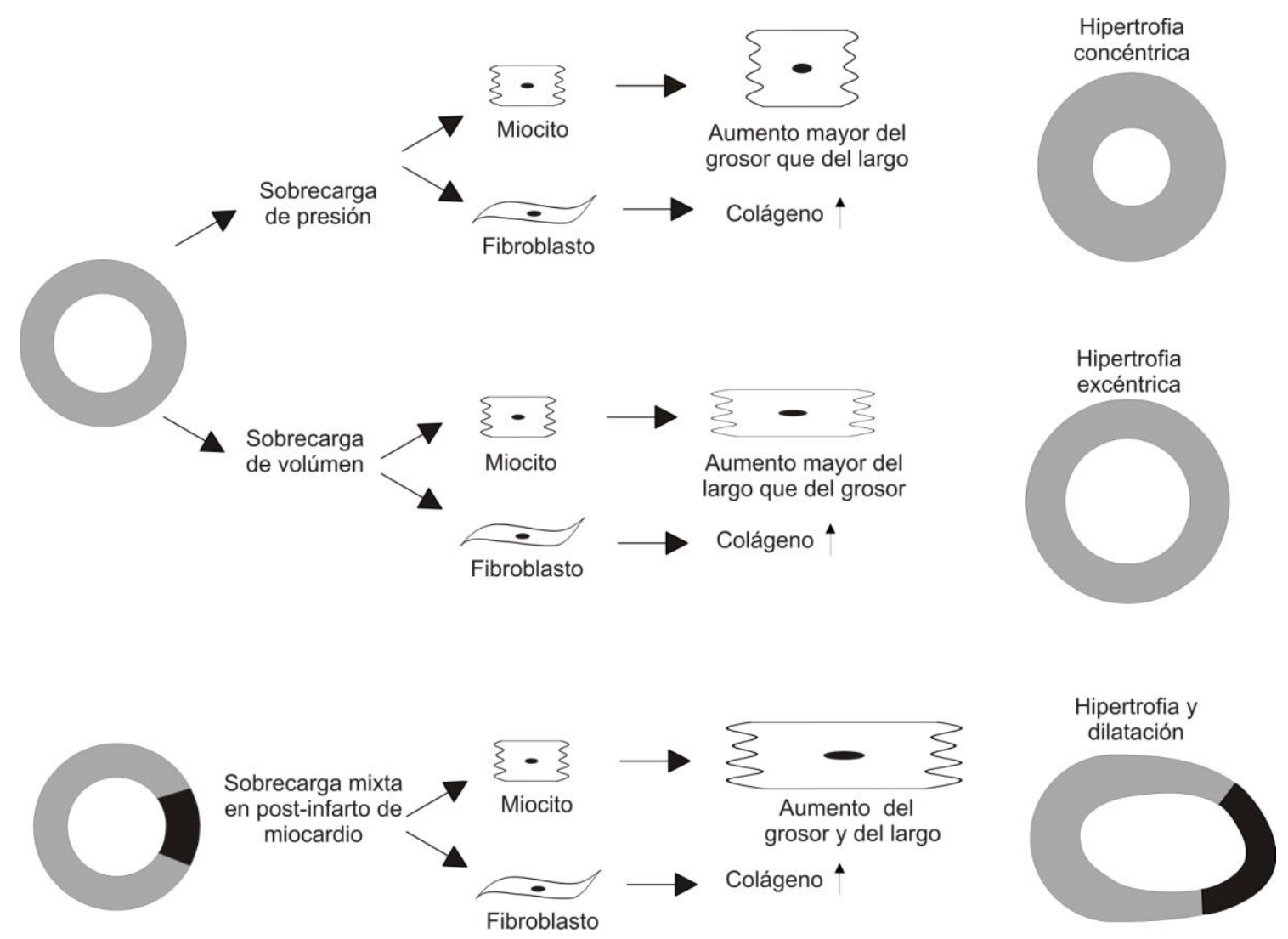

Figura 1I. Representación gráfica del corte transversal del ventrículo izquierdo, mostrando los tres patrones principales de HC según el tipo de sobrecarga hemodinámica que las origina.

Bases moleculares de la HC. El proceso de hipertrofia del miocardio es un evento de elevada complejidad, en el que se desarrollan fenómenos de comunicación celular iniciados por una variada gama de estímulos responsables de activar distintas vías de señalización intracelular que conducirán a cambios en la arquitectura y funcionamiento celular (25). La HC resulta de la interacción de diferentes vías de transducción de señales tales como tirosina quinasa, proteínas quinasas activadas por mitógenos (MAPK), fosfolipasa $C, D$ y $A_{2}$ (PLC, PLD y PLA $_{2}$, proteína quinasa $C$ (PKC), proteína quinasa janus (JNK), factor de crecimiento epidérmico (EGF) y factor de crecimiento de fibroblastos (FGF), entre otras (26).

A continuación abordaremos los principales estímulos responsables de la hipertrofia del cardiomiocito. 


\section{ESTÍMULOS HIPERTROFIANTES}

La actividad contráctil del corazón está regulada por mecanismos intrínsecos (autocrinos y paracrinos) y por mecanismos extrínsecos (endócrinos, nerviosos y electrofisiológicos) que le permiten adaptar su volumen minuto a las variaciones hemodinámicas. Muchas de las vías de señalización intracelular que en otros tejidos regulan la proliferación celular, en el miocito cardíaco en cambio, modulan el crecimiento hipertrófico $(27,28)$. En los complejos procesos moleculares que llevan al crecimiento del miocito cardíaco intervienen receptores de membrana, segundos mensajeros y factores de transcripción. Estos agentes intracelulares convergen en una vía final común en el núcleo donde activan o inhiben proteínas, conocidas como factores de transcripción, capaces de regular la expresión génica (29).

Entre los diversos factores que pueden actuar como estímulos hipertrofiantes sobre el cardiomiocito cabe mencionar a los factores humorales y al estiramiento del miocardio (30).

Dentro de los factores humorales encontramos:

- Un primer grupo compuesto por factores de crecimiento (TGF: factor de crecimiento transformante; FGF: factor de crecimiento fibroblástico; EGF: factor de crecimiento epidérmico; IGF: factor de crecimiento análogo a la insulina) que actúan sobre receptores de membrana con actividad tirosina quinasa y activan una cascada de segundos mensajeros relacionados con el crecimiento hipertrófico fisiológico (31).

- Un segundo grupo formado por sustancias como angiotensina II (All), endotelina $(E T)$, adrenalina y noradrenalina que estimulan a receptores unidos a proteína $G$ $\left(A T_{1}, E_{A}\right.$ y receptores a1-adrenérgicos, respectivamente) todos ellos relacionados con el desarrollo de HCP y su eventual progreso a IC $(27,32)$.

- Un tercer grupo constituído por las citoquinas inflamatorias entre las que se destaca la interleukina 6 (IL-6, una de las más estudiadas), un polipéptido de 185 aminoácidos (aa) que media su acción inflamatoria al unirse al receptor IL$6 \mathrm{R}$ y a la glucoproteína 130 (gp130) (33). Experimentalmente se ha observado en cardiomiocitos de ratones neonatos cultivados in vitro que al ser expuestos a dosis crecientes de IL-6, muestran un aumento de tamaño y sobreactivación de la vía de señalización de gp130 que conduce a HC (34). Estos resultados han sido ampliados en trabajos posteriores en los que se ha descripto en el miocardio de pacientes con HC, aumento de la expresión de IL-6 (35). 
El estrés mecánico producido por el estiramiento físico de los cardiomiocitos al cual es sometido el miocardio, es suficiente para inducir una respuesta genética y fenotípica hipertrófica (36). A pesar de no conocerse el mecanismo íntimo de este estímulo, su importancia está avalada por gran cantidad de evidencias experimentales (37-40).

\section{VÍAS DE SEÑALIZACIÓN QUE CONDUCEN A LA HC.}

La comunicación celular es un proceso que permite la coordinación funcional y estructural entre las células que componen un tejido. Una célula puede enviar una señal a otra mediante la producción de una molécula denominada ligando, que puede actuar en tejidos distantes (endócrino), en céulas cercanas del mismo tejido (paracrino) y sobre la misma célula que secreta la molécula señal (autócrino). La interacción entre el ligando y el receptor activa un sistema de transducción al que esta acoplado el receptor, denominado via de señalizacion, responsable del efecto biológico. Las vías de señalización son cascadas enzimáticas activadas por quinasas o fosfatasas.

Receptores de membrana. Los receptores de membrana son de naturaleza proteica y se unen a ligandos hidrosolubles que no pueden atravesar la membrana plasmática. Se clasifican en: receptores asociados a proteínas $G$ y receptores catalíticos.

\section{A. Receptores asociados a proteínas G (GPCR).}

Constituyen la familia más grande de receptores membranales, con más de 1000 miembros involucrados en la transmisión de señales. Son activados por una amplia variedad de ligandos, como neurotransmisores, hormonas y factores de crecimiento. Participan de múltiples funciones biológicas como la neurotransmisión, la regulación de la secreción endócrina y exócrina, el control del crecimiento y desarrollo celular y el control de la presión arterial.

Su estructura consiste en una sola cadena proteica que cruza siete veces la membrana plasmática, con el extremo amino terminal extracelular y el carboxilo terminal intracelular (Figura 2I). 


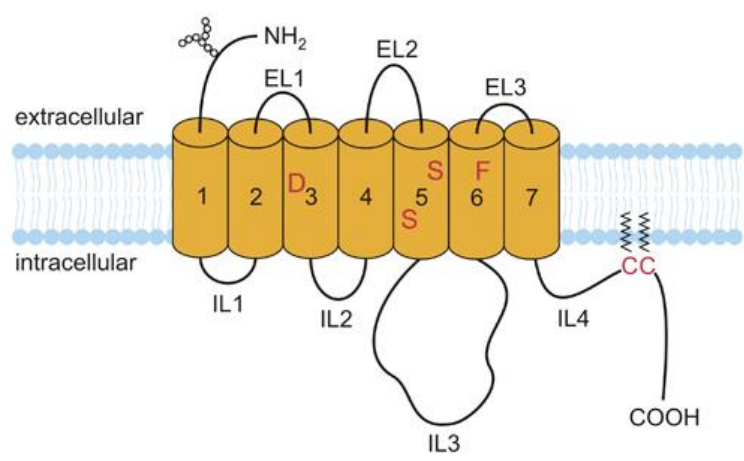

Figura 2I. Estructura de GPCR. Su estructura consiste en una sola cadena proteica de 550 a 1200 aa, que cruza siete veces la membrana plasmática por medio de siete dominios transmembrana (segmentos de 20-27aa), con el extremo amino terminal en la región extracelular y el carboxilo terminal en la intracelular. Los cruces repetidos en la membrana plasmática originan asas, 3 intracelulares (IL1-3) y 3 extracelulares (EL1-3). (Gráfico del Instituto Julich de biología estructural y biofísica).

Los GPCR adoptan la forma de un núcleo, en el cual la región carboxilo terminal y las asas intracelulares 2 y 3 son críticas para la transducción de señales hacia el interior célular, ya que son los sitios de unión a la proteína G correspondiente (Figura 3I).

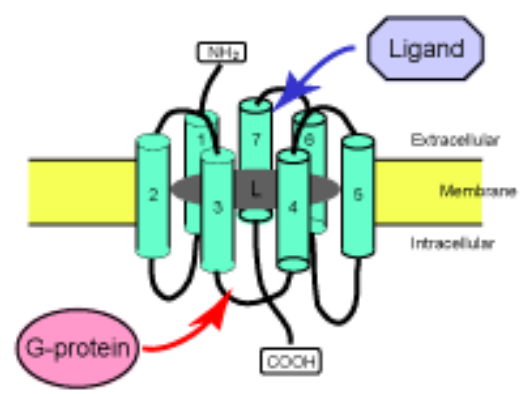

Figura 3I. Estructura tridimensional de GPCR. Los segmentos transmembrana altamente hidrofóbicos, permanecen en la parte externa del receptor $y$ en contacto con la membrana. Mientras que los otros segmentos que contienen residuos hidrofóbicos, iónicos y neutros, se mantienen en el centro de la estructura formando un núcleo que participa de la unión al ligando, junto con el extremo amino terminal y las asas extracelulares $(41,42)$. Las regiones amino y carboxilo terminales permiten regular la funcionalidad del receptor, ya que el extremo amino puede ser glicosilado y el carboxilo está expuesta a proteínas quinasas y proteínas arrestinas (43). (Gráfico del European Bioinformatics Institute).

Las proteínas G, denominadas así porque se unen a GTP, inician la transducción de señales al asociar al receptor con las proteínas efectoras localizadas en el interior celular. La proteína $G$ es un complejo proteico compuesto por 3 subunidades, alfa ( $\alpha$ ), beta $(\beta)$ y gama $(\mathrm{Y})$; funcionando estas dos últimas como una sola unidad al formar el complejo $\beta \gamma$. La subunidad $\alpha$ tiene el sitio de unión con alta afinidad por nucleótidos de guanina (GTP o GDP) así como actividad GTPasa, que le permite hidrolizar el GTP a GDP. Durante el estado inactivo, se encuentra unida a una molécula de GDP (44). 
Cuando el ligando se une al receptor, se produce un cambio conformacional en el receptor que influye sobre la proteína $G$ asociada a este, modificando la afinidad de la subunidad a por los nucleótidos de guanina, haciéndola más afín por el GTP. Al intercambiar GDP por GTP, la subunidad a se activa, se desensambla tanto del receptor como del complejo $\beta$ y y viaja por la membrana hasta alcanzar una enzima a la que activa. En el estado activo, tanto la subunidad a como el complejo $\beta y$ actúan sobre proteínas efectoras (Figura 4I).

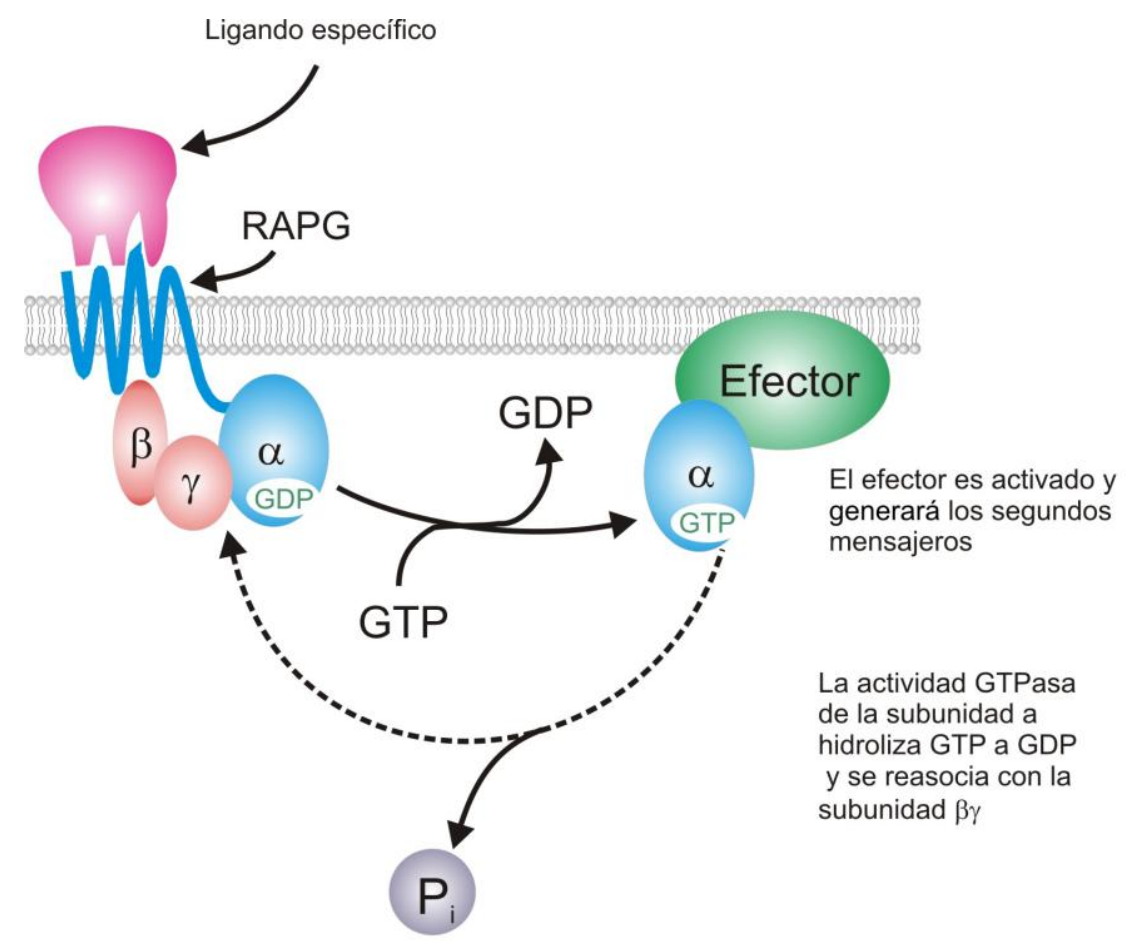

Figura 4I. Mecanismo general de acción de los GPCR.

La cascada de señalización que se active va a depender de la proteína $G$ a la que se encuentra acoplado el receptor. Existen tres tipos: Gaq, Gas y Gai.

- La proteína Gaq actúa sobre la enzima fosfolipasa C $\beta$ (PLC- $\beta$ ), que hidroliza fosfoinosítidos de membrana $\left(\mathrm{PIP}_{2}\right)$ generando Inositol-1,4,5-trifosfato (IP3) y Diacilglicerol (DAG) como segundos mensajeros (Figura 5I).

- Las proteínas Gas ó Gai actúan sobre la enzima adenil ciclasa (AC), que cataliza la conversión de ATP a AMPc (monofosfato cíclico de adenosina), estimulándola e inhibiéndola, respectivamente. El $A M P c$ se une a las subunidades reguladoras de la proteína quinasa $A(P K A)$, haciendo que se 


\section{Introducción}

separe de sus subunidades catalíticas. PKA reconocerá y forforilará a proteínas que contengan secuencias específicas, modificando así su función.

- Las subunidades $\beta y$, actúan sobre canales iónicos y enzimas. Activan vías de señalización involucradas en la desensibilización y apoptosis.

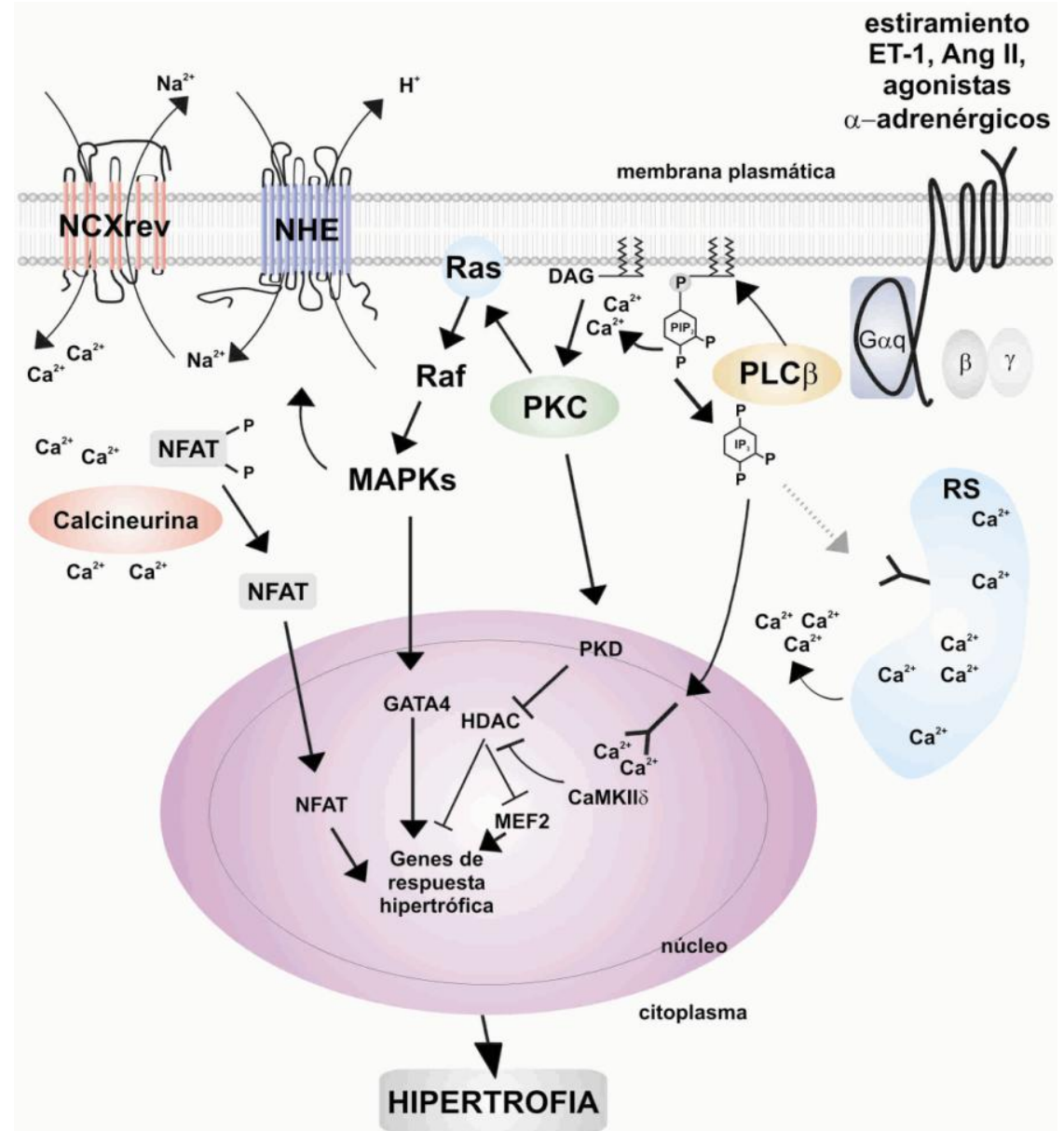

Figura 5I. Activación de la vía Gaq en la HC. La proteína Gaq actúa sobre la PLC- $\beta$, que hidroliza PIP 2 generando IP3 y DAG. Al formarse estos segundos mensajeros, el IP3 por su naturaleza hidrofílica difunde hacia el citosol mientras que el DAG de naturaleza lipofílica permanece en la membrana plasmática. EI IP3 se une a receptores ionotrópicos del retículo sarcoplasmático, induciendo su apertura y debido al gradiente de concentración existente, se produce la salida de iones de $\mathrm{Ca}^{2+}$ al citosol. Por otro lado el DAG, solo o junto con $\mathrm{Ca}^{2+}$, activa a las isoformas nuevas y clásicas de la PKC, respectivamente. PKC posee varias isoformas, las "nuevas" ( $\delta, \varepsilon, \eta, \theta$; dependientes de DAG), las "clásicas" $\left(\alpha, \beta 1, \beta 2, \gamma\right.$; dependientes de $\mathrm{Ca}^{+2}$ y DAG) y las "atípicas" (M弓; independientes de ambos) (45). La PKC fosforila canales iónicos y enzimas (como JAK-STAT y MAPK), en residuos de serina y treonina contenidos en secuencias específicas, modulando así su función (46). 


\section{B. Receptores catalíticos.}

El receptor posee un dominio citosólico que funciona como una enzima, es decir que cataliza una reacción, o se asocia estrechamente a una enzima. Se las denomina proteína transmembrana unipaso ya que atraviesan la bicapa lipidica una única vez. Dentro de este grupo encontramos: 1) Receptores con actividad tirosina quinasa, 2) Receptores asociados a proteínas quinasa y 3) Integrinas asociados a proteínas quinasa.

\section{Receptores con actividad tirosina quinasa (RTK).}

Son proteínas transmembrana que poseen en el extremo carboxilo terminal, intracelular, un dominio con actividad tirosina quinasa capaz de transferir un fosfato (obtenido del ATP) a una tirosina. Junto a este dominio se encuentran residuos de tirosina susceptibles de ser fosforilados. El extremo amino terminal, extracelular, posee dominios ricos en cisteína que participan en la dimerización del receptor (47).

La unión del ligando induce cambios conformacionales en el receptor, que favorecen su interacción con otro receptor, formando un dímero (Figura 6I). Esta unión activa al dominio tirosina quinasa del receptor, el cual fosforila múltiples residuos de tirosina de su homólogo (fenómeno denominado autofosforilación). Las regiones fosforiladas del receptor pueden ser reconocidas por proteínas (como GRB2) que poseen dominios SH2 (llamados asi por su homologia con los dominios 2 de la proteína Src) capaces de reconocer las fosfotirosinas del RTK y activar a proteínas que carecen de dicho dominio. 


\section{Introducción}

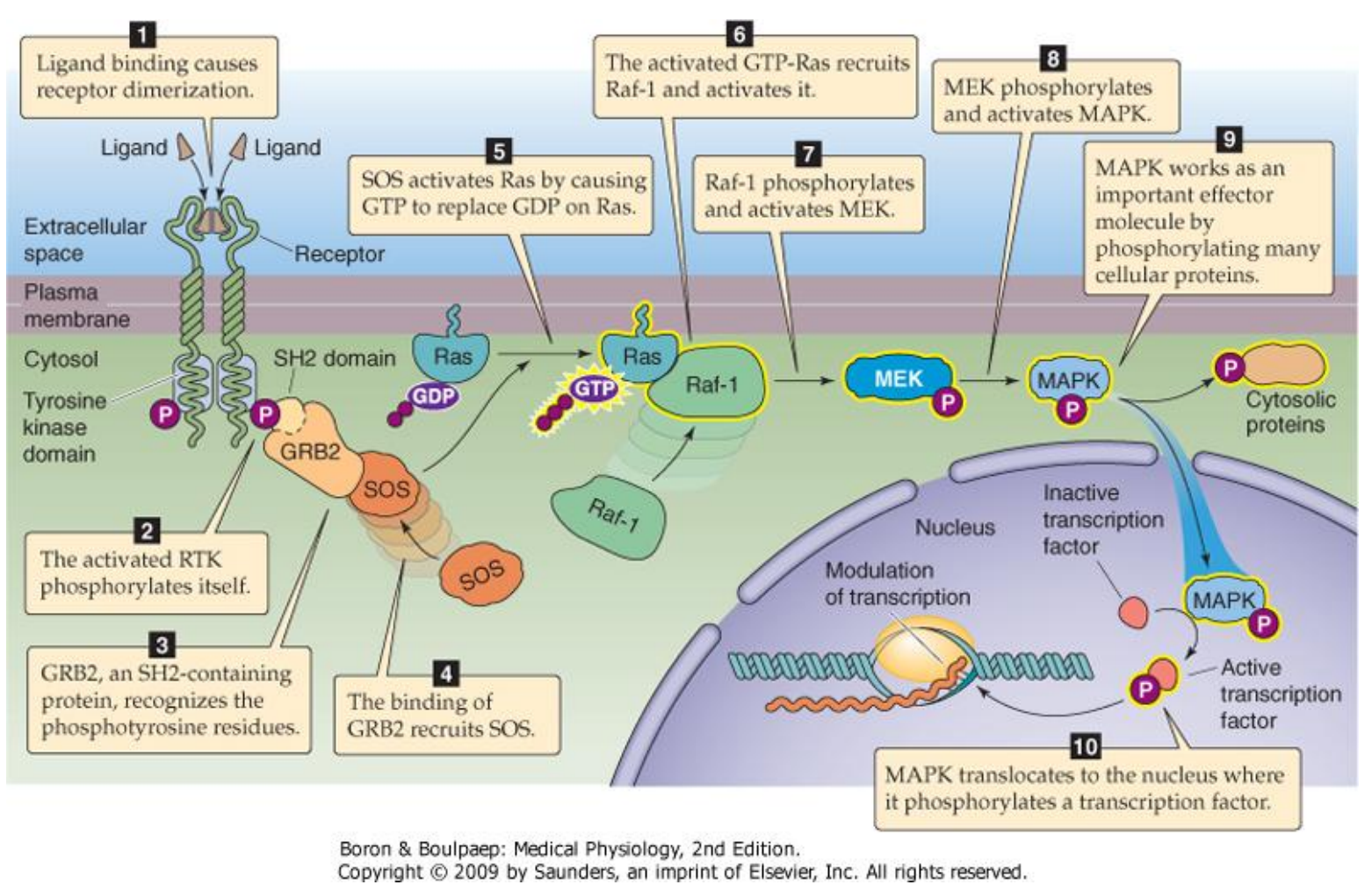

Figura 6I. Vía de los RTK. La unión del ligando favorece la dimerización del receptor (1). Esta unión activa al dominio tirosina quinasa del receptor, autofosforilando a su homólogo (2). Tanto GRB2 ("proteína de unión al factor de crecimiento"), GAP (proteínas que activa GTPasa), PLC-y (fosfolipasa $\mathrm{C}$ ) y $\mathrm{PI} 3 \mathrm{~K}$ (quinasa del 3 '-fosfatidilinositol), poseen dominios $\mathrm{SH} 2$ que reconocen las fosfotirosinas del RTK activado (3) y reclutar a Sos ("son-of-sevenless", un factor intercambiador de nucleotidos de guanina) (4) el cual estimula la liberación de GDP y la subsiguiente carga de GTP por proteínas GTPasas monomericas, activándolas (5). La actividad de estas GTPasas es también modulada por GAP (activada por RTK activo), que hidroliza el GTP unido a estas proteínas, inactivándolas. La adición de una molécula de ácido graso, les permite fijarse a la membrana. Dentro de ellas encontramos a las proteínas Ras y Rac, implicadas en la activación de quinasas. $\underline{\text { Ras }}$ tras ser activada por Sos, forma el complejo activo GTP-Ras, el cual recluta hacia la membrana a la proteína serina-treonina quinasa Raf-1 (factor activado por Ras) (6). Raf1 fosforila y activa a la proteína quinasa MEK (7). MEK fosforila residuos de serina y tirosina de proteínas MAPK como ERK1 y ERK2 (“quinasa regulada por señal extracelular”) (8). Esta última activa tanto a proteínas citosólicas (9) como nucleares, ya que tienen la capacidad de trasladarse al núcleo y fosforilar a proteínas que son factores de transcripción, estimulando su unión o liberación al ADN y con ello activando o reprimiendo la transcripción de genes (10) (Boron W.;Boulpaep E.,"Medical Physiology”, modificado, capítulo 3, editorial Saunders, 2008).

La mayoría de los RTK son receptores para factores de crecimiento, como el receptor del factor de crecimiento epidérmico (EGFR). Su estimulación activa vías de señalización esenciales para la proliferación y diferenciación celular, en la que participan cascadas de fosforilaciones llamadas "vías de las MAPK" 
(proteínas quinasas activadas por mitógenos", es decir por un inductor de proliferación y diferenciación celular como insulina, IGF-1, AMPK, Akt, GSK3 y p70S6K).Con el fin de poder comparar las cascadas se ha dando un nombre según el nivel en que se encuentran las quinasas. De este modo tenemos MAP4K (por ejemplo PKC, GAP, PKA y enzimas sin actividad quinasa como PLC) que es la quinasa de MAP3K; MAP3K (ej. RAF-1) que es la quinasa de MAP2K; y así sucesivamente con MAP2K (ej. MEK), MAP1K o MAPK (ej. ERK) y finalmente KA MAPK (ej. RSK o quinasa ribosomal S6) que es la quinasa activada por MAP1K (Figura 7I).

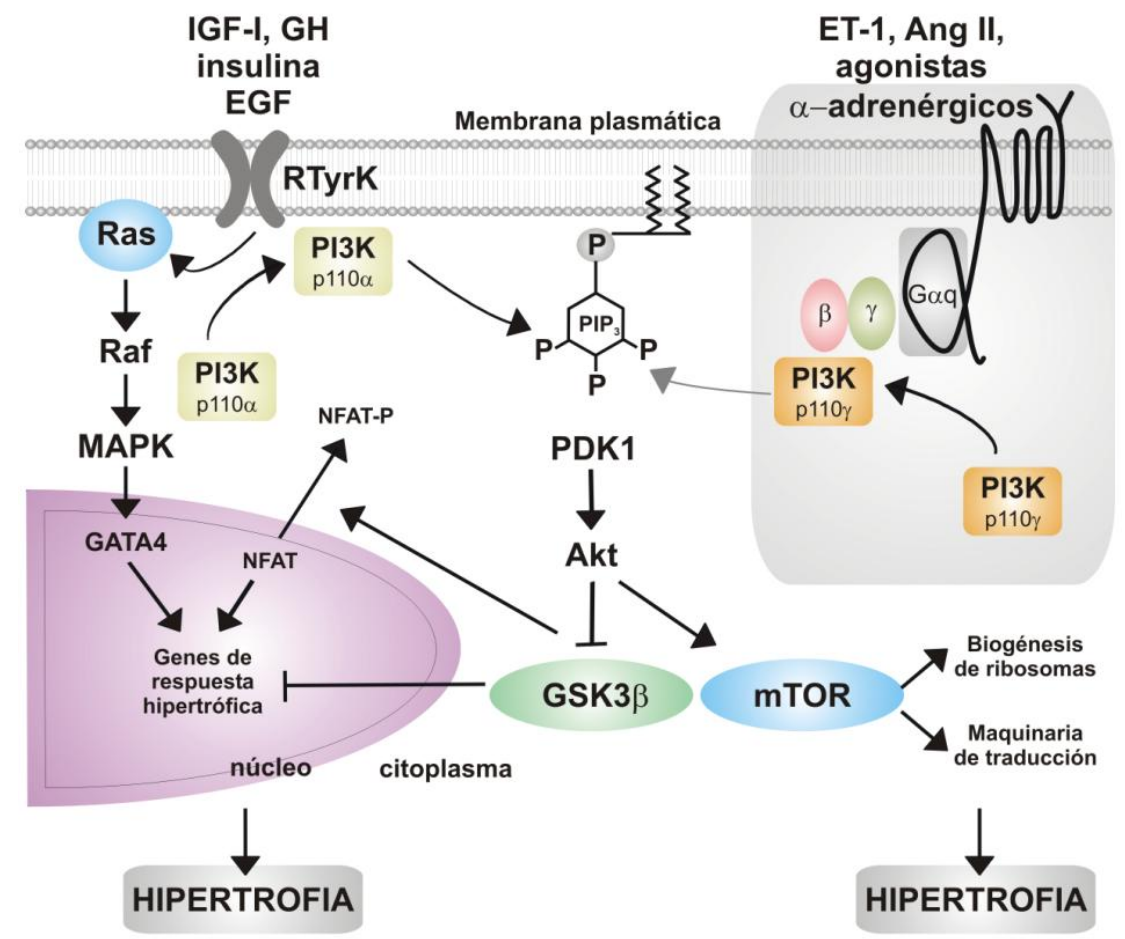

Figura 7I. Activación de la vía RTK en la HC. La unión de factores de crecimiento, como IGF-1, EGF, insulina y GH a sus receptores produce la activación de la vía Ras/Raf/MAPK. Por otro lado, puede producirse la traslocación de la isoforma p110a de la PI3K y la fosforilación por esta quinasa de fosfatidilinositoles de la membrana en la posición 3' del anillo inositol. Los lípidos fosforilados de esta manera, junto con PDK1, activan a la quinasa Akt (PKB). Akt es capaz de activar a mTOR, un regulador central de la síntesis proteica, por sus efectos sobre la biogénesis de ribosomas como sobre la maquinaria de traducción proteica. Akt también fosforila e inhibe la GSK3 $\beta$ (quinasa $3 \beta$ de la glicógeno sintasa). Dado que la GSK3 $\beta$ es un inhibidor clave del proceso de traducción de factores de transcripción relacionados con la inducción del programa hipertrófico, la inhibición de la GSK3 $\beta$ promueve tanto la síntesis de proteínas como la transcripción génica. En el recuadro sombreado de la esquina superior derecha de la figura se muestra cómo esta vía puede además ser activada mediante la estimulación de los GPCRs, en este caso participa la isoforma p110y de la PI3K y las subunidades By de la proteína $\mathrm{G}$ para promover la activación de Akt. 


\section{Introducción}

\section{Receptores asociados a proteínas quinasas.}

Existen receptores que no tienen zonas con actividad catalítica y para poder transducir se asocian a proteínas que si la posee. Estas proteínas fosforilan al receptor permitiendo que sean reconocidas por la siguiente molécula en la vía de transducción, tal como ocurre con los RTK. Pertenecen a este grupo el receptor de las citoquinas, el cual se asocia a la familia Janus (JAKs, con actividad tirosina quinasa) (Figura 8I).

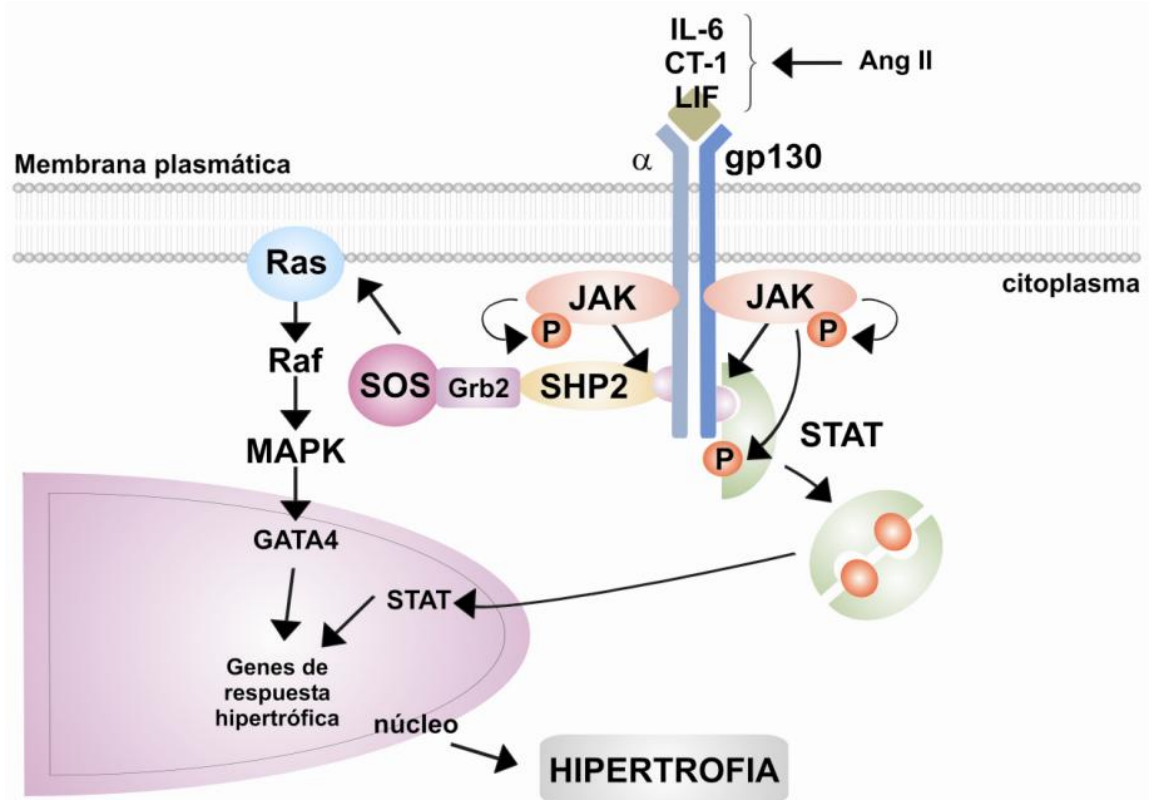

Figura 8I. Activación de la vía gp130. La vía de señalización se inicia cuando la citoquinas se unen a su receptor $\alpha$, promoviendo así la unión con gp130. Una vez dimerizado el receptor se le unen dos proteínas JAK que, activadas por fosforilación recíproca, fosforilan al receptor en tirosina. Dicha acción proporciona un sitio de anclaje para los STAT ("traductor de señales y activador de la transcripción") en gp130, donde serán fosforilados. Luego liberados del receptor, y tras dimerizarse, se dirigen al núcleo, donde estimulan la transcripción génica. La fosforilación del receptor por las JAK también provee un sitio de anclaje para la SHP2 (tirosina fosfatasa con dominio SH2), que es a su vez fosforilada por JAK, permitiendo la unión del complejo Grb2/SOS. El reclutamiento de SOS al complejo, promueve la activación de Ras e induce la vía de señalización Ras/Raf/MAPK. 


\section{Introducción}

3. Integrinas asociadas a proteínas quinasas.

Las integrinas son proteínas integrales de membrana implicadas en la unión de la célula a la matriz extracelular y además median mecanismos de transducción, de un modo similar al grupo anterior, ya que las integrinas no posee actividad catalítica pero se pueden unir a proteínas que si la poseen. Constituídas por dos subunidades a y $\beta$, que se extienden a través de la membrana plasmática, un dominio extracelular extenso que le permite unirse a proteínas de la matriz (como laminina y fibronectina), y una cola citoplasmática corta mediante la cual interactúa con los filamentos de actina a través de proteínas accesorias (como vinculina, filamina y a-actinina)(48)(Figura 9I).

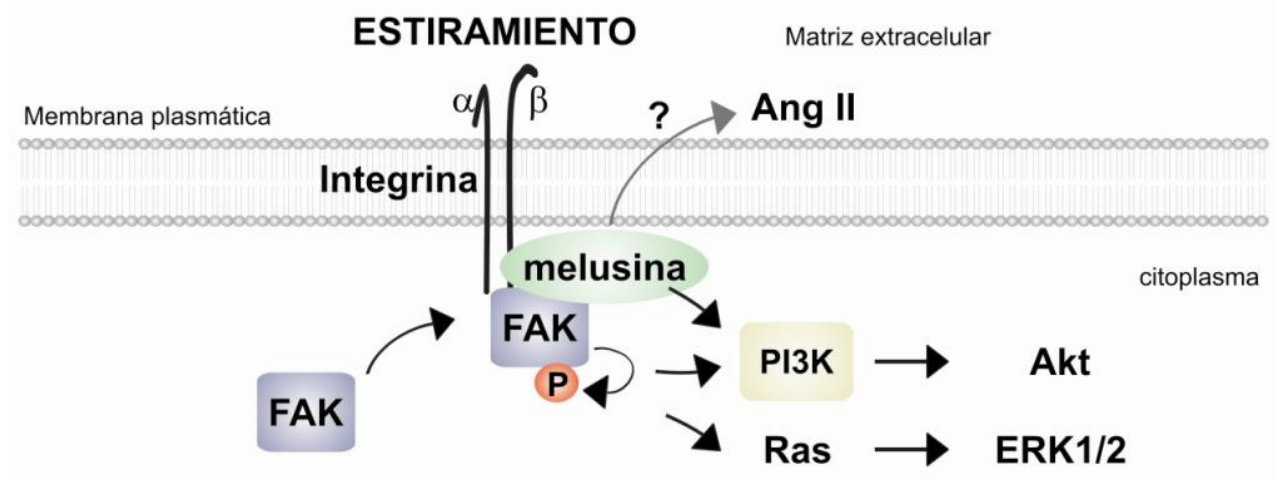

Figura 9I. La unión de la integrina a un determinado sustrato o como respuesta al estiramiento, produce la activación de proteínas como FAK (quinasa de adhesion focal) y melusina. FAK se activa por autofosforilación, induciendo las vías hipertróficas PI3K/Akt y Ras/ERK1/2 (49). Melusina activa la vía hipertrofiante PI3K/AKT, como respuesta al estiramiento (50). 
Integración de señales. Las distintas vías de transducción se entrecruzan unas con otras, permitiendo que la llegada de una señal pueda activar a mas de una vía. De esta forma se garantiza que la señal logre su efecto, pues la contribución de una única vía podría resultar crítica para lograrlo. Este sistema de transducción de una célula se asemeja más a una red que a un sistema de vías independientes (Figura 10I).

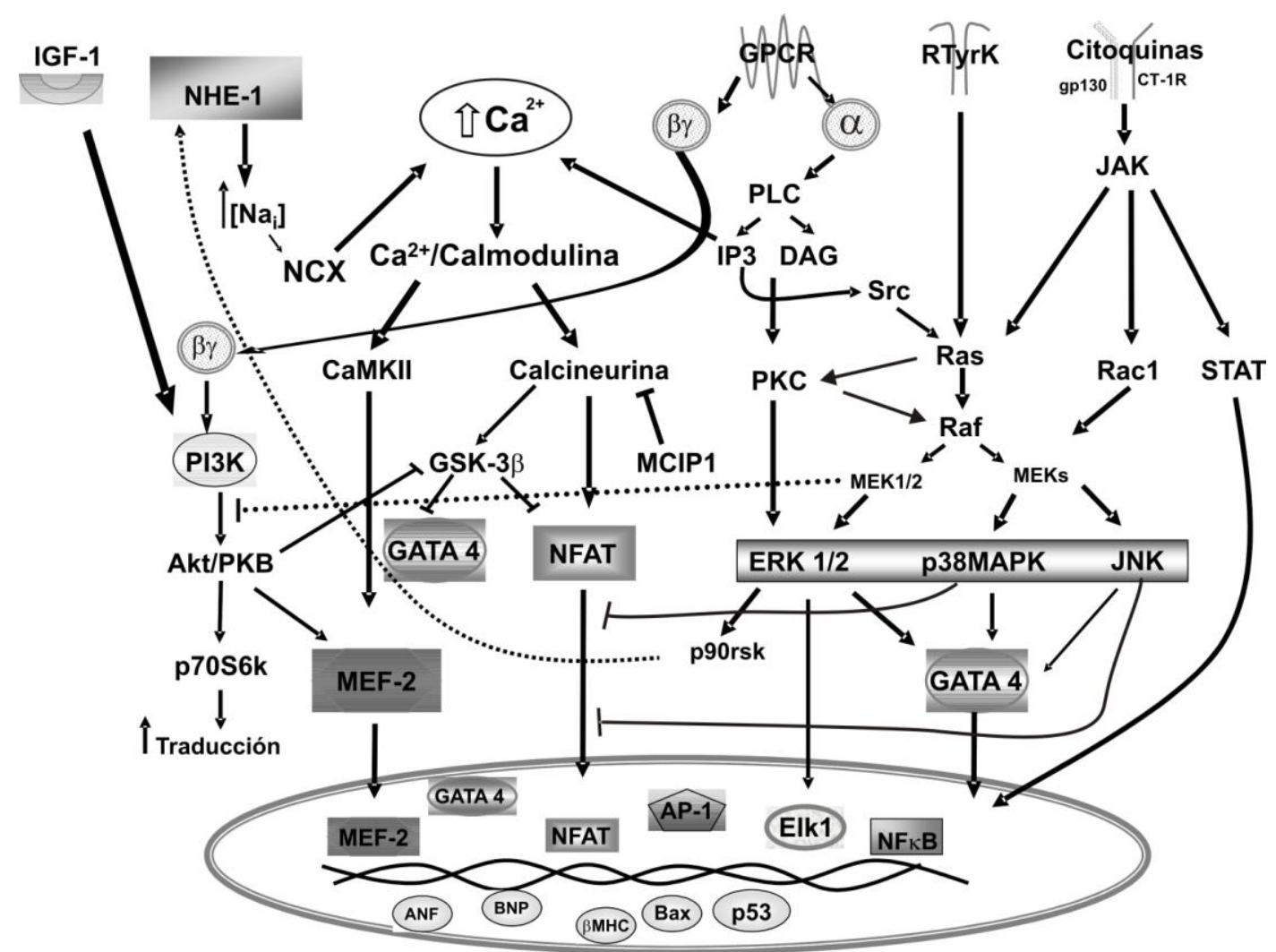

Figura 10I. Vías intracelulares que conducen a la HC. Una amplia variedad de condiciones fisiológicas o patológicas son capaces de inducir $\mathrm{HC}$ al activar diferentes receptores de membrana y vías de señalización intracelular. Como puede apreciarse, existen diversos puntos de contacto entre las vías activadas por GPCR, RTK y los receptores de citoquinas, y comparten la estimulación de la cascada de las MAPK. Las tres familias de MAPK (ERK1/2, p38 MAPK y JNK) estimulan proteínas y factores de transcripción involucrados en la génesis de la HC. En el caso particular de las ERK1/2, éstas también han sido implicadas en la estimulación del NHE-1 a través de la quinasa p90rsk. La mayoría de las vías intracelulares que participan en el desarrollo de $\mathrm{HC}$ confluyen en la producción de un incremento de la $\left[\mathrm{Ca}^{2+}\right] \mathrm{i}$, señal hipertrofiante ampliamente reconocida, que luego de interactuar con calmodulina puede activar al menos dos rutas distintas: la proteína quinasa II (CaMKII) y/ó la fosfatasa calcineurina. Ambas vías conducen a la activación y traslado al núcleo de factores de transcripción que estimulan la transcripción génica. Ninguna cascada de señalización intracelular regula la hipertrofia de los cardiomiocitos de manera aislada, sino que por el contrario, existe un gran entrecruzamiento entre ellas. 


\section{EL ESTIRAMIENTO MIOCARDICO CONDUCE A LA HC.}

La sobrecarga hemodinámica por aumento de la presión y/o de volumen se traduce en el estiramiento del miocardio seguido de una contracción más poderosa, posibilitando al corazón adaptar su volumen minuto a diferentes condiciones hemodinámicas. Esto constituye el mecanismo de Frank-Starling que permite que el corazón pueda aumentar su volumen latido luego de un aumento en el retorno venoso (aumento de la precarga) o bien eyectar el mismo volumen latido ante un aumento en la resistencia aórtica a la eyección por ejemplo por hipertensión arterial (aumento de la post carga).

Cuando la duración de estrés parietal al que está sometido el corazón pasa de ser transitoria a permanente, se producen profundos cambios histológicos asociados a anormalidades celulares. La tensión mecánica generada por el estiramiento es el estímulo inicial que activa cascadas de señalización intracelular que al llegar al núcleo promueven el aumento de la transcipción génica y consiguientemente de la síntesis proteica, provocando así el desarrollo de HC.

Los miocitos cardíacos son capaces de detectar el estiramiento aún en ausencia de factores neurohumorales (37). Se ha propuesto que la tensión generada en la membrana plasmática es detectada por una molécula mecano-sensible que se encargaría de la transducción de la señal, pero no se sabe con certeza que moléculas son activadas directamente por el estiramiento e indirectamente por otros factores (37). La fuerza generada por la deformación de la membrana activa a una variedad de receptores mecano-sensibles entre los que se destacan los GPCR, los canales iónicos (51), las integrinas (52), las citoquinas y las RTK (53). Por otro lado, experimentos realizados en cardiomiocitos aislados demostraron que el estiramiento provoca liberación de All y ET-1 de manera "autócrina" $(54,55)$, péptidos íntimamente vinculados al desarrollo de HC. Dado que el miocardio posee además fibroblastos y células endoteliales, estos se constituyen en sitios potenciales para la liberación paracrina de All y ET-1.

Características generales de la segunda Fase de Fuerza (SFF) post estiramiento. En 1973, Parmley y Chuck (56) reprodujeron el efecto contractil del estiramiento empleando tiritas aisladas de miocardio y observaron que al estirarse el músculo hay aumentos rápidos y aumentos lentos de la fuerza desarrollada, es decir, 
se produce un aumento bifásico en la contractilidad. Primero se aprecia un incremento inmediato en la fuerza, que se atribuye al mecanismo de Frank-Starling y es debido a un aumento en la respuesta de los miofilamentos al calcio. A continuación y durante los próximos 10 a 15 minutos tiene lugar un aumento lento llamado segunda fase de fuerza (SFF o efecto Anrep), asociado a un incremento en los transitorios de calcio intracelular (luego de cada potencial de acción o sea en cada contracción), secundario al incremento de la concentración intracelular de sodio $\left(\left[\mathrm{Na}^{+}\right]_{\mathrm{i}}\right)$ (Figura 11I).
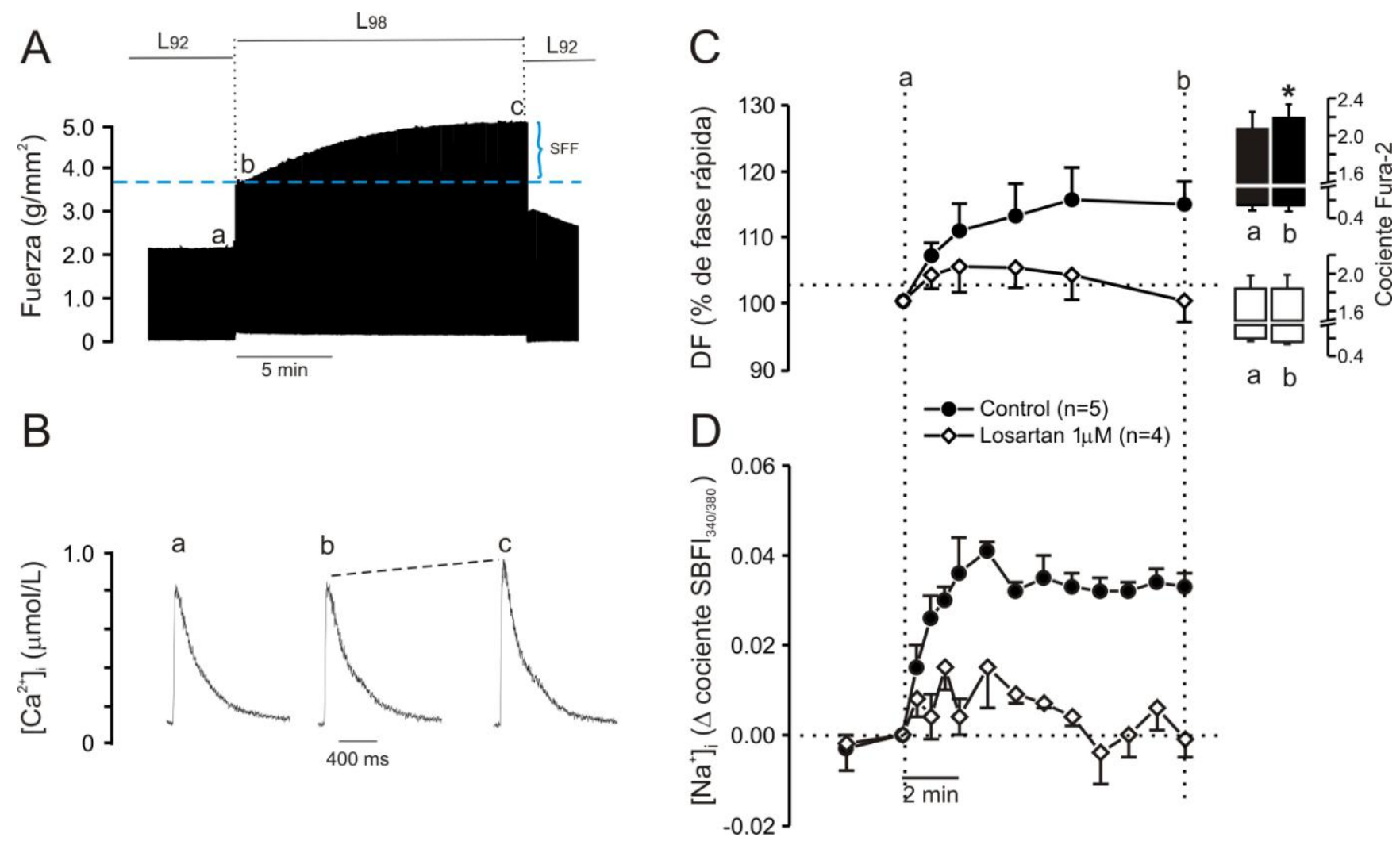

Figura 11I. Luego de estirar un músculo papilar desde el 92 al 98\% de Lmáx (longitud a la que desarrolla la fuerza máxima), aumenta inmediatamente la fuerza (de a a b, panel A) debido al mecanismo de FrankStarling. Posteriormente se desarrolla un incremento progresivo en la fuerza, la SFF, que es debida un incremento en los transitorios de $\mathrm{Ca}^{2+}$ (panel B), secundario al incremento de la [ $\left.\mathrm{Na}^{+}\right]_{\mathrm{i}}$ (panel $\mathrm{D}$ "control"). La SFF, el incremento en la $\left[\mathrm{Na}^{+}\right]_{i}$ y el incremento de los transitorios de $\mathrm{Ca}^{2+}$ son abolidos al bloquear los receptores $\mathrm{AT}_{1}$ de A Il con losartán (paneles C y D). Modificado de News Physiol Sci 16:88-91, 2001.

Estudios en diferentes laboratorios sugieren que el incremento en el transitorio de calcio, no sería debido a la entrada de calcio por los canales $L$ (45) ni a la liberación de calcio desde el retículo sarcoplasmático (RS) (57). El origen del incrementro de calcio permaneció desconocido hasta que se propuso un nexo entre la activación del 
intercambiador sodio-hidrógeno miocárdico (NHE-1) producido por el estiramiento y el posterior influjo de calcio mediado por el intercambiador sodio-calcio (NCX) en su modo inverso (58-60).

Los mecanismos que subyacen al desarrollo de la SFF son similares a las vías de señalización intracelular que conducen a la $\mathrm{HC}$, lo cual ha permitido usar a este mecanismo agudo de adaptación del miocardio como modelo para analizar la fisiopatología cardiovascular $(61,62)$.

NHE-1, NCX y SFF. En 1998 Cingolani y col. (63), utilizando músculos papilares de gato detectaron que el estiramiento del miocardio en una solución libre de bicarbonato provocaba alcalinización intracelular, la cual era debida a la activación del NHE-1 consecuencia de la liberación de All y ET endógenas. Posteriormente se demostró la participación del NCX en su modo inverso, secundario al incremento de sodio por el NHE-1, como ruta de ingreso del calcio responsable de la SFF (63-69). La mayor contribución del trabajo citado fue la de detectar en preparaciones multicelulares de corazones de animales adultos, la existencia de un mecanismo inducido por el estiramiento que se inhibía por el bloqueo de receptores $A T_{1}$ y $E T_{A}$, lo que llevó a proponer que All y ET eran mediadores autocrino-paracrino de dicho fenómeno.

NHE-1, AE y SFF. Prosiguiendo con estos estudios comprobaron que el incremento del $\mathrm{pH}$ intracelular no se detectaba si el estiramiento se producía en un medio con bicarbonato $\left(\mathrm{CO}_{3} \mathrm{H}^{-}\right)$, mientras que si se observaba aumento de la fuerza $(63,65)$. Este hecho se debe a que All, a través de la liberación y formación de ET y posterior activación de PKC, estimula simultáneamente al NHE-1 (mecanismo alcalinizante e independiente de $\mathrm{CO}^{-} \mathrm{H}^{-}$) y al intercambiador cloro/bicarbonato ( $\mathrm{AE}$, mecanismo acidificante e independiente de sodio), dos intercambiadores antagónicos que minimizan el cambio de $\mathrm{pH}$ sin comprometer el aumento de la SFF (70) (Figura 12I). Por lo tanto, detectar la activación del NHE mediante el incremento del $\mathrm{pH}$, es sólo factible si el medio carece de $\mathrm{CO}_{3} \mathrm{H}^{-}$, pero el incremento de sodio se manifiesta ya sea que el medio posea o no este anión. Experimentalmente es muy frecuente la utilización de buffers como el HEPES, debido a que si bien en condiciones fisiológicas está presente el sistema $\mathrm{CO}_{2} / \mathrm{CO}_{3} \mathrm{H}^{-}$, es común su reemplazo debido a las dificultades de obtener mezclas gaseosas exactas, a la necesidad de burbujear los medios y a la 


\section{Introducción}

gran permeabilidad del $\mathrm{CO}_{2}$ que se escapa a través de las gomas siliconadas.

\section{Buffer bicarbonato}

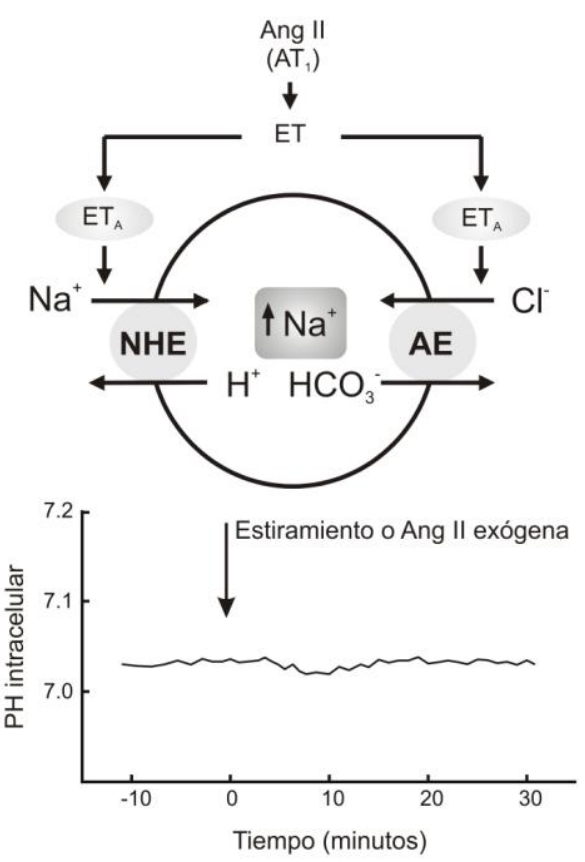

Buffer HEPES

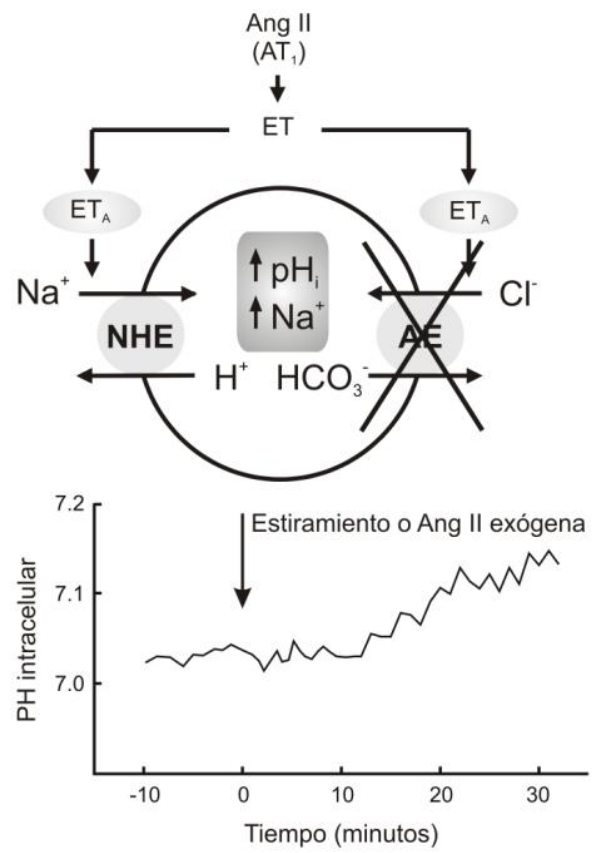

Figura 12I. Mecanismo propuesto para el efecto del estiramiento sobre los mecanismos reguladores del $\mathrm{pH}_{\mathrm{i}}$. La activación simultánea del NHE y del AE previene el aumento del $\mathrm{pH}_{\mathrm{i}}$ pero no el incremento de la $\left[\mathrm{Na}^{+}\right]_{\text {i }}$. Un incremento en el $\mathrm{pH}_{\mathrm{i}}$, luego del estiramiento, puede tener lugar en ausencia de bicarbonato (buffer HEPES).

NBC. All estimula al cotransportador $\mathrm{Na}+/ \mathrm{CO}_{3} \mathrm{H}^{-}$(NBC) (15), el cual media el cotransporte iónico de $1 \mathrm{Na}^{+}: 1 \mathrm{CO}_{3} \mathrm{H}^{-}$(electroneutro), pudiendo también catalizar el transporte de $1 \mathrm{Na}^{+}: 2$ o $3 \mathrm{CO}_{3} \mathrm{H}^{-}$(electrogénico). $\mathrm{NBC}$ forma parte de las denominadas proteínas transportadoras de bicarbonato que catalizan el movimiento transmembrana de dicho ión, junto con el $\mathrm{AE}$ y los intercambiadores $\mathrm{Cl}^{-} / \mathrm{CO}_{3} \mathrm{H}^{-}$noveles (SLC26A). Los AE son intercambiadores electroneutros $\left(1 \mathrm{Cl}^{-}: 1 \mathrm{CO}_{3} \mathrm{H}^{-}\right)$. Los SLC26A difieren de los $A E$ tanto en su secuencia aminoacídica como en su estequiometría $\left(1 \mathrm{Cl}^{-}: 2 \mathrm{CO}_{3} \mathrm{H}^{-}\right)(71)$. 


\section{VÍAS DE SEÑALIZACIÓN INDUCIDAS POR EL ESTIRAMIENTO.}

La vía de señalización activada por el estiramiento, propuesta por nuestro grupo de trabajo es la siguiente:

1. Liberación de All y activación de sus receptores $A T_{1}$.

2. Liberación de ET-1 y activación de sus receptores $\mathrm{ET}_{\mathrm{A}}$.

3. Transactivación del EGFR.

4. Producción de especies reactivas del oxígeno (ROS).

5. Activación de la MAP quinasa ERK 1/2 (quinasa redox sensible) por los ROS.

6. Fosforilación y activación del NHE-1.

7. Aumento en la concentración intracelular de sodio.

8. Activación del NCX en su modo inverso.

9. HC promovida por el incremento en el calcio. (Figura 13I).

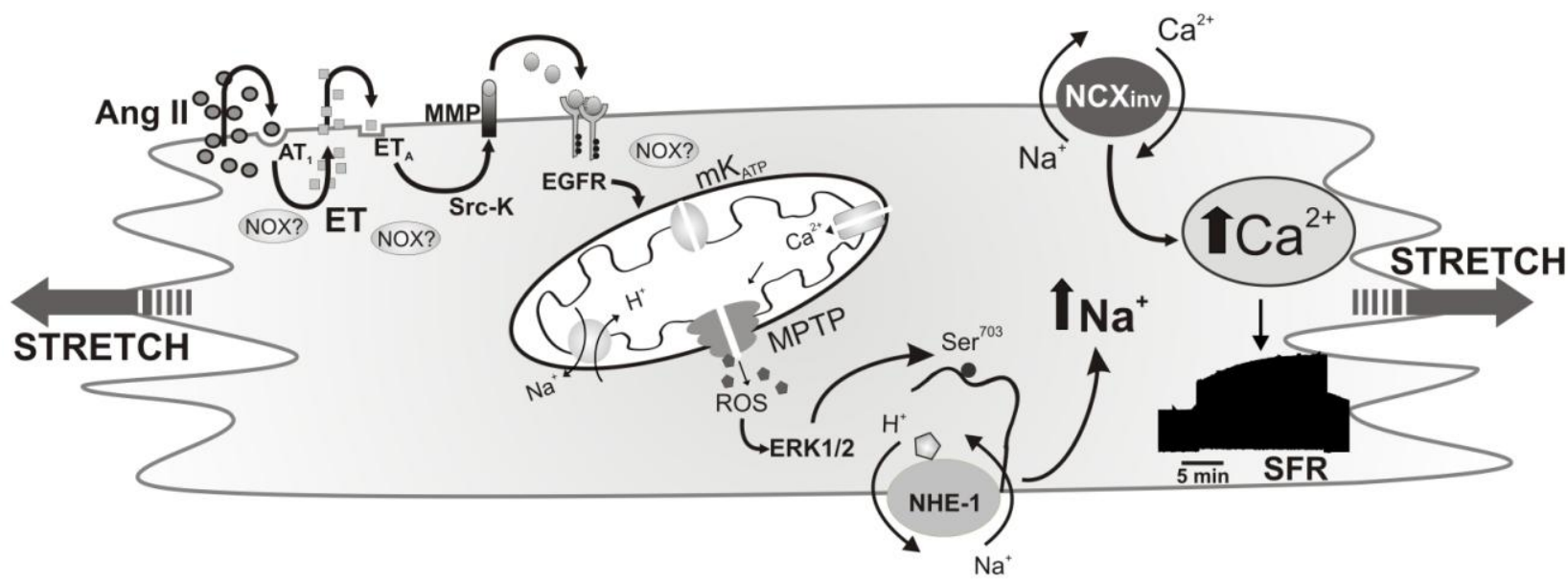

Figura 13I. Esta figura esquematiza nuestras contribuciones al mecanismo que genera el Efecto Anrep y por lo tanto las señales precoces en la ruta hacia la $\mathrm{HC}$ (72).

\section{Liberación de All y activación de sus receptores.}

Función y síntesis de All. All es una hormona multifuncional. Posee numerosos efectos actuando sobre músculo liso vascular, riñón, glándulas suprarrenales, cerebro y corazón, desempeñando un papel muy importante en la regulación de la presión arterial y en el balance de líquidos y electrolitos.

- A nivel vascular produce vasoconstricción arteriolar, aumentando la resistencia periférica y de esta manera la presión arterial. Favorece la liberación y reducción de la recaptación de noradrenalina de las terminaciones nerviosas vasculares, lo que a su vez potencia el efecto 
vasoconstrictor. Además, promueve el crecimiento de las células musculares lisas vasculares.

- Sobre el riñón produce vasoconstricción de ambas arteriolas, en especial la aferente, influyendo sobre la tasa de filtración glomerular. También aumenta la reabsorción proximal de sodio e inhibe la secreción de renina.

- Actúa sobre la corteza de la glándula suprarrenal, estimulando la liberación de aldosterona, que favorece la reabsorción renal de sodio a nivel del túbulo distal.

- Sobre el sistema nervioso central estimula la sed y aumenta la secreción de hormona antidiurética o vasopresina, incrementando de este modo la reabsorción de agua en los túbulos colectores renales.

- Sobre el corazón posee efecto inotrópica positiva (EIP), estimula la síntesis proteica, la proliferación de fibroblastos, la producción de colágeno y la hipertrofia miocítica (73).

El aparato yuxtaglomerular, cuyos componentes son la arteriola aferente, eferente y la mácula densa, contiene células especializadas denominadas células yuxtaglomerulares que sintetizan, almacenan y liberan renina. La mácula densa actúa como un sensor que monitoriza la presión y la concentración de $\mathrm{CINa}$, y ante una disminución de la presión arterial o una disminución del $\mathrm{Na}^{+}$extracelular a nivel sistémico, las células yuxtaglomerulares renales liberan renina al plasma. La renina es sintetizada como una preprohormona (llamada preprorrenina), la cual en el retículo endoplasmático se desdobla formando una glicoproteína inactiva (prorrenina), que se almacena en los gránulos del aparato de Golgi, para posteriormente convertirse en una glicoproteína activa (enina). Esta proteasa ejerce su acción sobre el angiotensinógeno, un glucopolipéptido circulante perteneciente a la familia de las $\alpha$-2-globulinas y sintetizado principalmente por el hígado, generando un producto de 10 aa, conocido como angiotensina I (Al) que posee poca o nula actividad biológica. La enzima convertidora de angiotensina (ECA), carboxipeptidasa presente principalmente en pulmón, cliva la Al produciendo el octapéptido All. Ésta tiene una vida media muy corta (menos de un minuto) ya que es degradada y removida de la circulación por distintas peptidasas (angiotensinasas) presentes en los tejidos, dando como producto angiotensina III (AIII) de menor actividad (74) (Figura 14I). 


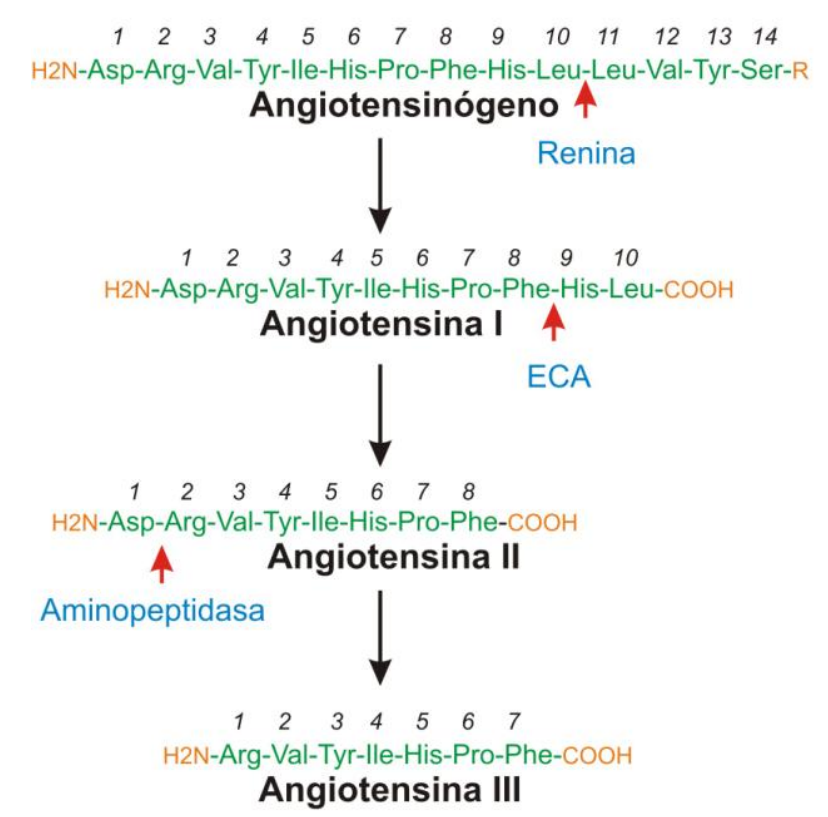

Figura 14I. SRA. Etapas de la generación y degradación de All.

Originariamente el sistema renina-angiotensina (SRA) fue descripto como un sistema endocrino (75), pero luego varios de sus componentes fueron encontrados en distintos tejidos y se demostró la síntesis local de All en órganos aislados como cerebro y pulmón (76). En el músculo cardíaco se comprobó la expresión de ARN mensajeros (ARNm) para el angiotensinógeno, la ECA y los receptores de All (77), sustentando la posibilidad de una síntesis local del péptido. Actualmente se conoce la existencia del SRA local en el miocardio (78). Las concentraciones de Al y All medidas en el intersticio miocárdico se hallan en el rango nanomolar, valores que superan aproximadamente 100 veces la concentración plasmática de ambos péptidos $(79,80)$.

Receptores de All. Los receptores de All están localizados en la membrana plasmática de las células blanco. Se han encontrado dos tipos de receptores de All en diferentes tejidos: $\mathrm{AT}_{1}$ sensible al bloqueo con losartan y $\mathrm{AT}_{2}$ inhibido por PD123319 (81-83). Ambos receptores se expresan en el corazón de rata, gato y humano $(84,85)$. Estos receptores pertenecen a la familia de receptores acoplados a proteínas $G$ especialmente de tipo $q(\mathrm{Gq})(86)$.

Los receptores $\mathrm{AT}_{1}$ y $\mathrm{AT}_{2}$ tienen acciones opuestas en lo que respecta al crecimiento celular (87). Los $A T_{1}$ favorecen la vasoconstricción, el EIP, la fibrosis y la síntesis proteica que conducen a $\mathrm{HC}$ (88). En cambio, los receptores $\mathrm{AT}_{2}$ median efectos antiproliferativos, aumentan la producción de óxido nítrico (NO) y disminuyen la 
frecuencia cardiaca (89).

Vía de señalización de All. La mayoría de las acciones de All son a través de AT1. Dicha unión produce la activación de la fosfolipasa C (PLC), dando lugar a la liberación de IP3 y DAG, los cuales están involucrados en el aumento de la concentración intracelular de calcio $\left(\left[\mathrm{Ca}^{+2}\right]_{\mathrm{i}}\right)$ y su movilización de los depósitos intracelulares por activación de la PKC (90) (Figura 15I).

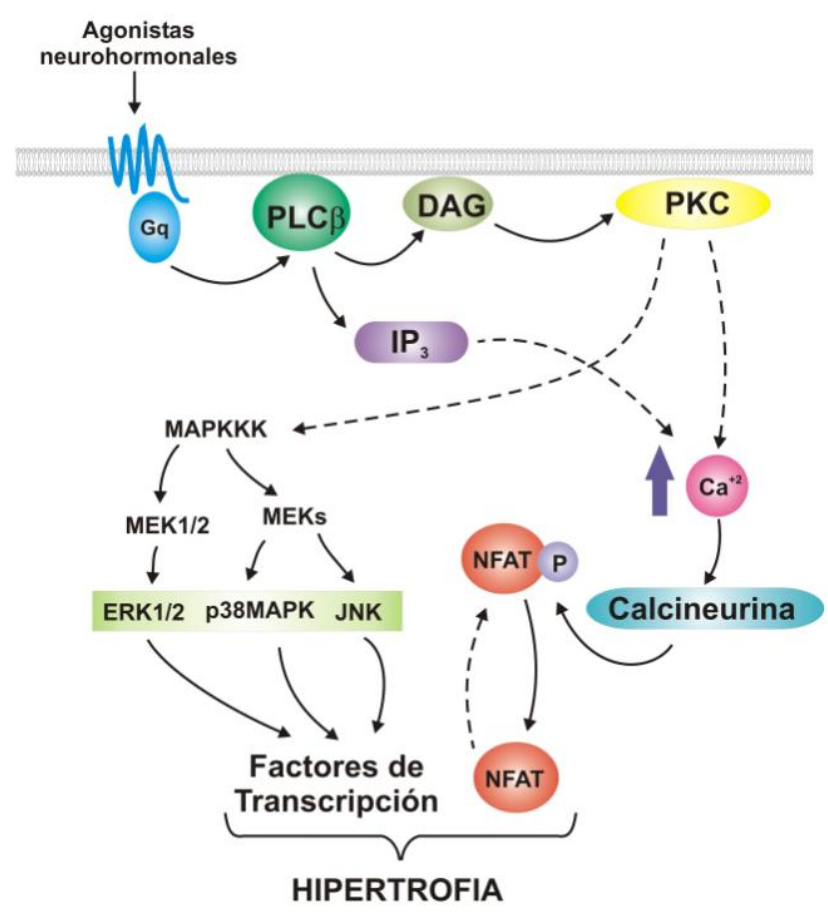

Figura 15I. Vía de señalización activada por la quinasa PKC: promueve el aumento de $\left[\mathrm{Ca}^{+2}\right]_{i}$ y la activación de moléculas implicadas en vías de señalización intracelular que estimulan la síntesis proteica y la transcripción de genes, procesos estrechamente relacionados con el EIP y el desarrollo de HC.

\section{Liberación de ET-1 y activación de sus receptores.}

Síntesis, clasificación y función de ET. ET es una familia de péptidos con propiedades vasoconstrictoras muy potentes. Existen tres tipos, ET-1, ET-2 y ET-3, todas ellas con 18 aa. Se originan como una proteína (de aproximadamente 212 aa) denominada preproendotelina, la cual es clivadas por una peptidasa dando las respectivas ET-grandes (o "big-ETs") de 38 aa (91). Posteriormente son transformadas en ET activa por una metalopeptidasa llamada enzima convertidora de endotelina (ECE) para dar los polipéptidos de 21 aa. (Libro de Fuster V.; Wayne Alexander R.; O'Rourke R, “The Heart”, editorial McGraw-Hill, USA, 2004.). (Figura 16I). 


\section{Introducción}

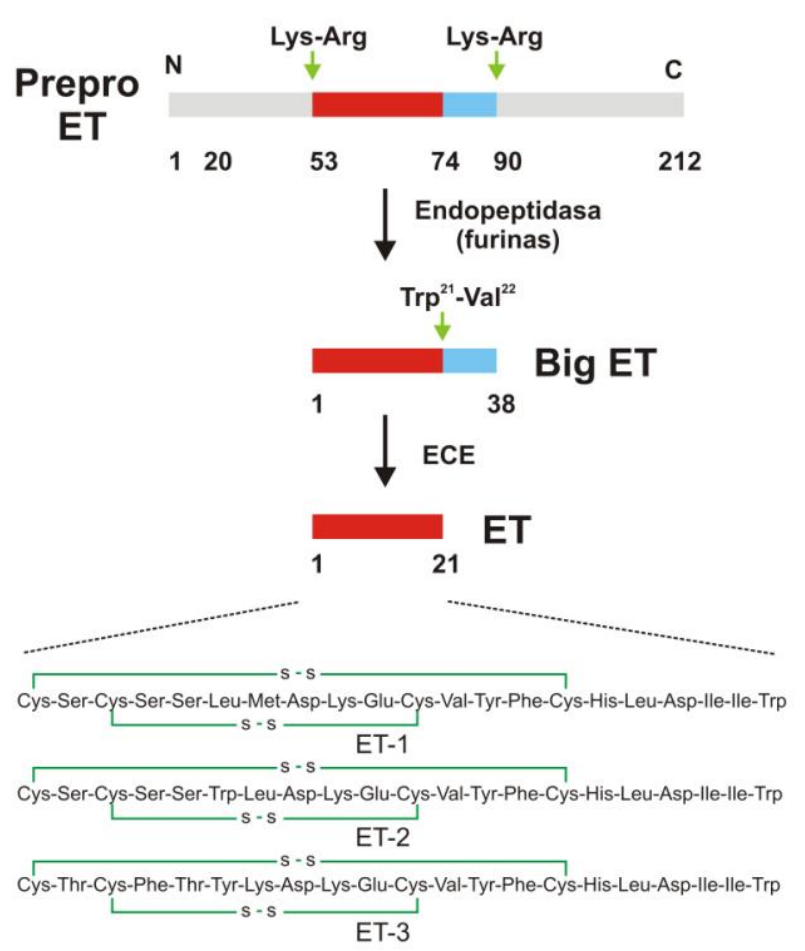

Figura 16I. Procesamiento de la prepro-ET e isoformas de ET.

Las distintas isoformas de ET son producidas por gran variedad de tejidos y tipos celulares. ET-1 se genera en células endoteliales y músculo liso vascular, miocardio, riñón y sistema nervioso central $(92,93)$. ET-2 es sintetizada en riñón, intestino, placenta, útero, corazón y células endoteliales (94). Finalmente, ET-3 es producida en cerebro, miocardio y tracto gastrointestinal (95).

En preparaciones de miocardio se observó que las tres ETs tienen EIP de potencia similar, siendo además ET-1 un potente factor de crecimiento con efecto vasoconstrictor $(96,97)$. Ennis y col. (98), trabajando en preparaciones multicelulares observaron que el estiramiento miocárdico libera ET-3, y ésta sería la responsable del EIP, aunque no se descarta que pudiera ser además responsable de la síntesis y liberación de ET-1, la cual a su vez induciría el crecimiento celular.

Receptores de ET. El efecto de ET, al igual que All, está mediado por la activación de receptores de membrana acoplados a proteína $\mathrm{G}$. Se han descripto tres tipos de receptores: $\underline{E T}_{A}, \underline{E T}_{B}$ y $\underline{E T}_{\underline{C}}$. En los vasos se encontró que $\underline{E T}_{\underline{A}}$ predomina en el músculo liso y $\underline{E T}_{\underline{B}}$ en las células endoteliales. Estos dos tipos de receptores se los ha identificado en el corazón de diferentes especies (99). La activación de $\underline{E T}_{\mathrm{A}}$ produce un potente efecto vasoconstrictor (por aumento de la $\left[\mathrm{Ca}^{+2}\right]_{\mathrm{i}}$ ), mientras que la activación 
de $\underline{E T}_{\underline{B}}$ favorece la vasodilatación (por liberación de NO).

Se ha propuesto la existencia de 2 subtipos de receptores $E T_{A}$, $\underline{E T}_{A 1}$ y $\underline{E T}_{A 2}$, con diferente sensibilidad a las diferentes isoformas de ET (96). En forma general, la activación de los $\mathrm{ET}_{\mathrm{A}}$ está estrechamente asociada con vasoconstricción y EIP. EI mecanismo involucrado es mediante la disociación de la proteína Gq y ésta, a su vez activa la PLC $\beta$ que produce activación de PKC (100). Existen evidencias de 2 subtipos de receptores $\mathrm{ET}_{\mathrm{B}}$, $\underline{\mathrm{ET}}_{\underline{B} 1}$ y $\underline{\mathrm{ET}}_{\underline{B} 2}$, los cuales se asocian a efectos vasodilatadores (mediados por NO y prostaglandina- $\mathrm{I}_{2}$ ) y vasoconstrictores (93).

All y ET. Distintos efectos cardiovasculares inicialmente atribuídos a All, se consideran actualmente que en realidad se deben a la acción autócrina/paracrina de ET-1 liberada por All. Estos dos se comunican de manera unidireccional, desde All a ET-1 y no en sentido contrario, dado que el efecto de All exógena se anula con el agregado de bloqueantes de ET-1; mientras que antagonistas AT1, como Losartan, no bloquean el efecto de ET exógena $(60,63)$. Comprobándose de esta manera que el bloqueo de los receptores de ET evita efectos atribuidos a All como el desarrollo de hipertensión provocado por su administración crónica (101), el efecto hipertrófico sobre miocitos cardíacos (55) y la activación del NHE (64) y del AE (58).

Por otra parte, los efectos de All mediados por ET serían evidentes cuando la concentración de All es pequeña (del orden nanomolar o inferiores) (102) y el EIP es producido por la activación de la vía All/ET/NHE/ NCX modo inverso. Mientras que cuando su concentración es del orden micromolar se observan los efectos directos de la All (103) y evidencias previas sugieren que el mecanismo responsable del EIP sería por la activación de la corriente de calcio tipo $L$ e independiente de ET (104).

Además, mediante experimentos realizados con la técnica de RT-PCR en tiempo real se ha demostrado que la administración de All estimula la expresión del ARNm de la preproendotelina. Estos resultados sugieren que la All aumenta la expresión de ET-1 con el posible fin de restaurar el pool intracelular de este péptido que estaría siendo liberado desde el miocito cardíacos por acción de la All (105).

\section{Transactivación del EGFR.}

El fenómeno de transactivación es el proceso por el cual la estimulación de GPCR, resulta en la activación de RTK en ausencia de un ligando específico para estos últimos, generando señales mitogénicas (Figura 17I). 
Trabajos recientes demuestran a través de distintos experimentos la importancia de la transactivación de RTK, como el EGFR, debido a la activación GPCR por agonistas (como All y ET) en el miocardio (72, 106-108).

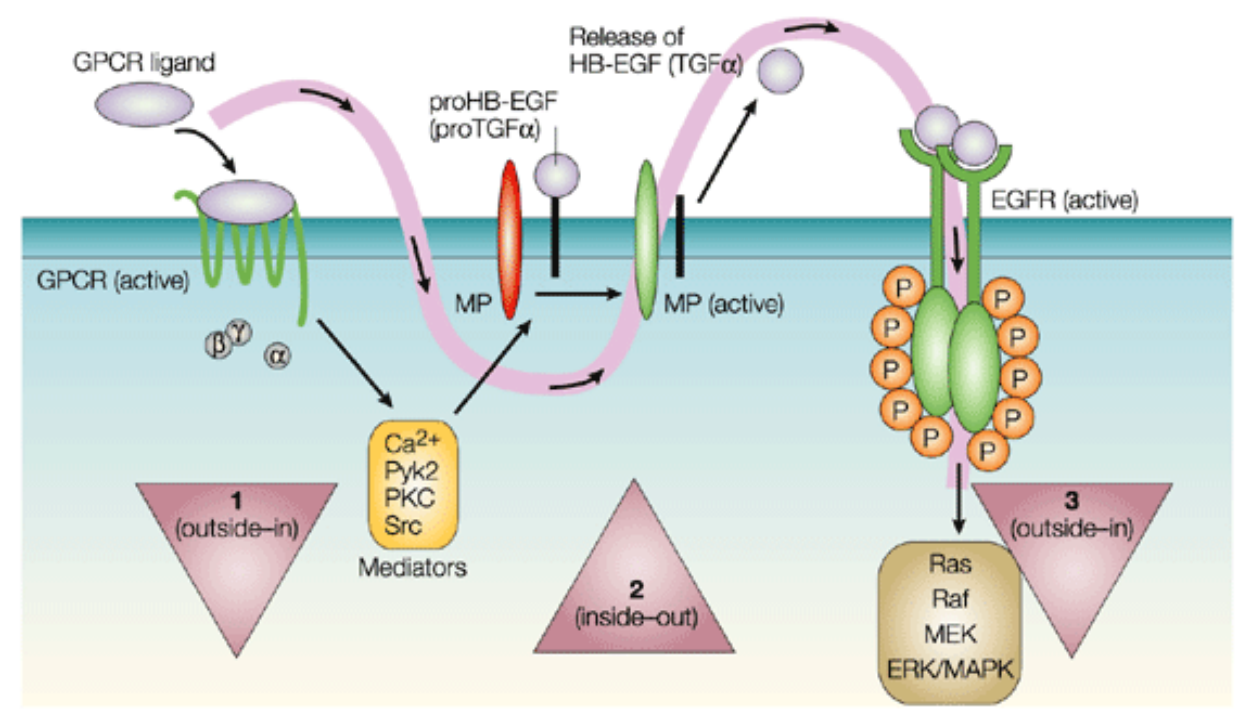

Nature Reviews | Molecular Cell Biology

Figura 17I. Transactivación del EGFR. La estimulación de GPCR, resulta en la activación de RTK y a continuación de las MAPK. El proceso de transactivación involucra no sólo a distintos mediadores como la quinasa Src y PKC sino también a las metaloproteasas de la matriz (MMP), quienes inducen el clivado de pro-HB-EGF y la posterior liberación del HB-EGF (EGF-asociado a heparina). Este último activa al EGFR, quien estimulará la vía de las MAPK (109).

Estudios efectuados en miocitos cardíacos de ratas neonatas muestran que el EGFR es transactivado durante el estiramiento $(106,107)$. Villa-Abrille y col. (72), decidieron investigar si la transactivación del EGFR participaría en la SFF. Para ello se trabajó sobre la Src tirosina quinasa y el HB-EGF (un factor similar al EGF que actúa como agonista del EGFR), dos conocidos mediadores de la transactivación del EGFR. Los resultados obtenidos demuestran que la SFF fue completamente abolida por inhibición de la quinasa Src (empleando PP1) o por inhibición de las MMP (evitando la liberación del HB-EGF). Además, la SFF fue abolida por inhibición específica del EGFR con AG1478, que previene la fosforilación del receptor (72). Por otro lado, Anderson y col. demostró que la ET liberada por el estiramiento del miocardio induce el clivado de proHB-EGF por las MMP, y la consiguiente liberación desde la membrana plasmática del HB-EGF. Observando además, que dicho efecto fue cancelado con el uso de antioxidantes ( $\mathrm{N}$-acetilcisteina) e inhibidores de la NADPH (apocinina) (107). 
Introducción

\section{Producción de ROS.}

Aunque las especies reactivas del oxígeno (EROs o sus siglas en inglés ROS) fueron considerados clasicamente como moléculas deletereas, existen evidencias que postulan que podrían funcionar como moléculas intermediarias intracelulares en vías fisiológicas de señalización. Las fuentes principales de ROS en el miocardio son: NADPH oxidasa, xantina oxidasa, oxido nítrico sintetasa desacoplada y la cadena respiratoria mitocondrial. Durante el estiramiento se produce la liberación de All que induce la formación/liberación de ET, ambos activadores de la NADPH oxidasa. Caldiz y col. (110), demostraron que el estiramiento incrementa la producción de ROS. Estos y el desarrollo de la SFF fueron bloqueados con el empleo de scavengers (como el MPG y EUK8). En los mismos esperimentos se vio que la SFF fue abolida con el uso de inhibidores de la NADPH oxidasa (como apocinina) así como también con inhibidores de los canales de potasio de la mitocondria "mKATP" (como 5-HD y glibenclamida), confirmando de esta manera que la fuente de ROS son la NADPH oxidasa y la mitocondria. Estos resultados confirman la hipótesis de Zorov y col. y Kimura y col. $(111,112)$ quienes proponen que la producción de ROS por la NADPH oxidasa induce la liberación de mayores cantidades de ROS desde la mitocondria.

En resumen, el estiramiento del miocardio ocasionado por situaciones de sobrecarga hemodinámica y/o la presencia de factores neurohumorales pro-hipertróficos como All, ET-1 y Aldosterona, activan vías de señalización intracelular que involucran el aumento de la producción de ROS, fundamentalmente de origen mitocondrial, que confluyen en la activación del NHE-1. El prevenir la liberación de ROS es suficiente para bloquear la SFF (110).

Activación de NADPH oxidasa. La generación de ROS por All y/o ET ha sido involucrada tanto en señales fisiológicas $(113,114)$ como patológicas $(115,116)$. Hong y col., trabajando en miocitos de músculo liso vascular, sugirieron que la All induce la formación de ET-1 a través de la producción de ROS (114). Por otro lado, Sand y col. demostraron, en aurícula de rata que el EIP es en parte mediado por ROS (113). Experimentos previos permiten suponer que los ROS están involucrados en el EIP inducido por ET-1 endógena liberada por All, ya que cuando se utilizó MPG, se bloqueó totalmente el EIP inducido por All 1nM (110). Según las observaciones de Villa-Abrille y col. (117), no es aún posible discriminar si la producción de ROS se encuentra antes y/o después de la activación de los receptores de ET. 


\section{Activación de la MAP quinasa ERK1/2 (redox sensible) por los ROS.}

Las tres familias de MAPK (ERK 1/2, p38MAPK y JNK) han sido involucradas en la génesis de $\mathrm{HC}$ de diferentes modelos experimentales. Estas quinasas estimulan factores de transcripción nuclear y otras proteínas involucradas en la señalización intracelular. p38MAPK está incrementada en corazones sujetos a sobrecarga de volumen y JNK está específicamente activada en respuesta a sobrecarga de presión (118). La activación de ERK's requiere de su fosforilación en un residuo de treonina y en uno de tirosina, separados únicamente por un aminoácido. Esta función sólo puede ser realizada por una enzima altamente especializada, por lo que se considera que MEK es la enzima limitante en la activación de ERK's, haciendo altamente específico este proceso. La ERK fosforilada regula por fosforilación a quinasas y a otras proteínas reguladoras de la transcripción. En el caso particular de las ERK1/2, éstas también han sido implicadas en la estimulación del NHE a través de la quinasa p90 ${ }^{\mathrm{RSK}}$. Estas son consideradas quinasas redox sensibles activadas por el estiramiento. Trabajos previos demuestran que los ROS a través de las quinasas como ERK1/2 son capaces de producir la activación del NHE-1 $(110,119)$. El aumento en la fosforilación de ERK1/2 es abolido por el bloqueo del receptor AT1 con losartan (110). La activación de las MAPKs puede producirse a través de Raf por una vía independiente de Gaq que involucra a RTK. Luego de la unión del ligando al RTK, se activa Ras quien se une a Raf (una quinasa de serina/treonina) que a su vez fosforila y activa a la MEK, enzima que fosforila residuos de serina/treonina y de tirosina. La inhibición de la MEK, quinasa que fosforila a ERK1/2, cancela la SFF. Además al impedir la transactivación del EGFR, ya sea bloqueando la Src con PP1 o inhibiendo el EGFR con AG1478, también se evita la activación de ERK1/2 (72). El agregado exógeno del EGF incrementa la fosforilación de ERK1/2, efecto que fue cancelado al prevenir la formación de ROS. 


\section{Fosforilación y activación del NHE-1.}

NHE. El NHE es una glucoproteína integral de membrana que se encuentra distribuída en todas las células. Participa en la regulación del pH intracelular mediante el intercambio electroneutro de un hidrógeno intracelular por un sodio extracelular, a través de la membrana plasmática, evitando las consecuencias potencialmente dañinas de la formación de $\mathrm{H}+$.

Isoformas del NHE. Se han descripto nueve isoformas del NHE (1 a 9), las cuales difieren en su estructura primaria, distribución celular y sensibilidad a inhibidores; pero comparten una estructura secundaria similar. Ellas son:

- NHE-1 se encuentra en la membrana plasmática de todas las células, y es la única isoforma que se expresa en las células miocárdicas (120-122). El NHE-1 es la principal ruta de salida de los protones; su activación se produce en respuesta a factores humorales y de crecimiento, durante la acidosis intracelular y en respuesta al estiramiento. Cumple una función importante en el proceso de exitación-contracción de los cardiomiocitos, el cual se inhibe por acidosis intracelular. Esto se debe a que el calcio y los protones poseen los mismos sitios de unión en la troponina $C$ (proteína que regula la actividad de proteínas contráctiles como actina y miosina). Cuando el NHE-1 se activa, los protones son excretados de la célula, disminuyendo la competencia entre estos y el calcio por la troponina C. Como resultado, es mayor la capacidad de unión del calcio aumentando la contractilidad. NHE-1 participa de procesos celulares normales como proliferación, crecimiento, migración y apoptosis; y patológicos como IC (123).

- $\mathrm{NHE}-2$ y $\mathrm{NHE}-3$ se encuentran expresadas en las células epiteliales de tracto gastrointestinal y riñón; e intervienen en la reabsorción de sodio y agua (124) (125).

- NHE-4 se encuentra en las células epiteliales tubulares de riñón (126).

- $\quad$ NHE-5 se encuentra en las células del cerebro, participando de la regulación del $\mathrm{pH}$ neuronal (127).

- NHE-6 a 9 se encuentran en la membrana de las organelas, principalmente de aparato de golgi, endosomas y en el caso del NHE-6 en mitocondria. Están presentes en todo tipo de células participando de la regulación del $\mathrm{pH}$ de la organela (128). 
NHE-1: Estructura y regulación. El NHE-1 es una glucoproteína que contiene 815 aa y un peso molecular, en su forma glucosilada, de $110 \mathrm{kD}$. Está constituído por dos grandes dominios, el primero transmembrana y el segundo con la forma de una larga cola intracelular. Sus dos extremos, amino y carboxilo-terminal, orientados hacia el citoplasta (Figura 18I).

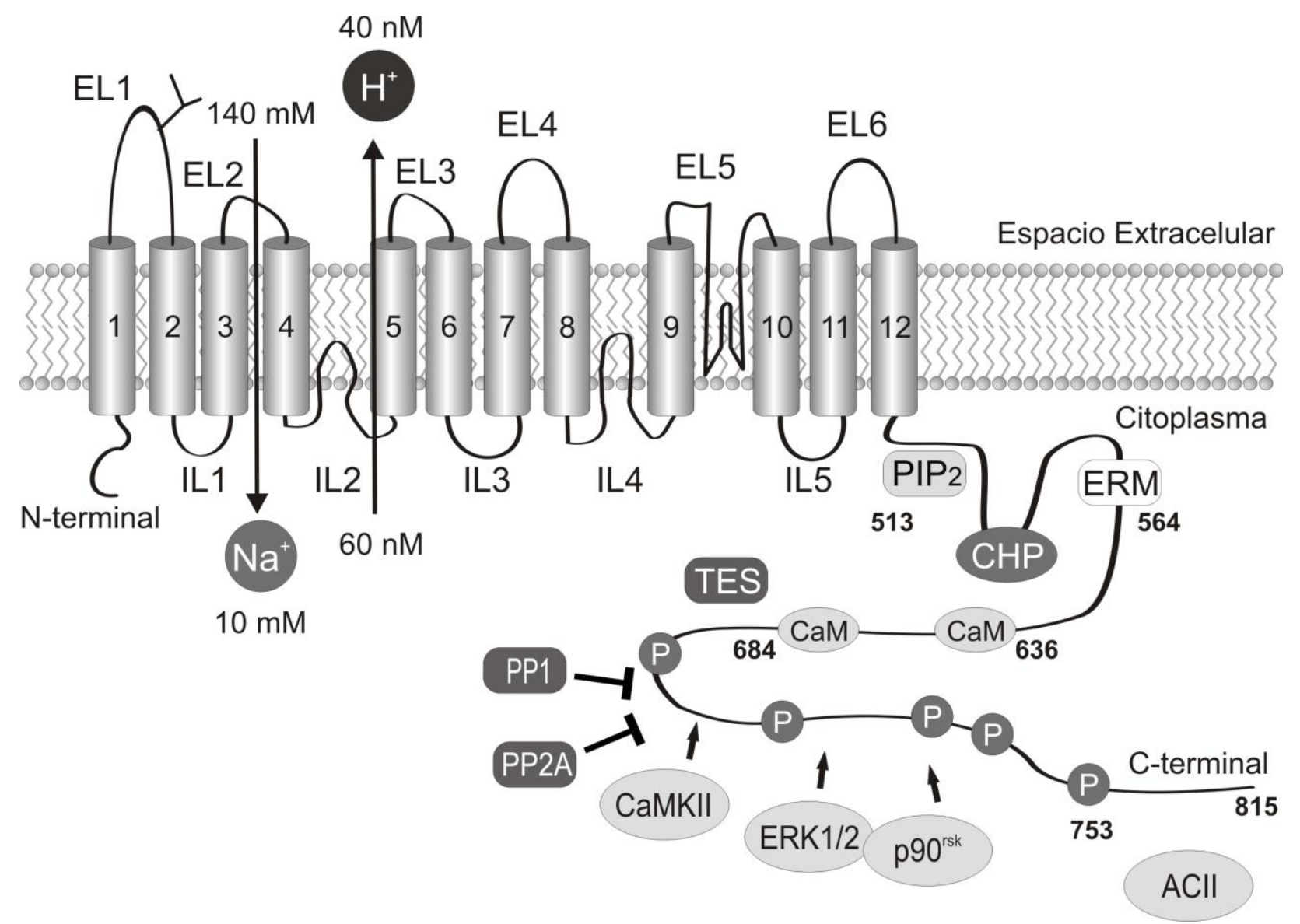

Figura 18I. Estructura y regulación del NHE-1. Se encuentran representados los 12 dominios transmembrana, los lazos intra y extracelulares (ILs y ELs); y la cola citosólica en el extremo C-terminal. En la cola citosólica se destacan los principales activadores (en color gris claro) e inhibidores (en color gris oscuro).

El extremo amino-terminal (de aproximadamente 500 aa) asociado al transporte iónico a través de la membrana plasmática, está compuesto por 12 regiones transmembrana, lazos intra y extracelulares (ILs, ELs) y un sitio alostérico que actúa como sensor intracelular de $\mathrm{H}^{+}$. El extremo carboxilo-terminal (de aproximadamente 300 aa) está involucrado en la regulación de la actividad del intercambiador y posee una larga cola que se divide en tres subdominios. 
El primer subdominio (entre los aa 513-564) incluye dos sitios de unión al $\underline{\mathrm{PIP}}_{2}$ involucrados en la regulación del NHE-1 por ATP (129). Si bien el intercambiador no utiliza directamente ATP, el nivel de $\mathrm{PIP}_{2}$ está directamente afectado por la cantidad de ATP disponible. La reducción de ATP o de $\mathrm{PIP}_{2}$ disminuyen la actividad transportadora del mismo (129). También contiene el sitio de unión para la familia de las proteínas ezrina- radixina-moesina ( $\underline{E R M})$, las cuales estimulan la adherencia de los filamentos de actina a la membrana, manteniendo la integridad estructural y participando de la migración celular $(130,131)$. La proteína 1 homóloga a calcineurina B ( $\underline{\mathrm{CHP}-1}$ ) interactua con un sitio de unión entre los aa 515-530 (132), su presencia no ha sido detectada en el miocardio humano pero si en células malignas (133). CHP-1 junto con tescalcina son proteínas fijadoras de calcio, que se asocian a este importante segunto mensajero permitiendo que transmita su información. Estas proteínas ejercen un efecto inhibitorio sobre el NHE-1 que se libera por el aumento en la $\left[\mathrm{Ca}^{+2}\right]$, permitiendo su activación.

El segundo subdominio posee un sitio de unión para Tescalcina, entre los aa 633-815 del extremo carboxilo terminal (134). Estudios realizados por Wakabayashi y col. muestran que el NHE-1 posee en el segundo subdominio (entre los aa 636-684) sitios de unión para $\underline{\mathrm{CaM}}$, de alta afinidad o "A" (aa 636-656) y de baja afinidad o "B" (aa 657684) (135). La unión de CaM a ambas regiones son estrictamente $\mathrm{Ca}^{2+}$ dependientes. En ausencia de $\mathrm{Ca}^{2+}$ y CaM, el sitio de unión de alta afinidad se une a otra región del NHE-1 funcionando como un "dominio de autoinhibición" (127). Cuando $\mathrm{Ca}^{2+}$ y CaM están presentes, se unen a los sitios de alta afinidad, bloqueando la interacción autoinhibitoria y activando al NHE-1 (135). La eliminación del sitio de unión de alta afinidad, resulta en un NHE-1 contitutivamente activo, imitando una situación en la que se produce sobrecarga de calcio intracelular (136). Es posible que el sitio de baja afinidad o "B" se una a $\mathrm{Ca}^{+2} / \mathrm{CaM}$ sólo ante altas concentraciones de $\left[\mathrm{Ca}^{+2}\right]$, y en estas condiciones estimule la actividad del NHE-1.

La actividad del NHE-1 es sumamente sensible a los cambios del pH intracelular, pero además de responder a los protones intracelulares puede ser activada por reacciones dependientes de la fosforilación que se llevan a cabo en su cola carboxiterminal. Estas se producen principalmente en el tercer subdominio (entre los aa 700-815) ya que contiene residuos de serina y de treonina, suceptibles de ser fosforilados por proteínas 
quinasa en respuesta a hormonas (incluyendo noradrenalina, All y ET), factores de crecimiento y acidosis sostenida (137-139). La vía de las MAPK es el factor principal en la regulación de NHE-1. ERK1/2 y $\underline{\mathrm{p} 90^{\mathrm{RSK}}}$ fosforilan directamente el extremo C-terminal

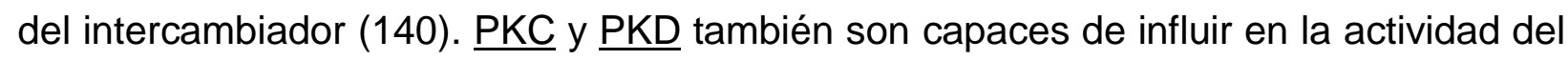
NHE-1 en respuesta a la estimulación por factores de crecimiento, pero no fosforilan directamente al intercambiador (141). Dado que el nivel de fosforilación depende no sólo de quinasas sino también de fosfatasas, es importante el rol de las fosfatasas MPK1, PP1 y PP2A. PKG es una quinasa que fosforila tirosina o serina en un sitio de consenso de entorno de aa básicos, presentes en el NHE-1 $(142,143)$. Pero PKG también es capáz de activar rutas de señalización mediadas por fosfatasas, tal como la fosfatasa de la MAPK, MAPK1 (144). De modo que la PKG podría modular la actividad del NHE-1 por fosforilación directa o a través de fosfatasas que actúan sobre el NHE-1 y de esta manera reducir su actividad. Yeves y col. (145), demostraron que la inhibición de la fosfodiesterasa 5 A (PDE5A), promueve la acumulación de guanosina monofosfato cíclico (GMPc) quien activa a PKG. Esta quinasa, por un mecanismo aún desconocido activa a la fosfatasa PP1, la cual desfosforila el sitio regulador de la cola citosólica del NHE-1, inhibiendo su actividad.

Otra enzima que regula la actividad del NHE-1 es la anhidrasa carbónica II ( $\underline{\mathrm{ACII}}$ ). La ACll cataliza la hidratación de $\mathrm{CO}_{2}$, que luego de disociarse produce $\mathrm{HCO}_{3}{ }^{-}$y $\mathrm{H}^{+}$. La enzima se une al dominio citosólico, siendo esta unión función del grado de fosforilación del NHE-1. Al inhibir la ACII disminuye la actividad del NHE-1 (146).

Inhibidores farmacológicos del NHE-1. La actividad exacerbada del NHE-1 en el miocardio ha sido vinculada al desarrollo de distintas patologías caracterizadas por un anormal crecimiento del tejido, particularmente en la $\mathrm{HC}$ y en el remodelamiento post-infarto de miocardio (147), condiciones que pueden conducir a la IC seguida de muerte. El hecho de que el NHE-1 haya sido vinculado de manera tan estrecha con el desarrollo de $\mathrm{HC}$, ha estimulado en los últimos años una intensa investigación dirigida a intentar dilucidar los mecanismos de regulación de este intercambiador, como paso previo a la elaboración de estrategias terapéuticas destinadas a prevenir su hiperactividad y por ende, sus consecuencias patológicas. Se han desarrollado numerosos inhibidores que intentan prevenir los aumentos de $\left[\mathrm{Na}^{+}\right]_{i}$ provocados por su 
hiperactividad y el consecuente aumento de $\left[\mathrm{Ca}^{+2}\right]_{i}$ producido por la activación secundaria del NCX, cuyo principal objetivo es la cardioprotección. El primer inhibidor del NHE descripto fue el amiloride, un diurético ahorrador de potasio, el cual posee mayor sensibilidad por las isoformas 1 y 2 del NHE, y además inhibe al NCX y a los canales de sodio (148). Con el fin de mejorar la potencia y selectividad sobre la isoforma 1 , se obtuvieron los derivados sintéticos del amiloride, entre los que se destacan el dimetil-amiloride (DMA), el hexametil-amiloride (HMA) y el etil-isopropilamiloride (EIPA), entre otros. Posteriomente surgieron nuevos compuestos con mayor selectividad por el NHE-1 como HOE694, HOE642 (cariporide) y EMD96785 (eniporide), entre otros, los cuales difieren en su solubilidad, vía de administración y la duración de su efecto $(149,150)$.

\section{Aumento en la concentración intracelular de sodio.}

Como se mencionó con anterioridad, la estimulación del NHE-1 aumenta la concentración intracelular sodio $\left(\left[\mathrm{Na}^{+}\right]_{i}\right)$, siendo responsable del $50 \%$ que ingresa a la célula. Este aumento de la $\left[\mathrm{Na}^{+}\right]_{i}$ es indispensable para que el $\mathrm{NCX}$ opere en su modo inverso, es decir, introduciendo un ion $\mathrm{Ca}^{2+}$ por cada tres $\mathrm{Na}^{+}$que extruye de la célula (63-69). Se demostró que el aumento de la $\left[\mathrm{Na}^{+}\right]_{i}$ inducido por el estiramiento y por All o ET-1 exógenas, a dosis que producen incrementos de fuerza similares a la SFF, fueron prevenidos al bloquear el $\operatorname{NHE}(59,60,64,65)$. Podría por ello suponerse que este mecanismo es el único determinante del efecto contráctil. Sin embargo cabe la posibilidad de que el incremento de la $\left[\mathrm{Na}^{+}\right]_{i}$ sea un mecanismo necesario pero no exclusivo para inducir el influjo de $\mathrm{Ca}^{+2}$ (a través del NCX en el modo inverso) o enlentecer la salida de $\mathrm{Ca}^{+2}$ (al deprimir la acción del NCX en su modo directo). El bloqueo del modo inverso del NCX abolió la contraparte mecánica. Luego de un incremento de la $\left[\mathrm{Na}^{+}\right]$, inducida por ET-1 o por inhibición de la bomba $\mathrm{Na}^{+} / \mathrm{K}^{+}$ATPasa, el aumento en la fuerza desarrollada fue mayor cuando la activación del modo inverso del NCX fue inducido por ET-1 que cuando la bomba de $\mathrm{Na}^{+}$fue inhibida (59). Estos resultados sugieren que factores adicionales al aumento de la $\left[\mathrm{Na}^{+}\right]_{i}$ afectan también el modo inverso del NCX y participan del incremento de fuerza producido por la ET-1. 


\section{Activación del intercambiador $\mathrm{Na}^{+} / \mathrm{Ca}^{+2}(\mathrm{NCX})$ en su modo inverso.}

Como se mencionó con anterioridad, estudios en diferentes laboratorios sugieren que el incremento en el transitorio de calcio, no sería debido a la entrada de calcio por los canales $L(45)$ ni a la liberación de calcio desde el RS (57). El origen del incremento de calcio permanecio desconocido hasta que se propuso un nexo entre la activación del NHE-1 producido por el estiramiento y el posterior influjo de calcio mediado por el NCX en su modo inverso (58-60).

NCX. El NCX se encuentra presente en la membrana plasmática de gran parte de las células de los mamíferos, constituyendo una segunda vía de ingreso de $\mathrm{Ca}^{+2}$ al miocito, además de los canales de $\mathrm{Ca}^{+2}$ del sarcolema. Al igual que el NHE, el NCX es una proteína integral de membrana. En el $\mathrm{NCX}$, los movimientos de $\mathrm{Ca}^{+2}$ están acoplados a movimientos recíprocos de $\mathrm{Na}^{+}$, promoviendo el transporte de 3 iones $\mathrm{Na}^{+}$ por cada $\mathrm{Ca}^{+2}\left(3 \mathrm{Na}^{+}: 1 \mathrm{Ca}^{+2}\right)$ en direcciones opuestas. Generándose el flujo de una carga neta positiva en cada ciclo (transportador electrogénico), contribuyendo así a mantener la homeostasis del $\mathrm{Ca}^{+2}$.

Se han encontrado 3 isoformas derivadas de 3 genes diferentes: NCX1 o cardíaca, NCX2 o muscular esquelética y NCX3 o cerebral (151-154). La isoforma NCX1 es la más ampliamente distribuido, encontrándose en mayor cantidad en tejido cardíaco y cerebral (155). La expresión del NCX1 ocurre en etapas muy tempranas de la cardiogénesis (156), siendo máxima cerca del nacimiento en mamíferos (157) decayendo luego, proceso opuesto al que ocurre con otra proteína vinculada al manejo del $\mathrm{Ca}^{2+}$, la calcio-ATPasa (también denominada SERCA por sus siglas en inglés sarcoplasmic-endoplasmic-reticulum calcium ATPase) cuya expresión aumenta durante la vida postnatal (158) y se encarga de introducir calcio desde el citosol al RS. Así, en los recién nacidos, la participación del NCX en el acoplamiento éxito-contráctil cardíaco sería más relevante que en los corazones adultos.

EI NCX1 tiene 970 aa y un peso molecular de 110 KDa (152). Posee 9 segmentos transmembrana, con la porción N-terminal extracelular, y el extremo C-terminal hacia el citoplasma (159). Posee además un gran lazo interno hidrofílico entre los segmentos transmembrana 5 y 6 (aa 250 y 796), el cual es importante para la regulación alostérica intracelular por $\mathrm{Ca}^{+2} \circ \mathrm{Na}^{+}$(160) (Figura 19I). 


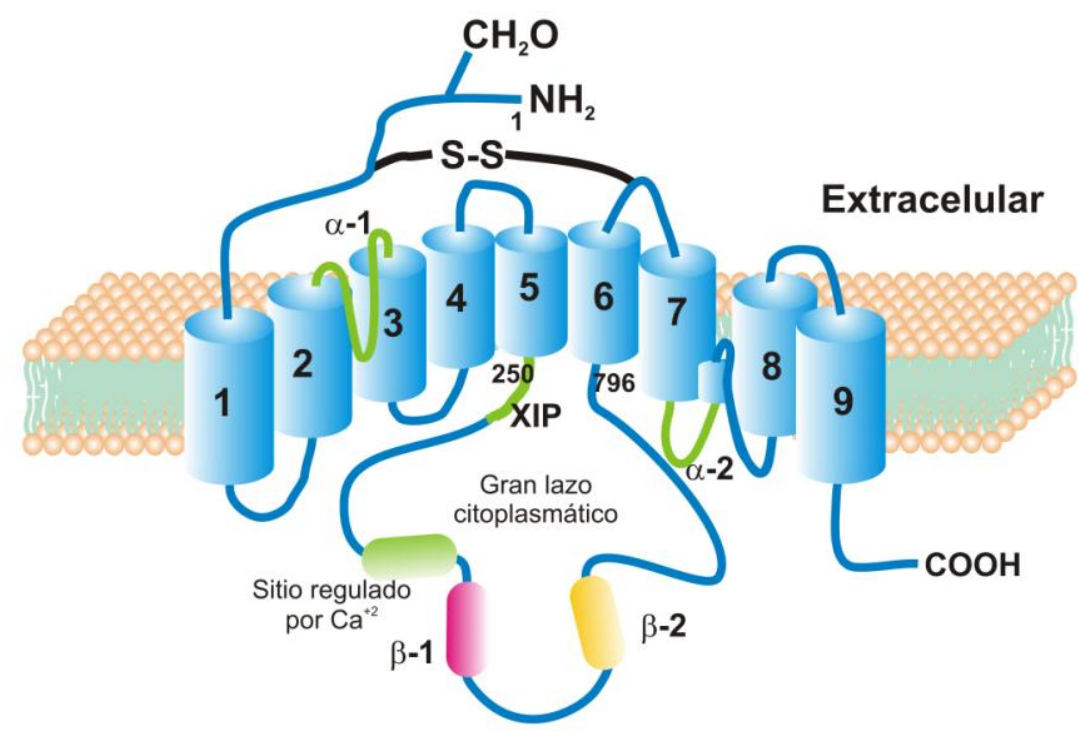

Figura 19I. Estructura del NCX.

La función principal del NCX es intercambiar $\mathrm{Ca}^{+2}$ intracelular por $\mathrm{Na}^{+}$extracelular, pudiendo funcionar en sentido inverso al comienzo de la meseta del potencial de acción. En condiciones fisiológicas y suponiendo que los gradientes de $\mathrm{Na}^{+}$y Ca$^{+2}$ permanecen constantes en el espacio subsarcolemal, podemos estimar que el potencial de inversión del NCX ( $E_{\mathrm{NCX}}$ ) (valor del potencial de membrana que anula el flujo iónico por gradiente de concentraciones a través del intercambiador), es aproximadamente $-40 \mathrm{mV}$. Dado que se trata de un transportador electrogénico, la fuerza impulsora $(\mathrm{FI})$ que actúa sobre el NCX está determinada por la diferencia entre el potencial de membrana $(\mathrm{Vm})$ y el $\mathrm{E}_{\mathrm{NCX}}\left(\mathrm{FI}=\mathrm{Vm}-\mathrm{E}_{\mathrm{NCX}}\right)$. Vemos así que:

- Cuando el Vm es igual al $\mathrm{E}_{\mathrm{NCX}}$ no se registra corriente, pues la Fl es cero.

- En reposo o diástole el NCX usa el gradiente electroquímico que favorece la entrada de $\mathrm{Na}^{+}$a la célula y la salida de $\mathrm{Ca}^{+2}$, el Vm toma valores más negativos que el $\mathrm{E}_{\mathrm{NCX}}$ (funcionando el modo directo o "forward" del NCX ( $\left.\mathrm{NCX}_{\text {dir }}\right)$ ), contribuyendo a la relajación de la célula muscular, al disminuir el $\mathrm{Ca}^{+2}$ intracelular.

- Cuando la célula se despolariza va modificando el gradiente electroquímico para el $\mathrm{Na}^{+}$y el $\mathrm{Ca}^{+2}$, el Vm toma valores más positivos que el $\mathrm{E}_{\mathrm{NCX}}$, y durante cierto período del potencial de acción (meseta) se registran flujos de estos iones en sentidos opuestos (funcionando el modo inverso o "reverse" del NCX (NCX $\left.X_{\text {inv }}\right)$ ). El hecho de que el $\mathrm{Vm}$ supere el valor teórico de $E_{\mathrm{NCX}}$ haría pensar que el $\mathrm{NCX}_{\text {inv }}$ participaría activamente en el ingreso de $\mathrm{Ca}^{+2}$ durante el acoplamiento 
éxito-contráctil. Sin embargo, existe gran controversia respecto de la contribución del $\mathrm{NCX}_{\text {inv }}$ a la contractilidad basal (161) debido a que durante el potencial de acción el nivel de $\mathrm{Ca}^{+2}$ aumenta, y esto modifica el $E_{\mathrm{NCX}}$ haciéndolo más positivo. Se ha demostrado que bajo ciertas condiciones farmacológicas y/o patológicas, el modo inverso puede cobrar mayor relevancia para la función contráctil (162). En la IC por ejemplo se encuentra aumentada la expresión del NCX, supuestamente como un mecanismo compensador para mantener la contractilidad ante la deficiente función del RS, por lo que el NCX contribuiría a la entrada de $\mathrm{Ca}^{+2}$ al citosol y, de esta manera mantendría la función contráctil (163).

Perez y col. y Alvarez y col. $(64,65)$ observaron que el aumento en la $\left[\mathrm{Na}^{+}\right]_{\mathrm{i}}$ producido por la activación del NHE-1 debido al estiramiento del miocito, desplazaba al $E_{\mathrm{NCx}}$ a valores más negativos, permitiendo de este modo que el modo $\mathrm{NCX}_{\text {inv }}$ actúe por más tiempo durante el potencial de acción. Lu y col, demostraron que la quinasa redox sensible $\mathrm{p} 90^{\mathrm{RSK}}$ prolonga la repolarización al inhibir al canal de potasio, evitando la salida de dicho catión y aumentando el tiempo durante el cual el modo $\mathrm{NCX}_{\text {inv }}$ está activo (164). Por otro lado, el aumento en $\left[\mathrm{Na}^{+}\right]_{\mathrm{i}}$ reduciría la salida de $\mathrm{Ca}^{+2}$ al deprimir la acción del $\mathrm{NCX}_{\text {dir }}$ durante la diástole y/o favorecería su entrada por el modo $\mathrm{NCX}_{\text {inv, }}$ produciéndose acumulación intracelular de $\mathrm{Ca}^{+2}$ que, de mantenerse en forma crónica, podría tener efectos nocivos (165). Además, la activación de quinasas redox sensibles, tras el estiramiento, fosforilan de manera directa al NCX contribuyen al ingreso de $\mathrm{Ca}^{+2}$ a la célula $(59,166,167)$. En resumen, es posible que el estiramiento y la vía All/ET, regulen el modo $\mathrm{NCX}_{\text {inv }}$ a través de la acción conjunta de tres mecanismos dependientes de ROS, que producen aumento de la $\left[\mathrm{Ca}^{+2}\right]_{i}$ :

- Por estimulación directa del NCX a través de PKC e independiente de $\mathrm{Na}^{+}$.

- Desplazando al $E_{\mathrm{NCX}}$ a valores más negativos, por aumento de la $\left[\mathrm{Na}^{+}\right]_{\mathrm{i}}$ por activación del NHE-1.

- Prolongando la duración del potencial de acción. 


\section{9. $\mathrm{HC}$ promovida por el incremento en el calcio.}

La mayoría de los estímulos que inducen HC maladaptativa en respuesta a una sobrecarga hemodinámica activan la vía de Gq y confluyen en el aumento de la $\left[\mathrm{Ca}^{+2}\right]_{\mathrm{i}}$ activando las vías de señalización intracelular dependientes de este ión. El aumento de la $\left[\mathrm{Ca}^{+2}\right]_{i}$ es uno de los fenómenos más importantes en el desarrollo de la respuesta hipertrófica y esto se ha confirmado provocando el aumento de la $\left[\mathrm{Ca}^{+2}\right]_{i}$ por medio de agonistas cálcicos (168), de ionóforos de $\mathrm{Ca}^{+2}$ (169), o mediante la elevación del $\mathrm{Ca}^{+2}$ extracelular (170), induciéndose en todos estos casos hipertrofia en cardiomiocitos in vitro.

Calmodulina. Muchas de las acciones del calcio se llevan a cabo mediante su interacción con Calmodulina ( $\mathrm{CaM}$ ), que actúa como un sensor intracelular de calcio y como respuesta a los cambios en su concentración, activa vías de señalización específicas (171).

CaM se encuentra en diferentes localizaciones incluyendo el citoplasma, las organelas y asociada a la membrana plasmática. Es una proteína fijadora de calcio que posee cuatro sitios de unión para el $\mathrm{Ca}^{+2}$, formando el complejo $\mathrm{Ca}^{+2} / \mathrm{CaM}$. Dado que no posee actividad enzimática intrínseca, la unión al calcio produce un cambio en la conformación de la CaM que le permite unirse a otras proteínas y activarlas (Boron W.;Boulpaep E.,"Medical Physiology”, capítulo 3, editorial Saunders, 2008). Muchas proteínas son incapaces de unir $\mathrm{Ca}^{+2}$ por sí mismas y por ello utilizan a CaM como sensor de calcio y transductor de señales (Figura 20I).

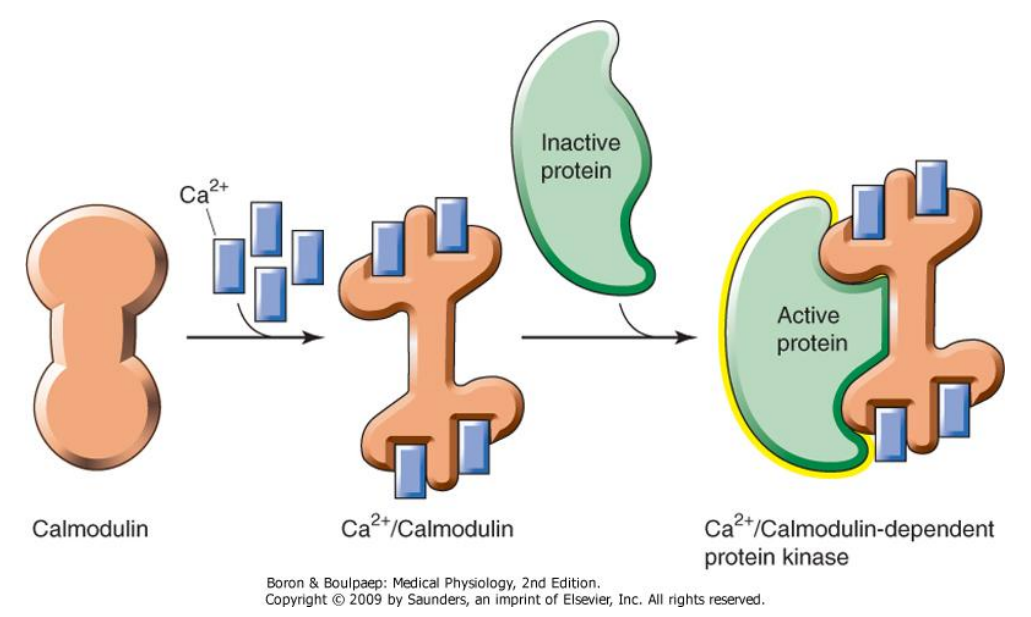

Figura 20I. La CaM es activada mediante su unión al $\mathrm{Ca}^{+2}$, formando el complejo $\mathrm{Ca}^{+2} / \mathrm{CaM}$.

(Boron W.;Boulpaep E.,"Medical Physiology”, capítulo 3, editorial Saunders, 2008). 
CaM puede realiza funciones indirectamente a través de otras proteínas, como por ejemplo la fosfatasa calcineurina, la quinasa $\mathrm{Ca}^{+2} / \mathrm{CaM}$ dependiente (CaMKII) y la quinasa de la cadena liviana de la miosina (MLCK). Estas enzimas poseen diferente localización subcelular y sensibilidad al calcio, lo cual les permite poder diferenciar entre distintos tipos de señales de calcio y así poder realizar determinadas funciones en el cardiomiocito. Así por ejemplo, calcineurina se activa en respuesta a aumentos sostenidos y de baja amplitud en los transitorios de $\mathrm{Ca}^{+2}$, mientras que CaMKII lo hace preferentemente por aumentos repentinos y de alta amplitud $(172,173)$.

CaMKII es una serina-treonina quinasa, con una importante función en la contractilidad cardíaca y el manejo de calcio. La isoforma $\delta$ de la CAMKII se expresa en mayor grado en el corazón (174). Una vez activada (por el aumento de la $\left[\mathrm{Ca}^{+2}\right]_{i}$ y la posterior formación del complejo $\mathrm{Ca}^{+2} / \mathrm{CaM}$ ) une ATP y se autofosforila, prolongando de esta manera su función (modo independiente de calcio) (175). Esto le permite a CAMKII mantener su actividad catalítica aún en ausencia de $\mathrm{Ca}^{+2}$, para actuar como un sensor de $\mathrm{Ca}^{+2}$ y poder regular su propia actividad (176). CAMKII participa de la regulación del $\left[\mathrm{Ca}^{+2}\right]$ i por el RS. La fosforilación de las proteínas del receptor de rianodina ("RyR", un canal liberador de $\mathrm{Ca}^{+2}$ ) produce la salida de $\mathrm{Ca}^{+2}$ del RS. Mientras que la re-captación se estimula a través de la fosforilación de las proteínas SERCA (una $\mathrm{Ca}^{+2}$ ATPasa) y fosfolamban ("PLN", en estado desfosforilado actúa como inhibidor de SERCA) (175).

La activación de MLCK por el complejo $\mathrm{Ca}^{+2} / \mathrm{CaM}$ permite la fosforilación de MLC-2, incrementando la sensibilidad del miofilamento por el calcio, aumentando la fuerza de contracción y estimulando la incorporación de filamentos de actina y miosina al sarcómero $(175,177)$.

Calcineurina. La Calcineurina (conocida también como PP2B) es una proteína fosfatasa calmodulina dependiente, que desfosforila proteínas en serina y treonina. Está compuesta por un heterodímero formado por dos subunidades:

- calcineurina $\mathrm{A}(\mathrm{CnA})$ : contiene un dominio amino-terminal catalítico por lo que se la considera la "subunidad catalítica", y regiones de unión para CnB y para CaM. El extremo carboxilo-terminal contiene un dominio autoinhibitorio que se pliega para ocluir el sitio activo cuando CaM no está unida. Posee un peso aproximado 
Introducción

de $59 \mathrm{KDa}$. Existen tres isoformas de $\mathrm{CnA}$, codificadas por tres genes distintos: $\mathrm{CnA \alpha}, \mathrm{CnA} \beta$ y $\mathrm{CnAy}$. En los cardiomiocitos se expresan las isoformas $\alpha$ y $\beta$ (178).

- calcineurina $B(\mathrm{CnB})$ : posee el centro fijador de calcio y se la considera la "subunidad reguladora". Con un peso aproximado de $19 \mathrm{KDa}$. Existen dos isoformas de $\mathrm{CnB}$, codificadas por dos genes distintos: $\mathrm{CnB} 1$ y $\mathrm{CnB2}$. En los cardiomiocitos se expresa la isoforma 1 (178).

El aumento sostenido de la $\left[\mathrm{Ca}^{+2}\right]_{i}$ (originado por estímulos mecánicos y neurohumorales) promueve la unión de dicho catión a $\mathrm{CnB}$ y a CaM. Una vez formado el complejo $\mathrm{Ca}^{+2} / \mathrm{CaM}$, este se une a $\mathrm{CnA}$, desplazando el dominio autoinhibitorio, permitiendo el acceso de los sustratos protéicos al dominio catalítico donde serán desfosforiladas. Posteriormente, cuando se reduzca la $\left[\mathrm{Ca}^{+2}\right]_{\mathrm{i}}, \mathrm{CnA}$ volverá a plegarse ocultando su centro catalítico (179).

Entre los sustratos de calcineurina se encuentran factores de transcripción como el NFAT (factor de transcripción nuclear de las células $T$ activadas), localizado en el citosol. NFAT posee residuos de fosfoserina que al ser desfosforilados por calcineurina, exponen secuencias de señalización que le indican al factor que debe dirigirse al núcleo. Posteriormente se une al $A D N$ e interactúan cooperativamente con otros factores de transcripción como AP-1 (activador proteico), GATA-4 y MEF2 (factor estimulador de la transcripción de miocitos) estimulando la transcripción de genes responsables de la HC $(169,180,181)$ (Figura 21I). 


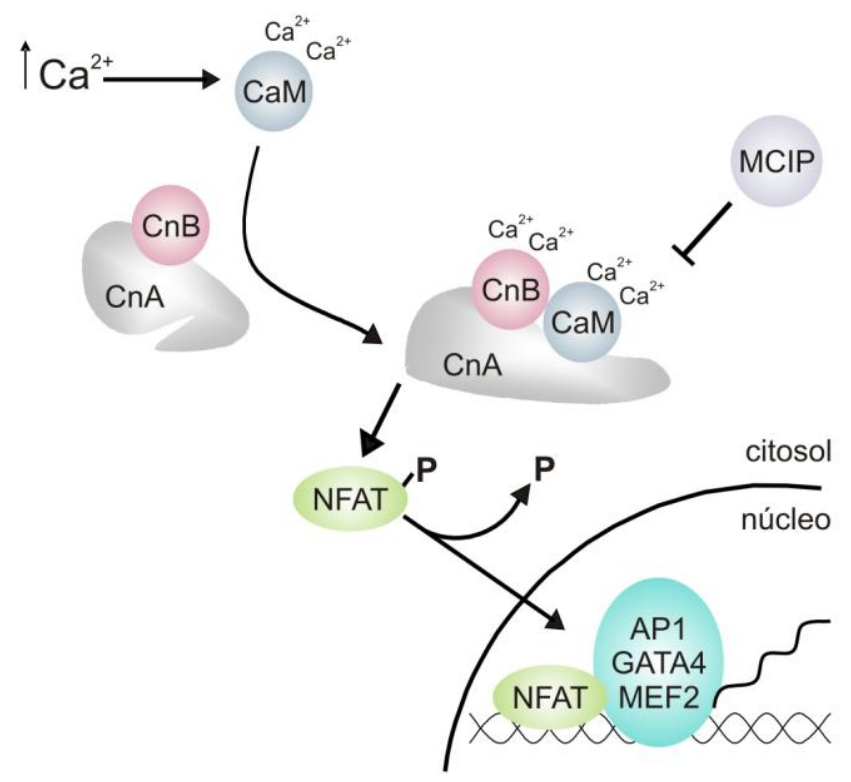

Figura 21I. La calcineurina es activada mediante la unión de $\mathrm{Ca}^{+2}$ y CaM.

MEF2 se asocia en el citosol con una familia de represores de la transcripción de genes, las histonas desacetilasas ("HDACs"). Las HDACs citoplasmáticas se unen a MEF2, reprimiéndolo. CaMKII y CaM fosforilan a las HDACs, permitiendo la liberación de MEF2, el cual se dirige al núcleo para interactuar con el ADN (182-184). Las HDACs nucleares eliminan grupos acetilo de las histonas, incrementando su carga positiva, logrando así un mayor empaquetamiento del ADN y disminuyendo con ello la transcripción.

La vía calcineurina/NFAT es una de las primeras vías que provee información molecular de como señales extracelulares viajan de la membrana celular al núcleo. De las cascadas intracelulares prohipertróficas dependendientes de $\mathrm{Ca}^{2+}$, la vía calcineurina/NFAT parece jugar un papel determinante en el desarrollo de HCP (185). Ratones transgénicos que sobreexpresan CnA o NFAT constitutivamente activos, desarrollan $\mathrm{HC}$ que evoluciona a IC al cabo de dos meses, sugiriendo que la CnA está involucrada en la respuesta maladaptativa. La activación de la calcineurina es una señal suficiente para inducir HC aunque posiblemente no estrictamente necesaria (172, 186). Trabajando con cultivos de cardiomiocitos estimulados por factores de crecimiento como All, se vio que el uso de Cyclosporina A (CsA), inhibidor de calcineurina, previene el crecimiento hipertrófico de los mismos. Recientemente se han descubierto proteínas celulares que actúan como inhibidores endógenos de 
calcineurina como calsarcina, MCIP y Cabin-1 (también llamado Cain). Estas nuevas familias de proteínas que interactúan tanto con calcineurina como CaM, modularían las señales que llevan a la HC. (187).

\section{REGRESIÓN DE LA HIPERTROFIA}

Dado que la $\mathrm{HC}$ es un factor independiente de riesgo de enfermedad cardiovascular, la regresión de la misma es considerada en la actualidad como un paso clave para la prevención del desarrollo futuro de IC. En la HTA la regresión de la HC se puede lograr con el empleo de fármacos. La relación entre la normalización de la actividad del NHE-1 y la regresión de la HC fue demostrada luego del tratamiento crónico con losartán, enalapril o nifedipina (188) y cariporide (189). El último estudio también demostró un hecho interesante, que la disminución de la HC fue independiente de la disminución de la presión arterial, es decir que el bloqueo del NHE-1 indujo su efecto anti-hipertrófico con cambios mínimos o sin cambios en la presión arterial. Existen evidencias claras de que el uso de inhibidores específicos del NHE-1 en patologías cardíacas hipertróficas es beneficioso (147, 189-191).

Es posible que los efectos adversos observados con el uso de estos inhibidores se deban a que no sólo inhiben la indeseada hiperfunción detectada en procesos fisiopatológicos sino también su importante función homeostática basal, pudiendo interferir además con mecanismos no miocárdicos, como lo sugiere el aumento del riesgo de accidente cerebrovascular. Esta incapacidad de discriminar entre ambos estados propia de los bloqueantes del NHE-1 podría ser la causa de la disparidad de efectos provocados por el cariporide (inhibidor específico del NHE-1) detectado en un estudio clínico denominado EXPEDITION, donde la inhibición del NHE-1 redujo la incidencia de infarto de miocardio en pacientes sujetos a bypass coronario pero incrementó la tasa general de eventos cerebrovasculares, lo que derivó en el abrupto cese del estudio (192). Por otro lado, dos estudios clínicos, uno con cariporide, (GUARDIAN (149)) y el otro con eniporide (ESCAMI (150)) diseñados para evaluar la inhibición farmacológica del NHE-1 en la isquemia miocárdica arrojaron resultados controvertidos. Se podría especular que la fosforilación del NHE-1 es un mecanismo ligado al desarrollo de procesos patológicos que involucran el mantenimiento de la acidosis por un determinado tiempo, 
el cual es crítico para que ello ocurra. En tanto que la función homeostática basal sería beneficiosa y sólo dependería del censado de los cambios de la concentración de $\mathrm{H}^{+}$ como resultado del metabolismo basal normal, sin intervención de la fosforilación del NHE-1. El problema adquiere mayor relevancia dado que este intercambiador es responsable de aproximadamente el $50 \%$ del $\mathrm{Na}^{+}$que ingresa a la célula modulando la actividad del intercambiador NCX y por este mecanismo la acumulación de $\mathrm{Ca}^{2+}$ intracelular y la contractilidad. Ante este contexto, resulta evidente la necesidad de buscar alternativas terapéuticas que involucren el control de la función exacerbada del NHE-1 sin alterar su actividad basal, lo cual será el futuro desafío de los investigadores.

La identificación precisa de las vía de señalización activadas en la HCP permitiría encontrar nuevos objetivos terapéutico. Surgen así nuevas estrategias de rehabilitación cardíaca en pacientes con HCP. Entre los cambios en el estilo de vida del paciente, uno de los más destacados consiste en la realización de ejercicio aeróbico efectuado regularmente. Se ha detectado una reducción significativa de la morbimortalidad cardiovascular en pacientes que realizan entrenamiento físico (193-196). En un grupo selecto de pacientes con IC, se ha demostrado que la actividad física no sólo es segura, sino también beneficiosa (197-199). A pesar de ello, aún se desconocen las vías por las cuales se produce este mecanismo. 
OBJETIVOS 


\section{OBJETIVOS.}

La regresión y/o modificación de la HCP es considerada en la actualidad como un paso clave en la prevención del desarrollo futuro de IC. Una forma de lograrlo es farmacológica y la otra es no farmacológica. Esta última consiste en la realización de ejercicio físico aeróbico en forma regular. En pacientes con cardiopatías (HC e IC) se ha demostrado que la actividad física programada no sólo es beneficiosa, sino también segura (197-199). Diferentes estudios clínicos muestran que la actividad física promueve un fenotipo "cardioprotector", pero los mecanismos íntimos a nivel celular aún se desconocen (200-202).

El objetivo general del presente trabajo consiste en estudiar experimentalmente los posibles mediadores intracelulares involucrados en la protección brindada por el ejercicio físico en la HC hipertensiva.

Para llevar acabo dicho objetivo se empleó el modelo de HC de las ratas SHR que desarrolla HTA, genéticamente determinada. La identificación precisa de los intermediarios de la vía de señalización, permitiría un mejor control terapéutico de los mismos.

Los experimentos diseñados intentaron responder los siguientes interrogantes:

1. ¿La actividad física produjo cambios funcionales en la HC de las SHR? De ser así, ¿qué características tuvieron?

A fin de responder esta pregunta los animales realizaron actividad física natatoria durante 60 días y se determinó el acortamiento medio ventricular, por ecocardiografía, al comenzar y finalizar el período experimental.

2. ¿Qué características morfológicas se observaron en la HC lograda por el ejercicio?

Para cuantificar la magnitud de los posibles cambios se evaluaron los siguientes parámetros: índice de masa ventricular izquierda, espesor de la pared del ventrículo izquierdo (VI), masa del VI y relación peso del VI/longitud de la tibia, entre otros. 
3. ¿Qué modificaciones histológicas se produjeron en el tejido miocárdico inducidas por el entrenamiento aeróbico?

Para ello se examinó el área de sección transversal del cardiomiocito, la fracción de colágeno y la densidad capilar.

4. ¿Qué cambios moleculares se observaron con el ejercicio?

Para ello se determinó la expresión de los marcadores moleculares ANF y MLC-2, y la participación de SERCA2a y NCX.

5. ¿Las vías de la fosfatasa calcineurina y de las quinasas PI3K/AKT se involucraron en la $\mathrm{HC}$ por el ejercicio?

Ello se evaluó mediante la expresión de dichas vías en el modelo utilizado.

6. ¿El ejercicio ejerció algún efecto sobre la cascáda apoptótica?

Para ello se estudió la expresión de caspasa-3 y PARP-1.

Las respuestas a estas preguntas son por lo tanto importantes y contribuirían al desarrollo de estrategias terapéuticas destinadas a inducir cardioprotección. 


\section{MATERIALES Y MÉTODOS}




\section{ANIMALES DE EXPERIMENTACIÓN}

Se utilizaron ratas macho de 4 meses de edad de la cepa Wistar y SHR. Los animales fueron criados en el Bioterio del Centro de Investigaciones Cardiovasculares, mantenidos en un microambiente ventilado, con temperaturas entre 18 y $22{ }^{\circ} \mathrm{C}$ y ciclos de 12 horas de luz/12 horas de oscuridad. Luego del destete a los 21 días se los colocó en cajas de acero inoxidable con lecho de viruta esterilizada y tapa tipo tolva para permitir el acceso ilimitado al alimento balanceado para rata y agua de la canilla que se administró en mamaderas. Los experimentos fueron llevados a cabo respetando las normativas generales para uso de animales de laboratorio estipuladas en la "Guide for the Care and Use of Laboratory Animals, NIH Publication No. 85-23, 1996".

\section{Wistar}

Las ratas Wistar constituyen una cepa de ratas albinas exocriadas pertenecientes a la especie Rattus norvegicus. Esta cepa fue desarrollada en 1906 en el Instituto Wistar de Filadelfia para su utilización en investigación biológica y médica por el fisiólogo Henry Donaldson. Las cepas de la mayoria de los laboratorios descienden de la colonia establecida en el Instituto Wistar, y actualmente es una de las cepas más populares en investigación. En el presente trabajo se utilizaron ratas Wistar como control normotenso y normotrófico.

\section{$\underline{\mathrm{SHR}}$}

Introducidas originalmente en el año 1963 por Okamoto y Aoki (203) mediante seis generaciones de endocría a partir de una pareja de ratas de la cepa Wistar que presentaba presión arterial persistentemente elevada. Constituyen un modelo para el estudio de la progresión natural de hipertrofia ventricular izquierda, producida por un aumento de la poscarga. Normalmente, el crecimiento postnatal del tejido cardíaco implica una hipertrofia de las miofibrillas e hiperplasia del tejido conectivo con un aumento en masa del órgano en proporción al aumento de masa corporal. En un corazón sometido a una mayor poscarga el crecimiento ocurre de una manera similar, sin embargo la respuesta, principalmente del ventrículo izquierdo, es desproporcional con respecto al peso corporal (204). En este modelo, el estiramiento mecánico y la HC ocurren de manera crónica y secundaria a un aumento de la presión arterial genéticamente determinado. 


\section{ACTIVIDADES Y PROTOCOLO.}

Se realizaron estudios en ratas, machos de 4 meses de edad, normotensos (Wistar) y espontáneamente hipertensos (SHR) con HC. Se sometió a un grupo de las SHR (SHR-E), elegidas al azar, a actividad física intensa y periódica (natación durante 90 minutos, 5 veces por semana, por 60 días) para evaluar su efecto sobre la HCP y compararla con la $\mathrm{HC}$ que desarrollan las ratas SHR que no realizaron ejercicio (SHRS). La temperatura del agua donde nadaban las ratas era de 30-32ํㅡ. La duración del ejercicio se fue incrementando gradualmente hasta que pudieron nadar por $90 \mathrm{~min}$. Las SHR-S y las Wistar nadaron durante 10 minutos, dos veces a la semana, para imitar el estrés al que fueron sometidas las SHR-E. Este protocolo de natación ha sido caracterizado por Medeiros y col., como un ejercicio de moderada intensidad y larga duración basándose en la capacidad oxidativa del músculo (205).

Se realizaron estudios morfológicos, histológicos y moleculares. En los animales en experimentación se evaluaron los siguientes parámetros que funcionan como índices de HC: cociente peso biventricular/peso corporal (PBV/PC), área de sección transversal de los cardiomiocitos (CSA), expresión de los marcadores moleculares de $\mathrm{HC}$ como el péptido natriuréticos atrial (ANP) y la cadena liviana de la miosina-2 (MLC-2), entre otros. 


\section{METODOLOGÍA APLICADA.}

\section{CARACTERÍSTICAS DE LOS GRUPOS EXPERIMENTALES.}

\section{- Frecuencia cardíaca, presión arterial sistólica y peso corporal.}

Se monitoreó la presión arterial sistólica y la frecuencia cardíaca, por el método de la cola. Además, previo a ser sacrificados, los animales fueron pesados.

\section{ESTUDIOS MORFOLÓGICOS.}

A fin de poder analizar el efecto de la actividad física periódica e intensa sobre la HCP y la función ventricular izquierda se realizaron varias determinaciones:

\section{- Estudios ecocardiográficos.}

Los animales fueron examinados por ecocardiografía con el fin de evaluar distintos parámetros que permitan caracterizar el tipo de $\mathrm{HC}$, así como poder "monitorear" periódicamente in vivo la masa ventricular. Esto se realizó a los animales de todos los grupos, al iniciar y finalizar el protocolo. Para ello, se los anestesió con pentobarbital sódico intraperitoneal, se depiló la zona torácica y se aplicó gel ultrasónico. El ecocardiograma transtorácico se logró utilizando un transductor de $7.5 \mathrm{mHz}$. Se obtuvieron imágenes bidimensionales de planos equivalentes al eje corto paraesternal en humanos. A partir de esas imágenes, se seleccionó la de mejor resolución y se realizó un registro. Las imágenes se digitalizaron para realizar las determinaciones. Las mediciones para el análisis de la estructura y función del ventrículo izquierdo $(\mathrm{VI})$ se efectuaron en 3 latidos consecutivos, de acuerdo a las recomendaciones de la American Society of Echocardiography $(206,207)$.

De cada registro se tomaron los siguientes parámetros: índice de masa ventricular izquierda, espesor de la pared del VI, diámetro diastólico del VI, relación entre el espesor del VI y el radio de la cavidad y acortamiento medio ventrícular izquierdo, según las técnicas previamente descriptas (206, 208-210). 


\section{- Masa del VI, masa del ventrículo derecho y la relación peso del VI/longitud de} la tibia (PVI/LT).

Finalmente al cumplirse el tiempo de protocolo experimental (entrenamiento físico) los animales fueron sacrificados bajo anestesia con eter y se extrajeron rápidamente los corazones, que luego de ser desprovistos del tejido conectivo adyacente y de los grandes vasos, fueron secados en papel de filtro y pesados para la determinar la masa del VI, masa del ventrículo derecho y el índice de HC, PVI/LT.

El tejido miocárdico se preservó de manera apropiada para posteriores determinaciones histológicas y moleculares.

\section{ESTUDIOS HISTOLÓGICOS.}

Con el objetivo siguiente de analizar los distintos cambios celulares que se desarrollan en la HC y la importancia de la actividad física, a continuación se examinó el área de sección transversal del cardiomiocito, la fracción de colágeno y la densidad capilar.

\section{- Determinación del área de sección transversal de los cardiomiocitos (AST) y} de la abundancia de colágeno intersticial.

El tejido ventricular se fijó en un buffer $10 \%$ formaldehído por 24 horas y se lo embebió en parafina. Se realizaron cortes coronales ecuatoriales de VI $(5 \mu \mathrm{m}$ de espesor), los cuales fueron teñidos para realizar el análisis del AST y de la fracción de colágeno. Para determinar el AST de los miocitos, los cortes fueron teñidos aplicando el método de la "Hematoxilina-eosina", y para cuantificar la presencia de colágeno en el miocardio se utilizó la técnica de "Picrosirius red" anteriormente descripta (189). Las imágenes microscópicas fueron captadas con una videocámara, digitalizadas y posteriormente procesadas mediante un programa de análisis de imágenes. Esto permitió analizar si la regresión de la hipertrofia se acompaña o no de una disminución de la fibrosis y/o del tamaño de los miocitos. 


\section{- Densidad capilar.}

La determinación de la densidad capilar se realizó mediante inmunohistoquímica utilizando la técnica previamente descripta por Xu (211). La misma fue expresada como el promedio de capilares por $\mathrm{mm}^{2}$. Para visualizar células endoteliales se utilizaron anticuerpos contra el factor de Von Willebrand (Dako) y contra transglutaminasa (Dako), y para visualizar células musculares lisas se utilizaron anticuerpos contra $\alpha$ actina de músculo liso (Dako). Como controles negativos, los anticuerpos primarios fueron reemplazados por inmunoglobulina $G$ de ratón. Se consideraron como capilares aquellos vasos que dieran positivos los anticuerpos contra el factor de Von Willebrand y contra transglutaminasa, sin células musculares y con un diámetro de menos de $10 \mu \mathrm{m}$. Se contaron como mínimo 5 campos distintos de cada sección con un aumento de $450 \mathrm{X}$.

\section{ESTUDIOS MOLECULARES.}

- Determinación de la expresión de marcadores moleculares de HC por medio de la técnica de la reacción en cadena de la polimerasa (PCR) en tiempo real ("real-time PCR").

Se realizó la cuantificación relativa de cada ARNm de interés con respecto al ARNm de GAPDH, que fue utilizado como control interno dado que su expresión se mantiene constante en las distintas maniobras experimentales propuestas. Se homogenizó el tejido cardíaco y se aisló el ARN total, se cuantificó espectrofotométricamente mediante la medida de la absorbancia a 260nm. Posteriormente se realizó la transcripción reversa (RT) a partir de una cantidad conocida de ARN total, utilizando cebadores específicos para los genes de interés como el péptido natriurético atrial (ANF), la cadena liviana de miosina-2 (MLC-2) y para GAPDH. La cuantificación se realizó mediante la técnica de real time PCR $(98,212)$. La reacción se llevó a cabo en un equipo para PCR en tiempo real (iCycler, BioRad).Todos los parámetros derivados de esta reacción se calcularon utilizando el programa Real-Time Detection System Software, versión 3.0 (Bio-Rad). 


\section{Determinación de ARNm}

Se realizó la determinación del ARNm del ANF a partir de ARN total aislado de ventrículo izquierdo, utilizando la técnica de real time RT-PCR. Se utilizó como estándar interno el ARNm de GAPDH.

\section{Aislamiento de ARN total}

A partir de 20-30 mg de tejido conservado en RNAlater (Qiagen) a $-80^{\circ} \mathrm{C}$ se realizó el asilamiento de ARN total utilizando el kit RNeasy (Qiagen) y siguiendo las instrucciones del fabricante. Las muestras de tejido, una vez descongeladas, se homogeneizaron durante 40 segundos en el buffer de lisis provisto por el kit, conteniendo isotiocianato de guanidina y $\beta$-mercaptoetanol para proveer condiciones desnaturalizantes y permitir la inmediata inactivación de ribonucleasas, empleando un homogenizador Glas-Col Model K-41 TRI-R STIR-R y vástago de teflón. A continuación se sometió el tejido homogeneizado a 10 minutos de digestión proteica a 55ํㅡ empleando proteinasa K (Invitrogen) y se cargaron las columnas del kit, previa adición de etanol para ajustar las condiciones de unión del ARN a la fase sólida. Se llevaron a cabo 3 pasos de lavado, digestión con desoxirribonucleasa (Qiagen) durante 15 minutos a temperatura ambiente para eliminar interferencias de ADN y finalmente se eluyó el ARN con $50 \mu \mathrm{L}$ de agua libre de nucleasas (Qiagen). Toda la manipulación de las muestras y preparación de soluciones a partir de la elución del ARN purificado se realizó con puntas de pipeta con filtro y agua libre de nucleasas.

\section{Determinación de la concentración de ARN}

La concentración de ARN se determinó mediante la lectura de absorbancia a 260 $\mathrm{nm}\left(\mathrm{A}_{260}\right)$ con el espectrofotómetro (SmartSpec 3000, Bio-Rad). Para ello se realizó una dilución apropiada en agua del ARN purificado, usualmente 1/10, para asegurar lecturas mayores de 0.15 unidades de absorbancia, y se midió la $A_{260}$ utilizando cubetas de 50 $\mu \mathrm{L}$ transparentes a la luz UV y llevando la absorbancia a cero con agua. Para la cuantificación se consideró que la absorbancia de 1 unidad a 260nm corresponde a una concentración de ARN de $40 \mu \mathrm{g} / \mathrm{mL}$. 


\section{Transcripción reversa}

Este paso tiene como objetivo la obtención de una cadena de ADN copia (ADNc) del ARNm de por ejemplo ANF, para poder ser utilizada como molde en la reacción de PCR. Se realizó utilizando transcriptasa reversa Omniscript (Qiagen). La enzima posee actividad de ADN-polimerasa dependiente del molde de ARN y actividad de exoribonucleasa dependiente de una doble cadena híbrida ARN:ADN. Los pasos de la reacción incluyen: a) hibridización de cebadores o "primers", necesarios como punto de partida para el inicio de la actividad de polimerización de la enzima; b) RT propiamente dicha, consistente en la síntesis de una cadena de ADN partiendo del primer y utilizando un molde de ARN; y c) degradación del ARN presente en cadenas híbridas ARN:ADN, esta actividad de exorribonucleasa solo actúa sobre el ARN hibridizado al ADNc sintetizado, y no afecta al ARN de cadena simple. Un esquema de los pasos mencionados se muestra en la Figura $\mathbf{1} \mathbf{M}$.

\section{Síntesis de ADNc}

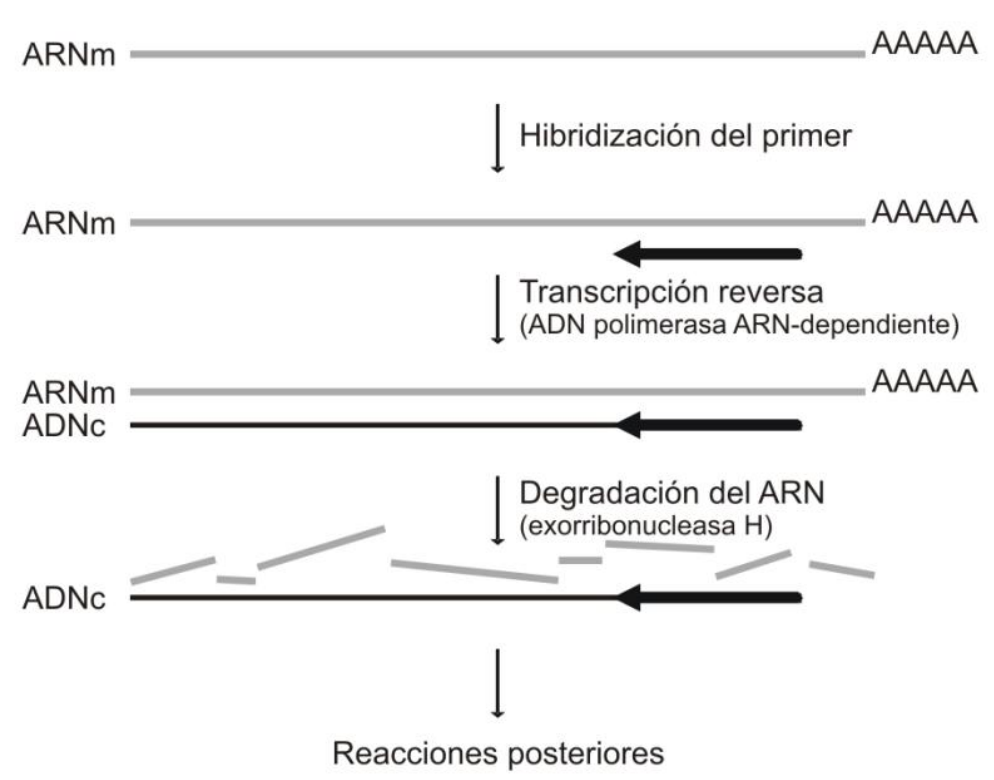

Figura 1M. Esquema de la transcripción reversa. La hibridización del primer con la secuencia complementaria del ARNm posibilita la acción enzimática de ADN polimerasa utilizando como molde el ARNm. La doble hebra híbrida formada es susceptible a la acción de ribonucleasa de la enzima, garantizando la formación de una única copia de ADNc por cada cadena de ARNm presente. 
Como cebadores de la reacción se utilizaron los primers antisentido diseñados a partir de la secuencia del gen de ANF y de GAPDH de rata:

- Primer antisentido para ANF: 5'-TCCAGGTGGTCTAGCAGGTT-3'.

- Primer antisentido para GAPDH: 5'-CCACAGTCTTCTGAGTGGCA-3'.

Para cada muestra experimental de ARN purificado se preparó la siguiente mezcla de reacción en tubos de PCR de $200 \mu \mathrm{L}$ libres de ribonucleasas y manipulando todos los reactivos en baño de hielo:

- Mezcla de desoxinucleótidos trifosfato (dNTPs): $0.5 \mathrm{mM}$ de cada uno (dATP, dCTP, dGTP, dTTP).

- Primer antisentido $1 \mu \mathrm{M}$ de cada uno (ANF y GAPDH).

- Inhibidor de ribonucleasas (Invitrogen): 10 Unidades.

- Transcriptasa reversa Omniscript (Qiagen): 4 Unidades.

- $1.6 \mu \mathrm{g}$ de ARN.

- Buffer de reacción (Qiagen): hasta completar $20 \mu \mathrm{L}$.

La reacción se llevó a cabo durante 60 minutos a $37^{\circ} \mathrm{C}$, seguidos de 5 minutos de inactivación de la enzima a $95^{\circ} \mathrm{C}$ y enfriado a $4^{\circ} \mathrm{C}$, en un ciclador térmico (PTC-150 Mini Cycler). Se conservó el ADNc obtenido a $-80^{\circ} \mathrm{C}$ hasta el momento de su utilización como molde en la real time PCR.

\section{Real time PCR}

\section{- Fundamento}

Este método conserva el fundamento de una PCR estándar, más la posibilidad adicional de seguir en tiempo real el curso de la reacción y calcular así parámetros mediante los cuales se puede estimar la cantidad inicial de ADNc utilizado como molde. Como en cualquier PCR, la real time PCR consiste en ciclos sucesivos de desnaturalización de la doble hebra de ADN, hibridización de los primers al ADN molde, síntesis de la cadena complementaria mediante una polimerasa resistente al calor (Taq polimerasa) y nuevamente desnaturalización del ADN doble cadena para recomenzar el ciclo (Figura 2M). 


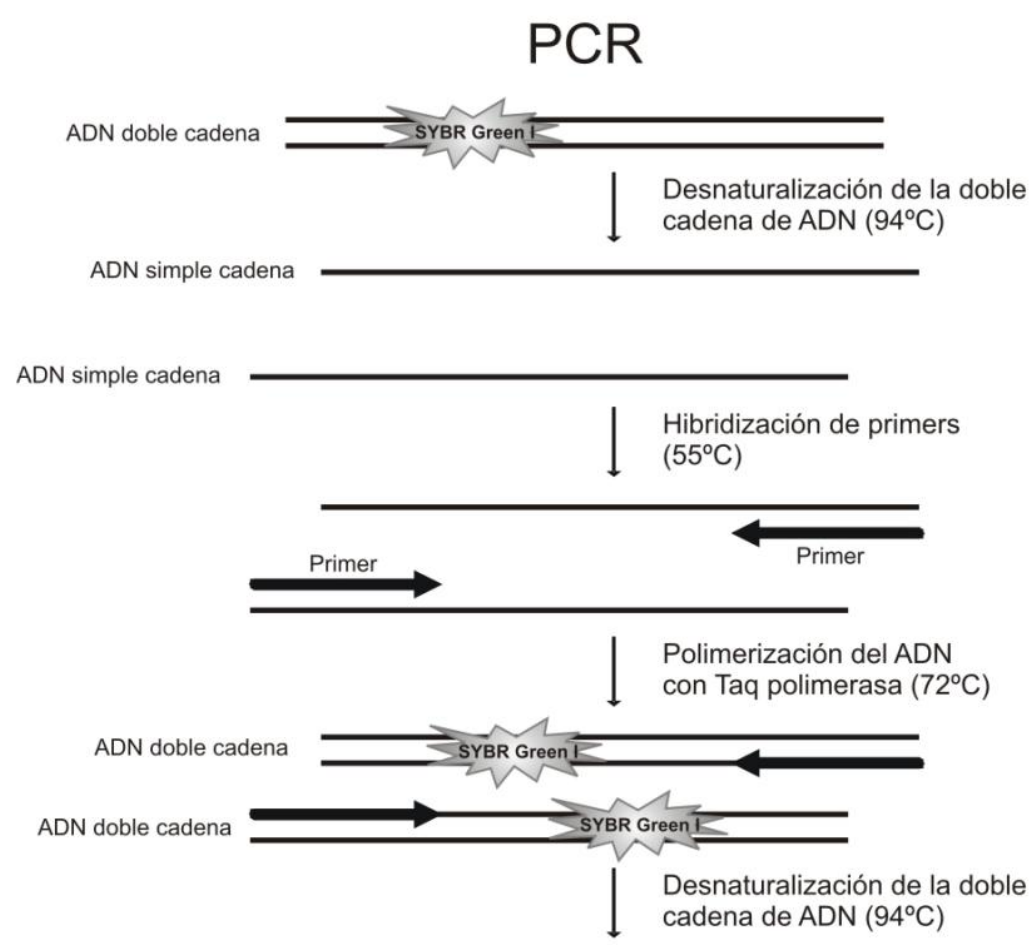

Figura 2M. Se esquematizan los pasos de una PCR: desnaturalización del ADN doble cadena, hibridización de primers y polimerización. El indicador SYBR Green I fluorece a $490 \mathrm{~nm}$ sólo cuando se une a ADN doble cadena.

En condiciones ideales, en cada ciclo la cantidad de ADN se duplica y podría calcularse el número de copias de $\operatorname{ADN}\left(\mathbf{N}_{\mathbf{n}}\right)$ en un ciclo dado $(\mathbf{n})$, teniendo en cuenta el número de copias inicial $\left(\mathbf{N}_{0}\right)$ según la siguiente ecuación:

$$
N_{n}=N_{0} \times 2^{n}
$$

El crecimiento exponencial del número de copias de ADN ocurre hasta que los reactivos se agotan y/o se produce inhibición por producto.

La real time PCR se lleva a cabo en un ciclador térmico que tiene acoplado un detector óptico que mide la fluorescencia en cada ciclo y en cada reacción individual. Se utilizó el indicador SYBR Green I, el cual emite fluorescencia a $490 \mathrm{~nm}$ al unirse al surco menor del ADN doble cadena (figura 2M). El equipo ciclador permite programar las condiciones para obtener una lectura de fluorescencia en cada ciclo, al finalizar la etapa de polimerización y antes de la etapa de desnaturalización de la doble hebra. De esta manera se obtiene para cada reacción individual una curva de amplificación, que se define como la curva de fluorescencia en función del número de ciclos, similar a la que se muestra en la figura 3M. En ella se distinguen tres fases: 1) una fase inicial en la que 
debido a una cantidad aun baja de ADN los cambios de fluorescencia no son detectados por el equipo y por lo tanto la señal es aproximadamente constante; 2) una fase exponencial donde se observa el mayor crecimiento de fluorescencia con el número de ciclos; y 3) una fase de meseta o declinación, en la que la fluorescencia es constante o crece más lentamente.

Intuitivamente es posible deducir que cuanto mayor sea la cantidad de ADN inicial, más pronto se observará un aumento significativo de fluorescencia en el curso de la reacción. La fase inicial de la curva de amplificación define una línea de base por encima de la cual se detecta la acumulación del producto de PCR. Al establecer arbitrariamente una línea umbral por encima de esta línea de base, se define el parámetro $\mathrm{C}_{\cup}$ (ciclo umbral) como el número fraccional de ciclos en el que la fluorescencia intersecta la línea umbral (Figura 3M).

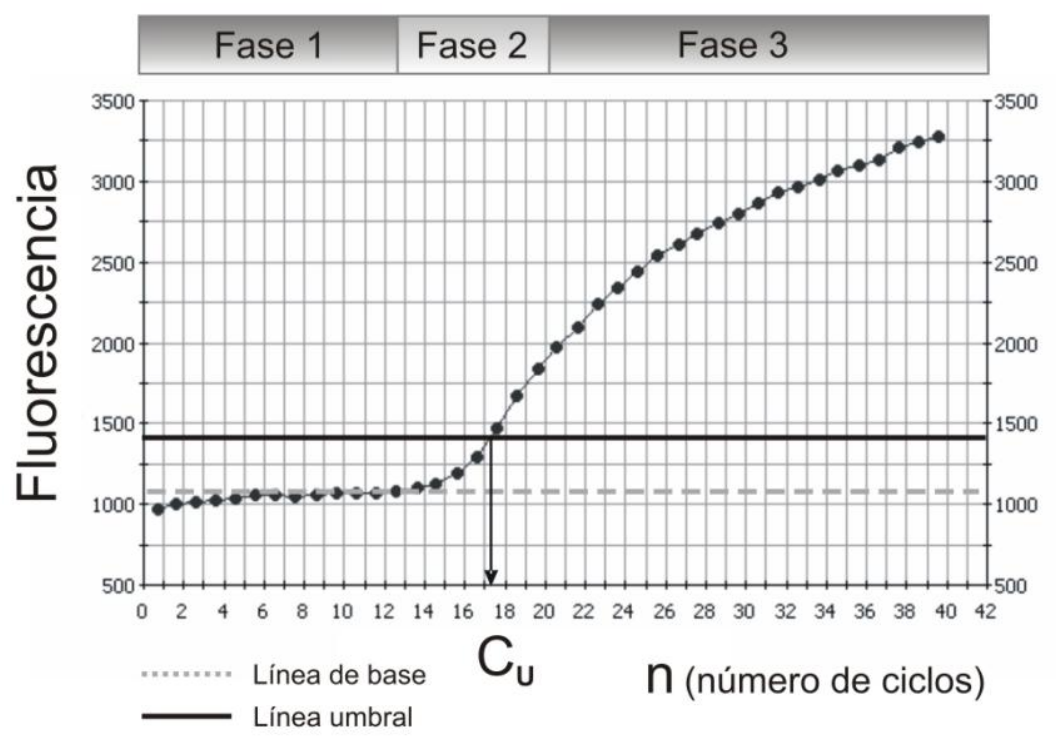

Figura 3M. Curva de amplificación: fluorescencia en función del número de ciclos de PCR. En la fase 1 no se detectan cambios de fluorescencia, en la Fase 2 la fluorescencia aumenta de manera exponencial y este aumento se hace más lento o desaparece en la Fase 3. El $\mathrm{C}_{\cup}$ se mide en la intersección de la curva con la línea umbral, que se fija en la zona exponencial y por encima de la línea de base. 
Si se realizan varias reacciones partiendo de distintas cantidades de ADN, el gráfico del logaritmo de la cantidad de ADN inicial en función del $\mathrm{C}_{U}$ de cada una de ellas, es una línea recta (siempre que los $\mathrm{C}_{\cup}$ se obtengan a partir de una línea umbral establecida en la fase exponencial de la curva de amplificación). Esta recta constituye una curva de calibración o curva de eficiencia (Figura 4M).

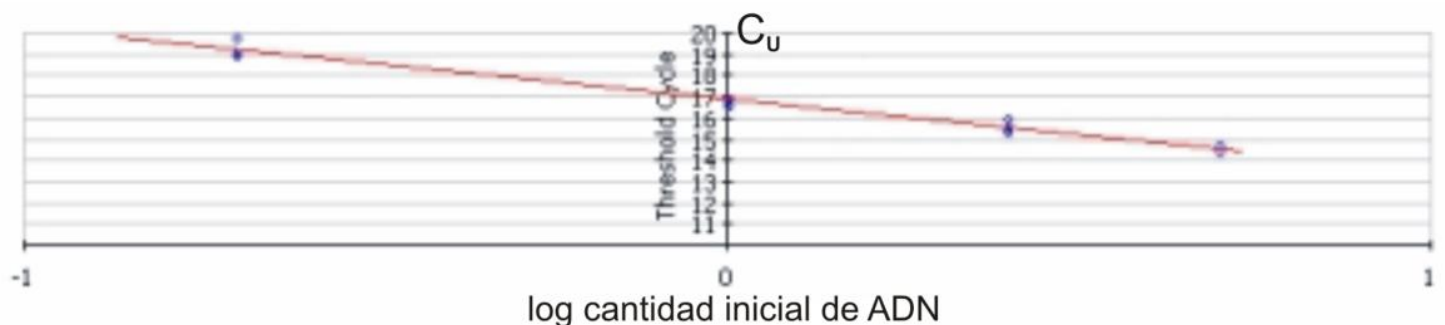

Figura 4M. Curva de calibración o de eficiencia: $C_{\cup}$ en función del logaritmo de la cantidad inicial de ADN. Se construye amplificando diluciones conocidas del ADNc.

Si en la fase exponencial el rendimiento de la reacción fuese ideal, sería posible calcular la cantidad inicial de ADN en una muestra desconocida a partir de un reordenamiento de la fórmula antes mencionada:

$$
\mathrm{N}_{0}=\mathrm{N}_{\mathrm{n}} / 2^{\mathrm{n}}
$$

Como en la práctica no ocurre de esta manera, es necesario reemplazar el factor "2" por la eficiencia real de amplificación, y el cálculo entonces sería:

$$
\mathrm{N}_{0}=\mathrm{N}_{\mathrm{n}} / \mathrm{E}^{\mathrm{n}}
$$

donde $\mathbf{E}$ es la eficiencia que se obtiene a partir de la pendiente de la curva de calibración o eficiencia:

$$
E=10^{-1 / \text { pendiente }}
$$

Si bien el modo más directo y sencillo de calcular la cantidad inicial de ADN (e inferir por lo tanto la cantidad de ARNm de partida) es el presentado en la ecuación ${ }^{(2)}$, se han desarrollado modelos matemáticos más complejos para mejorar dicho cálculo. Entre ellos el presentado por Pfaffl (213), que se ajusta adecuadamente a las condiciones experimentales del presente trabajo. Dicho modelo está diseñado para ser aplicado a la cuantificación relativa del $\mathrm{ARNm}$ de un gen dado, en una determinada condición experimental con respecto a una condición control. Al mismo tiempo corrige las posibles fluctuaciones de las reacciones de PCR, al normalizar el valor encontrado con respecto a un gen de referencia o estándar interno que no modifica su nivel de expresión en las 
condiciones experimentales empleadas. La fórmula utilizada para el cálculo es:

$$
R=\frac{\left(E_{A N F}\right)^{\Delta C_{U} A N F(\text { Control-Exp) }}}{\left(E_{\text {GAPDH }}\right)^{\Delta C_{U} \text { GAPDH (Control-Exp) }}}
$$

Donde $R$ es la relación de expresión relativa del gen de interés, ANF, entre una condición experimental (SHR-S o SHR-E) y la situación control (ratas Wistar); normalizada por la expresión del estándar interno, GAPDH en las mismas situaciones. El parámetro E es la eficiencia de amplificación de cada gen, determinado a partir de la curva de eficiencia correspondiente, y $\Delta \mathbf{C}_{u}$ se obtiene restando el $C_{u}$ en la condición experimental del $C_{u}$ en la situación control.

Para verificar la ausencia de formación de productos no deseados se realizan curvas de desnaturalización o "melting", una vez finalizada la PCR. Esta curva se obtiene midiendo la fluorescencia en función de la temperatura en un rango habitual entre 98-65드. La fluorescencia depende de la proporción de ADN doble cadena y desnaturalizado, y esto último de la temperatura y de el contenido de guanina + citosina, o sea de la secuencia del ADN analizado. Si existe un único producto, la derivada de la fluorescencia en función del número de ciclos dará una curva con un solo pico, como en la Figura 5M.

A

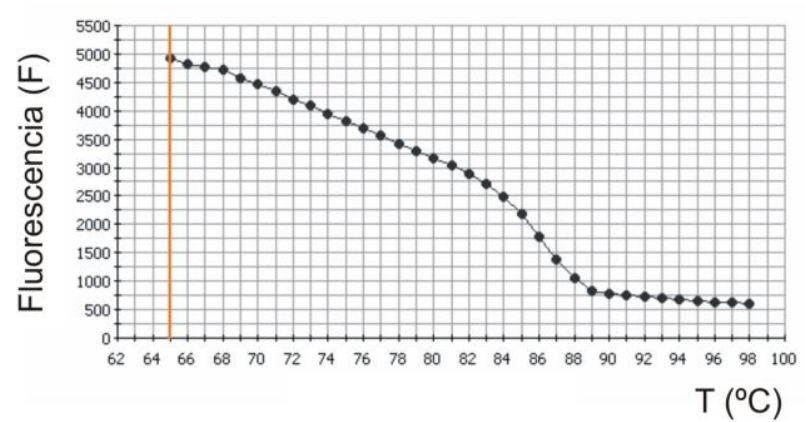

B

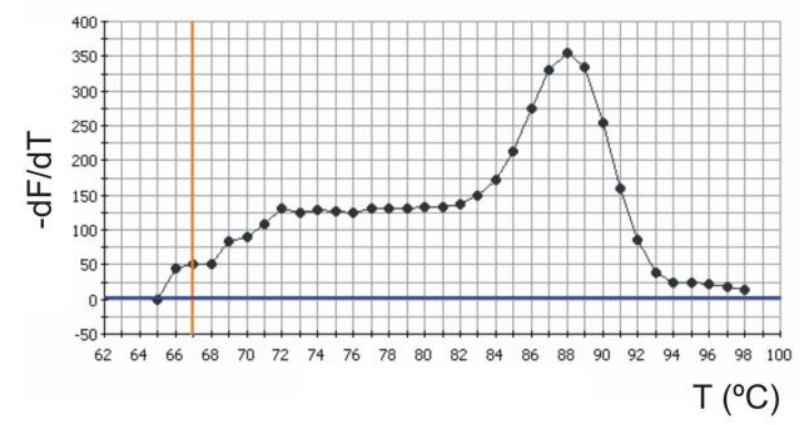

Figura 5M. Curvas de melting. Fluorescencia en función de la temperatura $(A)$ y $(-\mathrm{dF} / \mathrm{dT})$ en función de la temperatura. La presencia de un solo pico indica que sólo un producto ha sido amplificado. 
- Procedimiento

Cada PCR se realizó por triplicado, tanto para ANF como para GAPDH, partiendo de una dilución 1/10 del producto obtenido en la RT. Los primers utilizados fueron:

GAPDH: primer sentido 5'-GGGTGTGAACCACGAGAAAT-3' y

primer antisentido 5'-CCACAGTCTTCTGAGTGGCA-3';

ANF: primer sentido 5'-AGGGCTTCTTCCTCTTCCTG-3'.

primer antisentido 5'-TCCAGGTGGTCTAGCAGGTT-3'.

Las reacciones se prepararon en placa de 96 pocillos, con la siguiente composición

- dNTPs (Amersham) $0.2 \mathrm{mM}$ de cada uno.

- $\mathrm{MgCl}_{2}$ (Invitrogen) $1.5 \mathrm{mM}$.

- Fluoresceína (Bio-Rad) 10 nM.

- SYBR Green I (Molecular Probes) dilución 1/1000: $0.8 \mu \mathrm{L} /$ reacción.

- Primers (Operon) $0.5 \mu \mathrm{M}$ de primer sentido y $0.5 \mu \mathrm{M}$ de primer antisentido.

- Taq ADN polimerasa (Invitrogen) 1.25 Unidades/reacción.

- ADNc molde: dilución 1/10 de la RT.

- Buffer de PCR (Invitrogen): hasta un volumen de $25 \mu \mathrm{L} /$ reacción.

Además se realizó una curva de eficiencia para cada gen con diluciones 1/2, 1/10 y 1/100 de una mezcla constituída por todos los productos de RT obtenidos (pool), cada punto de la curva se realizó también por triplicado. Como control negativo se prepararon mezclas de reacción que en lugar de contener ANDc molde, se cargaron con agua bidestilada. Una vez armadas todas las mezclas de reacción se cubrió la placa con una pieza de film óptico (Bio-Rad) y se llevó a cabo la reacción en un equipo para PCR en tiempo real (iCycler, Bio-Rad). El protocolo de temperaturas utilizado se esquematiza en la Figura 6M.

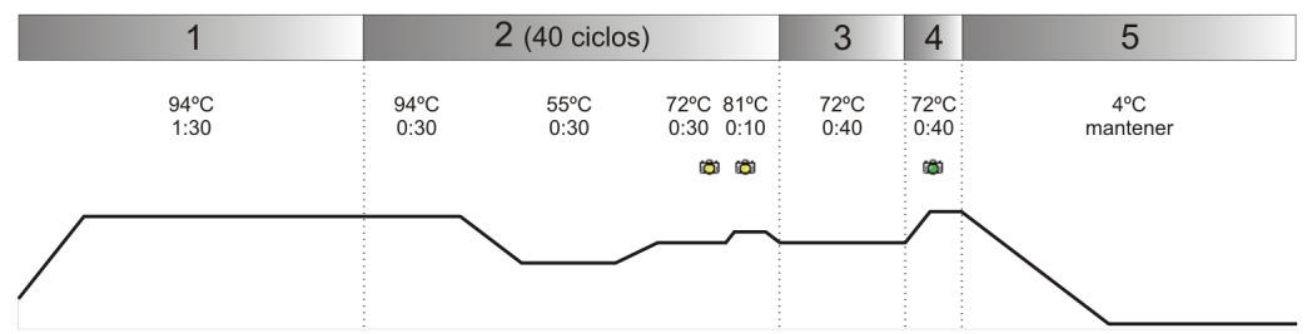

Figura 6M. Protocolo de temperatura utilizado. El software del equipo inserta el paso $1 \mathrm{con}$ la finalidad de ajustar posibles diferencias de volumen entre los distintos pocillos. En el paso 2 se permite desnaturalización del $A D N$ doble cadena $\left(94^{\circ} \mathrm{C}\right)$, hibridización de primers con el $A D N$ molde $\left(55^{\circ} \mathrm{C}\right)$ y polimerización $\left(72^{\circ} \mathrm{C}\right)$. Se toman lecturas de fluorescencia en los últimos 10 segundos de polimerización y 
en 10 segundos adicionales $\left(81^{\circ} \mathrm{C}\right)$. El paso completo se repite 40 veces. El paso 3 tiene como finalidad completar la polimerización. El paso 4 consiste en una rampa de incremento de $1^{\circ} \mathrm{C}$ cada 10 segundos, se toma una lectura de fluorescencia cada 10 segundos para construir las curvas de melting. En el paso 5 la temperatura desciende hasta $4^{\circ} \mathrm{C}$.

Todos los parámetros derivados de esta reacción fueron calculados utilizando el programa Real-Time Detection System Software, versión 3.0 (Bio-Rad).

Esta misma metodología se repitió para MLC-2, cuyos primers fueron: primer sentido 5'-CCATGTTTGAGCAGACCCAGA-3'. primer antisentido 5'-GCTGCGAACATCTGGTCGATC-3'.

- Determinación de las vías de señalización intracelular relacionadas con la producción de $\mathrm{HC}$ mediante la técnica de Western Blot.

Se midió la activación de quinasas y fosfatasas, entre otras, mediante la técnica de Western Blot, por la cual igual cantidad de proteína de cada muestra fue sometida a una electroforesis en gel de polyacrilamida siguiendo la técnica de SDS-PAGE. Para realizar la inmunodetección se emplearon anticuerpos específicos para calcineurina $A \beta$, caspasa-3, PARP-1 y PI3K p110a (Santa Cruz Biotechnology); NCX (Chemicon); fosfoAKT (Cell Signaling) y SERCa2A (AFFinity Bioreagents). GAPDH fue utilizado como control. La actividad de calcineurina se determinó midiendo por inmunoblot la expresión de la subunidad catalítica (calcineurina $A \beta$ ), dado que se ha demostrado que se correlaciona adecuadamente con la actividad de la fosfatasa $(187,214)$. Se utilizó un sistema de detección electroquimioluminiscente y una cámara CCD del equipo Chemidoc XRS que capturó y digitalizó las imágenes. Se cuantificó la intensidad de las bandas por densitometría utilizando el programa Scion Image.

\section{- Procedimiento}

Se determinó la expresión de proteínas específicas en preparados de homogenatos de ventrículo izquierdo.

\section{Preparación de homogenatos de ventrículo izquierdo.}

Para la determinación de la expresión proteica en homogenatos de ventrículo izquierdo las muestras congeladas se colocaron en 5 volúmenes $(5 \mathrm{ml} / \mathrm{g})$ de buffer de lisis 
(sacarosa $300 \mathrm{mmol} / \mathrm{l}$; DTT $1 \mathrm{mmol} / \mathrm{L}$; EGTA $4 \mathrm{mmol} / \mathrm{L}$, cocktail de inhibidores de proteasas (Complete Mini Roche) 1 pastilla/15 ml de buffer; Tris-HCl 20 mmol/L, pH 7.4), y se realizaron 3 pasos de homogeinización en baño de hielo utilizando la velocidad 6 del homogeinizador de tejidos Polytron (Brinkmann modelo PCU11), de 10 segundos cada uno, separados por 30 segundos. Luego de la homogeinización, las muestras se mantuvieron en baño de hielo durante 30 minutos para completar la acción del buffer de lisis. A continuación se realizó una centrifugación a baja velocidad: $5000 \times \mathrm{xg}$ a $4^{\circ} \mathrm{C}$ durante 15 minutos (Sorvall RC-5B Refrigerated Superspeed Centrifugue); para separar los restos de tejido no homogeneizado. El pellet fue descartado y el sobrenadante se sonicó 5 segundos y se conservó como homogenato de ventrículo izquierdo, a $-80^{\circ} \mathrm{C}$.

\section{Determinación de la concentración de proteínas.}

Para la medida de la concentración de proteínas en el homogenato se empleó el método espectrofotométrico de Bradford (BioRad Protein Assay) siguiendo las instrucciones del fabricante. Partiendo de diluciones apropiadas de las muestras se realizaron las determinaciones por triplicado, leyendo la absorbancia a $595 \mathrm{~nm}$, con sustracción del blanco de reactivos, en un espectrofotómetro UV/visible (SmartSpec 3000, Bio-Rad). La cuantificación se realizó a partir de una curva de calibración realizada con 4 diluciones de seroalbúmina bovina (Sigma-Aldrich).

\section{Determinación de la expresión de proteínas mediante la técnica de Western Blot.}

Mediante la técnica de western-blot se evaluó la expresión de las proteínas en los distintos grupos experimentales. Para ello se utilizó el sistema de cuba y buffers para electroforesis y transferencia Novex (Invitrogen). A continuación se describe el procedimiento en común para todas las determinaciones.

Preparación de las muestras: las muestras se descongelaron en baño de hielo. Se tomó el volumen adecuado según la proteína a analizar y se procedió a la desnaturalización y preparación para la electroforesis utilizando buffer de muestra y 10\% de agente reductor (ambos de Invitrogen). Se completó con agua bidestilada para alcanzar el volumen a sembrar en el gel en cada caso. Todo este procedimiento se realizó en baño de hielo. Las muestras se desnaturalizaron en baño termostático (Precision) a $70^{\circ} \mathrm{C}$ durante 10 minutos. 
Electroforesis: para la separación electroforética de las proteínas se utilizaron geles preensamblados de poliacrilamida en gradiente $4-12 \%$ Bis-Tris (Invitrogen) y dilución adecuada del buffer 20X (Invitrogen) de composición $1.00 \mathrm{~mol} /$ itro MOPS, $1.00 \mathrm{~mol} /$ itro Tris base, $69.3 \mathrm{mM}$ SDS, $20.5 \mathrm{mM}$ EDTA y agua bidestilada hasta $500 \mathrm{~mL}, \mathrm{pH}$ 7.7. Al buffer reconstituído utilizado para la cámara interna se le agregó agente reductor (Invitrogen) en una concentración final de $0.1 \%$. Se sembró un volumen apropiado de las muestras en el gel, más $1 \mu \mathrm{L}$ de marcador de pesos moleculares (MagicMarc, Invitrogen). La corrida electroforética se realizó a temperatura ambiente y a $200 \mathrm{~V}$, suministrados por una fuente de poder PS 251-2 (Sigma-Aldrich). La corrida se prolongó durante el tiempo necesario para que el frente de solvente alcanzara el extremo del gel (aproximadamente 45-60 minutos).

Transferencia: las proteínas separadas por su peso molecular fueron transferidas a membranas de PVDF (Millipore). Se empleó una dilución adecuada del buffer de transferencia 20X (Invitrogen) de composición 500mM bicina, 500mM Bis-Tris, $20.5 \mathrm{mM}$ EDTA, $1 \mathrm{mM}$ clorobutanol y agua ultra pura hasta $600 \mathrm{~mL}$. Al reconstituir el buffer se le adicionó metanol (Carlo Erba) y agente reductor (Invitrogen) en una concentración final de 10 y $0.1 \%$, respectivamente. Las membranas se activaron sumergiéndolas durante 30 segundo en metanol, luego se las enjuagó con agua bidestilada y se las dejó equilibrar en el buffer de transferencia varios minutos, al igual que los papeles de filtro y las esponjas utilizadas en el sándwich. La transferencia se llevó a cabo con la cuba en baño de hielo, utilizando el voltaje y el tiempo apropiados en cada caso. Una vez finalizada, se retiraron las membranas y se corroboró la presencia de proteínas en la misma mediante tinción reversible con Ponceau ( $0.1 \%$ Ponceau en $0.5 \%$ de ácido acético) y posteriormente se enjuagó con T-TBS (tris base 0.05M, NaCl 0.15M, Tween 20 0.1\%).

Bloqueo: las membranas se bloquearon durante 60 minutos en agitador orbital (Decalab) a temperatura ambiente con solución en T-TBS de leche en polvo descremada (Molico) o de BSA en concentración apropiada.

Incubación con anticuerpo primario específico: luego de un breve enjuague con T-TBS de la solución de bloqueo, se incubaron las membranas con $10 \mathrm{~mL}$ de la dilución correspondiente de anticuerpo primario contra la proteína de interés, en T-TBS 
adicionado con $1 \%$ de BSA. Este procedimiento se realizó "over-night", a $4^{\circ} \mathrm{C}$ y con agitación orbital.

Lavado del anticuerpo primario: para eliminar el anticuerpo primario que se hubiere adherido inespecíficamente a la membrana, luego de retirar el anticuerpo primario se realizaron 4 lavados con T-TBS a temperatura ambiente en agitador orbital. El primero de 5 minutos y los tres siguientes de 10 minutos.

Incubación con anticuerpo secundario: las membranas se incubaron durante 60 minutos a temperatura ambiente y con agitación, con $10 \mathrm{~mL}$ de la dilución apropiada del anticuerpo secundario correspondiente en T-TBS adicionado con $1 \%$ de BSA. El anticuerpo secundario está acoplado a la enzima peroxidasa de rábano (HRP) y está diseñado para reconocer la fracción Fc específica de la especie en la que se obtuvo el anticuerpo primario, haciendo de nexo de esta manera entre la proteína de interés y el sistema posterior de detección.

Lavado del anticuerpo secundario: se realizó de la misma manera que el lavado del anticuerpo primario.

Revelado: se utilizó el sistema de detección ECL Plus (Amersham) de acuerdo a las instrucciones del fabricante. La reacción se basa en la generación de éster de acridinio a partir de un sustrato, agua oxigenada y la HRP, en las condiciones alcalinas del medio esta sustancia se oxida generando un producto excitado que emite señal quimioluminiscente que puede ser detectada y cuantificada. La detección se realizó mediante la cámara CCD de un equipo Chemidoc XRS (Bio-Rad), que captura y digitaliza las imágenes.

Cuantificación: se cuantificó la intensidad de las bandas por densitometría utilizando el programa Scion Image. 


\section{ANÁLISIS ESTADÍSTICO}

Los datos se presentan como media \pm Error Standard. El análisis estadístico utilizado dependió del protocolo experimental. Las comparaciones fueron hechas por test de $t$ de Student para muestras apareadas, cuando se compararon dos grupos distintos. Pero para comparar 2 o más intervenciones diferentes se usó ANOVA de una vía para muestras apareadas seguido de un test de Student-Newman-Keuls. Se usó el programa Primer of biostatistics (McGraw Hill) para realizar estas pruebas estadísticas. Se consideró a un valor como estadísticamente significativo, cuando la probabilidad $(p)$ fue menor a 0.05 . 
RESULTADOS 
Las enfermedades cardiovasculares, a pesar del importante avance terapéutico, continuan siendo las principales causas de morbimortalidad. Dado que la $\mathrm{HC}$ es el mayor predictor de enfermedad cardíaca, resulta por ello imperativo investigar nuevas terapias para su prevención y tratamiento (215-219).

Los tratamientos farmacológicos y no farmacológicos son cada día más promisorios. Dentro de las alternativas no farmacológicas, son numerosos los estudios que avalan el beneficio de la actividad física realizada regularmente (220-223). Actualmente se ha tomado conciencia de su importancia y comienza a ser implementada en la prevención primaria y secundaria de las enfermedades cardíacas (224). El ejercicio físico no sólo desciende la presión arterial en pacientes hipertensos, sino que además mejora los valores de glucemia, colesterol, triglicéridos, así como también la oxigenación tisular (225). Evidencias en diferentes modelos experimentales indican que el ejercicio en el corazón atenúa los procesos de remodelación del ventrículo izquierdo, tales como la $\mathrm{HC}$ y la fibrosis, aumentando además la capacidad oxidativa del miocardio y promoviendo la sobrevida de los cardiocitos (226).

Los beneficios del ejercicio pueden percibirse principalmente por las modificaciones que se producen a nivel vascular, miocárdico y del músculo esquelético $(227,228)$. No obstante, los mecanismos celulares aún no se encuentran bien caracterizados. En particular en lo referente a las vías de señalización intracelular del cardiomiocito en la HC.

El presente estudio experimental fue programado para evaluar la adaptación cardíaca inducida por el ejercicio (actividad natatoria) utilizando el modelo de hipertensión arterial de las SHR. A continuación se presentarán los resultados morfológicos, histológicos y moleculares, que se observaron principalmente al final del período experimental en un grupo de SHR sometidas a actividad física (SHR-E), de acuerdo al protocolo descripto en la metodología, y se las comparó con dos grupos controles constituídos por ratas SHR sedentarias (SHR-S) y ratas Wistar normotensas. 


\section{CARACTERÍSTICAS DE LOS GRUPOS EXPERIMENTALES.}

En los animales de experimentación, previo a ser sacrificados, se determinó su peso corporal. Se encontró en ambos grupos de SHR valores similares pero significativamente menores que las Wistar de la misma edad y sexo. En la Figura 1R se muestran los pesos corporales al día 1 y 60 .

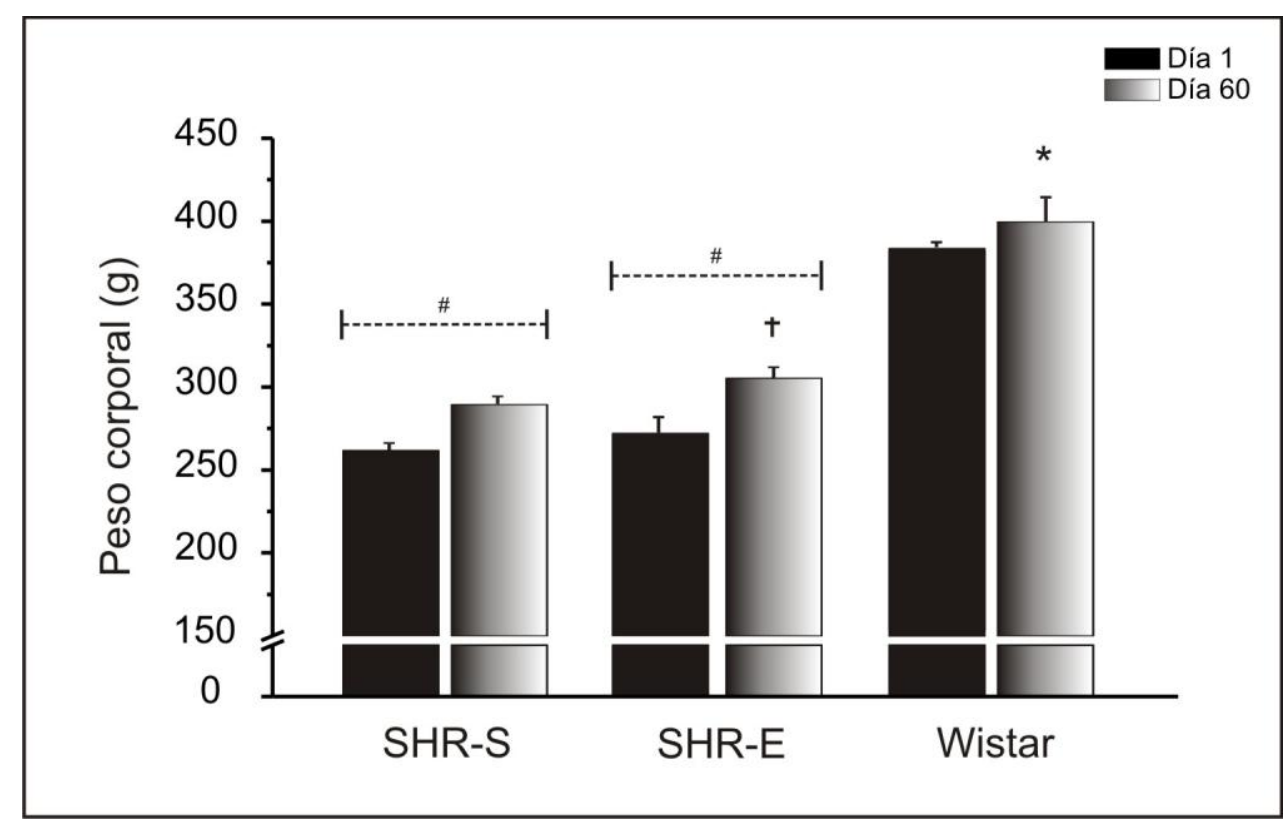

Figura 1R. Peso corporal. * $P<0.05$ vs. SHR-S, $\dagger P<0.05$ vs. Wistar (ANOVA). $\# P<0.05$ vs. el mismo grupo (Test-T).

La diferencia de pesos de las SHR con respecto a las Wistar podría dar un cociente erroneo al analizar el IMVI (masa del VI/peso corporal). Debido a ello se analizará además la relación peso del VI / longitud de la tibia (PVI/LT).

Paralelamente se realizó el monitoreo de la frecuencia cardíaca y de la presión arterial sistólica (PA), por el método de la cola. No se observaron cambios en la frecuencia cardíaca, como puede verse en la Tabla $1 \mathbf{R}$, resultados que coinciden con otros estudios (229).

\begin{tabular}{|c|c|c|c|}
\hline Variable & SHR-S $(n=13)$ & SHR-E $(n=9)$ & Wistar $(n=5)$ \\
\hline $\begin{array}{c}\text { Frecuencia cardíaca } \\
\text { (latidos/min) }\end{array}$ & $430 \pm 11$ & $412 \pm 17$ & $450 \pm 13$ \\
\hline
\end{tabular}

Tabla 1R. Frecuencia cardíaca. 
La Figura 2R muestra que los valores de las PA sistólica de las SHR-S y SHR-E fueron significativamente mayores respecto de las Wistar, al comenzar y finalizar el período experimental.

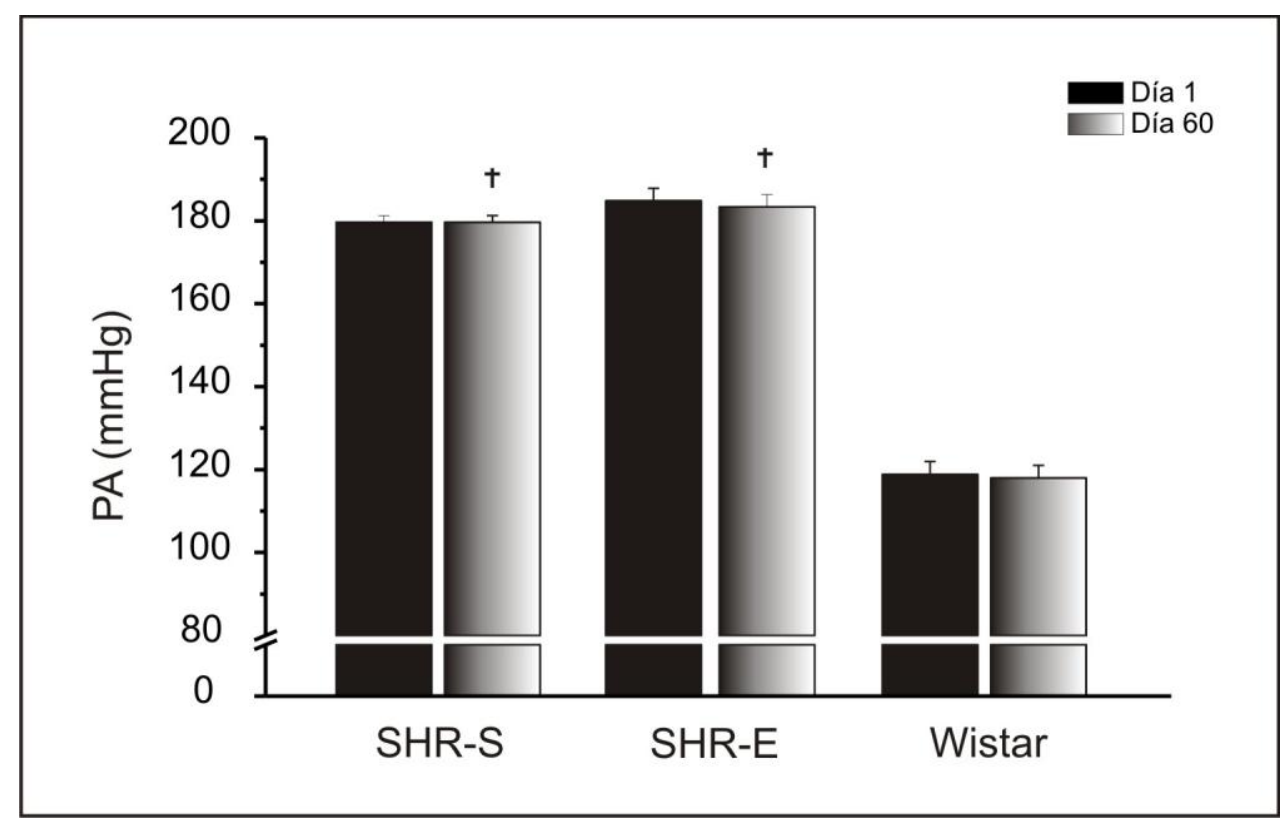

Figura 2R. Presión arterial. $\dagger P<0.05$ vs. Wistar (ANOVA).

\section{INFLUENCIA DEL EJERCICIO EN LA FUNCIÓN VENTRICULAR DE LAS SHR.}

Uno de los principales interrogantes que se planteó al comenzar el estudio era si la actividad física realizada durante un período de 60 días aportaría algún beneficio al corazón hipertrofiado de las SHR. Mediante el empleo de la ecocardiografía, técnica ampliamente reconocida por informar con precisión sobre la morfología y función ventricular (en humanos $(230,231)$, ratas y ratones $(208,232,233)$ ), se evaluó la geometría y función del VI preservando la vida del animal. Se eligió medir la fracción de acortamiento a nivel del tabique del VI (AMV), pues estudios previos demuestran que es un índice más exacto que medir la fracción de acortamiento del endocardio (234236). La fracción de acortamiento expresa en porcentaje cuanto se reduce el diámetro del VI durante la sístole. El estudio de los diámetros ventriculares posibilita estudiar la función sistólica. A continuación se muestra en la Figura 3R, los resultados obtenidos en los tres grupos experimentales. 


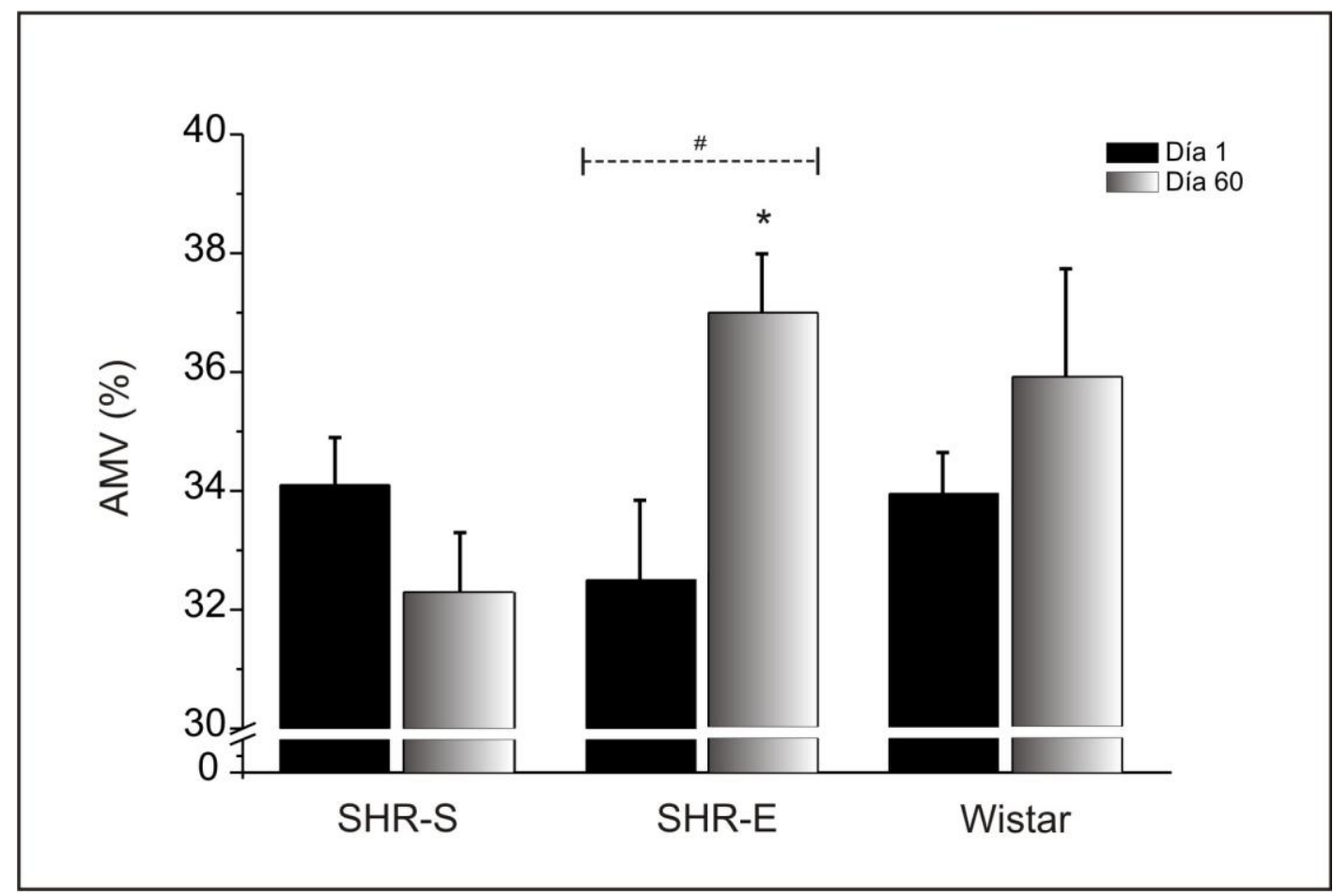

Figura 3R. Fracción de acortamiento medio ventrícular izquierdo. ${ }^{*} P<0.05$ vs. SHR-S (ANOVA). \# $P<0.05$ vs. el mismo grupo (Test-T).

Empleando el método de Devereux y col. (237) se determinó que al comienzo del período experimental (momento en el cual todas las SHR son sedentarias) no hubo diferencias en el AMV de los animales seleccionados para la actividad física y los controles sedentarios.

Al final del período experimental, las SHR-S no evidenciaron cambios significativos en el AMV, que tuvo una tendencia a disminuir sin ser estadísticamente significativa. Por el contrario las SHR-E al completar los 60 días de entrenamiento mostraron un incremento en el AMV, sugiriendo una mejora en la función cardíaca. El aumento del AMV de las SHR-E fue altamente significativo con respecto a las SHR-S, no apreciándose diferencias con respecto a las Wistar. 


\section{CARACTERÍSTICAS MORFOLÓGICAS DE LA HC EN LAS SHR EN EJERCICIO.}

\section{- ESTUDIOS MORFOLÓGICOS POR ECOCARDIOGRAFÍA.}

Previo sacrificio de los animales y con el objeto de poder caracterizar el tipo de $\mathrm{HC}$, se examinaron por ecocardiografía los siguientes parámetros:

-índice de masa ventricular izquierda, -espesor de la pared del VI, -diámetro diastólico del VI y -relación entre el espesor del ventrículo / radio de la cavidad.

Índice de masa ventricular izquierda (IMVI).

EI IMVI se obtuvo a través del cociente entre la masa ventricular izquierda, estimada por ecocardiografía, y el peso corporal del animal (Figura 4R).

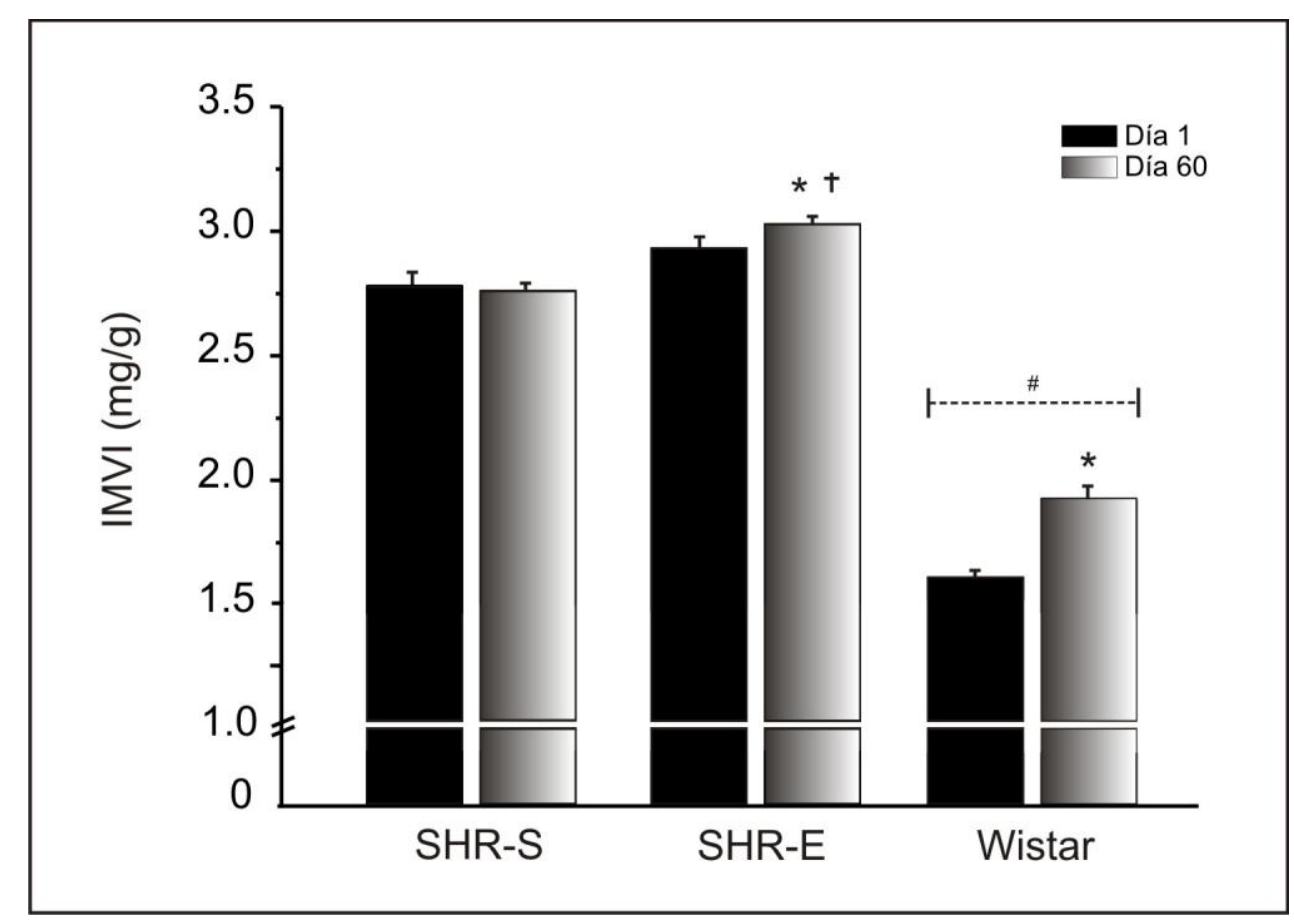

Figura 4R. Índice de masa ventricular izquierda. ${ }^{*} P<0.05$ vs. SHR-S, $\dagger P<0.05$ vs. Wistar (ANOVA). \# $P<0.05$ vs. el mismo grupo (Test-T). 
En esta figura se aprecia como el ejercicio físico provocó un aumento significativo del IMVI de las SHR-E respecto de las sedentarias. Además, se observó una diferencia significativa entre ambos grupos de SHR y las Wistar. Dado que el IMVI esta influenciado por el peso corporal de manera inversa, el menor peso encontrado por nosotros y otros investigadores en las SHR (238), podría dar valores incorrectos. Por ello se analizará posteriormente en estudios post-mortem el PVI/LT para confirmar la validez de estos resultados.

\section{Espesor de la pared ventricular izquierda (EPVI).}

Una de las formas de estimar la hipertrofia del ventrículo es mediante la cuantificación del EPVI. (Figura 5R).

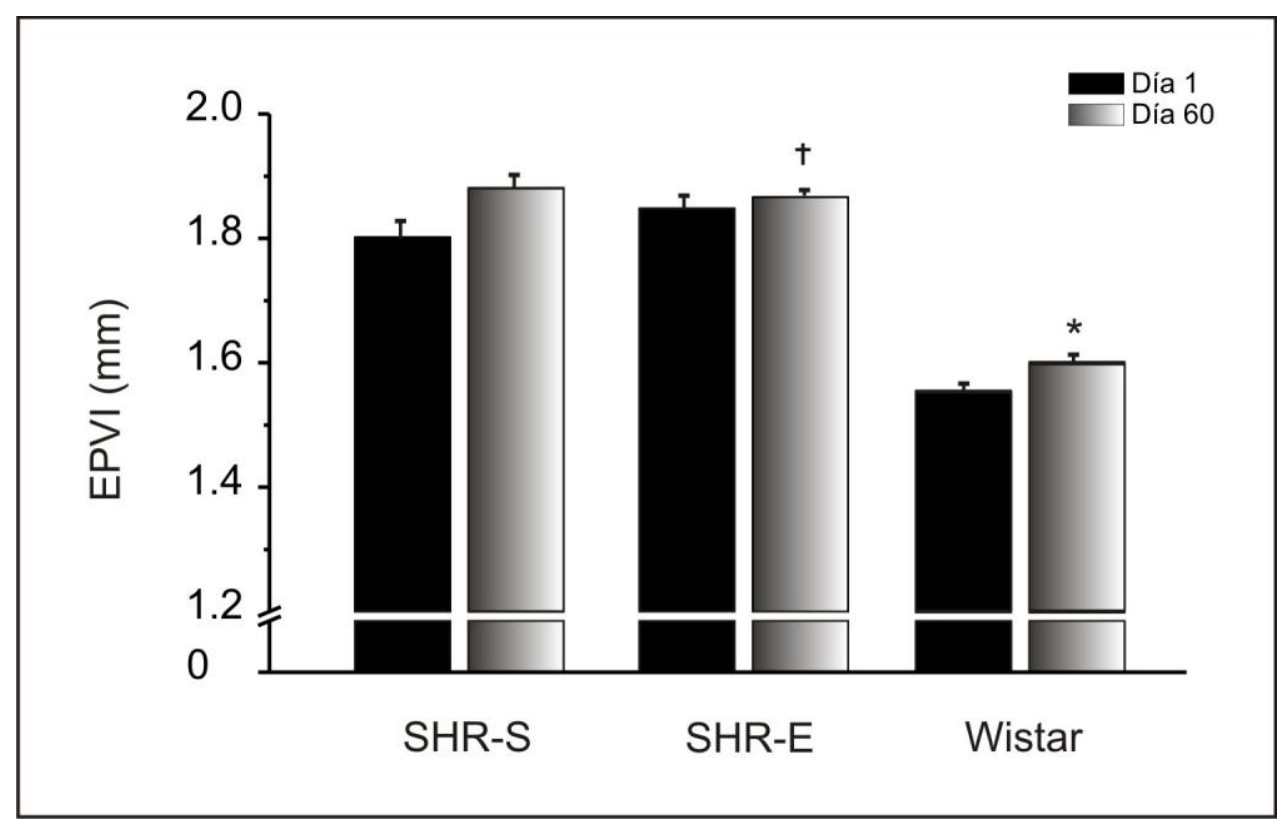

Figura 5R. Espesor de la pared ventricular izquierda. ${ }^{*} P<0.05$ vs. SHR-S, $\dagger P<0.05$ vs. Wistar (ANOVA).

El espesor parietal fue significativamente mayor en las SHR-S y en las SHR-E, respecto de las Wistar. Confirmando de esta manera el desarrollo de $\mathrm{HC}$ en los grupos de las SHR. 


\section{Diámetro diastólico del ventrículo izquierdo (DDVI).}

La Figura 6R muestra los registros ecocardiográficos de los DDVI obtenidos de los tres grupos en estudio.

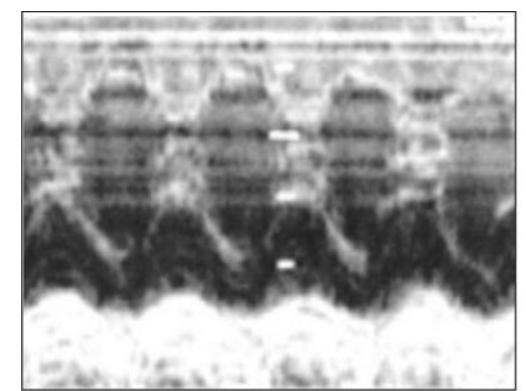

SHR-S

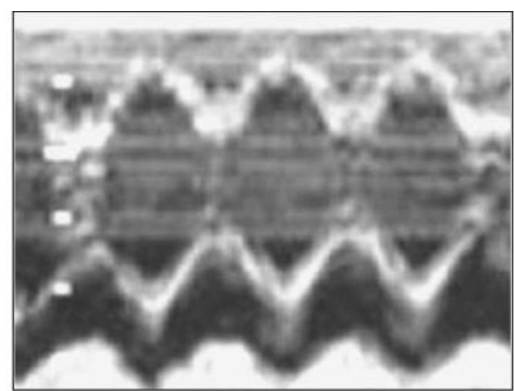

SHR-E

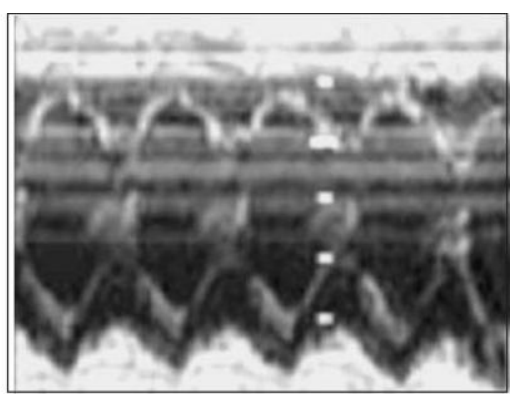

WISTAR

Figura 6R. Registros ecocardiográficos.

En la figura precedente se aprecia la notable diferencia de los diámetros diastólicos en los tres grupos al final del período experimental.

La Figura 7R muestra en un gráfico de barras los valores de los DDVI ( $\mathrm{mm})$ de los registros anteriores.

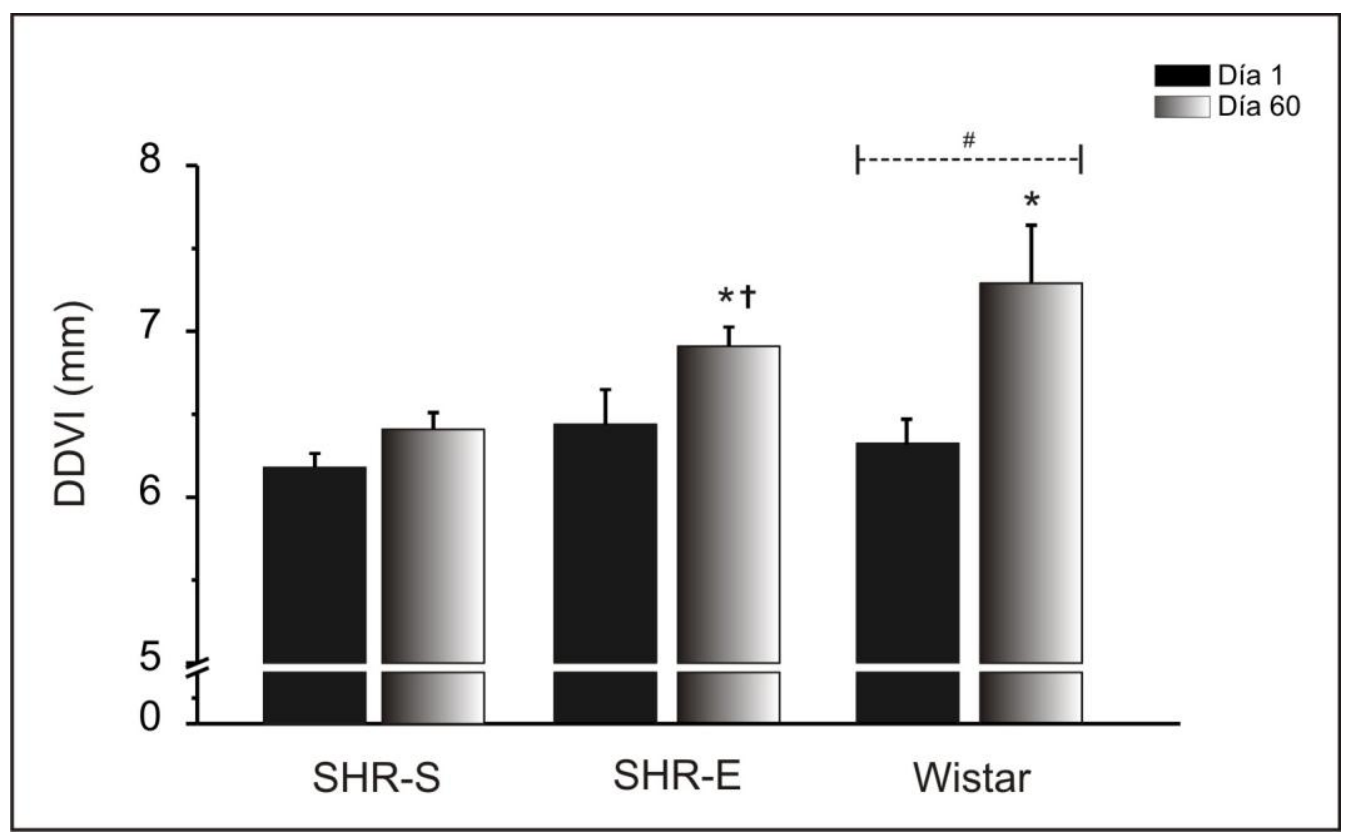

Figura 7R. Diámetro diastólico del ventrículo izquierdo. ${ }^{*} P<0.05$ vs. SHR-S, $\dagger P<0.05$ vs. Wistar (ANOVA). \# $P<0.05$ vs. el mismo grupo (Test-T). 
Se observó un incremento significativo en el DDVI al final del período experimental en las SHR-E respecto de las SHR-S. Este aumento nos indica que la geometría de la cámara del VI se modificó por el ejercicio natatorio, pasando de una $\mathrm{HC}$ concéntrica en las SHR-S a una HC excéntrica en las SHR-E.

\section{Relación entre el espesor del ventrículo izquierdo y el radio de la cavidad (E/R).}

La relación $E / R$ es una forma de evaluar el espesor parietal relativo. En el panel superior de la figura $6 \mathrm{R}$ se muestra esquemáticamente como se midieron los parámetros "E" y "R" en un corte transversal del VI, al final del experimento. En el panel inferior de la Figura $\mathbf{8 R}$, se presenta en un gráfico de barras los resultados experimentales obtenidos.

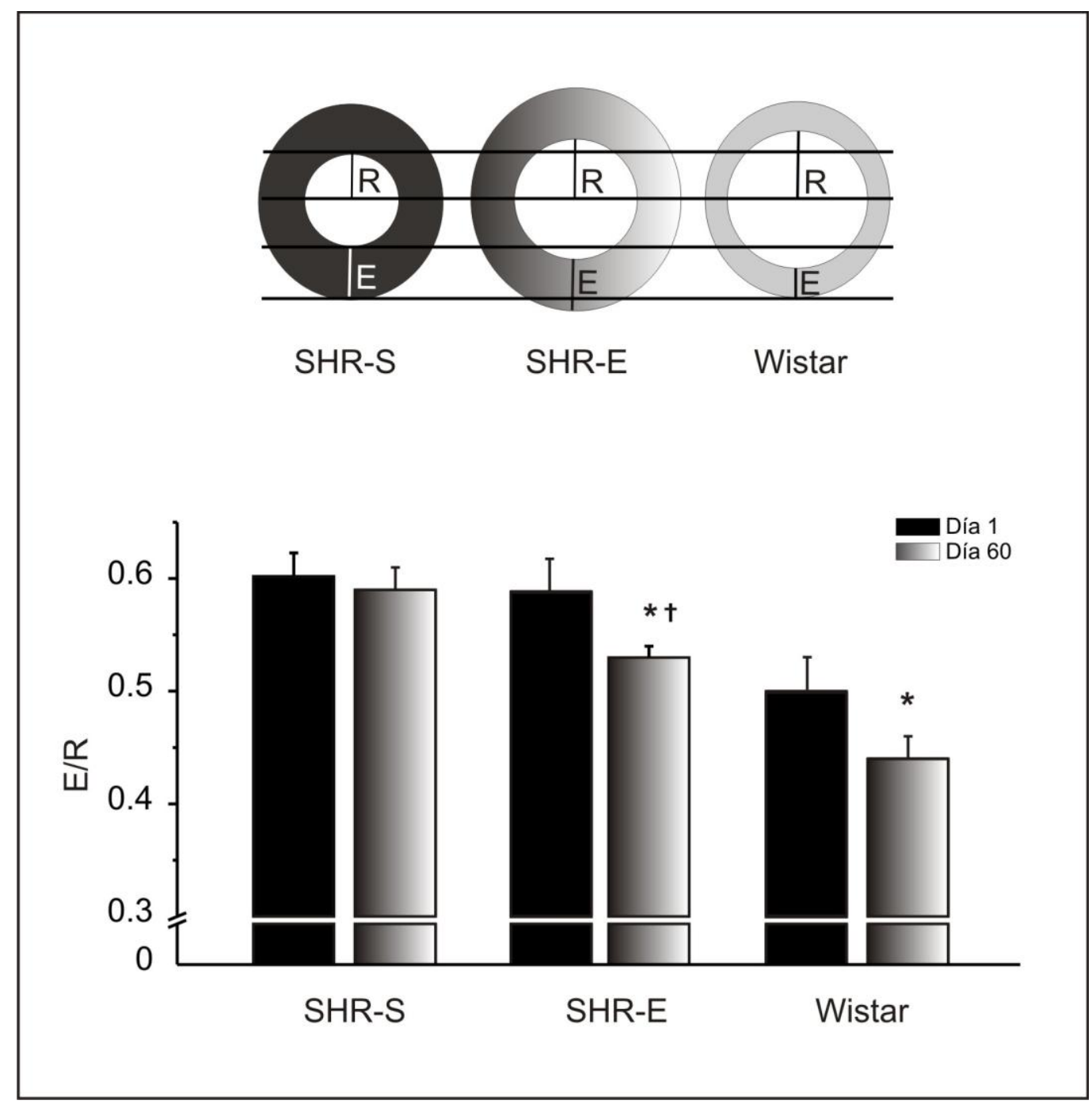

Figura 8R. Relación entre el espesor del ventrículo izquierdo y el radio de la cavidad.

${ }^{*} P<0.05$ vs. SHR-S, $\dagger P<0.05$ vs. Wistar (ANOVA). 
Los resultados que se muestran en la figura $8 \mathrm{R}$ concuerdan con los obtenidos previamente (figura $6 R$ y $7 R$ ). Los mismos indican una disminución de la relación $E / R$ en las SHR-E respecto de las SHR-S, confirmando de esta manera una reducción en la $\mathrm{HC}$ concéntrica del VI.

\section{- ESTUDIOS MORFOLÓGICOS POST-MORTEM.}

\section{Masa ventricular izquierda (MVI).}

A continuación se procedió a determinar la $\mathrm{MVI}$ en los tres grupos experimentales. Los resultados se muestran en la Tabla $\mathbf{2 R}$.

\begin{tabular}{|c|c|c|c|}
\hline Variable & SHR-S $(n=13)$ & SHR-E $(n=9)$ & Wistar $(n=5)$ \\
\hline $\begin{array}{c}\text { MVI } \\
(\mathrm{mg})\end{array}$ & $856 \pm 26$ & $931 \pm 24^{*} \dagger$ & $790 \pm 28$ \\
\hline
\end{tabular}

Tabla 2R. Masa ventricular izquierda. ${ }^{*} P<0.05$ vs. SHR-S, $\dagger P<0.05$ vs. Wistar (ANOVA).

Se pudo apreciar que las SHR-E presentan un incremento significativo de la masa del VI con respecto a las SHR-S y a las Wistar. La diferencia entre ambos grupos de SHR evidencia la magnitud de la $\mathrm{HC}$ por efecto del ejercicio.

\section{Masa ventricular derecha (MVD).}

Luego se examinó la MVD en los distintos grupos. Los resultados se muestran en la Tabla 3R.

\begin{tabular}{|c|c|c|c|}
\hline Variable & SHR-S $(n=13)$ & SHR-E $(n=9)$ & Wistar $(n=5)$ \\
\hline $\begin{array}{c}\text { MVD } \\
(\mathrm{mg})\end{array}$ & $166 \pm 7$ & $177 \pm 10$ & $192 \pm 4$ \\
\hline
\end{tabular}

Tabla 3R. Masa ventricular derecha.

No se observaron diferencias significativas entre los tres grupos. 
Relación entre el peso del ventrículo izquierdo y la longitud de la tibia (PVI/LT).

Con el objeto de confirmar la magnitud de la $\mathrm{HC}$ se determinó la relación PVI/LT $(\mathrm{mg} / \mathrm{cm})$. A efectos de poder realizar comparaciones más adecuadas, los valores de la masa ventricular fueron normalizados por la longitud de la tibia. (Figura 9R).

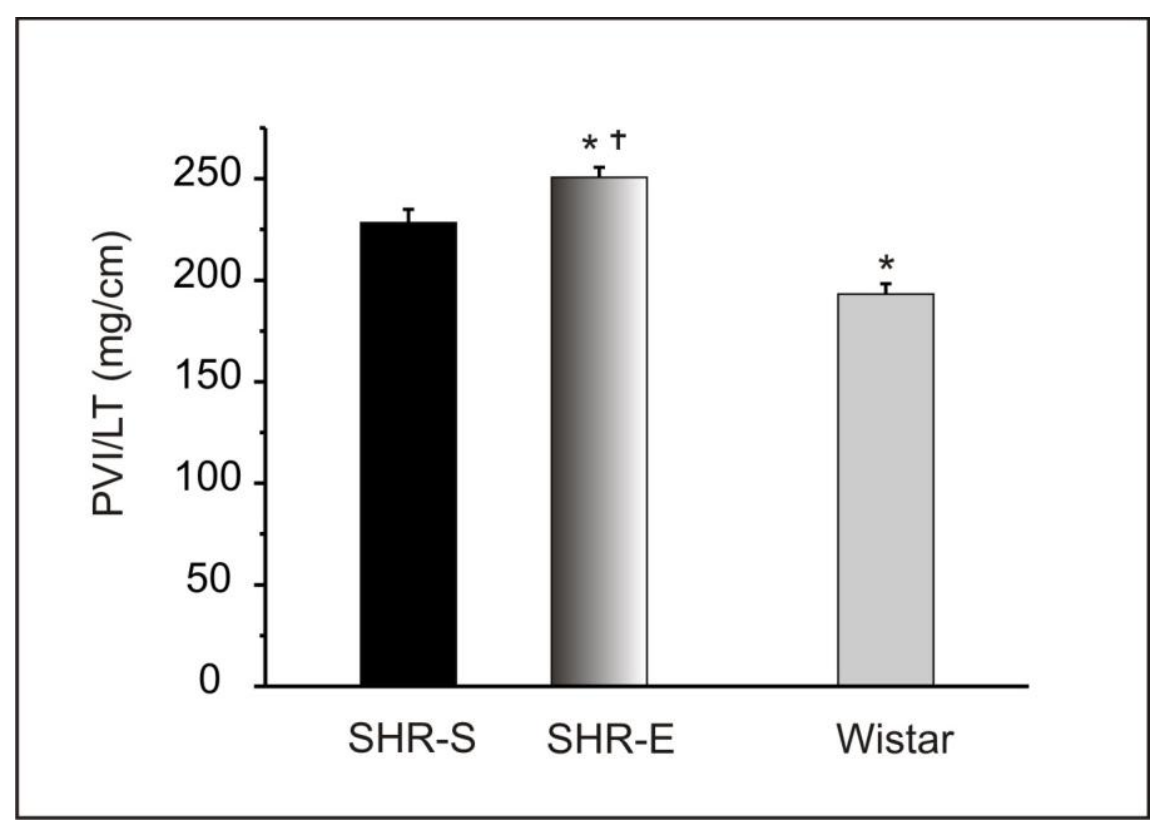

Figura 9R. Relación entre el peso del ventrículo izquierdo y la longitud de la tibia.

${ }^{*} P<0.05$ vs. SHR-S, $\dagger P<0.05$ vs. Wistar (ANOVA).

En esta figura se muestra como el ejercicio físico provocó un aumento significativo de la relación PVI/LT de las SHR-E respecto de las SHR-S. Observándose también una diferencia significativa entre ambos grupos de SHR y las Wistar. El peso del corazón normalizado por la longitud de la tibia es la forma más aceptada para definir el aumento del peso del corazón en las ratas. Se la considera a la longitud de la tibia un mejor índice por no estar sujeta a las variaciones del peso corporal. 


\section{Conclusión de estudios morfológicos.}

En resumen, los datos presentados permiten concluir que las SHR-E presentan con respecto a las SHR-S:

\begin{tabular}{|l|l|l|}
\hline Mayor & Igual & Menor \\
\hline IMVI & EPVI & E/R \\
DDVI & MVD & \\
MVI & & \\
PVI/LT & & \\
& & \\
\hline
\end{tabular}

En los resultados obtenidos se demuestra:

- En las SHR-S la existencia de una HC concéntrica en la cual el crecimiento de la pared ventricular es hacia el centro de la cavidad.

- En las SHR-E una HC excéntrica con el crecimiento de la pared ventricular predominantemente hacia afuera.

- La geometría de la cámara izquierda se modificó por el ejercicio pasando de una HC concéntrica a una HC excéntrica como lo demuestra la disminución en la relación E/R. 


\section{CARACTERÍSTICAS HISTOLÓGICAS DE LA HC EN LAS SHR EN EJERCICIO.}

El objetivo siguiente de nuestro estudio fue examinar los distintos cambios histológicos que se desarrollan en la HC debido a la actividad física. Desde el punto de vista histológico el miocardio está constituído por los miocitos y por el espacio intersticial. El principal componente de los miocitos son las miofibrillas, responsables de la contracción del músculo. Las miofibrillas están compuestas a su vez por filamentos gruesos de miosina y finos de actina interdigitados entre sí. El espacio intersticial está formado por fibras de colágeno, fibroblástos, vasos sanguineos, vasos linfáticos y terminaciones nerviosas.

Los parámetros examinados para evaluar los cambios histológicos fueron los siguientes:

- el área de sección transversal del cardiomiocito

- la fracción de colágeno

- la densidad capilar 


\section{- ÁREA DE SECCIÓN TRANSVERSAL DEL CARDIOMIOCITO (AST).}

Una de las principales características de la $\mathrm{HC}$ es el aumento del tamaño de los cardiomiocitos. El engrosamiento de estas células se produce a expensas del aumento del AST. En la Figura 10R se muestran cortes ecuatoriales del VI de los tres grupos experimentales, teñidos de manera adecuada para analizar el AST.

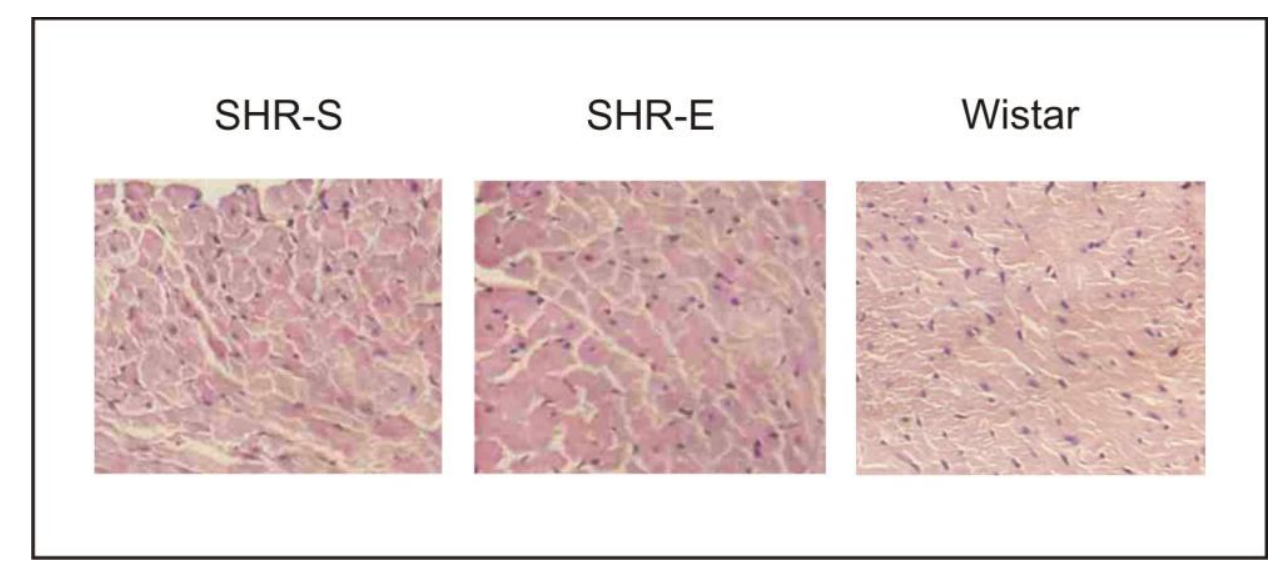

Figura 10R. Cortes histológicos del micardio teñido con hematoxilina-eosina. En estos cortes se observa como la hematoxilina (colorante básico) tiñe el núcleo del miocito (ácido) en un tono azul-púrpura. Mientras que la eosina (colorante ácido) tiñe el citoplasma del miocito (básico) en un tono rosa.

En estas micrografías se observa que los miocitos de mayor tamaño corresponden a los de las SHR-E, luego le siguen las SHR-S y finalmente las Wistar. 
La Figura 11R, muestra en un gráfico de barras los resultados experimentales obtenidos de los cortes histológicos anteriores.

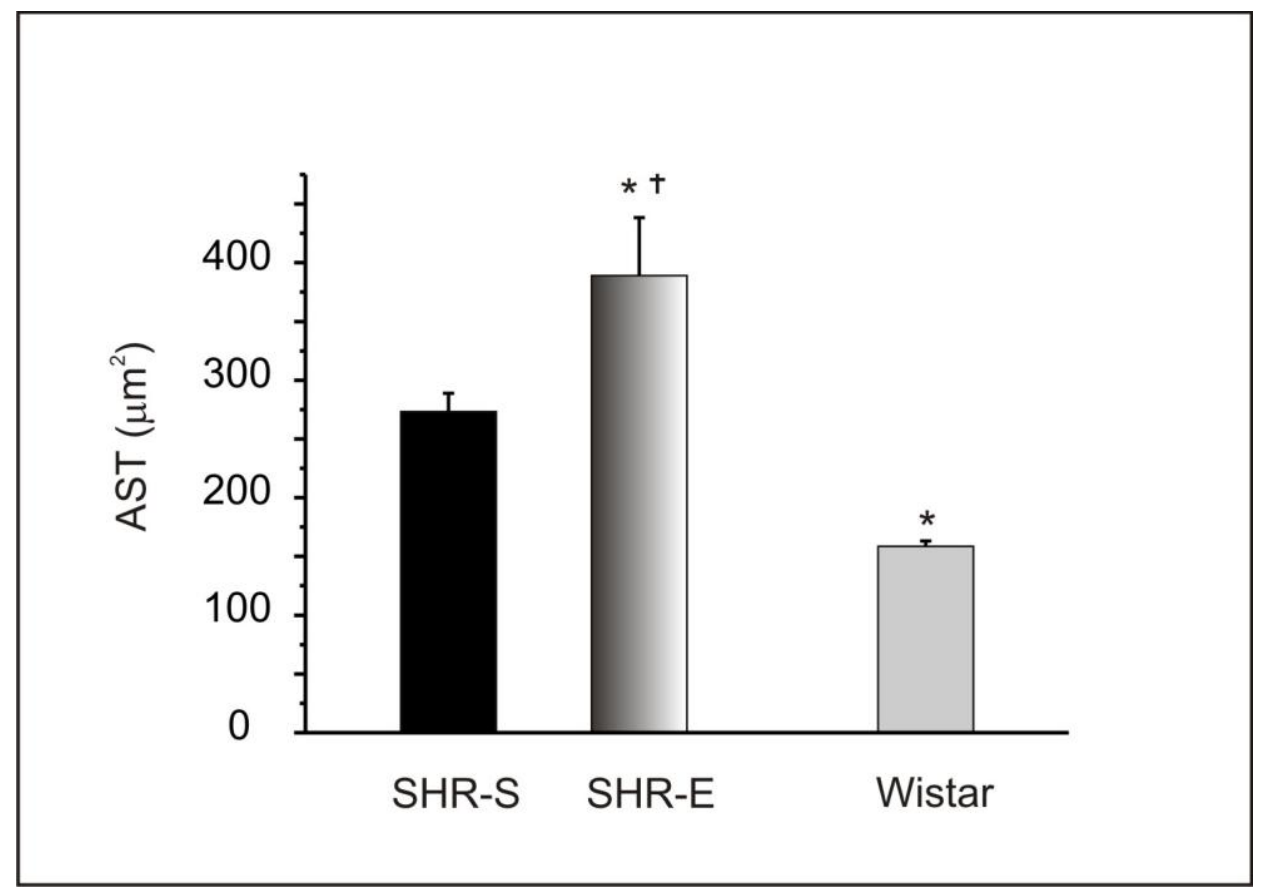

Figura 11R. Área de sección transversal del cardiocito. ${ }^{*} P<0.05$ vs. SHR-S, $\dagger P<0.05$ vs. Wistar (ANOVA).

En los experimentos efectuados se observa como el ejercicio induce un incremento altamente significativo de aproximadamente un $45 \%$ en el AST de los cardiomiocitos de las SHR-E, respecto de las SHR-S, indicando la existencia de una HC secundaria al ejercicio. 


\section{- FRACCIÓN DE COLÁGENO.}

El crecimiento hipertrófico necesario para soportar la sobrecarga biomecánica incluye el agrandamiento de los miocitos y también del sector no miocítico (tejido conectivo, capilares y nervios) (239-242). El tejido conectivo está principalmente compuesto por colágeno y cantidades menores de elastina, laminina y fibronectina. El colágeno tipo I constituye el $85 \%$ del total del colágeno del miocardio, encontrándose también el tipo III y V. Los fibroblastos son los responsables de la acumulación del colágeno, el cual contribuye a la rigidez anormal presente en la disfunción sistólica y diastólica del miocardio (243). Los fibroblastos poseen receptores AT1 y AT2, estando los primeros involucrados en el control de la síntesis de colágeno (244). Entre la hormonas que estimulan la producción de colágeno tipo I y fibronectina encontramos a All, aldosterona y también a ET-1, sintetizadas por miocitos y fibroblastos (240).

En la Figura 12R se muestran cortes ecuatoriales del VI de los tres grupos experimentales, teñidos de manera adecuada para cuantificar la presencia de colágeno.

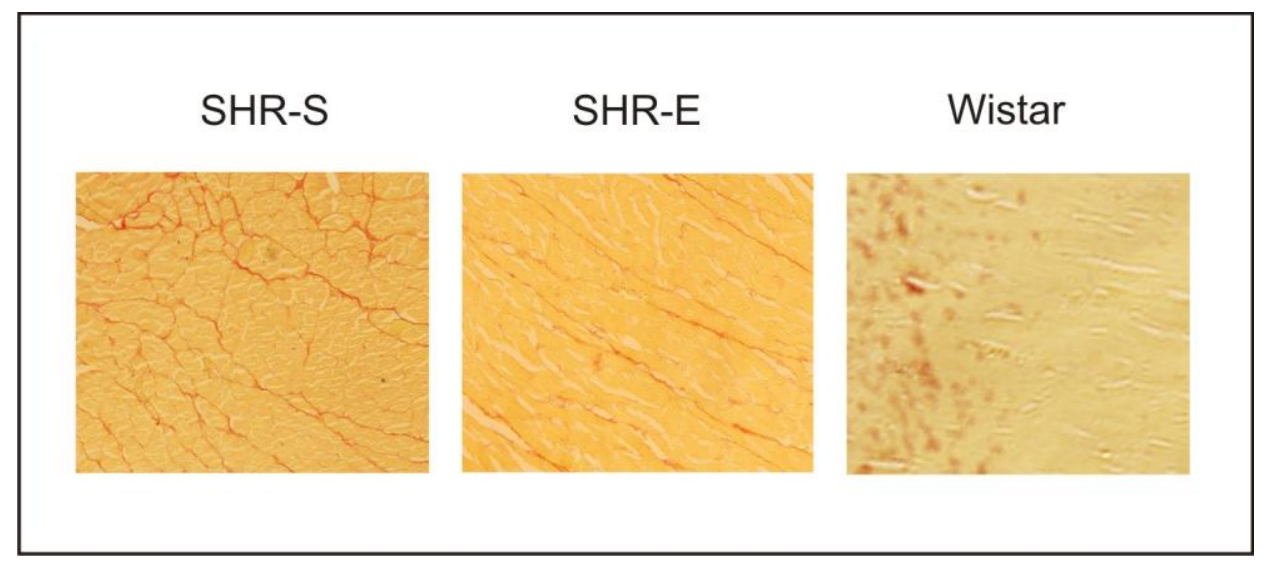

Figura 12R. Cortes histológicos del miocardio teñido con picrosirius-red. Esta tinción se une de manera específica a las fibras de colágeno, otorgándoles una coloración roja a las mismas sobre un fondo amarillo. Ello permite cuantificar la cantidad de colágeno en un área determinada (fracción de colágeno).

En estas micrografías se observa que las SHR-S presentan un evidente depósito de colágeno, mientras que las SHR-E y las Wistar poseen una cantidad notablemente menor. 
A continuación en la Figura 13R, se muestra en un gráfico de barras los resultados experimentales obtenidos de los cortes histológicos anteriores.

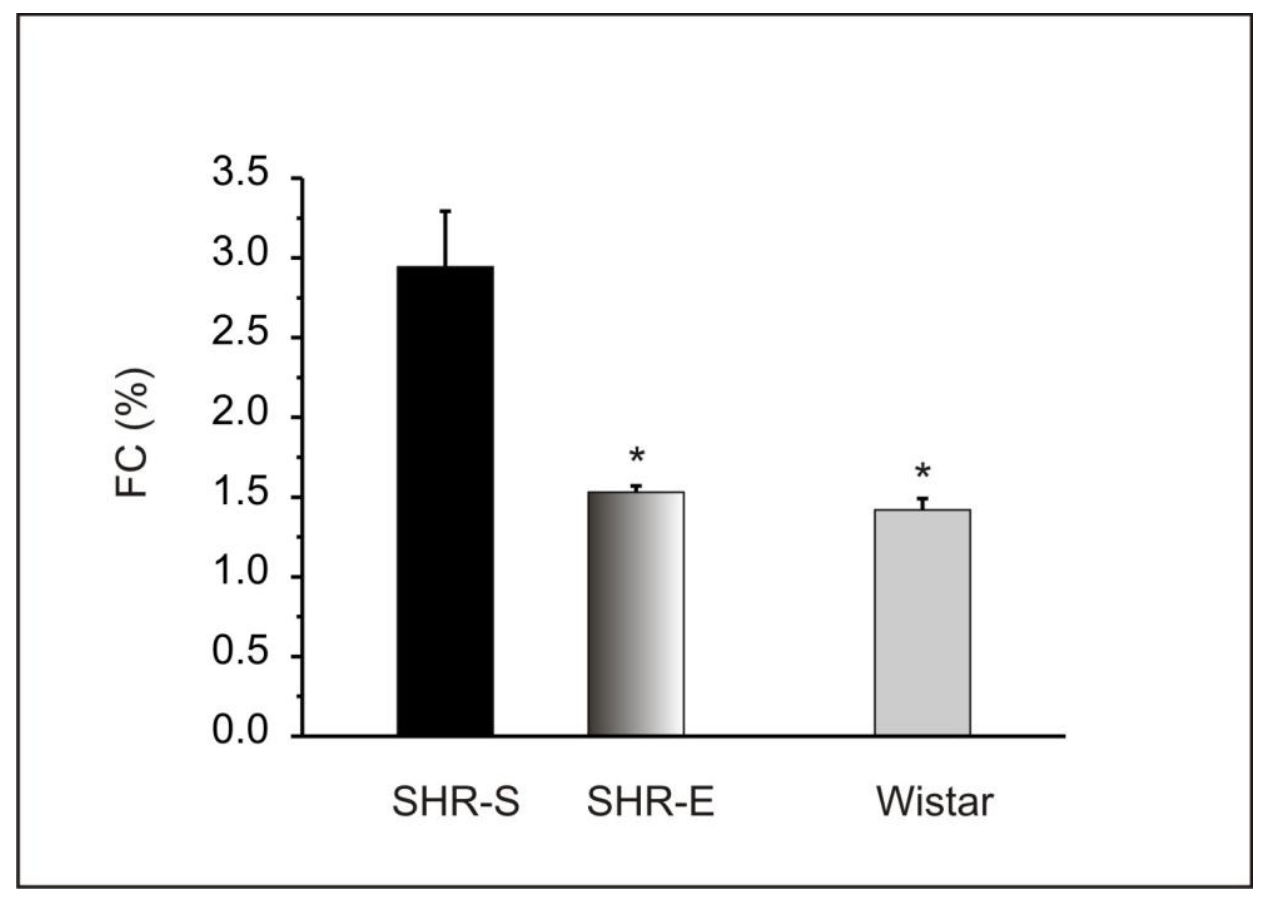

Figura 13R. Fracción de colágeno en el cardiocito. * $P<0.05$ vs. SHR-S (ANOVA).

Resultó de interés observar en las SHR-E que mientras se produce un incremento en el área del cardiocito, se observa en forma paralela una disminución significativa de aproximadamente un $50 \%$ en la fracción del colágeno, con respecto a las SHR-S. Lográndose así una regresión a valores similares a los que se observan en las Wistar. 


\section{- DENSIDAD CAPILAR MIOCÁRDICA.}

El siguiente objetivo fue determinar si las modificaciones histológicas se acompañaron de cambios en la densidad capilar. La Figura 14R muestra los resultados obtenidos.

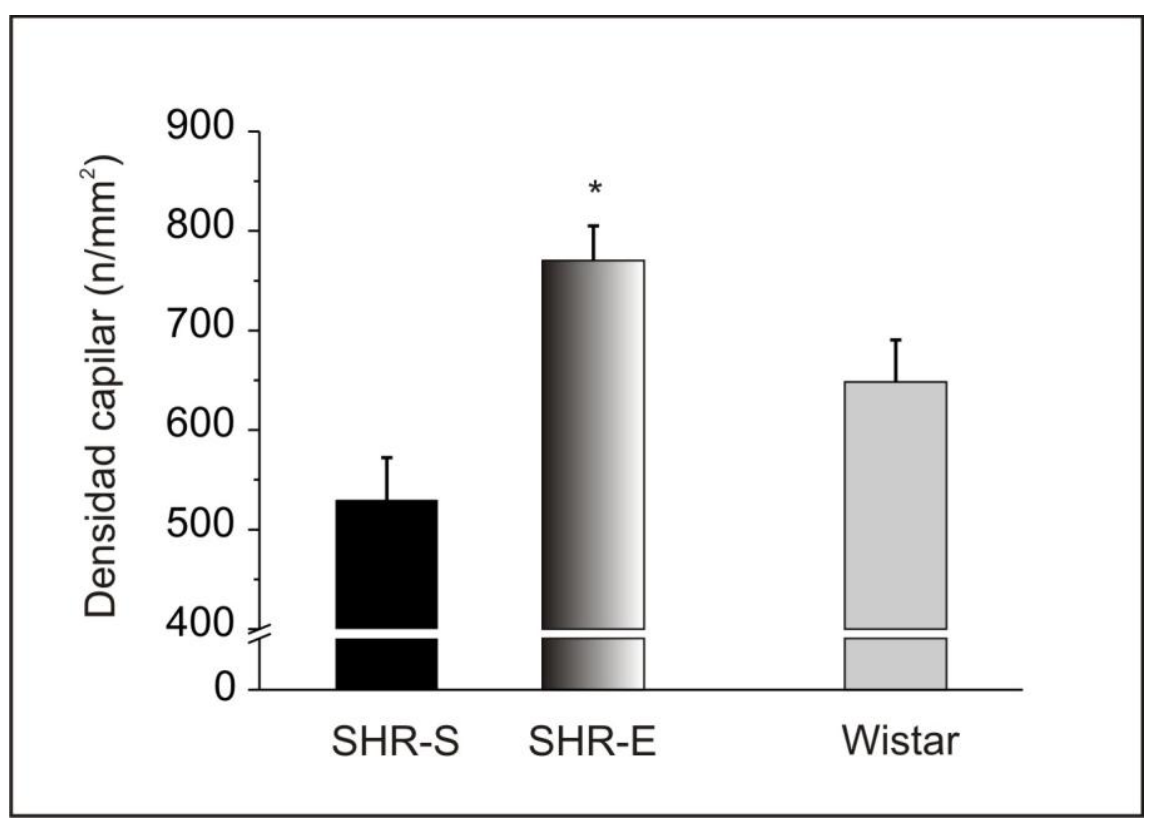

Figura 14R. Densidad capilar miocárdica. ${ }^{*} P<0.05$ vs. SHR-S (ANOVA).

Los cambios observados en el corazón de las SHR-E, fueron de importancia no sólo por la disminución de la fracción colágena sino por que además se observó un franco y significativo aumento de la densidad capilar del miocardio de alrededor del $45 \%$ con respecto a las SHR-S. 


\section{Conclusión de estudios histológicos.}

Como puede verse en los estudios histológicos realizados, la actividad física produjo en los cardiocitos de las SHR-E, con respecto a las SHR-S, las siguientes modificaciones:

- un incremento promedio del $45 \%$ en el AST.

- un incremento en la densidad capilar del $45 \%$.

- una disminución de la FC de aproximadamente un 50\%.

La normalización de la fibrosis intersticial y el incremento en la densidad capilar, sugieren un efecto favorable de la actividad física en las SHR-E. 


\section{CARACTERÍSTICAS MOLECULARES DE LA HC EN LAS SHR EN EJERCICIO.}

En los experimentos realizados se emplearon las siguientes técnicas:

- RT-PCR en tiempo real: para analizar la expresión de genes.

- Western blot: para estudiar la expresión de proteínas como CnAß y SERCA2a.

\section{- EXPRESIÓN GÉNICA.}

La HCP se caracteriza por la inducción de genes que sólo se expresan normalmente durante el desarrollo de la vida fetal, como el del factor natriurético atrial (ANF) y la cadena liviana de la miosina (MLC).

\section{ANF o ANP (factor o péptido natriurético atrial).}

ANF forma parte de los denominados peptidos natriuréticos, junto con BNP (peptido natriurético cerebral) y CNP (peptido natriurético de tipo $\mathrm{C}$ ), que son considerados marcadores moleculares de HC (245). ANF es un péptido secretado por los cardiomiocitos auriculares, en respuesta al aumento de la presión arterial y/o a la sobrecarga de volumen. Es un potente agente vasodilatador que además puede reducir el sodio y el agua del sistema circulatorio. Se ha observado que su expresión se encuentra aumentada en corazones sometidos a sobrecarga de presión y/o volumen $(18,246)$. Estímulos hipertrofiantes, como hormonas y el estiramiento, estimulan al gen del ANF induciendo su expresión en células ventriculares. Debido a ello resulta de gran utilidad como marcador genético de HCP (247). 
La expresión relativa de este marcador molecular se evaluó por RT-PCR en el miocardio de los tres grupos experimentales, como se aprecia en la Figura 15R.

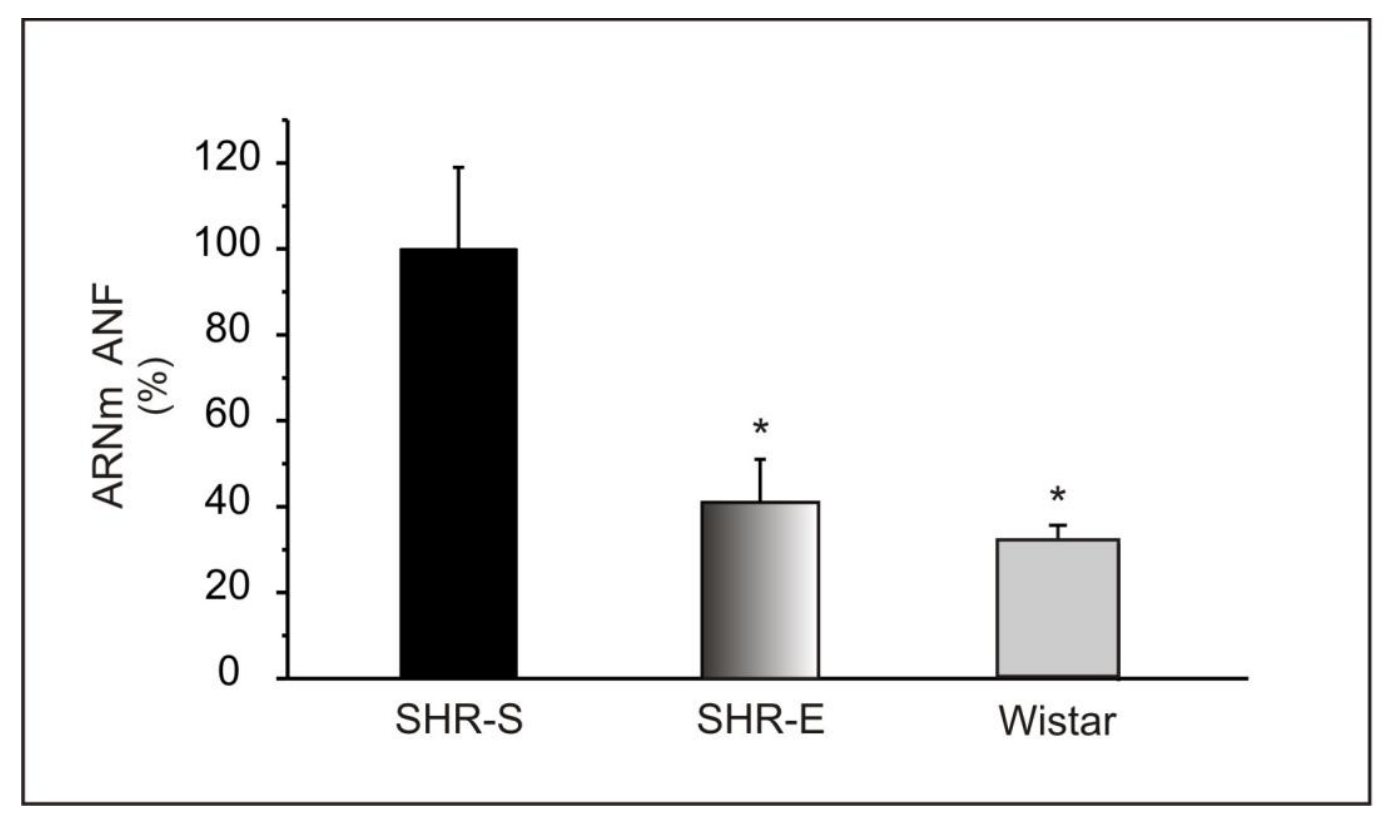

Figura 15R. Expresión génica de ANF. * $P<0.05$ vs. SHR-S (ANOVA).

Se detectó una reducción significativa en la cantidad de ARN del ANF en el corazón hipertrofiado de los animales sometidos a la rutina natatoria.

\section{MLC-2 (cadena liviana de la miosina, subunidad 2).}

La miosina tipo II participa del proceso de contracción de las células musculares. Está compuesta por 4 cadenas livianas (MLC) y 2 pesadas (MHC). Las MLC se dividen en dos subunidades esenciales o MLC-1 (de 17Kda) y dos subunidades reguladoras o MLC-2 (de $20 \mathrm{Kda}$ ), ubicadas alrededor del cuello de la cadena pesada (entre la cabeza y la cola). Se piensa que MLC-1 da rigidez al cuello estabilizando la cabeza globular de la miosina, mientras que MLC-2 participa de la contracción $(248,249)$. (Figura 16R). 


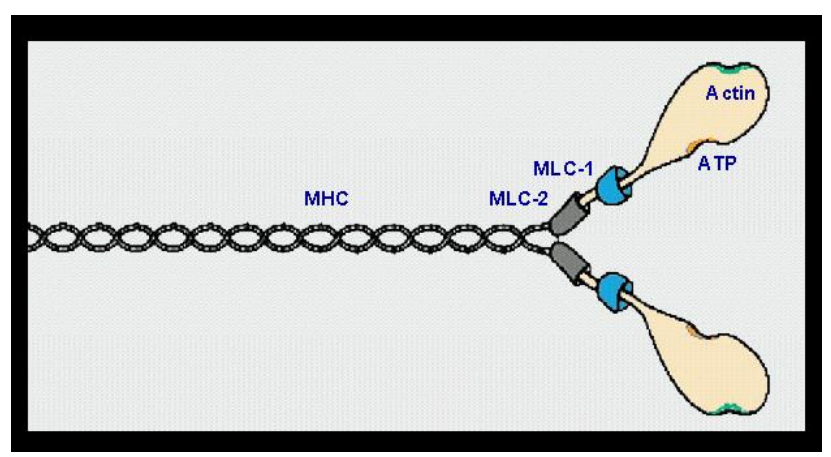

Figura 16R. Estructura de la miosina II.

La expresión relativa de MLC-2 se evaluó por RT-PCR en el miocardio de las SHR-S, SHR-E y Wistar, como se muestra en la Figura 17R.

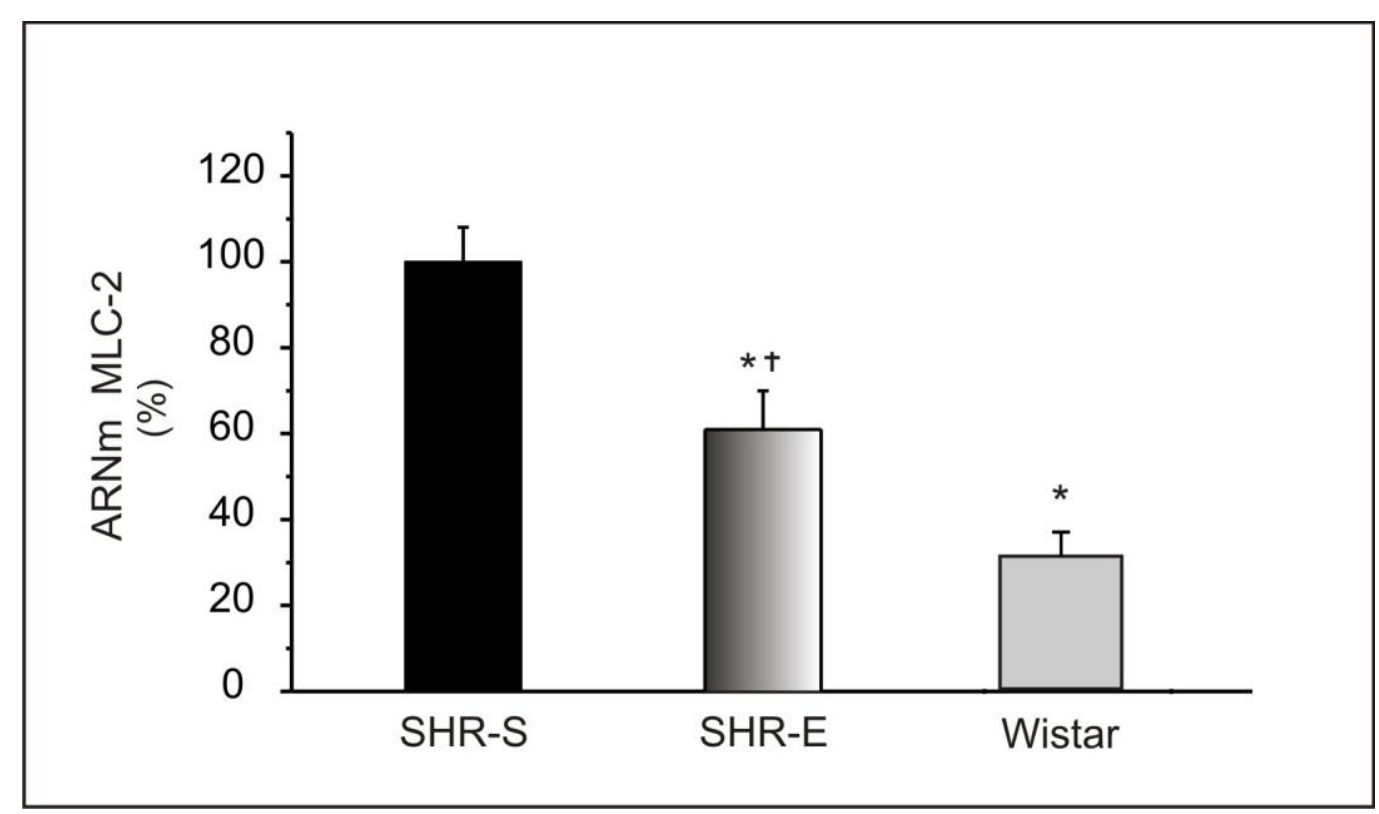

Figura 17R. Expresión génica de MLC-2. ${ }^{*} P<0.05$ vs. SHR-S, $\dagger P<0.05$ vs. Wistar (ANOVA).

Se detectó una reducción significativa en la cantidad de RNA de la MLC-2 en las SHR-E

Dado que se conoce que en la HCP se produce la expresión de genes fetales, como ANF y MLC-2, resultó de interés comprobar que la rutina natatoria disminuyó un $60 \%$ la expresión de ANF y un $40 \%$ la expresión de MLC-2 en las SHR-E. Estos resultados confirmarían que el entrenamiento físico impactaría benéficamente en el funcionamiento cardíaco aún en presencia de una HCP. 


\section{- EXPRESIÓN DE SERCA Y NCX.}

La bomba de $\mathrm{Ca}^{+2}$ o $\mathrm{Ca}^{+2}$-ATPasa (SERCA) es una proteína localizada en la membrana del RS, que junto con el NCX participan del ciclo del calcio en el cardiomiocito. SERCA actúa removiendo la mayor cantidad del $\mathrm{Ca}^{+2}$ intracelular, permitiendo la relajación del cardiomiocito. El restante calcio citoplasmático es removido principalmente por el NCX. La expresión de SERCA se encuentra disminuída en la HC severa, particularmente por sobrecarga de presión (250, 251). Diversos estudios han demostrado que la expresión y/o actividad del NCX se encuentran aumentadas en modelos animales de HC e IC, así como también en humanos con IC terminal $(252,253)$. Por este motivo se decidió estudiar la expresión de SERCA y NCX en el modelo experimental utilizado.

La Figura 18R muestra los resultados obtenidos al evaluar SERCA2a.

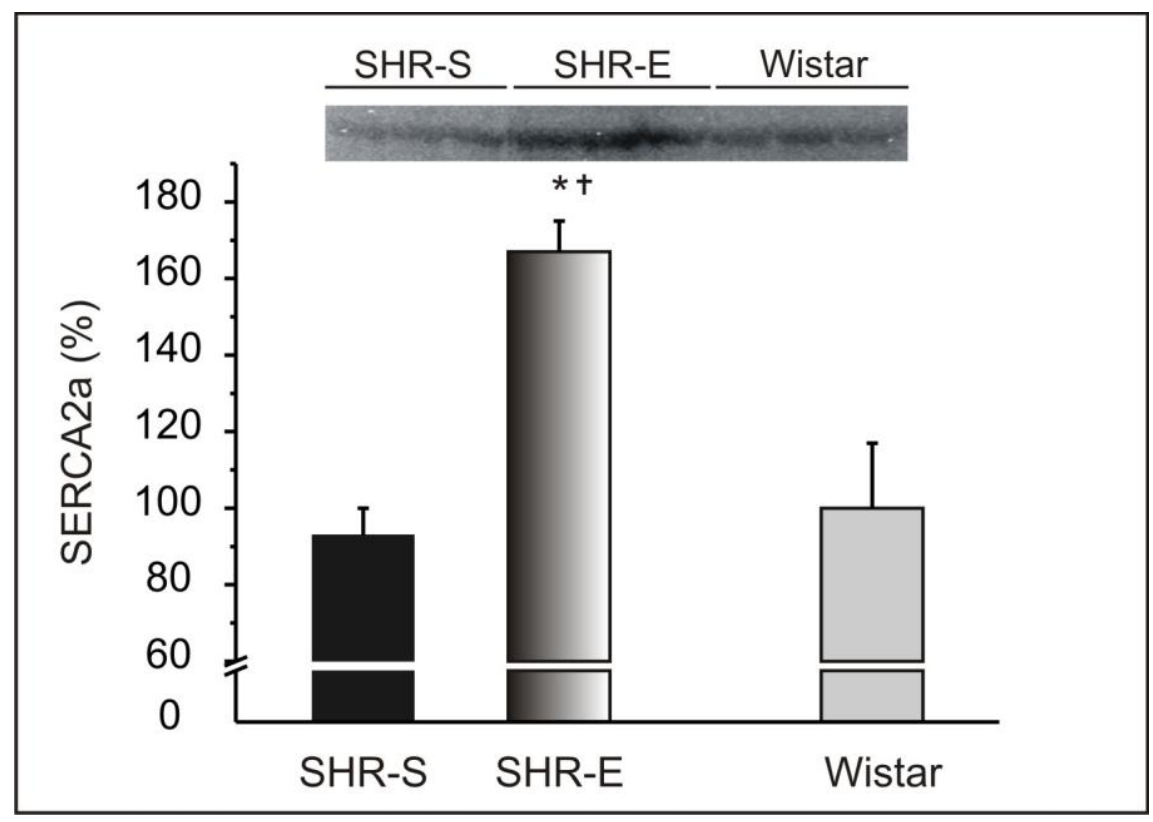

Figura 18R. Expresión de SERCA2a. * $P<0.05$ vs. SHR-S, $\dagger P<0.05$ vs. Wistar (ANOVA).

La actividad física indujo un incremento significativo de aproximadamente un $80 \%$ en la expresión miocárdica de SERCA2a. De esta manera se mejoraría la recaptación del $\mathrm{Ca}^{+2}$, beneficiando la función diastólica ventricular. 
A continuación en Figura 19R se muestra los resultados obtenidos al analizar el NCX.

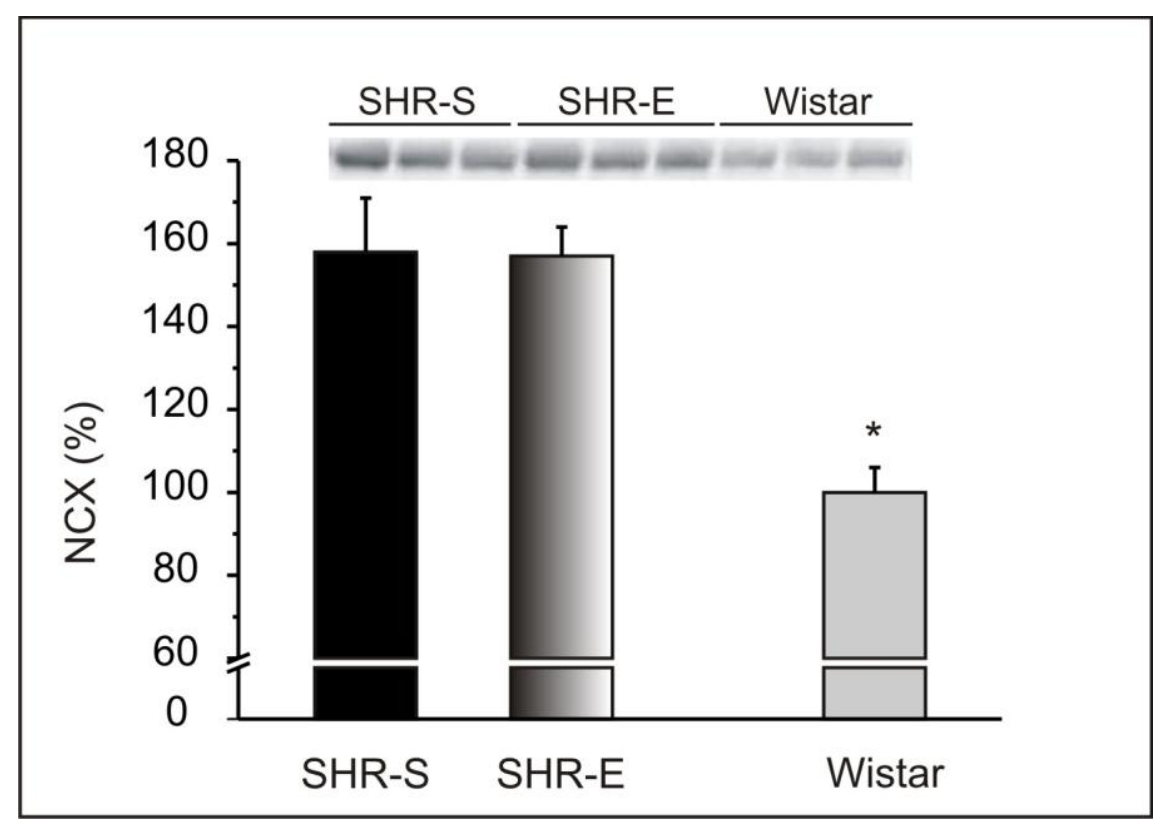

Figura 19R. Expresión del intercambiador NCX. ${ }^{*} P<0.05$ vs. SHR-S (ANOVA).

La expresión del NCX se encuentra aumentada en las SHR y no se modificó por el ejercicio. Se ha visto que la sobreexpresión del NCX en las SHR actuaría como un mecanismo que intenta compensar la disminución de SERCA, mejorando la relajación y con ello la función diastólica (254).

Nuestros resultados muestran que la actividad física induce un incremento significativo de SERCA2a pero no se apreciaron cambios en cuanto al NCX. El aumento de SERCA2a con el ejercicio resultaría beneficioso sobre el corazón. Estos resultados concuerdan con estudios realizados en IC, que demuestran que una mejor regulación del calcio intracelular beneficia la función ventricular $(255,256)$. 


\section{- CALCINEURINA Y ACTIVIDAD FÍSICA.}

Como se mencionó anteriormente, el aumento del calcio es uno de los fenómenos más importantes en el desarrollo de la HCP. Ante aumentos sostenidos en la $\left[\mathrm{Ca}^{+2}\right]$, la calcineurina es activada por el complejo $\underline{\mathrm{Ca}^{+2} / \text { calmodulina }}$ (CaM) y desfosforila a miembros de la familia NFAT en el citosol, permitiendo que estos se trasladen al núcleo e interactúen con factores que estimulan la transcripción génica. Debido a las evidencias existentes sobre el papel fundamental de la calcineurina en varios modelos de $\operatorname{HCP}(57,185,257,258)$, se decidió investigar acerca de su participación en el ejercicio. Los resultados obtenidos se muestran en la Figura 20R.

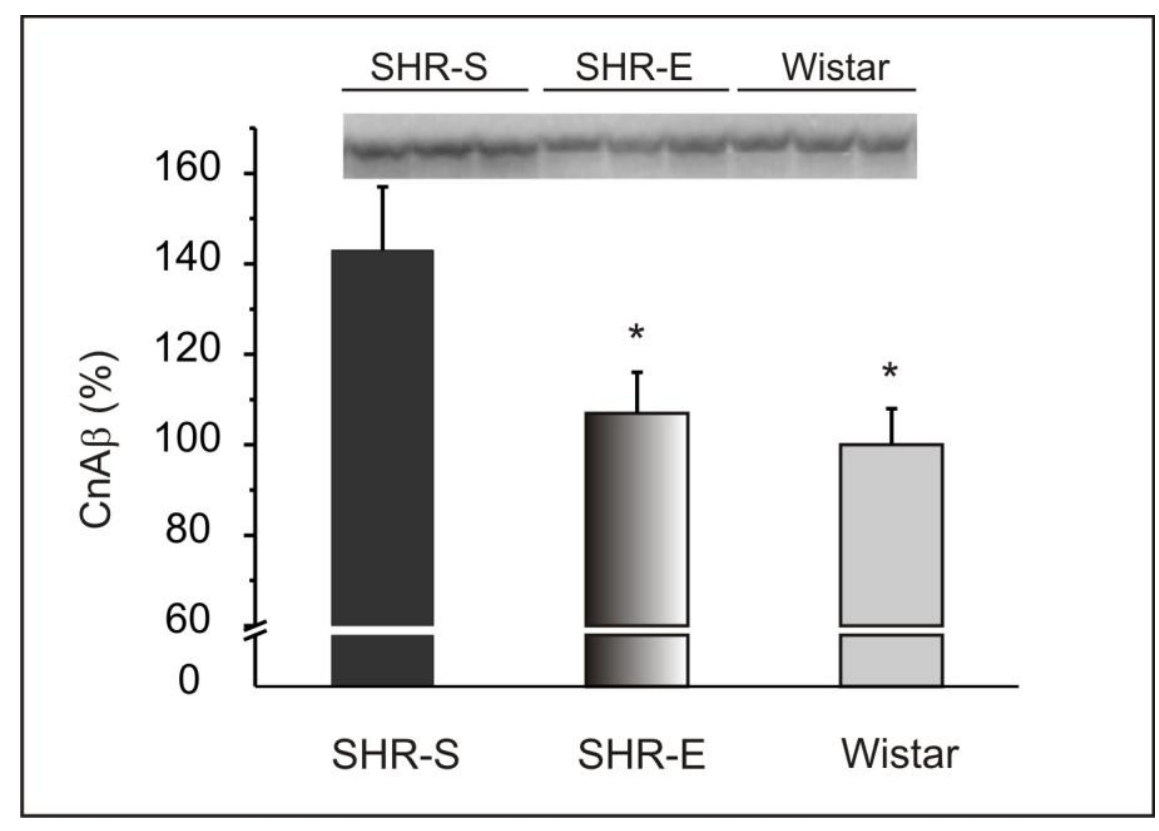

Figura 20R. Expresión de calcineurina. ${ }^{*} P<0.05$ vs. SHR-S (ANOVA).

La expresión de CnAß aumentó notablemente en el miocardio de la SHR-S y disminuyó significativamente en las SHR-E. Es decir que el ejercicio normalizó esta vía de señalización intracelular a valores similares a los encontrados en las Wistar. 


\section{- EXPRESIÓN DE LA VÍA PI3K/AKT.}

La vía de PI3K/Akt es una de las principales cascadas envueltas en el normal crecimiento cardiaco postnatal (259). Se ha demostrado que su activación induce tanto la HCF como la HCP (259-261). El fenotipo determinado puede estar en parte, relacionado al grado de regulación de Akt. La sobreestimulación de esta vía conduciría a HCP (262). Por otro lado se ha visto que la vía PI3K/Akt promueve la sobrevida del cardiomiocito al inhibir la cascada apoptótica en varios puntos (263). La Figura 21R muestra la vía de señalización de PI3K/Akt.

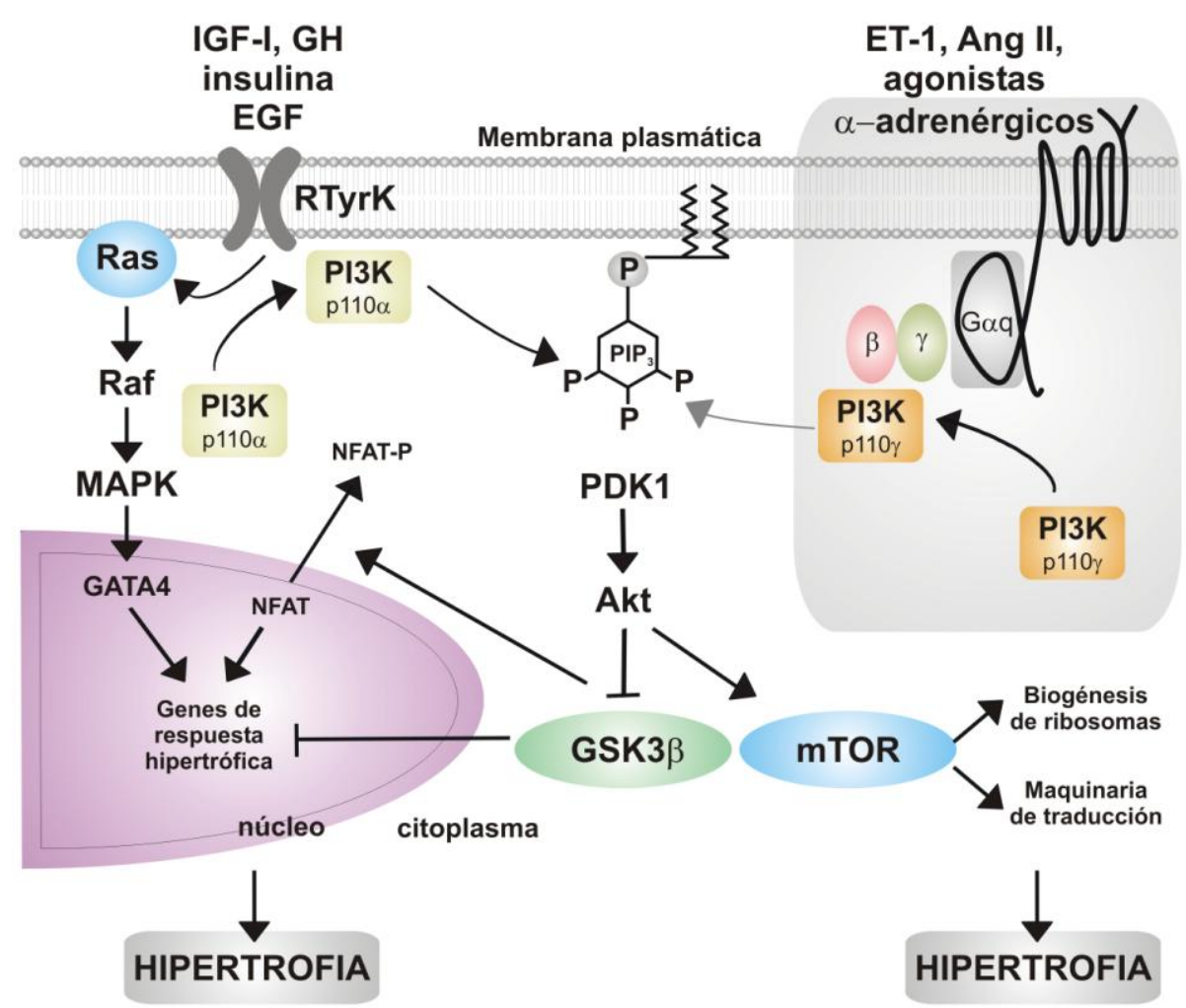

Figura 21R. Vía PI3K/Akt. La vía de PI3K/Akt puede ser activada por medio de los RTK y de los GPCR. RTK activa la isoforma $p 110 \alpha$ de la PI3K. GPCR y la subunidad $\beta y$ de su proteína $G$ asociada activan la isoforma $\mathrm{p} 110 \mathrm{y}$ de la PI3K. PI3K se traslada hacia la membrana y fosforila a sus lipidos, quienes junto con PDK1, activan a la quinasa Akt (o PKB). Akt es capaz de activar a mTOR, un regulador central de la síntesis proteica, por sus efectos sobre la biogénesis de ribosomas y sobre la maquinaria de traducción proteica. Akt también fosforila e inhibe la GSK3 $\beta$ quien inhibe la traducción de factores de transcripción relacionados con la inducción del programa hipertrófico, promoviendo la síntesis de proteínas y la transcripción génica. 
En este marco, nuestro próximo objetivo fue estudiar la expresión de ambas quinasas en el modelo experimental utilizado, como se muestra en las Figuras $22 \mathbf{R}$ y $\mathbf{2 3 R}$.

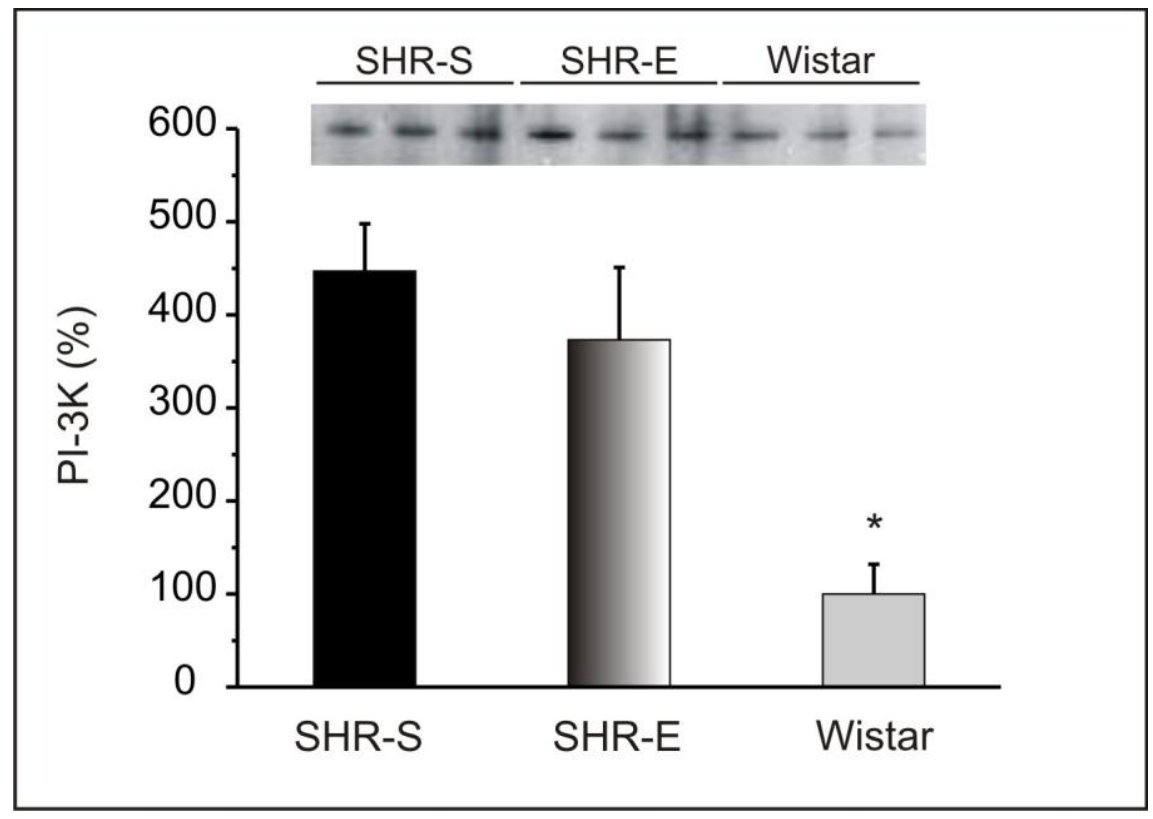

Figura 22R. Expresión de PI3K. * $P<0.05$ vs. SHR-S (ANOVA).

A continuación se muestra la Figura 23R:

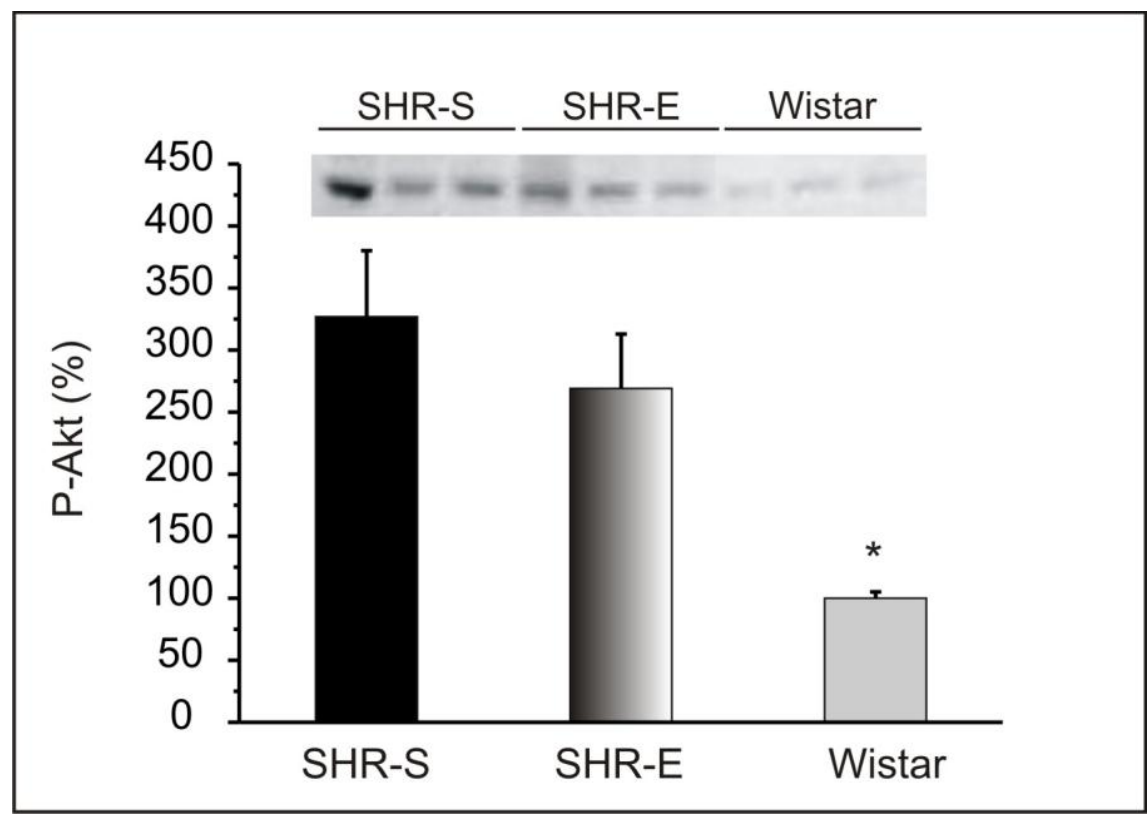

Figura 23R. Expresión de P-AKT. ${ }^{*} P<0.05$ vs. SHR-S (ANOVA).

La actividad física no mostró cambios significativos en la expresión de la vía PI3K/Akt 


\section{Conclusión de estudios moleculares.}

En resumen, los estudios moleculares realizados permiten concluir que las SHR-E presentan con respecto a las SHR-S, las siguientes modificaciones:

- Disminución de expresión génica de ANF y MLC-2.

- Aumento en la expresión de SERCA2a.

- No se modificó la expresión del NCX.

- Disminución de la expresión de calcineurina.

- No se modificó la expresión de la vía PI3K/AKT.

Los resultados obtenidos mostraron una tendencia a normalizar tanto la expresión génica como la vía de calcineurina, logrando así una mejor función cardíaca en los animales que realizaron ejercicio. 


\section{APOPTOSIS Y EJERCICIO.}

La muerte celular por apoptosis es un proceso fisiológico normal que se produce en las células al activarse un programa de muerte, pero también puede asociarse a situaciones patológicas. Distintos estudios han demostrado que la apoptosis participaría en la transición de HC a IC $(264,265)$. Debido a ello resultó de interés determinar si la actividad física era capaz de inducir un efecto inhibitorio sobre la apoptosis. En la activación de la apoptosis participan dos vías: la "vía extrínseca" (estimulada por la unión de ligandos a receptores de muerte de la membrana plasmática) y la "vía intrínseca" (originada en las mitocondrias). Ambas vías son mediadas por proteasas denominadas caspasas que degradan sustratos intracelulares. (Figura 24R).

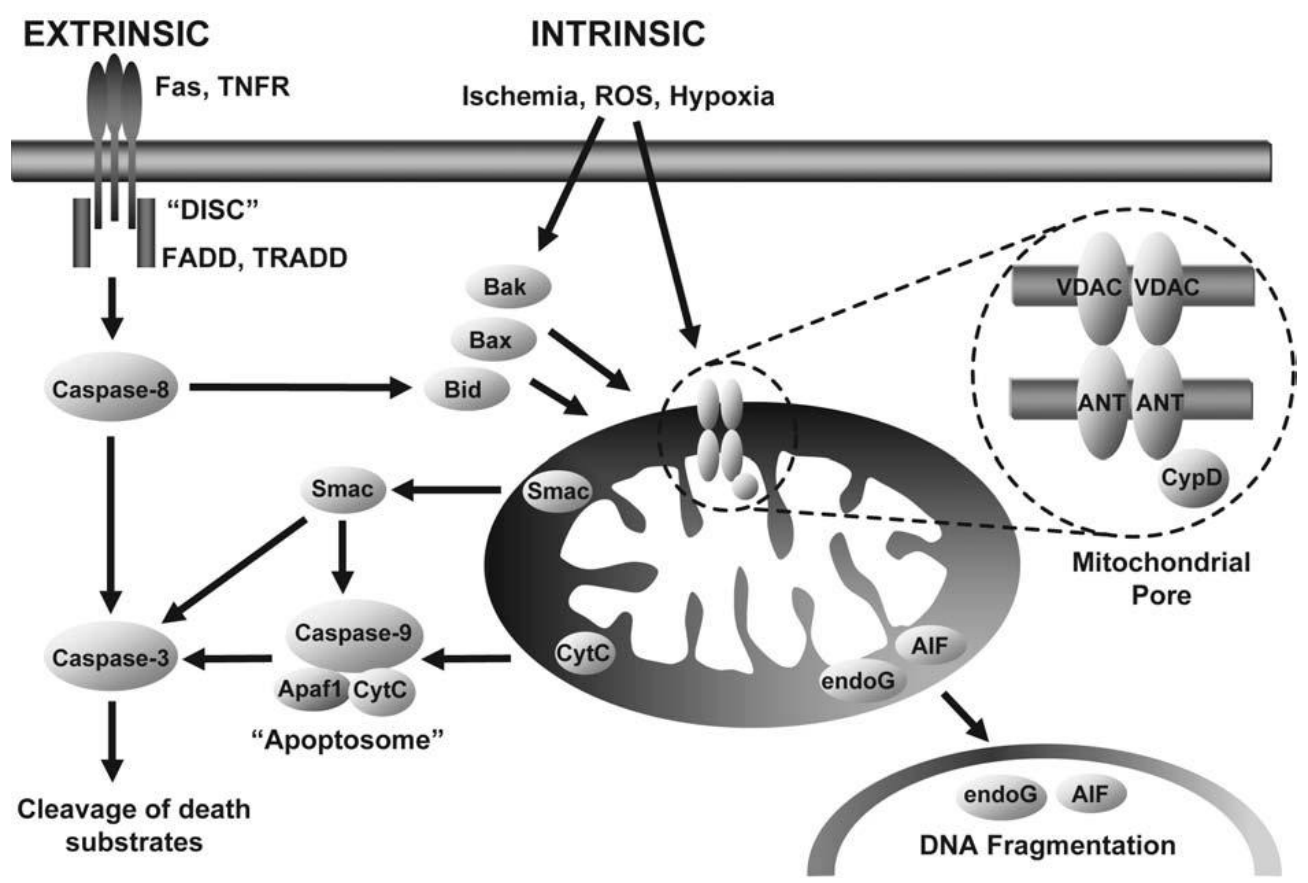

Figura 24R. Vías apoptóticas. La vía extrínseca se activa por la unión de ligandos, como TNF-a (factor de necrosis tumoral- $\alpha$ ) y el ligando de Fas (FasL), a los receptores extracelulares TNFR y Fas (266) (expresado en miocitos). Dicha unión provoca el reclutamiento a la membrana plasmática de la proteína adaptadora FADD (Fas-Associated-Death-Domain) y de pro-caspasa-8, formando el complejo DISC (death-inducing-signalling-complex) que activa a caspasa-8. Esta última activa a caspasa-3, que es capaz de romper proteínas estructurales y promover la fragmentación del DNA, resultando en la muerte celular. La vía intrínseca en el miocito se activa por estímulos como hipoxia, isquemia-reperfusión y estrés oxidativo. Caspasa-8 puede también promover esta vía mediante su interacción con la proteína proapoptótica Bid, generando el fragmento activo tBid (truncated Bid), que se traslada e insertarse en la membrana mitocondrial externa (MME) estimulando a Bax y Bak que inducen la liberación de CytC y smac/DIABLO $(267,268)$. CytC interacciona en el citosol con las proteínas Apaf-1 y pro-caspasa-9 constituyendo el apoptosoma, un complejo catalítico que activa a caspasa-9 y esta a caspasa-3. Con la 
permeabilización se liberan proteínas independientes de caspasas, que se dirigen al núcleo y fragmentan el DNA, como AIF (factor inductor de apoptosis) y Endo G (269). En la permeabilización participaría MPTP (poro de transición de la permeabilidad mitocondrial), un complejo multiproteico, situado entre MME y membrana mitocondrial interna (MMI), constituído por el canal aniónico voltaje-dependiente (VDAC) y el receptor periférico de benzodiacepinas (PBR) ambos en MME, la hexoquinasa (HKII, citosólica), la creatina kinasa (mtCK, en el espacio intermembrana), la adenina nucleótido translocasa (ANT, en MMI) y la ciclofilina D (Cyp-D, matricial) $(270,271)$. (C.P. Baines, J.D. Molkentin / Journal of Molecular and Cellular Cardiology 38 (2005) 47-62) (272).

\section{- EXPRESIÓN DE CASPASA - 3.}

La expresión de procaspasa-3 y caspasa-3 resulta de interés pues ellas participan de la degradación de sustratos que finalmente llevan a la muerte celular. Debido a ello se examinó por western blot la expresión de procaspasa-3 (barras negras) y de caspasa-3 (barras grises) en las SHR-S, SHR-E y en las Wistar, como se muestra en la Figura 25R.

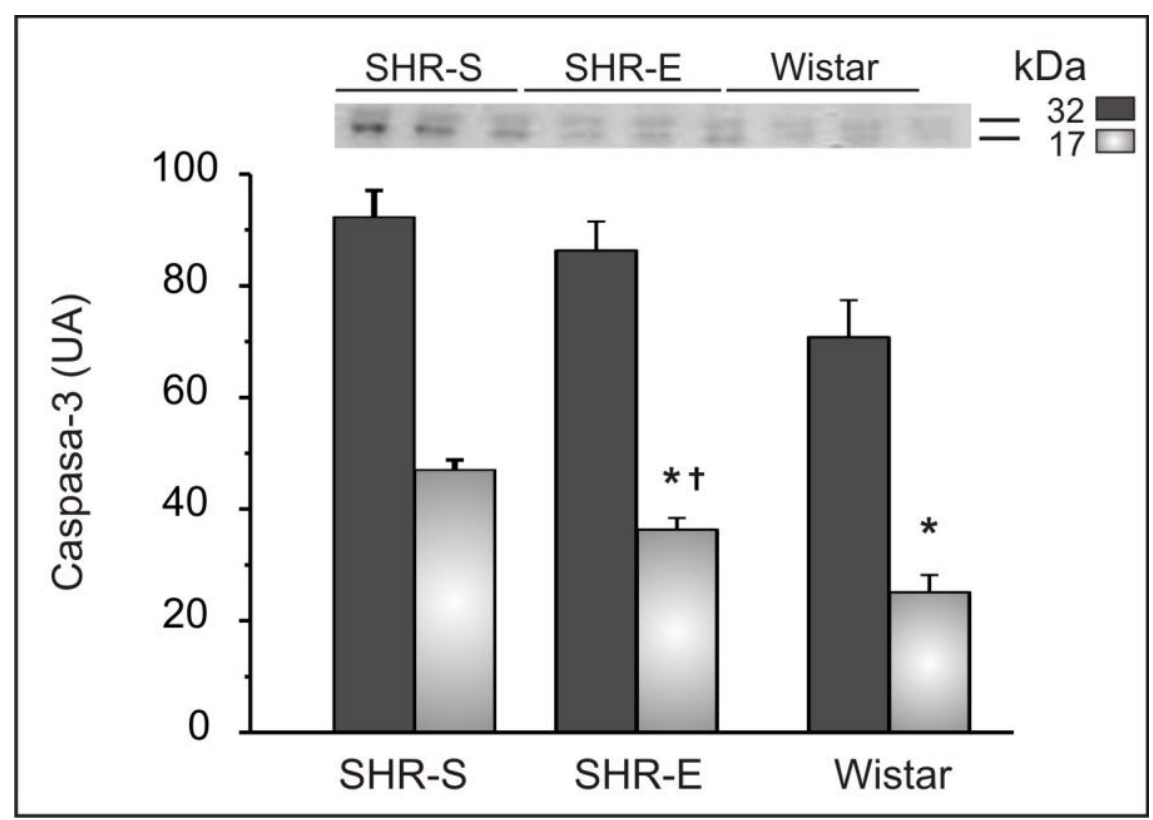

Figura 25R. Expresión de caspasa-3. ${ }^{*} P<0.05$ vs. SHR-S, $\dagger P<0.05$ vs. Wistar (ANOVA). 
Se puede observar en esta figura como el grado de apoptosis está aumentado en las SHR-S respecto de las Wistar, representado por los mayores niveles del fragmento de 17kDA de caspasa-3. La actividad física disminuyó significativamente el clivado de procaspasa-3 en caspasa-3, indicando una menor activación de este efector de la vía apoptótica. En la HC inducida por sobrecarga de presión, se ha encontrado que la actividad de caspasa-3 está aumentada así como también la expresión de sus genes $(273,274)$. Además se ha visto que caspasa-3 cliva a $\alpha$-actina, $\alpha$-actinina y troponina, dificultando la contracción (275). También se sabe que está implicada en la fragmentación del ADN, evento característico de la apoptosis (276).

\section{- EXPRESIÓN DE PARP-1.}

La poly-(ADP-ribosa)-polimerasa-1 (PARP-1) es una enzima que repara el ADN. Se encuentra presente en el núcleo y en las mitocondrias de los cardiomiocitos. La presencia de un fragmento de ADN de simple cadena es la señal que activa a PARP-1 y junto con la ADN polimerasa y la ADN ligasa, reparan el sector dañado (277). Sin embargo la sobreactivación de PARP-1 puede agotar las reservas de ATP e inducir a la célula a la apoptosis (por la vía intrínseca y a través de la liberación de AIF)(245). Se piensa que la sobreactivación de PARP-1 y la posterior inducción de la célula hacia la apoptosis, es importante en la progresión de la HCP hacia la IC (278-280). Dada la importancia de este efector en la vía apoptótica fue que se decidió su determinación por Western Blot (Figura 26R). 


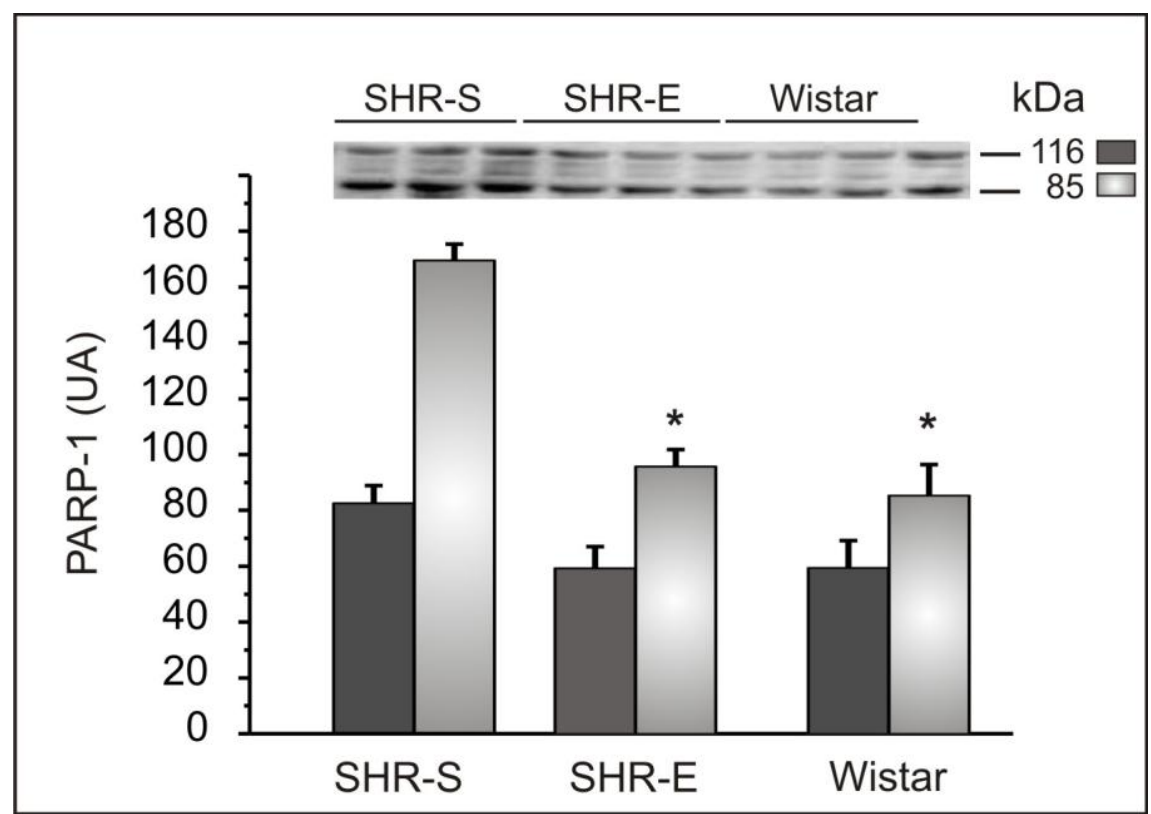

Figura 26R. Expresión de PARP-1. * $P<0.05$ vs. SHR-S, (ANOVA).

Un evento carácterístico de la apoptosis es el clivado proteolítico de PARP-1 de $116 \mathrm{KDa}$ (barras negras) por caspasa-3, generando un fragmento de 85KDa (barras grises) $(281,282)$. Se puede observar en esta figura anterior como el grado de apoptosis está aumentado en las SHR-S respecto de las Wistar, representado por los mayores niveles del fragmento de 85kDA de PARP-1. La actividad física disminuyó significativamente el clivado de PARP-1, indicando una menor activación de este efector apoptótico.

\section{Conclusión de estudios apoptóticos.}

En resumen, los estudios apoptóticos realizados permiten concluir que las SHR-E presentan con respecto a las SHR-S, las siguientes modificaciones:

- Disminución en la expresión de caspasa-3.

- Disminución en la expresión del fragmento de PARP-1.

Los resultados obtenidos indican una menor incidencia de apoptosis en las SHR-E, sugiriendo que la actividad física atenuó la progresión de la HCP. 
DISCUSIÓN Y CONCLUSIÓN 
El presente trabajo experimental muestra el efecto de la actividad física sobre la HCP. En el mismo se aprecia que el ejercicio sobreimpuesto a una HTA crónica impacta favorablemente en el remodelado del VI.

Los resultados obtenidos se resumen a continuación:

- En las SHR-S se desarrolló una HC concéntrica caracterizada por fibrosis, vascularización disminuída, aumento de la apoptosis, re-expresión de genes fetales y disfunción del VI.

- En las SHR-E se observó principalmente una HC excéntrica, con menor fibrosis intersticial, incremento de la densidad capilar, reducción en la expresión de ANF y de MLC-2, incremento en la expresión de SERCA2a, reducción en la expresión de calcineurina, sin afectar la vía de PI3k/Akt y finalmente disminución de la actividad proapoptótica.

- Los estudios precedentes muestran la importancia y la necesidad de la actividad física para prevenir y/o revertir la HCP. Los datos obtenidos experimentalmente con las SHR confirman que una HCP puede modificarse hacia una HCF a nivel estructural, molecular y funcional, retardando así su progresión hacia la IC.

- Estos resultados concuerdan con estudios en humanos en los cuales se observa que la actividad física resulta beneficiosa aún en pacientes con IC (197-199). Este estudio es una contribución al diseño de alternativas terapéuticas para prevenir la IC secundaria a la $\mathrm{HC}$ inducida por la HTA. 
En el presente estudio se investigó el efecto de la actividad física en la HCP empleando las SHR. Éste es un modelo de HCP experimental por sobrecarga de presión, que reproduce la HCP secundaria a HTA en humanos. Ha sido demostrado que las SHR desarrollan una miocardiopatia hipertensiva con alteraciones de la función diastólica por disminución de la relajación, incluso antes de evolucionar hacia IC (283). En pacientes hipertensos la HVI implica no sólo la hipertrofia del cardiocito sino también un aumento en los componentes del intersticio, principalmente del colágeno. Esto puede afectar la función diastólica, la geometría del VI, el flujo de calcio citosólico y la disponibilidad de AMPc (284). Durante la evolución de la HCP el corazón modifica su metabolismo, pasando de la oxidación de los ácidos grasos (principal fuente para generar ATP) al metabolismo de la glucosa $(201,285)$. Esta es una respuesta adaptativa que le permite al corazón producir ATP de manera más eficiente (286).

A continuación se analizarán los siguientes cambios observados en este estudio en la HCP y en la HCF:

- morfológicos

- histológicos

- moleculares

- apoptosis

- nuevas estrategias terapéuticas 
Las alteraciones morfológicas observadas en las SHR-S implican un remodelado celular y extracelular, caracterizado por presentar una $\mathrm{HC}$ concéntrica con aumento del espesor parietal y disminución del diámetro de la cavidad ventricular, con deterioro progresivo de la función del VI. Estas modificaciones se caracterizan no sólo por el aumento del tamaño de los cardiomiocitos sino también por el incremento de los fibroblastos y las fibras de colágeno. La excesiva proliferación de fibroblastos en los animales sedentarios, contribuye al desarrollo de una HCP caracterizada por incremento de la rigidez ventricular y disminución del volumen minuto cardíaco (287, 288).

No todas las formas de HC implican un daño a futuro, como puede verse en las SHR-E, que se encuentran bajo mejores condiciones aeróbicas gracias a la actividad física. En ellas se induce un crecimiento fisiológico, el cual es beneficioso para la función cardíaca, como lo demuestra el incremento en el AMV. Resulta importante destacar la influencia que tuvo la actividad física sobre la evolución de la HC. En las SHR-E se observó un remodelado excéntrico favorable con aumento de las dimensiones del VI, como lo demuestra la disminución en la relación E/R. Además, en las SHR-E se pueden ver los siguiente cambios estructurales del miocardio: mayor IMVI y MVI, junto con un aumento del DDVI y del PVI/LT. Estos resultados coinciden con los obtenidos en estudios con individuos no entrenados donde se vio que durante el ejercicio el volumen sistólico aumenta aproximadamente de $70 \mathrm{ml} /$ latido a $135 \mathrm{ml} /$ latido, mientras que en atletas puede superar los $200 \mathrm{ml} /$ latido (287). Diferentes estudios clínicos demuestran que el ejercicio provoca un remodelado fisiológico que resulta sumamente beneficioso aún en pacientes con IC, a los cuales les mejora la capacidad funcional al generarles un fenotipo protector (200-202). 
Lo más destacado de los cambios histológicos lo constituyen el AST, la fracción de colágeno y la densidad capilar. El miocardio está constituído por los miocitos y la matriz extracelular (MEC). Esta última formada por fibroblastos, colágeno, vasos sanguineos, linfáticos y terminaciones nerviosas. La relación entre la MEC y el miocito se altera en la $\mathrm{HC}$. El colágeno es sintetizado por los fibroblastos constituyendo una red que da soporte mecánico y rodea al miocardio, a las fibras musculares y a los miocitos individuales. Los fibroblastos también sintetizan y liberan metaloproteasas, enzimas que degradan el colágeno de la MEC, manteniendo así un balance entre la síntesis y degradación de la misma (289). La ruptura de dicho equilibrio, conduce a cambios fibróticos que junto con la $\mathrm{HC}$, la proliferación fibroblástica y la muerte celular constituyen el fenómeno de remodelación (13).

En los estudios realizados se observó que las SHR-S presentan aumentada el AST del cardiomiocito y la fracción de colágeno, con una tendencia a valores más bajos en la densidad capilar respecto de las Wistar. Como vimos anteriormente la muerte celular por apoptosis es mayor en las SHR-S que en las Wistar, lo que genera una falta de células contráctiles y el consiguiente reemplazo de estas por colágeno, fibroblastos, fibronectina y laminina. De esta manera se produce en la HCP la sustitución de un miocardio contráctil por otro fibroso. Trabajos previos demuestran que el incremento en el depósito de colágeno entre los cardiomiocitos, ya sea por aumento en su producción o por disminución en su degradación, provoca distorsión de la estructura tisular y fibrosis intersticial contribuyendo a las alteraciones diastólicas y acelerando el camino hacia la IC (290-292).

Como puede verse en los estudios histológicos realizados, la actividad física produjo en los cardiocitos de las SHR-E un aumento promedio del $45 \%$ en el AST. Resultó de interés observar como dichos cambios histológicos se acompañaron de un importante incremento en la densidad capilar. Simultáneamente, se observó que la fracción de colágeno disminuyó aproximadamente un 50\%. Los valores de esta fracción, luego del ejercicio no difieren significativamente de las Wistar. El incremento en la densidad capilar y la normalización de la fibrosis intersticial, evidencian un efecto favorable de la actividad física sobre la HCP. Se ha demostrado que la angiogénesis posee un efecto benéfico ya que ayuda a corregir procesos isquémicos (293). 
Uno de los objetivos del presente estudio fue examinar los mecanismos moleculares a través de los cuales se ejerce la cardioprotección, pues aún no se conocen con exactitud todos los eslabones que intervienen en esta vía de señalización. Como ya se mencionó, la HCP se asocia con un número importante de cambios moleculares y estructurales, dañinos para el corazón; mientras que la HCF no altera la función cardíaca, es reversible y no evoluciona a IC. En la Figura 1D se muestra un esquema simplificado de las vías que participarían en la HCP y la HCF.

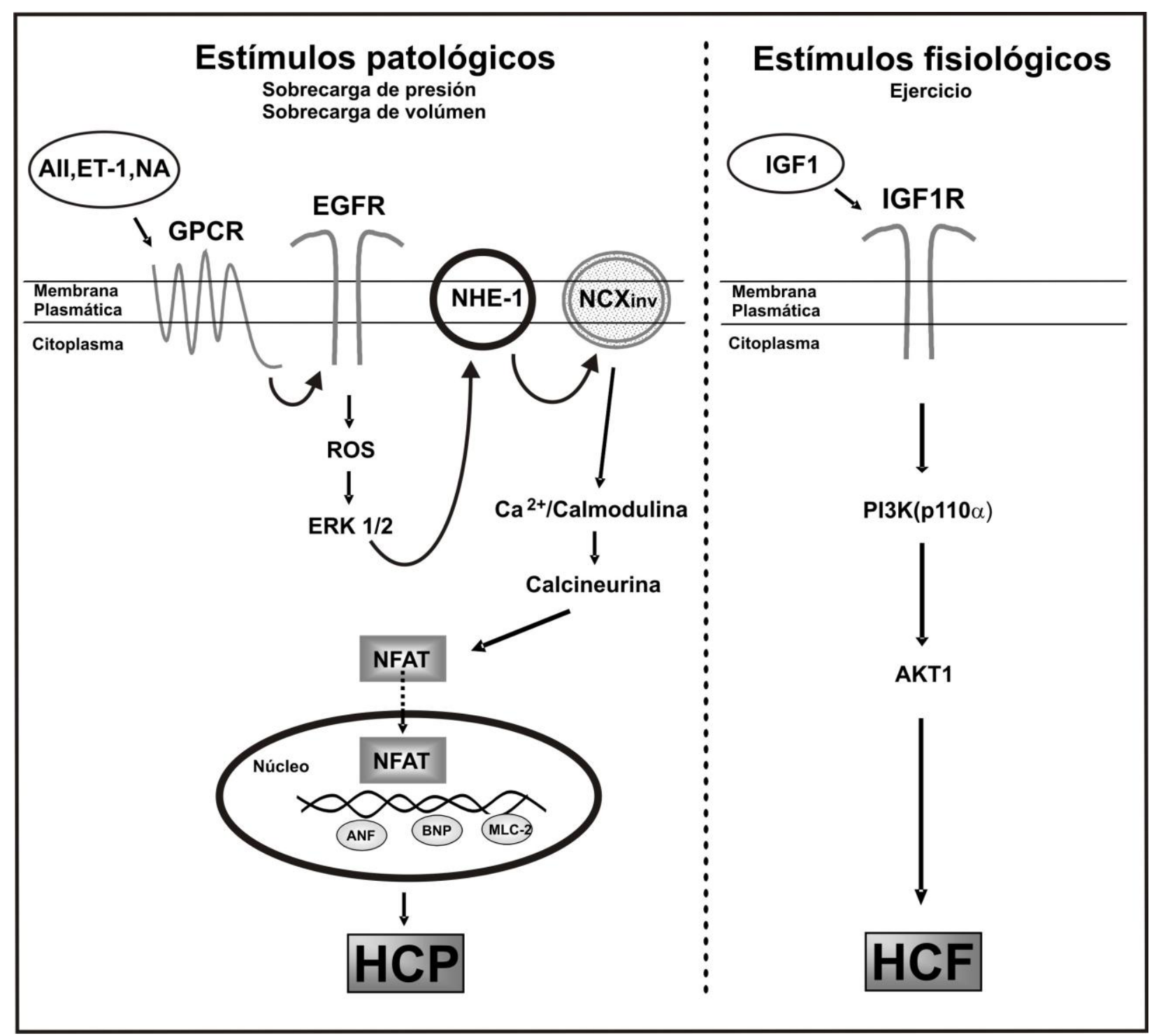

Figura 1D. Resumen de las vías de señalización involucradas en la HCP y la HCF. 
Es un hecho bien conocido que en la HCP se produce la inducción de genes normalmente expresados sólo durante el desarrollo fetal, tales como ANF y MLC-2. En los estudios realizados se observó que la HC de las SHR-S se acompañó de un importante incremento en los niveles de estos marcadores moleculares, lo cual confirma la reprogramación de la expresión génica. Se ha visto que los niveles de ANF se correlacionan positivamente con la severidad de la IC $(294,295)$. Además, en otros modelos experimentales de HCP se encontró que intermediarios como la PKC activan a genes como c-fos y c-jun, los cuales estimulan la expresión de ANF (296). Además de los péptidos natriuréticos, se sobre-expresan otros genes como los de la vía apoptótica, la cadena pesada de la miosina, la lactato deshidrogenasa y la creatín kinasa. Se piensa que la activación del programa de genes fetales permite la síntesis coordinada de las proteínas necesarias para incrementar el tamaño del cardiomiocito (297).

En las SHR-E resultó de interés comprobar que la rutina natatoria disminuyó un $60 \%$ la expresión de ANF y un 40\% la expresión de MLC-2. Ello confirma que el entrenamiento físico impacta benéficamente en patrón miocárdico molecular aún en presencia de una HCP. 
SERCA2a y NCX son dos proteínas relevantes involucradas en el ciclo intracelular del calcio. Se sabe que para una adecuada función cardíaca los mecanismos de remoción y de liberación de calcio, deben funcionar adecuadamente (254). En los estudios moleculares realizados por nosotros, se observó que la HC de las SHR-S se acompaña de menor expresión de SERCA2a y mayor expresión NCX. Coincidiendo con estos resultados, estudios de otros laboratorios encontraron que la expresión de ambas se encuentra alterada tanto en la $\mathrm{HC}$ de modelos experimentales como en la HC humana (254). La disminución de SERCA2a es un hecho de importancia en la HC, ya que contribuye a la disfunción del VI (298). Además, se observó que las SHR de 3 a 4 semanas de edad poseen aumentada la actividad del NCX, incluso antes de desarrollar HTA $(254,299)$.

Nuestros resultados muestran que la actividad física induce un incremento significativo de SERCA2a pero no se apreciaron cambios en cuanto al NCX. El aumento de SERCA2a con el ejercicio, sugiere un efecto beneficioso sobre el corazón. Estos datos coinciden con estudios previos realizados en IC, que demuestran que una mejor regulación del calcio intracelular favorece la función ventricular $(255,256)$. Se ha visto que la administración de isoproterenol en ratones, aumentó la expresión de SERCA y la capacidad relajante y contráctil del corazón, por ello se considera a SERCA como un objetivo terapéutico para intentar atenuar el pasaje de la HC a la IC (300). 
La activación de calcineurina es una señal importante para inducir HCP. En nuestro estudio se demostró que la fosfatasa calcineurina se encuentra hiperactivada en las SHR-S. Resultados similares se encontraron en pacientes con hipertrofia del VI e IC en los que la actividad de calcineurina estaba aumentada, mostrando así el carácter maladaptativo de la HCP (214). Evidencia de ello es la mortalidad prematura de las SHR-S, las cuales no suelen superar los 18 meses de vida (301). Es sabido que la mayoría de los estímulos que inducen HCP en respuesta a una sobrecarga hemodinámica confluyen en el aumento de la $\left[\mathrm{Ca}^{+2}\right]$. Como ya se mencionó, dicho aumento estimula la formación del complejo $\mathrm{Ca}^{+2} / \mathrm{CaM}$, el cual activa a calcineurina. $\mathrm{La}$ calcineurina activada desfosforila a factores de transcripción, como NFAT, en el citosol permitiendo que estos se trasladen al núcleo e interactúen con otros factores para estimular la transcripción génica.

En nuestros estudios observamos que la mayor expresión de calcineurina que se encontró en la HC de las SHR-S, disminuyó de manera significativa en las SHR-E, llegando a valores similares a los de las Wistar, lo cual sugiere que se detiene $\mathrm{y} / \mathrm{o}$ revierte el camino hacia la HCP. Ha sido demostrado que se encontraba aumentada la actividad de NFAT en ratones con sobrecarga de presión e IC, pero no en ratones con $\mathrm{HC}$ inducida por el ejercicio (57). 
PI3K/Akt es una vía que se activa en la HCF y en la HCP (259-261), ya que puede ser estimulada tanto por los RTK como por medio de los GPCR. PI3K es una kinasa lipídica que se activa en el corazón durante el desarrollo y en respuesta al entrenamiento físico, permitiendo su crecimiento fisiológico normal (302-304). Además se ha visto que en situaciones patológicas, como frente a una sobrecarga de presión, se encuentra activada (305). En nuestro estudio se observó que la HC de las SHR-S se acompaña de una mayor expresión de $\mathrm{PI} 3 \mathrm{~K}(\mathrm{p} 110 \alpha) / \mathrm{AKT}$, probablemente por transactivación del EGFR. Por otra parte, otros estudios demuestran que PI3K(p110y) tras ser activada por los $\mathrm{G}_{\beta \gamma} P C R$, induce la vía de HCP (306-309).

En las SHR-E nuestros resultados muestran que esta vía se mantiene activa. Esto podría deberse a que durante el ejercicio es liberado el IGF1 (factor de crecimiento de insulina de tipo1) que estimula a su receptor IGF1-R, el cual recluta hacia la membrana a la isoforma PI3K(p110 $)$, activándose la vía que induce $\operatorname{HCF}(303,304,310,311)$. Se sabe que la vía IGF1/IGF1-R/PI3K(p110a)/AKT1 tiene efectos beneficiosos no sólo porque estimula el crecimiento fisiológico del cardiomiocito, sino también porque inhibe la vía activada por los GPCR que inducen $\operatorname{HCP}(201,305,312)$. Se ha visto que cuando disminuyen los niveles de PI3K(p110a) aumenta tanto la fibrosis intersticial como la apoptosis, sugiriendo que actuaría como un regulador negativo de la fibrosis (305) y que tendría un efecto antiapoptótico (313-315).

El rol de $\underline{\mathrm{PI} 3 \mathrm{~K}(\mathrm{p} 110 \alpha)}$ en la HCF fue confirmado al demostrarse que ratones sin la subunidad reguladora $\mathrm{p} 85$, no se hipertrofiaban cuando eran sometidos a estímulos como el ejercicio (302). La subunidad reguladora (p85) es quien, activada por la unión del ligando al receptor, recluta a las subunidad catalíticas (p110a). Como se mencionó anteriormente $\mathrm{PI} 3 \mathrm{~K}(\mathrm{p} 110 \alpha)$ fosforila lípidos de la membrana plasmática formando $\mathrm{PIP}_{3}$, que fosforila y activa a AKT1 (316), isoforma más abundante del corazón (317), desarrollando $\operatorname{HCF}(303,311,318,319)$. Estudios realizados utilizando ratones a los que se les noqueó el gen de AKT1, cuando se los sometió a un estímulo natatorio no desarrollaron HCF (312). Además se encontró que cuando AKT es activada por la vía fisiológica, se traslada al RS donde fosforila a fosfolamban liberando a SERCA2a de su inhibición y permiendo que se almacene y libere más calcio en el RS, mejorando así la contractilidad cardíaca (320). 
La apoptosis es un proceso fisiológico normal y también sucede en situaciones patológicas como durante la transición de HC a IC $(264,265)$. Su activación puede producirse por dos vías, extrínseca y mitocondrial, ambas mediadas por caspasas que degradan sustratos intracelulares. Hayakawa mostró que el tratamiento de ratones transgénicos con un inhibidor de caspasa, redujo la muerte de los cardiomiocitos y atenuó la disfunción contráctil (321). Además, observaron que bajos niveles de apoptosis bastaron para producir dilatación del VI y alteraciones contráctiles (322). Estos estudios apoyan la hipótesis de que la pérdida crónica de miocitos por la vía apoptótica contribuye a la HCP (201).

La incidencia de apoptosis está aumentada en la HC hipertensiva, fue por ello que se examinaron dos efectores de la vía apoptótica en nuestro modelo experimental: procaspasa-3 y PARP-1. Se observó que ambos estaban hiperactivados en las SHR-S, las cuales mostraron mayor incidencia de apoptosis. Se ha visto que PARP-1 estimula a factores de transcripción y genes hipertróficos como NFK $\beta$ y TEF-1, responsables de la $\operatorname{HCP}(279,323,324)$. En la HC inducida por sobrecarga de presión, se encontró aumentada la actividad de caspasa-3 y la expresión de sus genes $(273,274)$. Se sabe que caspasa-3 cliva a $\alpha$-actina, $\alpha$-actinina y troponina, dificultando la contracción (275); y que está implicada en la fragmentación del ADN, evento característico de la apoptosis (276).

El paso siguiente fue explorar si la actividad física era capaz de inducir un efecto inhibitorio sobre la vía apoptótica. Los resultados obtenidos demuestran que la actividad física inhibió las señales proapoptóticas, al producirse una disminución significativa en el clivado de procaspasa-3 a caspasa así como también de PARP-1 en su fragmentos de $85 \mathrm{kDa}$. Todo ello contribuiría al mejoramiento de la función cardíaca, como lo evidencia el estudio ecocardiográfico en las SHR-E. El deterioro de la función mitocondrial es considerado un proceso clave en la muerte celular por apoptosis. Estudios recientes demuestran que el ejercicio disminuye la actividad de caspasa-3 y 9 , promoviendo un fenotipo de mitocondrias más resistente (325).

En la vía mitocondrial intervienen proteínas proapoptóticas (Bax) y antiapoptóticas (Bcl2), cuya proporción relativa parece ser relevante al momento de determinar el destino de una célula expuesta a un estímulo proapoptótico (326-328). Frente a una señal de muerte, Bax forma canales en la MME permeabilizándola $(329,330)$. En la 
permeabilización participa el MPTP, cuya apertura permite la transición de una baja permeabilidad de la membrana (agua y solutos hasta $1,5 \mathrm{kDa}$ ) a una conductancia elevada, ocasionado disipación del potencial de membrana, liberación de citocromo c, y la pérdida de funciones celulares esenciales (331). Se ha visto que la apertura del MPTP puede ser transitoria, no tratándose necesariamente de un proceso irreversible (332). Estudios demuestran que el ejercicio disminuye la suceptibilidad de la apertura del MPTP, inducida por el calcio, previniendo el daño sobre la función mitocondrial (325, 333). 


\section{Nuevas estrategias terapéuticas.}

La regresión de la $\mathrm{HC}$ es considerada en la actualidad como un paso clave para la prevención del desarrollo de IC. Una de las formas de lograr interrumpir y/o revertir el cuadro de HCP, es con el empleo de fármacos. Existen evidencias de que el uso de inhibidores específicos del NHE-1 es beneficioso en patologías cardíacas hipertróficas (147, 189-191). El tratamiento actual intenta evitar el desarrollo de IC mediante la administración de IECA, ARAll, $\beta$-bloqueantes y diuréticos, dependiendo del estadío de la enfermedad y de la severidad del cuadro $(334,335)$. Los IECA (inhibidores de la enzima convertidora de All) atenúan el remodelado del $\mathrm{VI}$ al prevenir la formación de All, mientras que los ARAll (bloqueantes de los receptores de All) evitan la interacción entre All y su receptor. Los $\beta$-bloqueantes bloquean los receptores adrenérgicos, disminuyendo el remodelado del VI (336). Los diuréticos son esenciales para disminuír la retención de líquidos, evitando el edema periférico y pulmonar (337). A pesar de los avances en los tratamientos farmacológicos, el pronóstico sigue siendo incierto y los pacientes sufren de una variedad de síntomas que les causan dificultades y reducen su calidad de vida (338). Pacientes con IC suelen presentar HTA, enfermedad renal crónica y diabetes, lo que aumenta las posibilidades de intolerancia e incompatibilidad entre drogas pudiendo ocasionar interacciones farmacológicas no deseadas (334, 339, 340).

Resulta por ello necesario buscar alternativas de tratamiento junto con la identificación de nuevos intermediarios de las vías de señalización, que puedan ser posibles blancos terapéuticos. Surgen así posibles nuevas estrategias para inducir el crecimiento fisiológico del cardiomiocito y otras que intentan bloquear nuevos eslabones del SRAA. Dentro de las primeras encontramos la activación de la vía IGF/PI3K/AKT mediante la práctica de actividad física, a través de fármacos y de terapia génica. Entre las segundas se encuentra el bloqueo de aldosterona, último eslabón del SRAA, con el empleo de fármacos más específicos como eplerenona para evitar la HCP. 
En estudios con pacientes que realizaron ejercicio se observó una significativa reducción de la morbi-mortalidad cardiovascular (193-196). El sedentarismo y la obesidad son factores de riesgo para una gran variedad de afecciones crónicas, incluyendo las enfermedades cardíacas. En un meta-análisis con 33 estudios y 900.000 participantes, se encontró que en pacientes que efectuaban actividad física el riesgo de muerte cardiovascular se redujo en un 35\% (341). Además en pacientes con IC, se ha demostrado que la actividad física es segura y beneficiosa (197-199). El entrenamiento físico se está volviendo un componente importante en programas de rehabilitación de pacientes con IC (342-344), ya que numerosos estudios han demostrado que el ejercicio físico realizado de manera regular mejora la capacidad funcional y la calidad de vida de estos pacientes (200-202, 345-349).

Antes de 1980 se les aconsejaba a los pacientes con patologías cardíacas que no realizaran ejercicio ya que podrían aumentar el riesgo de infarto (350). Actualmente el ejercicio se recomienda como parte integral del plan de tratamiento y prevención de enfermedades cardiovasculares $(351,352)$. El uso de una terapia combinada entre el ejercicio (que activa la vía que desarrolla la HCF y atenúa el remodelado patológico) y la administración de IECA y ARAll (que disminuyen la HCP), serían opciones recomendables en pacientes con riesgo de IC (201).

Si bien muchos de los beneficios del ejercicio se pueden explicar por lo cambios que se producen en los vasos y en el músculo esquelético $(227,228)$, los resultados presentados en este trabajo muestran que también se producen efectos favorables en el corazón al atenuar procesos de remodelamiento como la HCP y la fibrosis, mejorando así la capacidad funcional del miocardio y promoviendo la supervivencia del cardiomiocito. 
Como se mencionó previamente una de las estrategias terapéuticas ideadas para prevenir la IC, lo constituye la activación de la vía IGF/PI3K/AKT a través del ejercicio, fármacos y mediante terapia génica (353). Se ha visto que IGF1 se encuentra elevado en atletas que desarrollan HCF y que dicho aumento se correlaciona con el aumento de la masa del VI (310). IGF1 es una hormona peptídica que se libera durante el ejercicio (310) y es producida principalmente por el hígado y el miocardio (354). Estudios realizados en ratones transgénicos que sobreexpresan el receptor de IGF1 (IGF1-R) desarrollaron HCF y mejoraron su función sistólica (311). Se vio que si a un grupo de estos ratones se los hacía nadar, la respuesta hipertrófica era mayor (311). Por otro lado, ratones cuyo gen del IGF1 fue suprimido, mostraron una resistencia a desarrollar hipertrofia inducida por el ejercicio (355). La activación de IGF1-R por IGF induce la vía de PI3K(p110a) / AKT1 (302-304).

Una limitación de esta estrategia es que la vía PI3K está presente en numerosos tipos celulares interviniendo en procesos de crecimiento y diferenciación celular. El éxito de este tipo de tratamiento dependerá de la capacidad de poder diseñar fármacos que activan esta vía unicamente en el corazón.

Por otro lado, recientemente se ha encontrado en el corazón adulto la existencia de un pool de células progenitoras pluripotenciales (356), que tienen la capacidad de diferenciarse y formar cardiomiocitos en respuesta al aumento de la sobrecarga cardíaca (357). Otros estudios han detectado tanto en corazones normales como patológicos de ratas, ratones y humanos, la existencia de cardiomiocitos formados recientemente $(17,357-360)$. Un grupo de investigadores encontró que la sobrecarga ocasionada por nadar o correr genera un aumento en el número de células progenitoras y estimula su diferenciación hacia células cardíacas (361). 
Finalmente, evidencias crecientes en el estudio del SRAA muestran la relevancia de aldosterona en la fibrosis miocárdica y en la HCP (362-366). Si bien existen controversias, se ha publicado que los cardiomiocitos expresan las enzimas involucradas en la síntesis de aldosterona $(367,368)$. Se publicó que All estimula la secreción de aldosterona en varios tipos celulares $(369,370)$, y que el tratamiento con losartan previene parcialmente la HCP y la fibrosis miocardica inducida por aldosterona (371). Otros estudios demostraron que aldosterona potenció el efecto de All por un mecanismo dependiente del receptor de mineralocorticoides (MR) (372), el cual se expresa en el tejido cardíaco tanto a nivel del ARNm como de la proteína (373-375).

Aldosterona ejerce su efecto biológico a través de una vía genómica y otra nogenómica. La primera de ellas se produce cuando aldosterona se une al MR formando un complejo en el citosol, que luego se traslada al núcleo donde estimula la transcripción de genes y la síntesis de proteinas relacionadas con el control de electrolitos y la regulación del volumen $(376,377)$. Caldiz y col. (378) trabajando con inhibidores de la síntesis proteica (como cicloheximida) observaron que no se suprime la producción miocárdica de anión superóxido estimulada por aldosterona, sugiriendo que se trataría de un efecto no-genómico más rápido que el anterior. Este mismo grupo de investigadores demostró que el MR se encontraría corriente arriba del EGFR en la cascada de señalización (378).

Villa-Abrille y col. (72), postularon la posible participación de aldosterona, el MR y el EGFR en la cascada de señalización intracelular activada por el estiramiento y que conduce a la HCP. Demostraron que la fuerza generada por el estiramiento se cancelaba con el uso de inhibidores del MR, como así también con inhibidores de la quinasa Src (PP1) y de la MMP (MMPI), confirmando el fenómeno de transactivación.

La activación del EGFR por transactivación favorece la apertura de los canales de potasio mitocondriales ATP-dependientes (mitoKATP). De esta manera se hace posible el ingreso de potasio desde el citosol hacia la matriz, despolarizando la mitocondria y generando una mayor producción de ROS. La disipación del gradiente mitocondrial y la variacion del $\mathrm{pH}$ de la matriz predisponen la apertura del MPTP y la posterior salida de los ROS por el mismo. Caldiz y col. (378), observaron que los ROS procedían principalmente de la mitocondria y que podían activar a la vía ERK1/2-p90 RSK 
(considerada "redox sensible" $(72,110)$ ), efecto que se cancelaba con rotenona (inhibidor del complejo I de la cadena transportadora de electrones) y 5HD (bloqueante selectivo de los mitoKATP).

Estos resultados sugieren que tanto aldosterona, el MR y el EGFR constituyen eslabones necesarios en la cascada de señalización disparada por All en el miocardio y que promueven la activación de la vía de ERK1/2 a partir de un aumento en la producción de los ROS provenientes de la mitocondria. Basado en las evidencias presentadas anteriormente podría especularse que la disminución en la formación de los ROS contribuiría con el efecto favorable de la inhibición de la aldosterona. Posiblemente la coestimulación de All y aldosterona, acelere el daño al tejido cardiovascular y su remodelamiento. Por otra parte, es probable que resulte conveniente el uso de una terapia combinada que inhiba no sólo a NHE-1 sino también a otros eslabones de la cadena de señalización que se encuentren más arriba como el AT1, el MR, las MMP, el HB-EGF y el EGFR. Esta estrategia resultaría de utilidad en el intento de atenuar la progresión de la HCP hacia la IC. 
La Figura 2D resume en un esquema los resultados obtenidos en el presente trabajo. El entrenamiento físico fue efectivo para transformar una HCP en HCF, en un modelo experimental de HC inducida por hipertensión arterial. Los cambios beneficiosos incluyen el aumento de la densidad capilar, la disminución de la fibrosis, la disminución de la apoptosis, el aumento de la expresión de SERCA2a y la disminución de la actividad de calcineurina. Estos en conjunto, contribuirían a un mejoramiento de la función cardíaca. La rutina natatoria modificó la geometría cardíaca hacia un patrón fisiológico, como lo demuestra la disminución de la relación espesor de la pared del ventrículo izquierdo/radio de la cavidad ventricular.

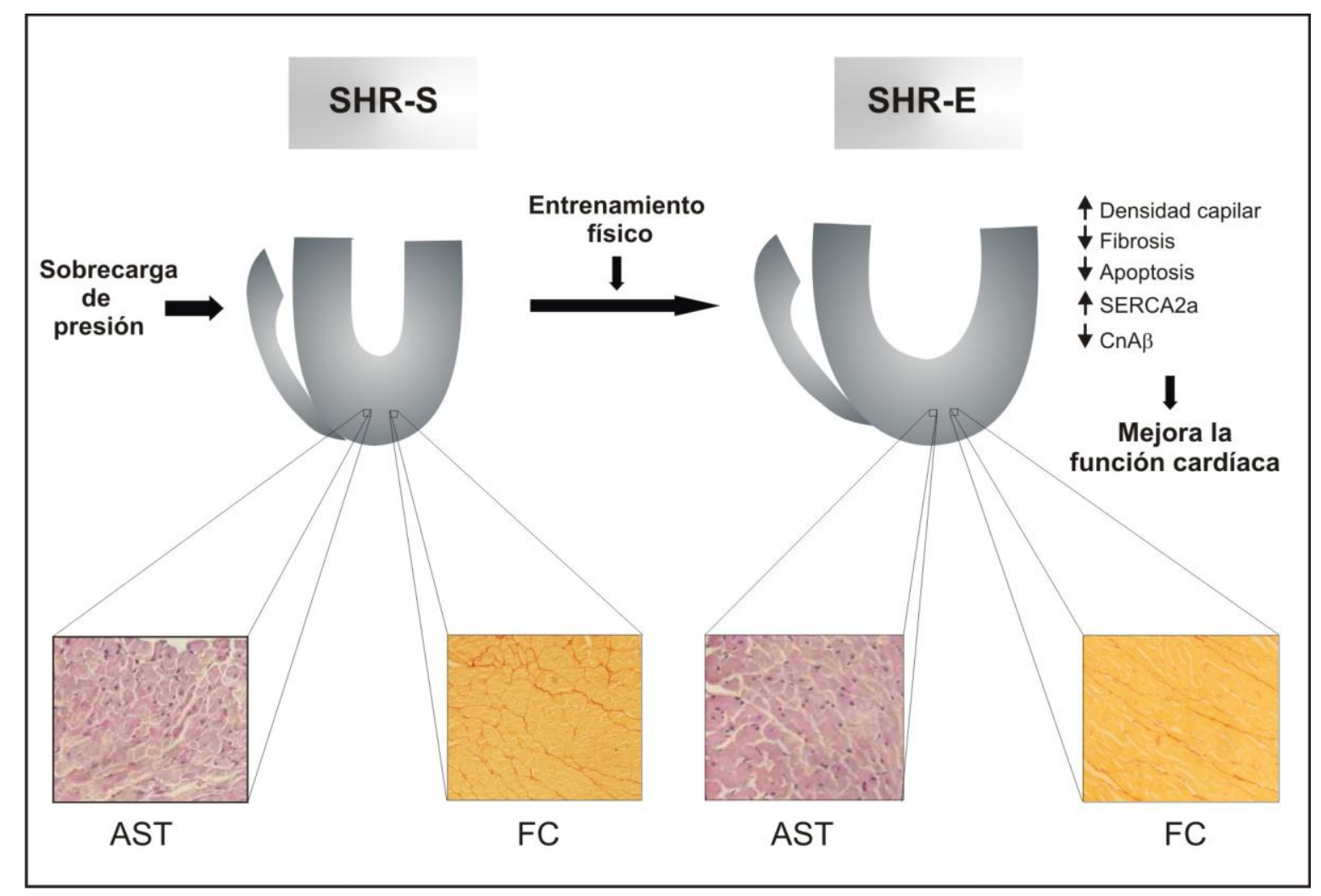

Figura 2D. Efecto del entrenamiento físico en la HC. En la parte superior se muestra dos esquemas representativos del corazón de SHR-S y SHR-E. En la parte inferior se muestran micrografías del área de sección transversal (AST) y de la fracción de colágeno (FC), teñidas de manera adecuada.

Los resultados precedentes sugieren la importancia y la necesidad de la actividad física para prevenir y/o revertir la HCP y su progresión hacia la IC. 


\section{CONCLUSIÓN FINAL}

La HC es un evento de elevada complejidad que implica la participación de estímulos, receptores, vías de señalización intracelular, factores de transcripción, genes y efectores. A pesar del avance en la identificación de nuevos intermediarios, los mecanismos moleculares que subyacen la respuesta fisiológica o patológica no están aún totalmente dilucidados. Esto se debe en parte a que las moléculas involucradas en esta respuesta no operan en forma aislada, sino que por el contrario participan de una complicada red de señalización con frecuentes puntos de entrecruzamiento. El conocimiento de los mecanismos implicados en la $\mathrm{HC}$ es necesario para prevenir la progresión a la IC.

Los resultados obtenidos experimentalmente con las SHR demuestran que una HCP puede transformarse en HCF a nivel molecular, estructural y funcional mediante la práctica de actividad física. La tendencia a la normalización de la fibrosis intersticial junto con el incremento en la densidad capilar y la disminución en la actividad apoptótica, evidencian el importante potencial del corazón para restaurar la estructura miocárdica y la capacidad funcional, debido al ejercicio. Esto último se confirmó con el incremento en el AMV, parámetro que es considerado el mejor indicador ecocardiográfico de la función sistólica.

Se observó también una reducción en la expresión de ANF y MLC-2 mostrando que disminuyó el estrés cardíaco asociado a la HTA, lo que indica que el ejercicio impacta beneficiosamente en presencia de una HCP. En este trabajo de tesis se han caracterizado dos cascadas de señalización con una importante participación en la HCP y en la HCF, la vía de la calcineurina y de la PI3K/AKT. El ejercicio normaliza la actividad de calcineurina, sin interferir con la vía de PI3K/AKT, resultado de relevancia ya que calcineurina mediaría la HCP pero no la HCF. Además la vía PI3K/AKT promueve la supervivencia celular al inhibir la apoptosis. Otro resultado de interés resultó ser el aumento en expresión de SERCA2a en el miocardio de las SHR sometidas a entrenamiento aeróbico, sugiriendo que el ejercicio podría mejorar la regulación intracelular del calcio. Podemos concluir así que la actividad física realizada con regularidad beneficiaría la función cardíaca en pacientes con patologías cardiovasculares.

Clásicamente las investigaciones y las terapias se han focalizado en intentar inhibir el proceso patológico (HCP). Actualmente, al valorizar la actividad física se da más importancia a los mecanismos naturales (HCF), lo que brinda un mejor pronóstico. 
El presente trabajo es una contribución al diseño de alternativas terapéuticas, basadas en promover el crecimiento fisiológico, para prevenir la IC secundaria a la $\mathrm{HC}$ inducida por la HTA. 
ABREVIATURAS 
- HC: hipertrofia cardíaca.

- HCP: hipertrofia cardíaca patológica.

- HCF: hipertrofia cardíaca fisiológica.

- IC: insuficiencia cardíaca.

- HTA: hipertensión arterial.

- Vl: ventrículo izquierdo.

- SFF: segunda fase de fuerza.

- ANF: factor atrial natriurético.

- MLC-2: cadena liviana de la miosina, subunidad 2.

- All: angiotensina 2.

- AT1: receptor de All.

- ET-1: endoletina 1.

- ET-A: receptor de ET-1.

- GPCR: receptores acoplados a proteina G.

- RTK: receptor tirosina quinasa.

- PKC: proteina quinasa $\mathrm{C}$.

- PLC: fosfolipasa C.

- DAG: diacilglicerol.

- IP3: inositol-tri-fosfato.

- MAPK: kinasa activada por mitógeno.

- EGF: factor de crecimiento epidérmico.

- EGFR: receptor del factor de crecimiento epidérmico.

- NHE-1: intercambiador sodio-hidrógeno.

- NCX: intercambiador sodio-calcio.

- CaM: calmodulina.

- CnAß: calcineurina A, isoforma beta.

- RS: retículo sarcoplasmático.

- ROS: especies reactivas del oxígeno.

- SHR: ratas espontáneamente hipertensas. 


\section{REFERENCIAS}




\section{REFERENCIAS}

1. Kannel WB. Vital epidemiologic clues in heart failure. Journal of clinical epidemiology 2000; 53(3):229-235.

2. Hobbs RE. Guidelines for the diagnosis and management of heart failure. American journal of therapeutics 2004; 11(6):467-472.

3. Levy D, Kenchaiah S, Larson MG, Benjamin EJ, Kupka MJ, Ho KK, Murabito JM, Vasan RS. Long-term trends in the incidence of and survival with heart failure. The New England journal of medicine 2002; 347(18):1397-1402.

4. Ho YL, Wu CC, Lin LC, Huang CH, Chen WJ, Chen MF, Liau CS, Lee YT. Assessment of the coronary artery disease and systolic dysfunction in hypertensive patients with the dobutamine-atropine stress echocardiography: effect of the left ventricular hypertrophy. Cardiology 1998; 89(1):52-58.

5. Levy D, Garrison RJ, Savage DD, Kannel WB, Castelli WP. Prognostic implications of echocardiographically determined left ventricular mass in the Framingham Heart Study. The New England journal of medicine 1990; 322(22):15611566.

6. Kannel WB, Gordon T, Offutt D. Left ventricular hypertrophy by electrocardiogram. Prevalence, incidence, and mortality in the Framingham study. Ann Intern Med 1969; 71(1):89-105.

7. Ruilope LM, Schmieder RE. Left ventricular hypertrophy and clinical outcomes in hypertensive patients. American journal of hypertension 2008; 21(5):500-508.

8. Braunwald E, Bristow MR. Congestive heart failure: fifty years of progress. Circulation 2000; 102(20 Suppl 4):IV14-23.

9. Liang $F$, Gardner DG. Mechanical strain activates BNP gene transcription through a p38/NF-kappaB-dependent mechanism. The Journal of clinical investigation 1999; 104(11):1603-1612.

10. Frey N, Katus HA, Olson EN, Hill JA. Hypertrophy of the heart: a new therapeutic target? Circulation 2004; 109(13):1580-1589.

11. Reiss K, Kajstura J, Capasso JM, Marino TA, Anversa P. Impairment of myocyte contractility following coronary artery narrowing is associated with activation of the myocyte IGF1 autocrine system, enhanced expression of late growth related genes, DNA synthesis, and myocyte nuclear mitotic division in rats. Experimental cell research 
1993; 207(2):348-360.

12. Kajstura J, Cheng W, Reiss K, Anversa P. The IGF-1-IGF-1 receptor system modulates myocyte proliferation but not myocyte cellular hypertrophy in vitro. Experimental cell research 1994; 215(2):273-283.

13. Swynghedauw B. Molecular mechanisms of myocardial remodeling. Physiological reviews 1999; 79(1):215-262.

14. Wettschureck N, Rutten H, Zywietz A, Gehring D, Wilkie TM, Chen J, Chien KR, Offermanns $S$. Absence of pressure overload induced myocardial hypertrophy after conditional inactivation of Galphaq/Galpha11 in cardiomyocytes. Nature medicine 2001; 7(11):1236-1240.

15. Schillaci G, Verdecchia P, Porcellati C, Cuccurullo O, Cosco C, Perticone F. Continuous relation between left ventricular mass and cardiovascular risk in essential hypertension. Hypertension 2000; 35(2):580-586.

16. Nadal-Ginard B, Kajstura J, Leri A, Anversa P. Myocyte death, growth, and regeneration in cardiac hypertrophy and failure. Circulation research 2003; 92(2):139150

17. Beltrami AP, Urbanek K, Kajstura J, Yan SM, Finato N, Bussani R, Nadal-Ginard B, Silvestri F, Leri A, Beltrami CA, Anversa P. Evidence that human cardiac myocytes divide after myocardial infarction. The New England journal of medicine 2001; 344(23):1750-1757.

18. Rohini A, Agrawal N, Koyani CN, Singh R. Molecular targets and regulators of cardiac hypertrophy. Pharmacol Res; 61(4):269-280.

19. Haider AW, Larson MG, Benjamin EJ, Levy D. Increased left ventricular mass and hypertrophy are associated with increased risk for sudden death. Journal of the American College of Cardiology 1998; 32(5):1454-1459.

20. Mathew J, Sleight P, Lonn E, Johnstone D, Pogue J, Yi Q, Bosch J, Sussex B, Probstfield J, Yusuf S. Reduction of cardiovascular risk by regression of electrocardiographic markers of left ventricular hypertrophy by the angiotensinconverting enzyme inhibitor ramipril. Circulation 2001; 104(14): 1615-1621.

21. Verdecchia P, Schillaci G, Borgioni C, Ciucci A, Gattobigio R, Zampi I, Reboldi G, Porcellati C. Prognostic significance of serial changes in left ventricular mass in essential hypertension. Circulation 1998; 97(1):48-54.

22. van Empel VP, De Windt LJ. Myocyte hypertrophy and apoptosis: a balancing 
act. Cardiovascular research 2004; 63(3):487-499.

23. Chien KR, Zhu H, Knowlton KU, Miller-Hance W, van-Bilsen M, O'Brien TX, Evans SM. Transcriptional regulation during cardiac growth and development. Annual review of physiology 1993; 55:77-95.

24. Lorell BH, Carabello BA. Left ventricular hypertrophy: pathogenesis, detection, and prognosis. Circulation 2000; 102(4):470-479.

25. Chien KR. Genomic circuits and the integrative biology of cardiac diseases. Nature 2000; 407(6801):227-232.

26. Sadoshima J, Takahashi T, Jahn L, Izumo S. Roles of mechano-sensitive ion channels, cytoskeleton, and contractile activity in stretch-induced immediate-early gene expression and hypertrophy of cardiac myocytes. Proceedings of the National Academy of Sciences of the United States of America 1992; 89(20):9905-9909.

27. Molkentin JD, Dorn GW, 2nd. Cytoplasmic signaling pathways that regulate cardiac hypertrophy. Annual review of physiology 2001; 63:391-426.

28. Passier R, Zeng H, Frey N, Naya FJ, Nicol RL, McKinsey TA, Overbeek P, Richardson JA, Grant SR, Olson EN. CaM kinase signaling induces cardiac hypertrophy and activates the MEF2 transcription factor in vivo. The Journal of clinical investigation 2000; 105(10):1395-1406.

29. Liang F, Lu S, Gardner DG. Endothelin-dependent and -independent components of strain-activated brain natriuretic peptide gene transcription require extracellular signal regulated kinase and p38 mitogen-activated protein kinase. Hypertension 2000; 35(1 Pt 2):188-192.

30. Carreno JE, Apablaza F, Ocaranza MP, Jalil JE. [Cardiac hypertrophy: molecular and cellular events]. Revista espanola de cardiologia 2006; 59(5):473-486.

31. Lupu F, Terwilliger JD, Lee K, Segre GV, Efstratiadis A. Roles of growth hormone and insulin-like growth factor 1 in mouse postnatal growth. Developmental biology 2001; 229(1):141-162.

32. Hunter JJ, Chien KR. Signaling pathways for cardiac hypertrophy and failure. The New England journal of medicine 1999; 341(17):1276-1283.

33. Kanda T, Takahashi T. Interleukin- 6 and cardiovascular diseases. Japanese heart journal 2004; 45(2):183-193.

34. Hirota H, Yoshida K, Kishimoto T, Taga T. Continuous activation of gp130, a signal-transducing receptor component for interleukin 6-related cytokines, causes 
myocardial hypertrophy in mice. Proceedings of the National Academy of Sciences of the United States of America 1995; 92(11):4862-4866.

35. Kaneko K, Kanda T, Yokoyama T, Nakazato Y, Iwasaki T, Kobayashi I, Nagai R. Expression of interleukin- 6 in the ventricles and coronary arteries of patients with myocardial infarction. Research communications in molecular pathology and pharmacology 1997; 97(1):3-12.

36. Diez J, Lopez B, Gonzalez A, Ardanaz N, Fortuno MA. [Genetics and molecular biology in cardiology (IV). Myocardial response to biomechanical stress]. Revista espanola de cardiologia 2001; 54(4):507-515.

37. Sadoshima J, Izumo S. The cellular and molecular response of cardiac myocytes to mechanical stress. Annual review of physiology 1997; 59:551-571.

38. Komuro I, Kaida T, Shibazaki Y, Kurabayashi M, Katoh Y, Hoh E, Takaku F, Yazaki Y. Stretching cardiac myocytes stimulates protooncogene expression. The Journal of biological chemistry 1990; 265(7):3595-3598.

39. Mann DL, Kent RL, Cooper Gt. Load regulation of the properties of adult feline cardiocytes: growth induction by cellular deformation. Circulation research 1989; 64(6):1079-1090.

40. Sadoshima J, Jahn L, Takahashi T, Kulik TJ, Izumo S. Molecular characterization of the stretch-induced adaptation of cultured cardiac cells. An in vitro model of loadinduced cardiac hypertrophy. The Journal of biological chemistry 1992; 267(15):1055110560.

41. Ji TH, Grossmann M, Ji I. G protein-coupled receptors. I. Diversity of receptorligand interactions. The Journal of biological chemistry 1998; 273(28):17299-17302.

42. Gether U, Kobilka BK. G protein-coupled receptors. II. Mechanism of agonist activation. The Journal of biological chemistry 1998; 273(29):17979-17982.

43. Lefkowitz RJ. G protein-coupled receptors. III. New roles for receptor kinases and beta-arrestins in receptor signaling and desensitization. The Journal of biological chemistry 1998; 273(30):18677-18680.

44. Rockman HA, Koch WJ, Lefkowitz RJ. Seven-transmembrane-spanning receptors and heart function. Nature 2002; 415(6868):206-212.

45. Wu X, Zhang T, Bossuyt J, Li X, McKinsey TA, Dedman JR, Olson EN, Chen J, Brown JH, Bers DM. Local InsP3-dependent perinuclear Ca2+ signaling in cardiac myocyte excitation-transcription coupling. The Journal of clinical investigation 2006; 
116(3):675-682.

46. Mattiazzi A. Positive inotropic effect of angiotensin II. Increases in intracellular $\mathrm{Ca} 2+$ or changes in myofilament $\mathrm{Ca} 2+$ responsiveness? Journal of pharmacological and toxicological methods 1997; 37(4):205-214.

47. Hurwitz DR, Emanuel SL, Nathan MH, Sarver N, Ullich A, Felder S, Lax I, Schlessinger J. EGF induces increased ligand binding affinity and dimerization of soluble epidermal growth factor (EGF) receptor extracellular domain. The Journal of biological chemistry 1991; 266(32):22035-22043.

48. Miranti CK, Brugge JS. Sensing the environment: a historical perspective on integrin signal transduction. Nature cell biology 2002; 4(4):E83-90.

49. Franchini KG, Torsoni AS, Soares PH, Saad MJ. Early activation of the multicomponent signaling complex associated with focal adhesion kinase induced by pressure overload in the rat heart. Circulation research 2000; 87(7):558-565.

50. Brancaccio M, Fratta L, Notte A, Hirsch E, Poulet R, Guazzone S, De Acetis M, Vecchione C, Marino G, Altruda F, Silengo L, Tarone G, Lembo G. Melusin, a musclespecific integrin beta1-interacting protein, is required to prevent cardiac failure in response to chronic pressure overload. Nature medicine 2003; 9(1):68-75.

51. Matsuda N, Hagiwara N, Shoda M, Kasanuki H, Hosoda S. Enhancement of the L-type Ca2+ current by mechanical stimulation in single rabbit cardiac myocytes. Circulation research 1996; 78(4):650-659.

52. Ross RS, Borg TK. Integrins and the myocardium. Circulation research 2001; 88(11):1112-1119.

53. Sadoshima J, Qiu Z, Morgan JP, Izumo S. Tyrosine kinase activation is an immediate and essential step in hypotonic cell swelling-induced ERK activation and cfos gene expression in cardiac myocytes. The EMBO journal 1996; 15(20):5535-5546.

54. Sadoshima J, Xu Y, Slayter HS, Izumo S. Autocrine release of angiotensin II mediates stretch-induced hypertrophy of cardiac myocytes in vitro. Cell 1993; 75(5):977-984.

55. Leri A, Claudio PP, Li Q, Wang X, Reiss K, Wang S, Malhotra A, Kajstura J, Anversa $P$. Stretch-mediated release of angiotensin II induces myocyte apoptosis by activating p53 that enhances the local renin-angiotensin system and decreases the Bcl2-to-Bax protein ratio in the cell. The Journal of clinical investigation 1998; 101(7):13261342. 
56. Parmley WW, Chuck L. Length-dependent changes in myocardial contractile state. The American journal of physiology 1973; 224(5):1195-1199.

57. Wilkins BJ, Dai YS, Bueno OF, Parsons SA, Xu J, Plank DM, Jones F, Kimball TR, Molkentin JD. Calcineurin/NFAT coupling participates in pathological, but not physiological, cardiac hypertrophy. Circulation research 2004; 94(1):110-118.

58. Camilion de Hurtado MC, Alvarez BV, Perez NG, Ennis IL, Cingolani HE. Angiotensin II activates $\mathrm{Na}+-$ independent $\mathrm{Cl}-\mathrm{HCO} 3-$ exchange in ventricular myocardium. Circulation research 1998; 82(4):473-481.

59. Aiello EA, Villa-Abrille MC, Dulce RA, Cingolani HE, Perez NG. Endothelin-1 stimulates the $\mathrm{Na}+/ \mathrm{Ca} 2+$ exchanger reverse mode through intracellular $\mathrm{Na}+(\mathrm{Na}+\mathrm{i})-$ dependent and Na+i-independent pathways. Hypertension 2005; 45(2):288-293.

60. Perez NG, Villa-Abrille MC, Aiello EA, Dulce RA, Cingolani HE, Camilion de Hurtado MC. A low dose of angiotensin II increases inotropism through activation of reverse $\mathrm{Na}(+) / \mathrm{Ca}(2+)$ exchange by endothelin release. Cardiovascular research 2003; 60(3):589-597.

61. Ennis IL, Cingolani HE, Garciarena CD, Camilión de Hurtado MC, Villa-Abrille MC, Aiello EA, Pérez NG. From Anrep's Phenomenon to myocardial hypertrophy: Role of the $\mathrm{Na}+/ \mathrm{H}+$ exchanger. Current Cardiology Reviews 2007; 3:149-164.

62. Cingolani HE, Ennis IL. Sodium-hydrogen exchanger, cardiac overload, and myocardial hypertrophy. Circulation 2007; 115(9):1090-1100.

63. Cingolani HE, Alvarez BV, Ennis IL, Camilion de Hurtado MC. Stretch-induced alkalinization of feline papillary muscle: an autocrine-paracrine system. Circulation research 1998; 83(8):775-780.

64. Perez NG, de Hurtado MC, Cingolani HE. Reverse mode of the Na+-Ca2+ exchange after myocardial stretch: underlying mechanism of the slow force response. Circulation research 2001; 88(4):376-382.

65. Alvarez BV, Perez NG, Ennis IL, Camilion de Hurtado MC, Cingolani HE. Mechanisms underlying the increase in force and $\mathrm{Ca}(2+)$ transient that follow stretch of cardiac muscle: a possible explanation of the Anrep effect. Circulation research 1999; 85(8):716-722.

66. Calaghan SC, White E. Contribution of angiotensin II, endothelin 1 and the endothelium to the slow inotropic response to stretch in ferret papillary muscle. Pflugers Arch 2001; 441(4):514-520. 
67. Calaghan $\mathrm{S}$, White $\mathrm{E}$. Activation of $\mathrm{Na}+\mathrm{H}+$ exchange and stretch-activated channels underlies the slow inotropic response to stretch in myocytes and muscle from the rat heart. The Journal of physiology 2004; 559(Pt 1):205-214.

68. von Lewinski D, Stumme B, Fialka F, Luers C, Pieske B. Functional relevance of the stretch-dependent slow force response in failing human myocardium. Circulation research 2004; 94(10):1392-1398.

69. von Lewinski D, Stumme B, Maier LS, Luers C, Bers DM, Pieske B. Stretchdependent slow force response in isolated rabbit myocardium is $\mathrm{Na}+$ dependent. Cardiovascular research 2003; 57(4):1052-1061.

70. de Hurtado MC, Alvarez BV, Ennis IL, Cingolani HE. Stimulation of myocardial $\mathrm{Na}(+)$-independent $\mathrm{Cl}(-)-\mathrm{HCO}(3)(-)$ exchanger by angiotensin $\mathrm{II}$ is mediated by endogenous endothelin. Circulation research 2000; 86(6):622-627.

71. Mount DB, Romero MF. The SLC26 gene family of multifunctional anion exchangers. Pflugers Arch 2004; 447(5):710-721.

72. Villa-Abrille MC, Caldiz Cl, Ennis IL, Nolly MB, Casarini MJ, Chiappe de Cingolani GE, Cingolani HE, Perez NG. The Anrep effect requires transactivation of the epidermal growth factor receptor. The Journal of physiology, 588(Pt 9):1579-1590.

73. Baker KM, Booz GW, Dostal DE. Cardiac actions of angiotensin II: Role of an intracardiac renin-angiotensin system. Annual review of physiology 1992; 54:227-241.

74. Tsai BS, Peach MJ, Khosla MC, Bumpus FM. Synthesis and evaluation of (DesAsp1)angiotensin I as a precursor for (Des-Asp1)angiotensin II ("Angiotensin III"). Journal of medicinal chemistry 1975; 18(12):1180-1183.

75. Braun-Menendez E, Fasciolo JC, Leloir LF, Munoz JM. The substance causing renal hypertension. The Journal of physiology 1940; 98(3):283-298.

76. Kunapuli SP, Kumar A. Molecular cloning of human angiotensinogen CDNA and evidence for the presence of its mRNA in rat heart. Circulation research 1987; 60(5):786-790.

77. Dostal DE, Baker KM. The cardiac renin-angiotensin system: conceptual, or a regulator of cardiac function? Circulation research 1999; 85(7):643-650.

78. Johnston $\mathrm{Cl}$, Burrell LM, Perich R, Jandeleit $\mathrm{K}$, Jackson B. The tissue reninangiotensin system and its functional role. Clinical and experimental pharmacology \& physiology 1992; 19:1-5.

79. Hirsch AT, Pinto YM, Schunkert H, Dzau VJ. Potential role of the tissue renin- 
angiotensin system in the pathophysiology of congestive heart failure. The American journal of cardiology 1990; 66(11):22D-30D; discussion 30D-32D.

80. Dostal DE, Rothblum KN, Conrad KM, Cooper GR, Baker KM. Detection of angiotensin I and II in cultured rat cardiac myocytes and fibroblasts. The American journal of physiology 1992; 263(4 Pt 1):C851-863.

81. Cingolani HE, Perez NG, Camilion de Hurtado MC. An autocrine/paracrine mechanism triggered by myocardial stretch induces changes in contractility. News Physiol Sci 2001; 16:88-91.

82. Peach MJ. Renin-angiotensin system: biochemistry and mechanisms of action. Physiological reviews 1977; 57(2):313-370.

83. Dudley DT, Panek RL, Major TC, Lu GH, Bruns RF, Klinkefus BA, Hodges JC, Weishaar RE. Subclasses of angiotensin II binding sites and their functional significance. Molecular pharmacology 1990; 38(3):370-377.

84. Whitebread S, Mele M, Kamber B, de Gasparo M. Preliminary biochemical characterization of two angiotensin II receptor subtypes. Biochemical and biophysical research communications 1989; 163(1):284-291.

85. Ishihata A, Endoh M. Species-related differences in inotropic effects of angiotensin II in mammalian ventricular muscle: receptors, subtypes and phosphoinositide hydrolysis. British journal of pharmacology 1995; 114(2):447-453.

86. de Gasparo M, Catt KJ, Inagami T, Wright JW, Unger T. International union of pharmacology. XXIII. The angiotensin II receptors. Pharmacological reviews 2000; 52(3):415-472.

87. Masaki H, Kurihara T, Yamaki A, Inomata N, Nozawa $Y$, Mori $Y$, Murasawa S, Kizima K, Maruyama K, Horiuchi M, Dzau VJ, Takahashi H, Iwasaka T, Inada M, Matsubara $\mathrm{H}$. Cardiac-specific overexpression of angiotensin II AT2 receptor causes attenuated response to AT1 receptor-mediated pressor and chronotropic effects. The Journal of clinical investigation 1998; 101(3):527-535.

88. Schmermund A, Lerman LO, Ritman EL, Rumberger JA. Cardiac production of angiotensin II and its pharmacologic inhibition: effects on the coronary circulation. Mayo Clinic proceedings 1999; 74(5):503-513.

89. Matsubara $\mathrm{H}$, Mori $\mathrm{Y}$, Masaki $\mathrm{H}$, Inada $\mathrm{M}$. [Pathophysiological function of angiotensin II AT1 and AT2 receptors and clinical application of AT1 antagonists]. Nippon rinsho 1998; 56(7):1912-1918. 
90. Berridge MJ. Inositol trisphosphate and calcium signalling. Nature 1993; 361(6410):315-325.

91. Laporte S, Denault JB, D'Orleans-Juste P, Leduc R. Presence of furin mRNA in cultured bovine endothelial cells and possible involvement of furin in the processing of the endothelin precursor. Journal of cardiovascular pharmacology 1993; 22 Suppl 8:S710.

92. Yanagisawa M, Inoue A, Takuwa $Y$, Mitsui $Y$, Kobayashi M, Masaki T. The human preproendothelin-1 gene: possible regulation by endothelial phosphoinositide turnover signaling. Journal of cardiovascular pharmacology 1989; 13 Suppl 5:S13-17; discussion S18.

93. Davenport AP, Maguire JJ. Is endothelin-induced vasoconstriction mediated only by ETA receptors in humans? Trends in pharmacological sciences 1994; 15(1):9-11.

94. Levin ER. Endothelins as cardiovascular peptides. American journal of nephrology 1996; 16(3):246-251.

95. Shinmi O, Kimura S, Sawamura T, Sugita $Y$, Yoshizawa T, Uchiyama $Y$, Yanagisawa M, Goto K, Masaki T, Kanazawa I. Endothelin-3 is a novel neuropeptide: isolation and sequence determination of endothelin-1 and endothelin-3 in porcine brain. Biochemical and biophysical research communications 1989; 164(1):587-593.

96. Endoh M, Fujita S, Yang HT, Talukder MA, Maruya J, Norota I. Endothelin: receptor subtypes, signal transduction, regulation of $\mathrm{Ca} 2+$ transients and contractility in rabbit ventricular myocardium. Life sciences 1998; 62(17-18):1485-1489.

97. Talukder MA, Norota I, Sakurai K, Endoh M. Inotropic response of rabbit ventricular myocytes to endothelin-1: difference from isolated papillary muscles. American journal of physiology 2001; 281(2):H596-605.

98. Ennis IL, Garciarena CD, Perez NG, Dulce RA, Camilion de Hurtado MC, Cingolani HE. Endothelin isoforms and the response to myocardial stretch. American journal of physiology 2005; 288(6):H2925-2930.

99. Gu XH, Ou RC, Casley DJ, Daly MJ, Nayler WG. Effect of age on endothelin-1 binding sites in rat cardiac ventricular membranes. Journal of cardiovascular pharmacology 1992; 19(5):764-769.

100. De Giusti VC, Correa MV, Villa-Abrille MC, Beltrano C, Yeves AM, de Cingolani GE, Cingolani HE, Aiello EA. The positive inotropic effect of endothelin-1 is mediated by mitochondrial reactive oxygen species. Life sciences 2008; 83(7-8):264-271. 
101. Rajagopalan S, Laursen JB, Borthayre A, Kurz S, Keiser J, Haleen S, Giaid A, Harrison DG. Role for endothelin-1 in angiotensin II-mediated hypertension. Hypertension 1997; 30(1 Pt 1):29-34.

102. Chua BH, Chua CC, Diglio CA, Siu BB. Regulation of endothelin-1 mRNA by angiotensin II in rat heart endothelial cells. Biochimica et biophysica acta 1993; 1178(2):201-206.

103. Petroff MG, Aiello EA, Palomeque J, Salas MA, Mattiazzi A. Subcellular mechanisms of the positive inotropic effect of angiotensin II in cat myocardium. The Journal of physiology 2000; 529 Pt 1:189-203.

104. Aiello EA, Cingolani HE. Angiotensin II stimulates cardiac L-type Ca(2+) current by a $\mathrm{Ca}(2+)$ - and protein kinase $\mathrm{C}$-dependent mechanism. American journal of physiology 2001; 280(4):H1528-1536.

105. Ito $H$, Hirata $Y$, Adachi S, Tanaka M, Tsujino M, Koike A, Nogami A, Murumo F, Hiroe M. Endothelin-1 is an autocrine/paracrine factor in the mechanism of angiotensin II-induced hypertrophy in cultured rat cardiomyocytes. The Journal of clinical investigation 1993; 92(1):398-403.

106. Duquesnes N, Vincent F, Morel E, Lezoualc'h F, Crozatier B. The EGF receptor activates ERK but not JNK Ras-dependently in basal conditions but ERK and JNK activation pathways are predominantly Ras-independent during cardiomyocyte stretch. The international journal of biochemistry \& cell biology 2009; 41(5):1173-1181.

107. Anderson HD, Wang F, Gardner DG. Role of the epidermal growth factor receptor in signaling strain-dependent activation of the brain natriuretic peptide gene. The Journal of biological chemistry 2004; 279(10):9287-9297.

108. Zhai P, Galeotti J, Liu J, Holle E, Yu X, Wagner T, Sadoshima J. An angiotensin II type 1 receptor mutant lacking epidermal growth factor receptor transactivation does not induce angiotensin II-mediated cardiac hypertrophy. Circulation research 2006; 99(5):528-536.

109. Wetzker R, Bohmer FD. Transactivation joins multiple tracks to the ERK/MAPK cascade. Nature reviews 2003; 4(8):651-657.

110. Caldiz Cl, Garciarena CD, Dulce RA, Novaretto LP, Yeves AM, Ennis IL, Cingolani HE, Chiappe de Cingolani G, Perez NG. Mitochondrial reactive oxygen species activate the slow force response to stretch in feline myocardium. The Journal of physiology 2007; 584(Pt 3):895-905. 
111. Zorov DB, Filburn CR, Klotz LO, Zweier JL, Sollott SJ. Reactive oxygen species (ROS)-induced ROS release: a new phenomenon accompanying induction of the mitochondrial permeability transition in cardiac myocytes. J Exp Med 2000; 192(7):1001-1014.

112. Kimura S, Zhang GX, Nishiyama A, Shokoji T, Yao L, Fan YY, Rahman M, Abe $Y$. Mitochondria-derived reactive oxygen species and vascular MAP kinases: comparison of angiotensin II and diazoxide. Hypertension 2005; 45(3):438-444.

113. Sand C, Peters SL, Pfaffendorf $M$, van Zwieten PA. The influence of endogenously generated reactive oxygen species on the inotropic and chronotropic effects of adrenoceptor and ET-receptor stimulation. Naunyn-Schmiedeberg's archives of pharmacology 2003; 367(6):635-639.

114. Hong HJ, Chan P, Liu JC, Juan SH, Huang MT, Lin JG, Cheng TH. Angiotensin II induces endothelin-1 gene expression via extracellular signal-regulated kinase pathway in rat aortic smooth muscle cells. Cardiovascular research 2004; 61(1):159-168.

115. Ortiz MC, Sanabria E, Manriquez MC, Romero JC, Juncos LA. Role of endothelin and isoprostanes in slow pressor responses to angiotensin II. Hypertension 2001; 37(2 Part 2):505-510.

116. Ortiz MC, Manriquez MC, Romero JC, Juncos LA. Antioxidants block angiotensin II-induced increases in blood pressure and endothelin. Hypertension 2001; 38(3 Pt 2):655-659.

117. Villa-Abrille MC, Cingolani HE, Garciarena CD, Ennis IL, Aiello EA. [Angiotensin II-induced endothelin-1 release in cardiac myocytes]. Medicina 2006; 66(3):229-236.

118. Wang Y. Signal transduction in cardiac hypertrophy--dissecting compensatory versus pathological pathways utilizing a transgenic approach. Current opinion in pharmacology 2001; 1(2):134-140.

119. Rothstein EC, Byron KL, Reed RE, Fliegel L, Lucchesi PA. $\mathrm{H}(2) \mathrm{O}(2)$-induced $\mathrm{Ca}(2+)$ overload in NRVM involves ERK1/2 MAP kinases: role for an NHE-1-dependent pathway. American journal of physiology 2002; 283(2):H598-605.

120. Paris S, Pouyssegur J. Biochemical characterization of the amiloride-sensitive $\mathrm{Na}+/ \mathrm{H}+$ antiport in Chinese hamster lung fibroblasts. The Journal of biological chemistry 1983; 258(6):3503-3508.

121. Fliegel $L$, Sardet $C$, Pouyssegur J, Barr A. Identification of the protein and cDNA of the cardiac $\mathrm{Na}+/ \mathrm{H}+$ exchanger. FEBS letters 1991; 279(1):25-29. 
122. Orlowski J, Grinstein S. Diversity of the mammalian sodium/proton exchanger SLC9 gene family. Pflugers Arch 2004; 447(5):549-565.

123. Karmazyn $M$, Sawyer $M$, Fliegel $L$. The $\mathrm{Na}(+) / \mathrm{H}(+)$ exchanger: a target for cardiac therapeutic intervention. Current drug targets 2005; 5(4):323-335.

124. Malakooti J, Dahdal RY, Schmidt L, Layden TJ, Dudeja PK, Ramaswamy K. Molecular cloning, tissue distribution, and functional expression of the human $\mathrm{Na}(+) / H(+)$ exchanger NHE2. The American journal of physiology 1999; $277(2 \mathrm{Pt}$ 1):G383-390.

125. Amemiya M, Loffing J, Lotscher M, Kaissling B, Alpern RJ, Moe OW. Expression of NHE-3 in the apical membrane of rat renal proximal tubule and thick ascending limb. Kidney international 1995; 48(4):1206-1215.

126. Pizzonia JH, Biemesderfer $D$, Abu-Alfa AK, Wu MS, Exner M, Isenring $P$, Igarashi $\mathrm{P}$, Aronson PS. Immunochemical characterization of $\mathrm{Na}+/ \mathrm{H}+$ exchanger isoform NHE4. The American journal of physiology 1998; 275(4 Pt 2):F510-517.

127. Malo ME, Fliegel L. Physiological role and regulation of the $\mathrm{Na}+/ \mathrm{H}+$ exchanger. Canadian journal of physiology and pharmacology 2006; 84(11):1081-1095.

128. Nakamura N, Tanaka S, Teko $\mathrm{Y}$, Mitsui $\mathrm{K}$, Kanazawa $\mathrm{H}$. Four $\mathrm{Na}+/ \mathrm{H}+$ exchanger isoforms are distributed to Golgi and post-Golgi compartments and are involved in organelle pH regulation. The Journal of biological chemistry 2005; 280(2):1561-1572.

129. Aharonovitz O, Zaun HC, Balla T, York JD, Orlowski J, Grinstein S. Intracellular $\mathrm{pH}$ regulation by $\mathrm{Na}(+) / \mathrm{H}(+)$ exchange requires phosphatidylinositol 4,5-bisphosphate. The Journal of cell biology 2000; 150(1):213-224.

130. Putney LK, Denker SP, Barber DL. The changing face of the $\mathrm{Na}+/ \mathrm{H}+$ exchanger, NHE1: structure, regulation, and cellular actions. Annual review of pharmacology and toxicology 2002; 42:527-552.

131. Denker SP, Barber DL. Cell migration requires both ion translocation and cytoskeletal anchoring by the Na-H exchanger NHE1. The Journal of cell biology 2002; 159(6):1087-1096.

132. Pang $\mathrm{T}$, Su X, Wakabayashi S, Shigekawa M. Calcineurin homologous protein as an essential cofactor for $\mathrm{Na}+/ \mathrm{H}+$ exchangers. The Journal of biological chemistry 2001; 276(20):17367-17372.

133. Pang $T$, Wakabayashi S, Shigekawa M. Expression of calcineurin B homologous protein 2 protects serum deprivation-induced cell death by serum-independent 
activation of $\mathrm{Na}+/ \mathrm{H}+$ exchanger. The Journal of biological chemistry 2002; 277(46):43771-43777.

134. Li X, Liu Y, Kay CM, Muller-Esterl W, Fliegel L. The $\mathrm{Na}+\mathrm{H}+$ exchanger cytoplasmic tail: structure, function, and interactions with tescalcin. Biochemistry 2003; 42(24):7448-7456.

135. Bertrand B, Wakabayashi S, Ikeda T, Pouyssegur J, Shigekawa M. The $\mathrm{Na}+/ \mathrm{H}+$ exchanger isoform 1 (NHE1) is a novel member of the calmodulin-binding proteins. Identification and characterization of calmodulin-binding sites. The Journal of biological chemistry 1994; 269(18):13703-13709.

136. Wakabayashi S, Bertrand B, Ikeda T, Pouyssegur J, Shigekawa M. Mutation of calmodulin-binding site renders the $\mathrm{Na}+/ \mathrm{H}+$ exchanger ( $\mathrm{NHE} 1$ ) highly $\mathrm{H}(+)$-sensitive and Ca2+ regulation-defective. The Journal of biological chemistry 1994; 269(18):13710-13715.

137. Sardet C, Counillon L, Franchi A, Pouyssegur J. Growth factors induce phosphorylation of the $\mathrm{Na}+/ \mathrm{H}+$ antiporter, glycoprotein of $110 \mathrm{kD}$. Science (New York, NY1990; 247(4943):723-726.

138. Sardet C, Fafournoux $\mathrm{P}$, Pouyssegur J. Alpha-thrombin, epidermal growth factor, and okadaic acid activate the $\mathrm{Na}+/ \mathrm{H}+$ exchanger, $\mathrm{NHE}-1$, by phosphorylating a set of common sites. The Journal of biological chemistry 1991; 266(29):19166-19171.

139. Haworth RS, McCann C, Snabaitis AK, Roberts NA, Avkiran M. Stimulation of the plasma membrane $\mathrm{Na}+/ \mathrm{H}+$ exchanger $\mathrm{NHE} 1$ by sustained intracellular acidosis. Evidence for a novel mechanism mediated by the ERK pathway. The Journal of biological chemistry 2003; 278(34):31676-31684.

140. Wang $H$, Silva NL, Lucchesi PA, Haworth R, Wang K, Michalak M, Pelech S, Fliegel L. Phosphorylation and regulation of the $\mathrm{Na}+/ \mathrm{H}+$ exchanger through mitogenactivated protein kinase. Biochemistry 1997; 36(30):9151-9158.

141. Haworth RS, Sinnett-Smith J, Rozengurt E, Avkiran M. Protein kinase D inhibits plasma membrane $\mathrm{Na}(+) / \mathrm{H}(+)$ exchanger activity. The American journal of physiology 1999; 277(6 Pt 1):C1202-1209.

142. Kennelly PJ, Krebs EG. Consensus sequences as substrate specificity determinants for protein kinases and protein phosphatases. The Journal of biological chemistry 1991; 266(24):15555-15558.

143. Blom N, Sicheritz-Ponten T, Gupta R, Gammeltoft S, Brunak S. Prediction of 
post-translational glycosylation and phosphorylation of proteins from the amino acid sequence. Proteomics 2004; 4(6):1633-1649.

144. Hayashi D, Kudoh S, Shiojima I, Zou Y, Harada K, Shimoyama M, Imai $Y$, Monzen K, Yamazaki T, Yazaki Y, Nagai R, Komuro I. Atrial natriuretic peptide inhibits cardiomyocyte hypertrophy through mitogen-activated protein kinase phosphatase-1. Biochemical and biophysical research communications 2004; 322(1):310-319.

145. Yeves AM, Garciarena CD, Nolly MB, Chiappe de Cingolani GE, Cingolani HE, Ennis IL. Decreased activity of the $\mathrm{Na}+/ \mathrm{H}+$ exchanger by phosphodiesterase $5 \mathrm{~A}$ inhibition is attributed to an increase in protein phosphatase activity. Hypertension; 56(4):690-695.

146. Li X, Alvarez B, Casey JR, Reithmeier RA, Fliegel L. Carbonic anhydrase II binds to and enhances activity of the $\mathrm{Na}+/ \mathrm{H}+$ exchanger. The Journal of biological chemistry 2002; 277(39):36085-36091.

147. Karmazyn M, Gan XT, Humphreys RA, Yoshida H, Kusumoto K. The myocardial $\mathrm{Na}(+)-\mathrm{H}(+)$ exchange: structure, regulation, and its role in heart disease. Circulation research 1999; 85(9):777-786.

148. Masereel B, Pochet L, Laeckmann D. An overview of inhibitors of $\mathrm{Na}(+) / \mathrm{H}(+)$ exchanger. European journal of medicinal chemistry 2003; 38(6):547-554.

149. Theroux P, Chaitman BR, Danchin N, Erhardt L, Meinertz T, Schroeder JS, Tognoni G, White HD, Willerson JT, Jessel A. Inhibition of the sodium-hydrogen exchanger with cariporide to prevent myocardial infarction in high-risk ischemic situations. Main results of the GUARDIAN trial. Guard during ischemia against necrosis (GUARDIAN) Investigators. Circulation 2000; 102(25):3032-3038.

150. Zeymer U, Suryapranata H, Monassier JP, Opolski G, Davies J, Rasmanis G, Linssen G, Tebbe U, Schroder R, Tiemann R, Machnig T, Neuhaus KL. The $\mathrm{Na}(+) / H(+)$ exchange inhibitor eniporide as an adjunct to early reperfusion therapy for acute myocardial infarction. Results of the evaluation of the safety and cardioprotective effects of eniporide in acute myocardial infarction (ESCAMI) trial. Journal of the American College of Cardiology 2001; 38(6):1644-1650.

151. Li Z, Matsuoka S, Hryshko LV, Nicoll DA, Bersohn MM, Burke EP, Lifton RP, Philipson KD. Cloning of the NCX2 isoform of the plasma membrane $\mathrm{Na}(+)-\mathrm{Ca} 2+$ exchanger. The Journal of biological chemistry 1994; 269(26):17434-17439.

152. Nicoll DA, Longoni S, Philipson KD. Molecular cloning and functional expression 
of the cardiac sarcolemmal $\mathrm{Na}(+)-\mathrm{Ca} 2+$ exchanger. Science (New York, NY 1990; 250(4980):562-565.

153. Linck B, Qiu Z, He Z, Tong Q, Hilgemann DW, Philipson KD. Functional comparison of the three isoforms of the $\mathrm{Na}+/ \mathrm{Ca} 2+$ exchanger (NCX1, NCX2, NCX3). The American journal of physiology 1998; 274(2 Pt 1):C415-423.

154. Nicoll DA, Quednau BD, Qui Z, Xia YR, Lusis AJ, Philipson KD. Cloning of a third mammalian Na+-Ca2+ exchanger, NCX3. The Journal of biological chemistry 1996; 271(40):24914-24921.

155. Komuro I, Wenninger KE, Philipson KD, Izumo S. Molecular cloning and characterization of the human cardiac $\mathrm{Na}+/ \mathrm{Ca} 2+$ exchanger cDNA. Proceedings of the National Academy of Sciences of the United States of America 1992; 89(10):4769-4773. 156. Koushik SV, Bundy J, Conway SJ. Sodium-calcium exchanger is initially expressed in a heart-restricted pattern within the early mouse embryo. Mechanisms of development 1999; 88(1):119-122.

157. Boerth SR, Zimmer DB, Artman M. Steady-state mRNA levels of the sarcolemmal $\mathrm{Na}(+)-\mathrm{Ca} 2+$ exchanger peak near birth in developing rabbit and rat hearts. Circulation research 1994; 74(2):354-359.

158. Koban MU, Moorman AF, Holtz J, Yacoub MH, Boheler KR. Expressional analysis of the cardiac $\mathrm{Na}-\mathrm{Ca}$ exchanger in rat development and senescence. Cardiovascular research 1998; 37(2):405-423.

159. Cook $\mathrm{O}$, Low $\mathrm{W}$, Rahamimoff $\mathrm{H}$. Membrane topology of the rat brain $\mathrm{Na}+-\mathrm{Ca} 2+$ exchanger. Biochimica et biophysica acta 1998; 1371(1):40-52.

160. Matsuoka S, Nicoll DA, Reilly RF, Hilgemann DW, Philipson KD. Initial localization of regulatory regions of the cardiac sarcolemmal $\mathrm{Na}(+)-\mathrm{Ca} 2+$ exchanger. Proceedings of the National Academy of Sciences of the United States of America 1993; 90(9):3870-3874.

161. Satoh H, Ginsburg KS, Qing K, Terada H, Hayashi H, Bers DM. KB-R7943 block of $\mathrm{Ca}(2+)$ influx via $\mathrm{Na}(+) / \mathrm{Ca}(2+)$ exchange does not alter twitches or glycoside inotropy but prevents $\mathrm{Ca}(2+)$ overload in rat ventricular myocytes. Circulation 2000; 101(12):1441-1446.

162. Studer R, Reinecke H, Vetter R, Holtz J, Drexler H. Expression and function of the cardiac $\mathrm{Na}+/ \mathrm{Ca} 2+$ exchanger in postnatal development of the rat, in experimentalinduced cardiac hypertrophy and in the failing human heart. Basic research in 
cardiology 1997; 92 Suppl 1:53-58.

163. Mattiello JA, Margulies KB, Jeevanandam V, Houser SR. Contribution of reversemode sodium-calcium exchange to contractions in failing human left ventricular myocytes. Cardiovascular research 1998; 37(2):424-431.

164. Lu Z, Abe J, Taunton J, Lu Y, Shishido T, McClain C, Yan C, Xu SP, Spangenberg TM, $\mathrm{Xu} \mathrm{H}$. Reactive oxygen species-induced activation of $p 90$ ribosomal S6 kinase prolongs cardiac repolarization through inhibiting outward $\mathrm{K}+$ channel activity. Circulation research 2008; 103(3):269-278.

165. Kusuoka H, Camilion de Hurtado MC, Marban E. Role of sodium/calcium exchange in the mechanism of myocardial stunning: protective effect of reperfusion with high sodium solution. Journal of the American College of Cardiology 1993; 21(1):240248.

166. Eigel BN, Gursahani H, Hadley RW. ROS are required for rapid reactivation of $\mathrm{Na}+/ \mathrm{Ca} 2+$ exchanger in hypoxic reoxygenated guinea pig ventricular myocytes. American journal of physiology 2004; 286(3):H955-963.

167. Iwamoto T, Pan Y, Wakabayashi S, Imagawa T, Yamanaka HI, Shigekawa M. Phosphorylation-dependent regulation of cardiac $\mathrm{Na}+/ \mathrm{Ca} 2+$ exchanger via protein kinase C. The Journal of biological chemistry 1996; 271(23):13609-13615.

168. Sei CA, Irons CE, Sprenkle AB, McDonough PM, Brown JH, Glembotski CC. The alpha-adrenergic stimulation of atrial natriuretic factor expression in cardiac myocytes requires calcium influx, protein kinase $\mathrm{C}$, and calmodulin-regulated pathways. The Journal of biological chemistry 1991; 266(24):15910-15916.

169. Sonnenberg $\mathrm{H}$. Mechanisms of release and renal tubular action of atrial natriuretic factor. Federation proceedings 1986; 45(7):2106-2110.

170. LaPointe MC, Deschepper CF, Wu JP, Gardner DG. Extracellular calcium regulates expression of the gene for atrial natriuretic factor. Hypertension 1990; 15(1):20-28.

171. Chin D, Means AR. Calmodulin: a prototypical calcium sensor. Trends in cell biology 2000; 10(8):322-328.

172. Dolmetsch RE, Lewis RS, Goodnow CC, Healy JI. Differential activation of transcription factors induced by $\mathrm{Ca} 2+$ response amplitude and duration. Nature 1997; 386(6627):855-858.

173. Timmerman LA, Clipstone NA, Ho SN, Northrop JP, Crabtree GR. Rapid shuttling 
of NF-AT in discrimination of Ca2+ signals and immunosuppression. Nature 1996; 383(6603):837-840.

174. Braun AP, Schulman $\mathrm{H}$. The multifunctional calcium/calmodulin-dependent protein kinase: from form to function. Annual review of physiology 1995; 57:417-445.

175. Frey N, McKinsey TA, Olson EN. Decoding calcium signals involved in cardiac growth and function. Nature medicine 2000; 6(11):1221-1227.

176. Couchonnal LF, Anderson ME. The role of calmodulin kinase II in myocardial physiology and disease. Physiology (Bethesda, Md 2008; 23:151-159.

177. Sweeney HL, Bowman BF, Stull JT. Myosin light chain phosphorylation in vertebrate striated muscle: regulation and function. The American journal of physiology 1993; 264(5 Pt 1):C1085-1095.

178. Heineke J, Molkentin JD. Regulation of cardiac hypertrophy by intracellular signalling pathways. Nature reviews 2006; 7(8):589-600.

179. Rothermel BA, Vega RB, Williams RS. The role of modulatory calcineurininteracting proteins in calcineurin signaling. Trends in cardiovascular medicine 2003; 13(1):15-21.

180. Crabtree GR. Generic signals and specific outcomes: signaling through Ca2+, calcineurin, and NF-AT. Cell 1999; 96(5):611-614.

181. Klee $\mathrm{CB}$, Ren $\mathrm{H}$, Wang $\mathrm{X}$. Regulation of the calmodulin-stimulated protein phosphatase, calcineurin. The Journal of biological chemistry 1998; 273(22):1336713370.

182. McKinsey TA, Zhang CL, Lu J, Olson EN. Signal-dependent nuclear export of a histone deacetylase regulates muscle differentiation. Nature 2000; 408(6808):106-111. 183. Youn HD, Grozinger CM, Liu JO. Calcium regulates transcriptional repression of myocyte enhancer factor 2 by histone deacetylase 4 . The Journal of biological chemistry 2000; 275(29):22563-22567.

184. Blaeser F, Ho N, Prywes R, Chatila TA. Ca(2+)-dependent gene expression mediated by MEF2 transcription factors. The Journal of biological chemistry 2000; 275(1):197-209.

185. Molkentin JD, Lu JR, Antos CL, Markham B, Richardson J, Robbins J, Grant SR, Olson EN. A calcineurin-dependent transcriptional pathway for cardiac hypertrophy. Cell 1998; 93(2):215-228.

186. Hogan PG, Chen L, Nardone J, Rao A. Transcriptional regulation by calcium, 
calcineurin, and NFAT. Genes \& development 2003; 17(18):2205-2232.

187. Taigen T, De Windt LJ, Lim HW, Molkentin JD. Targeted inhibition of calcineurin prevents agonist-induced cardiomyocyte hypertrophy. Proceedings of the National Academy of Sciences of the United States of America 2000; 97(3):1196-1201.

188. Alvarez BV, Ennis IL, De Hurtado MC, Cingolani HE. Effects of antihypertensive therapy on cardiac sodium/hydrogen ion exchanger activity and hypertrophy in spontaneously hypertensive rats. Can J Cardio/2002; 18(6):667-672.

189. Camilion de Hurtado MC, Portiansky EL, Perez NG, Rebolledo OR, Cingolani HE. Regression of cardiomyocyte hypertrophy in SHR following chronic inhibition of the $\mathrm{Na}(+) / \mathrm{H}(+)$ exchanger. Cardiovascular research 2002; 53(4):862-868.

190. Cingolani HE, Rebolledo OR, Portiansky EL, Perez NG, Camilion de Hurtado MC. Regression of hypertensive myocardial fibrosis by $\mathrm{Na}(+) / \mathrm{H}(+)$ exchange inhibition. Hypertension 2003; 41(2):373-377.

191. Karmazyn M, Sostaric JV, Gan XT. The myocardial $\mathrm{Na}+/ \mathrm{H}+$ exchanger: a potential therapeutic target for the prevention of myocardial ischaemic and reperfusion injury and attenuation of postinfarction heart failure. Drugs 2001; 61(3):375-389.

192. Mentzer RM, Jr., Bartels C, Bolli R, Boyce S, Buckberg GD, Chaitman B, Haverich A, Knight J, Menasche P, Myers ML, Nicolau J, Simoons M, Thulin L, Weisel $\mathrm{RD}$. Sodium-hydrogen exchange inhibition by cariporide to reduce the risk of ischemic cardiac events in patients undergoing coronary artery bypass grafting: results of the EXPEDITION study. The Annals of thoracic surgery 2008; 85(4):1261-1270.

193. Konhilas JP, Watson PA, Maass A, Boucek DM, Horn T, Stauffer BL, Luckey SW, Rosenberg $P$, Leinwand LA. Exercise can prevent and reverse the severity of hypertrophic cardiomyopathy. Circulation research 2006; 98(4):540-548.

194. Sharma S, Firoozi S, McKenna WJ. Value of exercise testing in assessing clinical state and prognosis in hypertrophic cardiomyopathy. Cardiology in review 2001; 9(2):70-76.

195. Firoozi S, Sharma S, McKenna WJ. The role of exercise testing in the evaluation of the patient with hypertrophic cardiomyopathy. Current cardiology reports 2001; 3(2):152-159.

196. Guyatt GH, Devereaux PJ. A review of heart failure treatment. The Mount Sinai journal of medicine, New York 2004; 71(1):47-54.

197. Wisloff U, Stoylen A, Loennechen JP, Bruvold M, Rognmo O, Haram PM, Tjonna 
AE, Helgerud J, Slordahl SA, Lee SJ, Videm V, Bye A, Smith GL, Najjar SM, Ellingsen O, Skjaerpe T. Superior cardiovascular effect of aerobic interval training versus moderate continuous training in heart failure patients: a randomized study. Circulation 2007; 115(24):3086-3094.

198. Kemi OJ, Ellingsen O, Smith GL, Wisloff U. Exercise-induced changes in calcium handling in left ventricular cardiomyocytes. Front Biosci2008; 13:356-368.

199. Hambrecht R, Gielen S, Linke A, Fiehn E, Yu J, Walther C, Schoene N, Schuler G. Effects of exercise training on left ventricular function and peripheral resistance in patients with chronic heart failure: A randomized trial. Jama 2000; 283(23):3095-3101. 200. Davies EJ, Moxham T, Rees K, Singh S, Coats AJ, Ebrahim S, Lough F, Taylor RS. Exercise training for systolic heart failure: Cochrane systematic review and metaanalysis. European journal of heart failure; 12(7):706-715.

201. Owen KL, Pretorius L, McMullen JR. The protective effects of exercise and phosphoinositide 3-kinase (p110alpha) in the failing heart. Clin Sci (Lond) 2009; 116(5):365-375.

202. Smart N. Exercise Training for Heart Failure Patients with and without Systolic Dysfunction: An Evidence-Based Analysis of How Patients Benefit. Cardiology research and practice; 2011.

203. Okamoto K, Aoki K. Development of a strain of spontaneously hypertensive rats. Japanese circulation journal 1963; 27:282-293.

204. Pfeffer JM, Pfeffer MA, Fishbein MC, Frohlich ED. Cardiac function and morphology with aging in the spontaneously hypertensive rat. The American journal of physiology 1979; 237(4):H461-468.

205. Medeiros A GR, Kalil LMP, Bacurau RFP, Rosa LFBC, Negrao CE, Brum PC. Efeito do treinamento fisico de natacao sobre o sistema cardiovascular de ratos normotensos. Revista Paulista de Educacao Fisica 2000; 14:7-15.

206. Sahn DJ, DeMaria A, Kisslo J, Weyman A. Recommendations regarding quantitation in M-mode echocardiography: results of a survey of echocardiographic measurements. Circulation 1978; 58(6):1072-1083.

207. Lang RM, Bierig M, Devereux RB, Flachskampf FA, Foster E, Pellikka PA, Picard MH, Roman MJ, Seward J, Shanewise JS, Solomon SD, Spencer KT, Sutton MS, Stewart WJ. Recommendations for chamber quantification: a report from the American Society of Echocardiography's Guidelines and Standards Committee and the Chamber 
Quantification Writing Group, developed in conjunction with the European Association of Echocardiography, a branch of the European Society of Cardiology. J Am Soc Echocardiogr 2005; 18(12):1440-1463.

208. Escudero EM, Camilion de Hurtado MC, Perez NG, Tufare AL. Echocardiographic assessment of left ventricular midwall mechanics in spontaneously hypertensive rats. Eur J Echocardiogr 2004; 5(3):169-175.

209. Pascual M, Pascual DA, Soria F, Vicente T, Hernandez AM, Tebar FJ, Valdes M. Effects of isolated obesity on systolic and diastolic left ventricular function. Heart (British Cardiac Society) 2003; 89(10):1152-1156.

210. Quinones MA, Mokotoff DM, Nouri S, Winters WL, Jr., Miller RR. Noninvasive quantification of left ventricular wall stress. Validation of method and application to assessment of chronic pressure overload. The American journal of cardiology 1980; 45(4):782-790.

211. Xu J, Nagata K, Obata K, Ichihara S, Izawa H, Noda A, Nagasaka T, Iwase M, Naoe T, Murohara T, Yokota M. Nicorandil promotes myocardial capillary and arteriolar growth in the failing heart of Dahl salt-sensitive hypertensive rats. Hypertension 2005; 46(4):719-724.

212. Bustin SA. Absolute quantification of mRNA using real-time reverse transcription polymerase chain reaction assays. Journal of molecular endocrinology 2000; 25(2):169193.

213. Pfaffl MW. A new mathematical model for relative quantification in real-time RTPCR. Nucleic acids research 2001; 29(9):e45.

214. Haq S, Choukroun G, Lim H, Tymitz KM, del Monte F, Gwathmey J, Grazette L, Michael A, Hajjar R, Force T, Molkentin JD. Differential activation of signal transduction pathways in human hearts with hypertrophy versus advanced heart failure. Circulation 2001; 103(5):670-677.

215. Zannad F, Briancon S, Juilliere $Y$, Mertes PM, Villemot JP, Alla F, Virion JM. Incidence, clinical and etiologic features, and outcomes of advanced chronic heart failure: the EPICAL Study. Epidemiologie de I'Insuffisance Cardiaque Avancee en Lorraine. Journal of the American College of Cardiology 1999; 33(3):734-742.

216. Cowie MR, Wood DA, Coats AJ, Thompson SG, Suresh V, Poole-Wilson PA, Sutton GC. Survival of patients with a new diagnosis of heart failure: a population based study. Heart (British Cardiac Society) 2000; 83(5):505-510. 
217. Bleumink GS, Knetsch AM, Sturkenboom MC, Straus SM, Hofman A, Deckers JW, Witteman JC, Stricker BH. Quantifying the heart failure epidemic: prevalence, incidence rate, lifetime risk and prognosis of heart failure The Rotterdam Study. European heart journal2004; 25(18):1614-1619.

218. Stewart S, MacIntyre K, Capewell S, McMurray JJ. Heart failure and the aging population: an increasing burden in the 21 st century? Heart (British Cardiac Society) 2003; 89(1):49-53.

219. Kostis JB, Davis BR, Cutler J, Grimm RH, Jr., Berge KG, Cohen JD, Lacy CR, Perry HM, Jr., Blaufox MD, Wassertheil-Smoller S, Black HR, Schron E, Berkson DM, Curb JD, Smith WM, McDonald R, Applegate WB. Prevention of heart failure by antihypertensive drug treatment in older persons with isolated systolic hypertension. SHEP Cooperative Research Group. Jama 1997; 278(3):212-216.

220. Powell KE, Thompson PD, Caspersen CJ, Kendrick JS. Physical activity and the incidence of coronary heart disease. Annual review of public health 1987; 8:253-287.

221. Berlin JA, Colditz GA. A meta-analysis of physical activity in the prevention of coronary heart disease. American journal of epidemiology 1990; 132(4):612-628.

222. Haskell WL, Lee IM, Pate RR, Powell KE, Blair SN, Franklin BA, Macera CA, Heath GW, Thompson PD, Bauman A. Physical activity and public health: updated recommendation for adults from the American College of Sports Medicine and the American Heart Association. Circulation 2007; 116(9):1081-1093.

223. Schocken DD, Benjamin EJ, Fonarow GC, Krumholz HM, Levy D, Mensah GA, Narula J, Shor ES, Young JB, Hong Y. Prevention of heart failure: a scientific statement from the American Heart Association Councils on Epidemiology and Prevention, Clinical Cardiology, Cardiovascular Nursing, and High Blood Pressure Research; Quality of Care and Outcomes Research Interdisciplinary Working Group; and Functional Genomics and Translational Biology Interdisciplinary Working Group. Circulation 2008; 117(19):2544-2565.

224. Piepoli MF, Scott AC, Capucci A, Coats AJ. Skeletal muscle training in chronic heart failure. Acta physiologica Scandinavica 2001; 171(3):295-303.

225. Smart N, Marwick TH. Exercise training for patients with heart failure: a systematic review of factors that improve mortality and morbidity. The American journal of medicine 2004; 116(10):693-706.

226. Kavazis AN, McClung JM, Hood DA, Powers SK. Exercise induces a cardiac 
mitochondrial phenotype that resists apoptotic stimuli. American journal of physiology 2008; 294(2):H928-935.

227. Larsen Al, Lindal S, Aukrust $\mathrm{P}$, Toft I, Aarsland T, Dickstein K. Effect of exercise training on skeletal muscle fibre characteristics in men with chronic heart failure. Correlation between skeletal muscle alterations, cytokines and exercise capacity. International journal of cardiology 2002; 83(1):25-32.

228. Duscha BD, Schulze PC, Robbins JL, Forman DE. Implications of chronic heart failure on peripheral vasculature and skeletal muscle before and after exercise training. Heart failure reviews 2008; 13(1):21-37.

229. Dickhout JG, Lee RM. Blood pressure and heart rate development in young spontaneously hypertensive rats. The American journal of physiology 1998; 274(3 Pt 2):H794-800.

230. Devereux RB, Alonso DR, Lutas EM, Gottlieb GJ, Campo E, Sachs I, Reichek N. Echocardiographic assessment of left ventricular hypertrophy: comparison to necropsy findings. The American journal of cardiology 1986; 57(6):450-458.

231. Reichek N, Devereux RB. Left ventricular hypertrophy: relationship of anatomic, echocardiographic and electrocardiographic findings. Circulation 1981; 63(6):13911398.

232. de Simone G, Wallerson DC, Volpe M, Devereux RB. Echocardiographic measurement of left ventricular mass and volume in normotensive and hypertensive rats. Necropsy validation. American journal of hypertension 1990; 3(9):688-696.

233. Collins KA, Korcarz CE, Shroff SG, Bednarz JE, Fentzke RC, Lin H, Leiden JM, Lang RM. Accuracy of echocardiographic estimates of left ventricular mass in mice. American journal of physiology 2001; 280(5):H1954-1962.

234. Shimizu G, Hirota $Y$, Kita $Y$, Kawamura K, Saito T, Gaasch WH. Left ventricular midwall mechanics in systemic arterial hypertension. Myocardial function is depressed in pressure-overload hypertrophy. Circulation 1991; 83(5):1676-1684.

235. Shimizu G, Hirota $Y$, Kawamura K. Empiric determination of the transition from concentric hypertrophy to congestive heart failure in essential hypertension. Journal of the American College of Cardiology 1995; 25(4):888-894.

236. Ono K, Masuyama T, Yamamoto K, Doi R, Sakata Y, Nishikawa N, Mano T, Kuzuya $\mathrm{T}$, Takeda $\mathrm{H}$, Hori M. Echo doppler assessment of left ventricular function in rats with hypertensive hypertrophy. J Am Soc Echocardiogr 2002; 15(2):109-117. 
237. Devereux RB, Reichek N. Echocardiographic determination of left ventricular mass in man. Anatomic validation of the method. Circulation 1977; 55(4):613-618. 238. Escudero EM, Pinilla OA, Carranza VB. [Echocardiographic study of left ventricular geometry in spontaneously hypertensive rats]. Medicina 2009; 69(3):335340 .

239. Brilla CG, Rupp H. Myocardial collagen matrix remodeling and congestive heart failure. Cardiologia (Rome, Italy) 1994; 39(12 Suppl 1):389-393.

240. Weber KT, Brilla CG. Pathological hypertrophy and cardiac interstitium. Fibrosis and renin-angiotensin-aldosterone system. Circulation 1991; 83(6):1849-1865.

241. Brilla CG, Maisch B. Regulation of the structural remodelling of the myocardium: from hypertrophy to heart failure. European heart journal 1994; 15 Suppl D:45-52.

242. Brecher P. Angiotensin II and Cardiac Fibrosis. Trends in cardiovascular medicine 1996; 6(6):193-198.

243. Weber KT, Brilla CG, Janicki JS. Myocardial remodeling and pathologic hypertrophy. Hospital practice (Office ed 1991; 26(4):73-80.

244. Yamazaki T, Lee JD, Shimizu H, Uzui H, Ueda T. Circulating matrix metalloproteinase-2 is elevated in patients with congestive heart failure. European journal of heart failure 2004; 6(1):41-45.

245. Balakumar $\mathrm{P}$, Jagadeesh $\mathrm{G}$. Multifarious molecular signaling cascades of cardiac hypertrophy: can the muddy waters be cleared? Pharmacol Res; 62(5):365-383.

246. Schwartz JC, Gros C, Lecomte JM, Bralet J. Enkephalinase (EC 3.4.24.11) inhibitors: protection of endogenous ANF against inactivation and potential therapeutic applications. Life sciences 1990; 47(15):1279-1297.

247. Needleman P, Blaine EH, Greenwald JE, Michener ML, Saper CB, Stockmann PT, Tolunay HE. The biochemical pharmacology of atrial peptides. Annual review of pharmacology and toxicology 1989; 29:23-54.

248. Hernandez OM, Jones M, Guzman G, Szczesna-Cordary D. Myosin essential light chain in health and disease. American journal of physiology 2007; 292(4):H16431654.

249. Arner A, Pfitzer G. Regulation of cross-bridge cycling by Ca2+ in smooth muscle. Reviews of physiology, biochemistry and pharmacology 1999; 134:63-146.

250. Qi M, Shannon TR, Euler DE, Bers DM, Samarel AM. Downregulation of sarcoplasmic reticulum $\mathrm{Ca}(2+)$-ATPase during progression of left ventricular 
hypertrophy. The American journal of physiology 1997; 272(5 Pt 2):H2416-2424.

251. Delbridge LM, Satoh H, Yuan W, Bassani JW, Qi M, Ginsburg KS, Samarel AM, Bers DM. Cardiac myocyte volume, Ca2+ fluxes, and sarcoplasmic reticulum loading in pressure-overload hypertrophy. The American journal of physiology 1997; 272(5 Pt 2): $\mathrm{H} 2425-2435$.

252. Pogwizd SM, Qi M, Yuan W, Samarel AM, Bers DM. Upregulation of $\mathrm{Na}(+) / \mathrm{Ca}(2+)$ exchanger expression and function in an arrhythmogenic rabbit model of heart failure. Circulation research 1999; 85(11):1009-1019.

253. Hasenfuss G, Schillinger W, Lehnart SE, Preuss M, Pieske B, Maier LS, Prestle J, Minami K, Just H. Relationship between Na+-Ca2+-exchanger protein levels and diastolic function of failing human myocardium. Circulation 1999; 99(5):641-648.

254. Sipido KR, Volders PG, Vos MA, Verdonck F. Altered Na/Ca exchange activity in cardiac hypertrophy and heart failure: a new target for therapy? Cardiovascular research 2002; 53(4):782-805.

255. Medeiros A, Rolim NP, Oliveira RS, Rosa KT, Mattos KC, Casarini DE, Irigoyen MC, Krieger EM, Krieger JE, Negrao CE, Brum PC. Exercise training delays cardiac dysfunction and prevents calcium handling abnormalities in sympathetic hyperactivityinduced heart failure mice. J App/ Physiol 2008; 104(1):103-109.

256. Rolim NP, Medeiros A, Rosa KT, Mattos KC, Irigoyen MC, Krieger EM, Krieger JE, Negrao CE, Brum PC. Exercise training improves the net balance of cardiac Ca2+ handling protein expression in heart failure. Physio/ Genomics 2007; 29(3):246-252.

257. Nagata K, Somura F, Obata K, Odashima M, Izawa H, Ichihara S, Nagasaka T, Iwase M, Yamada Y, Nakashima N, Yokota M. AT1 receptor blockade reduces cardiac calcineurin activity in hypertensive rats. Hypertension 2002; 40(2):168-174.

258. Bueno OF, Wilkins BJ, Tymitz KM, Glascock BJ, Kimball TF, Lorenz JN, Molkentin JD. Impaired cardiac hypertrophic response in Calcineurin Abeta -deficient mice. Proceedings of the National Academy of Sciences of the United States of America 2002; 99(7):4586-4591.

259. Shiojima I, Yefremashvili M, Luo Z, Kureishi Y, Takahashi A, Tao J, Rosenzweig A, Kahn CR, Abel ED, Walsh K. Akt signaling mediates postnatal heart growth in response to insulin and nutritional status. The Journal of biological chemistry 2002; 277(40):37670-37677.

260. Matsui T, Li L, Wu JC, Cook SA, Nagoshi T, Picard MH, Liao R, Rosenzweig A. 
Phenotypic spectrum caused by transgenic overexpression of activated Akt in the heart. The Journal of biological chemistry 2002; 277(25):22896-22901.

261. Condorelli G, Drusco A, Stassi G, Bellacosa A, Roncarati R, laccarino G, Russo MA, Gu Y, Dalton N, Chung C, Latronico MV, Napoli C, Sadoshima J, Croce CM, Ross $\mathrm{J}$, Jr. Akt induces enhanced myocardial contractility and cell size in vivo in transgenic mice. Proceedings of the National Academy of Sciences of the United States of America 2002; 99(19):12333-12338.

262. O'Neill BT, Abel ED. Akt1 in the cardiovascular system: friend or foe? The Journal of clinical investigation 2005; 115(8):2059-2064.

263. Matsui T, Nagoshi T, Rosenzweig A. Akt and PI 3-kinase signaling in cardiomyocyte hypertrophy and survival. Cell Cycle 2003; 2(3):220-223.

264. Li Z, Bing OH, Long X, Robinson KG, Lakatta EG. Increased cardiomyocyte apoptosis during the transition to heart failure in the spontaneously hypertensive rat. The American journal of physiology 1997; 272(5 Pt 2):H2313-2319.

265. van Empel VP, Bertrand AT, Hofstra L, Crijns HJ, Doevendans PA, De Windt LJ. Myocyte apoptosis in heart failure. Cardiovascular research 2005; 67(1):21-29.

266. Shimizu M, Fukuo K, Nagata S, Suhara T, Okuro M, Fuji K, Higashino Y, Mogi $M$, Hatanaka $Y$, Ogihara T. Increased plasma levels of the soluble form of Fas ligand in patients with acute myocardial infarction and unstable angina pectoris. Journal of the American College of Cardiology 2002; 39(4):585-590.

267. Adams JM, Cory S. Apoptosomes: engines for caspase activation. Current opinion in cell biology 2002; 14(6):715-720.

268. Cory S, Adams JM. The Bcl2 family: regulators of the cellular life-or-death switch. Nat Rev Cancer 2002; 2(9):647-656.

269. van Gurp M, Festjens N, van Loo G, Saelens X, Vandenabeele P. Mitochondrial intermembrane proteins in cell death. Biochemical and biophysical research communications 2003; 304(3):487-497.

270. Zamzami N, Kroemer G. The mitochondrion in apoptosis: how Pandora's box opens. Nature reviews 2001; 2(1):67-71.

271. Zamzami N, Maisse C, Metivier D, Kroemer G. Measurement of membrane permeability and permeability transition of mitochondria. Methods in cell biology 2001; 65:147-158.

272. Baines CP, Molkentin JD. STRESS signaling pathways that modulate cardiac 
myocyte apoptosis. Journal of molecular and cellular cardiology 2005; 38(1):47-62.

273. Philipp S, Pagel I, Hohnel K, Lutz J, Buttgereit J, Langenickel T, Hamet P, Dietz $R$, Willenbrock R. Regulation of caspase 3 and Fas in pressure overload-induced left ventricular dysfunction. European journal of heart failure 2004; 6(7):845-851.

274. Teiger E, Than VD, Richard L, Wisnewsky C, Tea BS, Gaboury L, Tremblay J, Schwartz K, Hamet P. Apoptosis in pressure overload-induced heart hypertrophy in the rat. The Journal of clinical investigation 1996; 97(12):2891-2897.

275. Communal C, Sumandea M, de Tombe P, Narula J, Solaro RJ, Hajjar RJ. Functional consequences of caspase activation in cardiac myocytes. Proceedings of the National Academy of Sciences of the United States of America 2002; 99(9):6252-6256.

276. Saraste A, Pulkki K. Morphologic and biochemical hallmarks of apoptosis. Cardiovascular research 2000; 45(3):528-537.

277. Chiarugi A. Poly(ADP-ribose) polymerase: killer or conspirator? The 'suicide hypothesis' revisited. Trends in pharmacological sciences 2002; 23(3):122-129.

278. Virag L, Szabo C. The therapeutic potential of poly(ADP-ribose) polymerase inhibitors. Pharmacological reviews 2002; 54(3):375-429.

279. Pillai JB, Russell HM, Raman J, Jeevanandam V, Gupta MP. Increased expression of poly(ADP-ribose) polymerase-1 contributes to caspase-independent myocyte cell death during heart failure. American journal of physiology 2005; 288(2):H486-496.

280. Bartha E, Solti I, Kereskai L, Lantos J, Plozer E, Magyar K, Szabados E, Kalai T, Hideg K, Halmosi R, Sumegi B, Toth K. PARP inhibition delays transition of hypertensive cardiopathy to heart failure in spontaneously hypertensive rats. Cardiovascular research 2009; 83(3):501-510.

281. Kaufmann SH, Desnoyers S, Ottaviano Y, Davidson NE, Poirier GG. Specific proteolytic cleavage of poly(ADP-ribose) polymerase: an early marker of chemotherapyinduced apoptosis. Cancer research 1993; 53(17):3976-3985.

282. Lazebnik YA, Kaufmann SH, Desnoyers S, Poirier GG, Earnshaw WC. Cleavage of poly(ADP-ribose) polymerase by a proteinase with properties like ICE. Nature 1994; 371(6495):346-347.

283. Cingolani $\mathrm{OH}$, Yang XP, Cavasin MA, Carretero OA. Increased systolic performance with diastolic dysfunction in adult spontaneously hypertensive rats. Hypertension 2003; 41(2):249-254. 
284. Jennings $G$, Wong J. Regression of left ventricular hypertrophy in hypertension: changing patterns with successive meta-analyses. J Hypertens Supp/ 1998; 16(6):S2934.

285. Sack MN, Rader TA, Park S, Bastin J, McCune SA, Kelly DP. Fatty acid oxidation enzyme gene expression is downregulated in the failing heart. Circulation 1996; 94(11):2837-2842.

286. Witteles RM, Fowler MB. Insulin-resistant cardiomyopathy clinical evidence, mechanisms, and treatment options. Journal of the American College of Cardiology 2008; 51(2):93-102.

287. Weeks KL, McMullen JR. The athlete's heart vs. the failing heart: can signaling explain the two distinct outcomes? Physiology (Bethesda, Md, 26(2):97-105.

288. Cohn JN, Ferrari R, Sharpe N. Cardiac remodeling--concepts and clinical implications: a consensus paper from an international forum on cardiac remodeling. Behalf of an International Forum on Cardiac Remodeling. Journal of the American College of Cardiology 2000; 35(3):569-582.

289. Manabe I, Shindo T, Nagai R. Gene expression in fibroblasts and fibrosis: involvement in cardiac hypertrophy. Circulation research 2002; 91(12):1103-1113. 290. Jalil JE, Doering CW, Janicki JS, Pick R, Shroff SG, Weber KT. Fibrillar collagen and myocardial stiffness in the intact hypertrophied rat left ventricle. Circulation research 1989; 64(6):1041-1050.

291. Brower GL, Gardner JD, Forman MF, Murray DB, Voloshenyuk T, Levick SP, Janicki JS. The relationship between myocardial extracellular matrix remodeling and ventricular function. Eur J Cardiothorac Surg 2006; 30(4):604-610.

292. Karmazyn M, Liu Q, Gan XT, Brix BJ, Fliegel L. Aldosterone increases NHE-1 expression and induces NHE-1-dependent hypertrophy in neonatal rat ventricular myocytes. Hypertension 2003; 42(6):1171-1176.

293. Isner JM, Losordo DW. Therapeutic angiogenesis for heart failure. Nature medicine 1999; 5(5):491-492.

294. Brandt RR, Wright RS, Redfield MM, Burnett JC, Jr. Atrial natriuretic peptide in heart failure. Journal of the American College of Cardiology 1993; 22(4 Suppl A):86A92A.

295. Burnett JC, Jr., Kao PC, Hu DC, Heser DW, Heublein D, Granger JP, Opgenorth TJ, Reeder GS. Atrial natriuretic peptide elevation in congestive heart failure in the 
human. Science (New York, NY 1986; 231(4742):1145-1147.

296. Komuro I, Yazaki Y. Control of cardiac gene expression by mechanical stress. Annual review of physiology 1993; 55:55-75.

297. Frohlich ED, Gonzalez A, Diez J. Hypertensive left ventricular hypertrophy risk: beyond adaptive cardiomyocytic hypertrophy. Journal of hypertension; 29(1):17-26. 298. Zarain-Herzberg A. Regulation of the sarcoplasmic reticulum Ca2+-ATPase expression in the hypertrophic and failing heart. Canadian journal of physiology and pharmacology 2006; 84(5):509-521.

299. David-Dufilho M, Pernollet MG, LeQuan Sang H, Benlian P, De Mendonca M, Grichois ML, Cirillo M, Meyer P, Devynck MA. Active Na+ and Ca+transport, Na+-Ca2+ exchange, and intracellular $\mathrm{Na}+$ and $\mathrm{Ca} 2+$ content in young spontaneously hypertensive rats. Journal of cardiovascular pharmacology 1986; 8 Suppl 8:S130-135.

300. Pinz I, Tian R, Belke D, Swanson E, Dillmann W, Ingwall JS. Compromised myocardial energetics in hypertrophied mouse hearts diminish the beneficial effect of overexpressing SERCA2a. The Journal of biological chemistry, 286(12):10163-10168.

301. Grana DR, Beigelman R, Milei J. [Genetically hypertensive rats: a model for essential arterial hypertension]. Medicina 1989; 49(4):379-386.

302. Luo J, McMullen JR, Sobkiw CL, Zhang L, Dorfman AL, Sherwood MC, Logsdon MN, Horner JW, DePinho RA, Izumo S, Cantley LC. Class IA phosphoinositide 3-kinase regulates heart size and physiological cardiac hypertrophy. Molecular and cellular biology 2005; 25(21):9491-9502.

303. McMullen JR, Shioi T, Zhang L, Tarnavski O, Sherwood MC, Kang PM, Izumo S. Phosphoinositide 3-kinase(p110alpha) plays a critical role for the induction of physiological, but not pathological, cardiac hypertrophy. Proceedings of the National Academy of Sciences of the United States of America 2003; 100(21):12355-12360.

304. Shioi T, Kang PM, Douglas PS, Hampe J, Yballe CM, Lawitts J, Cantley LC, Izumo $\mathrm{S}$. The conserved phosphoinositide 3-kinase pathway determines heart size in mice. The EMBO journa/2000; 19(11):2537-2548.

305. McMullen JR, Amirahmadi F, Woodcock EA, Schinke-Braun M, Bouwman RD, Hewitt KA, Mollica JP, Zhang L, Zhang Y, Shioi T, Buerger A, Izumo S, Jay PY, Jennings GL. Protective effects of exercise and phosphoinositide 3-kinase(p110alpha) signaling in dilated and hypertrophic cardiomyopathy. Proceedings of the National Academy of Sciences of the United States of America 2007; 104(2):612-617. 
306. Oudit GY, Crackower MA, Eriksson U, Sarao R, Kozieradzki I, Sasaki T, IrieSasaki J, Gidrewicz D, Rybin VO, Wada T, Steinberg SF, Backx PH, Penninger JM. Phosphoinositide 3-kinase gamma-deficient mice are protected from isoproterenolinduced heart failure. Circulation 2003; 108(17):2147-2152.

307. Crackower MA, Oudit GY, Kozieradzki I, Sarao R, Sun H, Sasaki T, Hirsch E, Suzuki A, Shioi T, Irie-Sasaki J, Sah R, Cheng HY, Rybin VO, Lembo G, Fratta L, Oliveira-dos-Santos AJ, Benovic JL, Kahn CR, Izumo S, Steinberg SF, Wymann MP, Backx PH, Penninger JM. Regulation of myocardial contractility and cell size by distinct PI3K-PTEN signaling pathways. Cel/2002; 110(6):737-749.

308. Perrino C, Schroder JN, Lima B, Villamizar N, Nienaber JJ, Milano CA, Naga Prasad SV. Dynamic regulation of phosphoinositide 3-kinase-gamma activity and betaadrenergic receptor trafficking in end-stage human heart failure. Circulation 2007; 116(22):2571-2579.

309. Kerfant BG, Rose RA, Sun H, Backx PH. Phosphoinositide 3-kinase gamma regulates cardiac contractility by locally controlling cyclic adenosine monophosphate levels. Trends in cardiovascular medicine 2006; 16(7):250-256.

310. Neri Serneri GG, Boddi M, Modesti PA, Cecioni I, Coppo M, Padeletti L, Michelucci A, Colella A, Galanti G. Increased cardiac sympathetic activity and insulinlike growth factor-I formation are associated with physiological hypertrophy in athletes. Circulation research 2001; 89(11):977-982.

311. McMullen JR, Shioi T, Huang WY, Zhang L, Tarnavski O, Bisping E, Schinke M, Kong S, Sherwood MC, Brown J, Riggi L, Kang PM, Izumo S. The insulin-like growth factor 1 receptor induces physiological heart growth via the phosphoinositide 3kinase(p110alpha) pathway. The Journal of biological chemistry 2004; 279(6):47824793.

312. DeBosch B, Treskov I, Lupu TS, Weinheimer C, Kovacs A, Courtois M, Muslin AJ. Akt1 is required for physiological cardiac growth. Circulation 2006; 113(17):20972104.

313. Kulik G, Klippel A, Weber MJ. Antiapoptotic signalling by the insulin-like growth factor I receptor, phosphatidylinositol 3-kinase, and Akt. Molecular and cellular biology 1997; 17(3):1595-1606.

314. Kuwahara K, Saito Y, Kishimoto I, Miyamoto Y, Harada M, Ogawa E, Hamanaka I, Kajiyama N, Takahashi N, Izumi T, Kawakami R, Nakao K. Cardiotrophin-1 
phosphorylates akt and $\mathrm{BAD}$, and prolongs cell survival via a PI3K-dependent pathway in cardiac myocytes. Journal of molecular and cellular cardiology 2000; 32(8):13851394.

315. Dhanasekaran A, Gruenloh SK, Buonaccorsi JN, Zhang R, Gross GJ, Falck JR, Patel PK, Jacobs ER, Medhora M. Multiple antiapoptotic targets of the PI3K/Akt survival pathway are activated by epoxyeicosatrienoic acids to protect cardiomyocytes from hypoxia/anoxia. American journal of physiology 2008; 294(2):H724-735.

316. Franke TF, Kaplan DR, Cantley LC, Toker A. Direct regulation of the Akt protooncogene product by phosphatidylinositol-3,4-bisphosphate. Science (New York, NY 1997; 275(5300):665-668.

317. Matsui $\mathrm{T}$, Rosenzweig A. Convergent signal transduction pathways controlling cardiomyocyte survival and function: the role of PI 3-kinase and Akt. Journal of molecular and cellular cardiology 2005; 38(1):63-71.

318. Kemi OJ, Ceci M, Wisloff U, Grimaldi S, Gallo P, Smith GL, Condorelli G, Ellingsen $O$. Activation or inactivation of cardiac Akt/mTOR signaling diverges physiological from pathological hypertrophy. Journal of cellular physiology 2008; 214(2):316-321.

319. O'Neill BT, Kim J, Wende AR, Theobald HA, Tuinei J, Buchanan J, Guo A, Zaha VG, Davis DK, Schell JC, Boudina S, Wayment B, Litwin SE, Shioi T, Izumo S, Birnbaum MJ, Abel ED. A conserved role for phosphatidylinositol 3-kinase but not Akt signaling in mitochondrial adaptations that accompany physiological cardiac hypertrophy. Cell metabolism 2007; 6(4):294-306.

320. Catalucci D, Latronico MV, Ceci M, Rusconi F, Young HS, Gallo P, Santonastasi M, Bellacosa A, Brown JH, Condorelli G. Akt increases sarcoplasmic reticulum Ca2+ cycling by direct phosphorylation of phospholamban at Thr17. The Journal of biological chemistry 2009; 284(41):28180-28187.

321. Hayakawa $Y$, Chandra M, Miao W, Shirani J, Brown JH, Dorn GW, 2nd, Armstrong RC, Kitsis RN. Inhibition of cardiac myocyte apoptosis improves cardiac function and abolishes mortality in the peripartum cardiomyopathy of Galpha(q) transgenic mice. Circulation 2003; 108(24):3036-3041.

322. Wencker D, Chandra M, Nguyen K, Miao W, Garantziotis S, Factor SM, Shirani J, Armstrong RC, Kitsis RN. A mechanistic role for cardiac myocyte apoptosis in heart failure. The Journal of clinical investigation 2003; 111(10):1497-1504. 
323. Kraus WL, Lis JT. PARP goes transcription. Cel/2003; 113(6):677-683.

324. Hassa PO, Buerki C, Lombardi C, Imhof R, Hottiger MO. Transcriptional coactivation of nuclear factor-kappaB-dependent gene expression by $\mathrm{p} 300$ is regulated by poly(ADP)-ribose polymerase-1. The Journal of biological chemistry 2003; 278(46):45145-45153.

325. Lumini-Oliveira J, Magalhaes J, Pereira CV, Moreira AC, Oliveira PJ, Ascensao A. Endurance training reverts heart mitochondrial dysfunction, permeability transition and apoptotic signaling in long-term severe hyperglycemia. Mitochondrion; 11(1):54-63. 326. Yamaguchi S, Yamaoka M, Okuyama M, Nitoube J, Fukui A, Shirakabe M, Shirakawa K, Nakamura N, Tomoike H. Elevated circulating levels and cardiac secretion of soluble Fas ligand in patients with congestive heart failure. The American journal of cardiology 1999; 83(10):1500-1503, A1508.

327. Park DS, Stefanis L, Greene LA. Ordering the multiple pathways of apoptosis. Trends in cardiovascular medicine 1997; 7(8):294-301.

328. Javelaud D, Besancon F. Inactivation of p21WAF1 sensitizes cells to apoptosis via an increase of both p14ARF and p53 levels and an alteration of the Bax/Bcl-2 ratio. The Journal of biological chemistry 2002; 277(40):37949-37954.

329. Park JR, Hockenbery DM. BCL-2, a novel regulator of apoptosis. Journal of cellular biochemistry 1996; 60(1):12-17.

330. Basanez G, Sharpe JC, Galanis J, Brandt TB, Hardwick JM, Zimmerberg J. Baxtype apoptotic proteins porate pure lipid bilayers through a mechanism sensitive to intrinsic monolayer curvature. The Journal of biological chemistry 2002; 277(51):4936049365.

331. Green DR, Kroemer G. The pathophysiology of mitochondrial cell death. Science (New York, NY2004; 305(5684):626-629.

332. Huser J, Blatter LA. Fluctuations in mitochondrial membrane potential caused by repetitive gating of the permeability transition pore. The Biochemical journal 1999; 343 Pt 2:311-317.

333. Boudina S, Abel ED. Diabetic cardiomyopathy revisited. Circulation 2007; 115(25):3213-3223.

334. Adorisio R, De Luca L, Rossi J, Gheorghiade M. Pharmacological treatment of chronic heart failure. Heart failure reviews 2006; 11(2):109-123.

335. Remme WJ, Swedberg K. Guidelines for the diagnosis and treatment of chronic 
heart failure. European heart journa/ 2001; 22(17):1527-1560.

336. Gourine A, Bondar SI, Spyer KM, Gourine AV. Beneficial effect of the central nervous system beta-adrenoceptor blockade on the failing heart. Circulation research 2008; 102(6):633-636.

337. Wang DJ, Gottlieb SS. Diuretics: still the mainstay of treatment. Critical care medicine 2008; 36(1 Suppl):S89-94.

338. Blinderman CD, Homel P, Billings JA, Portenoy RK, Tennstedt SL. Symptom distress and quality of life in patients with advanced congestive heart failure. Journal of pain and symptom management 2008; 35(6):594-603.

339. McMurray JJ, Pfeffer MA. Heart failure. Lancet 2005; 365(9474):1877-1889.

340. Kramer BK, Schweda F, Riegger GA. Diuretic treatment and diuretic resistance in heart failure. The American journal of medicine 1999; 106(1):90-96.

341. Nocon M, Hiemann T, Muller-Riemenschneider F, Thalau F, Roll S, Willich SN. Association of physical activity with all-cause and cardiovascular mortality: a systematic review and meta-analysis. Eur J Cardiovasc Prev Rehabil2008; 15(3):239-246.

342. Rees K, Taylor RS, Singh S, Coats AJ, Ebrahim S. Exercise based rehabilitation for heart failure. Cochrane database of systematic reviews (Online) 2004; (3):CD003331.

343. Myers J. Principles of exercise prescription for patients with chronic heart failure. Heart failure reviews 2008; 13(1):61-68.

344. Braith RW, Beck DT. Resistance exercise: training adaptations and developing a safe exercise prescription. Heart failure reviews 2008; 13(1):69-79.

345. Hambrecht R, Niebauer J, Fiehn E, Kalberer B, Offner B, Hauer K, Riede U, Schlierf G, Kubler W, Schuler G. Physical training in patients with stable chronic heart failure: effects on cardiorespiratory fitness and ultrastructural abnormalities of leg muscles. Journal of the American College of Cardiology 1995; 25(6):1239-1249. 346. Experience from controlled trials of physical training in chronic heart failure. Protocol and patient factors in effectiveness in the improvement in exercise tolerance. European Heart Failure Training Group. European heart journal 1998; 19(3):466-475. 347. Sturm B, Quittan M, Wiesinger GF, Stanek B, Frey B, Pacher R. Moderateintensity exercise training with elements of step aerobics in patients with severe chronic heart failure. Archives of physical medicine and rehabilitation 1999; 80(7):746-750.

348. Piepoli MF, Davos C, Francis DP, Coats AJ. Exercise training meta-analysis of 
trials in patients with chronic heart failure (ExTraMATCH). BMJ (Clinical research ed 2004; 328(7433):189.

349. Jonsdottir S, Andersen KK, Sigurosson AF, Sigurosson SB. The effect of physical training in chronic heart failure. European journal of heart failure 2006; 8(1):97-101.

350. Coats AJ. Exercise training in heart failure. Current controlled trials in cardiovascular medicine 2000; 1(3):155-160.

351. Thompson PD, Buchner D, Pina IL, Balady GJ, Williams MA, Marcus BH, Berra K, Blair SN, Costa F, Franklin B, Fletcher GF, Gordon NF, Pate RR, Rodriguez BL, Yancey AK, Wenger NK. Exercise and physical activity in the prevention and treatment of atherosclerotic cardiovascular disease: a statement from the Council on Clinical Cardiology (Subcommittee on Exercise, Rehabilitation, and Prevention) and the Council on Nutrition, Physical Activity, and Metabolism (Subcommittee on Physical Activity). Circulation 2003; 107(24):3109-3116.

352. Shephard RJ, Balady GJ. Exercise as cardiovascular therapy. Circulation 1999; 99(7):963-972.

353. Pretorius L, Owen KL, Jennings GL, McMullen JR. Promoting physiological hypertrophy in the failing heart. Clin Exp Pharmacol Physio/ 2008; 35(4):438-441.

354. Bernardo BC, Weeks KL, Pretorius L, McMullen JR. Molecular distinction between physiological and pathological cardiac hypertrophy: experimental findings and therapeutic strategies. Pharmacology \& therapeutics; 128(1):191-227.

355. Kim J, Wende AR, Sena S, Theobald HA, Soto J, Sloan C, Wayment BE, Litwin SE, Holzenberger M, LeRoith D, Abel ED. Insulin-like growth factor I receptor signaling is required for exercise-induced cardiac hypertrophy. Molecular endocrinology (Baltimore, Md 2008; 22(11):2531-2543.

356. Torella D, Ellison GM, Karakikes I, Nadal-Ginard B. Resident cardiac stem cells. Cell Mol Life Sci 2007; 64(6):661-673.

357. Urbanek K, Quaini F, Tasca G, Torella D, Castaldo C, Nadal-Ginard B, Leri A, Kajstura J, Quaini E, Anversa P. Intense myocyte formation from cardiac stem cells in human cardiac hypertrophy. Proceedings of the National Academy of Sciences of the United States of America 2003; 100(18):10440-10445.

358. Overy HR, Priest RE. Mitotic cell division in postnatal cardiac growth. Laboratory investigation; a journal of technical methods and pathology 1966; 15(6):1100-1103.

359. Anversa $\mathrm{P}$, Kajstura J. Ventricular myocytes are not terminally differentiated in 
the adult mammalian heart. Circulation research 1998; 83(1):1-14.

360. Hsieh PC, Segers VF, Davis ME, MacGillivray C, Gannon J, Molkentin JD, Robbins J, Lee RT. Evidence from a genetic fate-mapping study that stem cells refresh adult mammalian cardiomyocytes after injury. Nature medicine 2007; 13(8):970-974.

361. Ellison GM, Waring CD, Vicinanza C, Torella D. Physiological cardiac remodelling in response to endurance exercise training: cellular and molecular mechanisms. Heart (British Cardiac Society); 98(1):5-10.

362. Takeda Y. Pleiotropic actions of aldosterone and the effects of eplerenone, a selective mineralocorticoid receptor antagonist. Hypertens Res 2004; 27(11):781-789.

363. Rocha R, Funder JW. The pathophysiology of aldosterone in the cardiovascular system. Annals of the New York Academy of Sciences 2002; 970:89-100.

364. Brilla CG, Pick R, Tan LB, Janicki JS, Weber KT. Remodeling of the rat right and left ventricles in experimental hypertension. Circulation research 1990; 67(6):13551364 .

365. Young M, Head G, Funder J. Determinants of cardiac fibrosis in experimental hypermineralocorticoid states. The American journal of physiology 1995; $269(4 \mathrm{Pt}$ 1):E657-662.

366. Stockand JD, Meszaros JG. Aldosterone stimulates proliferation of cardiac fibroblasts by activating Ki-RasA and MAPK1/2 signaling. American journal of physiology 2003; 284(1):H176-184.

367. Silvestre JS, Robert V, Heymes C, Aupetit-Faisant B, Mouas C, Moalic JM, Swynghedauw B, Delcayre C. Myocardial production of aldosterone and corticosterone in the rat. Physiological regulation. The Journal of biological chemistry 1998; 273(9):4883-4891.

368. Ye P, Kenyon CJ, MacKenzie SM, Jong AS, Miller C, Gray GA, Wallace A, Ryding AS, Mullins JJ, McBride MW, Graham D, Fraser R, Connell JM, Davies E. The aldosterone synthase (CYP11B2) and 11beta-hydroxylase (CYP11B1) genes are not expressed in the rat heart. Endocrinology 2005; 146(12):5287-5293.

369. Takeda Y, Miyamori I, Yoneda T, Hatakeyama H, Inaba S, Furukawa K, Mabuchi $H$, Takeda R. Regulation of aldosterone synthase in human vascular endothelial cells by angiotensin II and adrenocorticotropin. The Journal of clinical endocrinology and metabolism 1996; 81(8):2797-2800.

370. Xiao F, Puddefoot JR, Vinson GP. Aldosterone mediates angiotensin II- 
stimulated rat vascular smooth muscle cell proliferation. The Journal of endocrinology 2000; 165(2):533-536.

371. Takeda $\mathrm{Y}$, Yoneda $\mathrm{T}$, Demura M, Usukura M, Mabuchi $\mathrm{H}$. Calcineurin inhibition attenuates mineralocorticoid-induced cardiac hypertrophy. Circulation 2002; 105(6):677679.

372. Mazak I, Fiebeler A, Muller DN, Park JK, Shagdarsuren E, Lindschau C, Dechend R, Viedt C, Pilz B, Haller H, Luft FC. Aldosterone potentiates angiotensin IIinduced signaling in vascular smooth muscle cells. Circulation 2004; 109(22):27922800.

373. Pearce P, Funder JW. High affinity aldosterone binding sites (type I receptors) in rat heart. Clin Exp Pharmacol Physiol 1987; 14(11-12):859-866.

374. Lombes $M$, Alfaidy $N$, Eugene E, Lessana A, Farman N, Bonvalet JP. Prerequisite for cardiac aldosterone action. Mineralocorticoid receptor and 11 betahydroxysteroid dehydrogenase in the human heart. Circulation 1995; 92(2):175-182.

375. Lombes M, Oblin ME, Gasc JM, Baulieu EE, Farman N, Bonvalet JP. Immunohistochemical and biochemical evidence for a cardiovascular mineralocorticoid receptor. Circulation research 1992; 71(3):503-510.

376. Beesley AH, Hornby D, White SJ. Regulation of distal nephron K+ channels (ROMK) mRNA expression by aldosterone in rat kidney. The Journal of physiology 1998; 509 ( Pt 3):629-634.

377. Kolla $\mathrm{V}$, Litwack $\mathrm{G}$. Transcriptional regulation of the human Na/K ATPase via the human mineralocorticoid receptor. Molecular and cellular biochemistry 2000; 204(12):35-40.

378. Caldiz Cl, Diaz RG, Nolly MB, Chiappe de Cingolani GE, Ennis IL, Cingolani HE, Perez NG. Mineralocorticoid receptor activation is crucial in the signalling pathway leading to the Anrep effect. The Journal of physiology, 589(Pt 24):6051-6061. 